PNL-2498

UC-12

\title{
A Description and Cost Analysis of a Deluge Dry/Wet Cooling System
}

June 1978

Pacific Northwest Laboratory

Richland, Washington 99352

Operated for the

U.S. Department of Energy

by

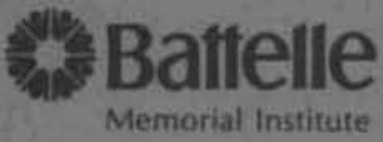




\title{
NOTICE
}

This report was prepared as an account of work sponsored by the United States Covernment. Neither the United States nor the Department of Energy, nor any of their employees, nor any of their contractors. subcontractors, or their employees, makes any warranty, express or implied, or assumes any legal liability or responsibility for the accuracy, completeness or usefuiness of any information, apparatus, product or process disclosed, or represents that its use would not infringe privately owned rights.

The views, opinions and conclusions contained in this report are those of the contractor and do not necessarily represent those of the United States Government or the United States Department of Energy.

\author{
PACIFIC NORTHWEST LABORATORY \\ operated by \\ BATTELLE \\ for the \\ UNITED STATES DEPARTMENT OF ENERGY \\ Under Contract EY-76-C-06-1830
}
Printed in the United States of America
Availabie from
National Technical Information Service
United States Deoartment of Commerce
5285 Port Royal Road
Springfieid, Virginia 22151

Price: Printed Copy S__: Microliche $\$ 3.00$

$$
\text { NTIS }
$$

•Pages

Selling Price

$001-025$

$025-050$

$051-075$

$076-100$

$101-125$

$126-150$

$151-175$

$176-200$

$201-225$

$226 \cdot 259$

$251-275$

5450

$55 . \infty$

55.50

56.00

56.50

57.00

5775

58.50

58.75

59.00

510.00

$206-300$

510.25

$\bullet$ 
by

L. E. Wiles

J. A. Bamberger Daniel J. Braun

David J. Braun

D. W. Faletti

C. E. Willingham

June 1978

PACIFIC NORTHWEST LABORATORY

Richland, Washington 99352

Operated by

BATTELLE MEMORIAL INSTITUTE 


\section{FOREWORD}

The Dry Cooling Enhancement Program at Pacific Northwest Laboratory (PNL) was initiated with a program scope that included the following near-term and ultimate emphases.

Near-Term Objectives:

- Develop economic and performance models for cost optimization of total heat rejection systems using dry and dry/wet cooling.

- Analyze and disseminate operating experience on existing drycooled plant performance.

- Demonstrate certain features of existing technology equipment to provide confidence for specification by utilities.

Ultimate Objective:

- Promote water conservation through industry use of dry cooling by developing and demonstrating the reliability of lowercost systems. The development of advanced dry/wet systems is also considered to be within this scope.

The following documents have been issued, reporting the results of the work toward these objectives.

Cost optimization of dry-cooled heat rejection systems:

A REVIEW AND ASSESSMENT OF ENGINEERING ECONOMIC STUDIES OF DRY COOLED ELECTRICAL GENERATING PLANTS. B. C. Fryer, BNWL-1976, March 1976.

HEAT TRANSFER AND PRESSURE DROP CHARACTERISTICS OF DRY TOWER EXTENDED SURFACES. PART I : HEAT TRANSFER AND PRESSURE DROP DATA. PFR Engineering Systems, Inc., PFR 7-100, March 1976.

HEAT TRANSFER AND PRESSURE DROP CHARACTERISTICS OF DRY TOWER EXTENDED SURFACES. PART II: DATA ANALYSIS AND CORRELATION. PFR Engineering Systems, Inc., PFR 7-102, June 1976. 
Analysis of performance of existing dry-cooled plants:

DRY COOLING TOWER PROGRAM: RESULTS OF INDUSTRIAL CONTACTS THROUGH AUGUST 1974. BNWL-1878, November 1, 1974.

A SURVEY OF MATERIALS AND CORROSION PERFORMANCE IN DRY COOLING APPLICATIONS. A. B. Johnson, Jr., D. R. Pratt and G. E. Zima, BNWL-1958, March 1976.

EUROPEAN DRY COOLING TOWER OPERATING EXPERIENCE.

J. G. DeSteese and K. Simhan, BNAL-1995, March 1976.

MATHEMATICAL AND EXPERIMENTAL INVESTIGATIONS ON DISPERSION AND RECIRCULATION OF PLUMES FROM DRY COOLING TOWERS AT WYODAK POWER PLANT IN WYOMING. Y. Onishi and

D. S. Trent, BNWL-1982, February 1976.

Advanced dry (dry/wet) cooled systems:

PRELIMINARY EVALUATION OF WET/DRY COOLING CONCEPTS FOR POWER PLANTS. W. V. Loscutoff, BNWL-1969.

COMPATABILITY OF AMMONIA WITH CANDIDATE DRY COOLING SYSTEM MATERIALS. D. R. Pratt, BNWL-1992, Apri1 1976.

SCALE FORMATION IN DELUGED DRY COOLING SYSTEMS. D. R. Pratt, BNWL-2060, March 1976.

AMMONIA AS AN INTERMEDIATE HEAT EXCHANGE FLUID FOR DRY

COOLED TOWERS. R. T. Allemann, B. M. Johnson, and

G. C. Smith, BNWL-SA-5997, September 1976.

A group of reports (including this report) has recently been issued. This group serves the dual purpose of developing cost optimization models for dry cooling systems based on available technology and comparing the results of analyzing the costs of these systems with the projected cost of several advanced dry and dry/wet systems. Included in this group are:

AN ENGINEERING AND COST COMPARISON OF THREE DIFFERENT ALL-DRY COOLING SYSTEMS. B.:C. Fryer, D. W. Faletti, Daniel J. Braun, David J. Braun and L. E. Wiles, BNWL-2121, September 1976.

A STUDY OF THE COMPARATIVE COSTS OF FIVE WET/DRY COOLING TOWER CONCEPTS. F. R. Zaloudek, R. T. Allemann, D. W. Faletti, B. M. Johnson, H. L. Parry, G. C. Smith,

R. D. Tokarz, and R. A. Walter, BNWL-2122, September 1976. 
DRY COOLING OF POWER GENERATING STATIONS: A SUMMARY OF THE ECONOMIC EVALUATION OF SEVERAL ADVANCED CONCEPTS VIA A DESIGN OPTIMIZATION STUDY AND A CONCEPTUAL DESIGN AND COST ESTIMATE. B. M. Johnson, R. T. Allemann, D. W. Faletti, B. C. Fryer and F. R. Zaloudek, BNWL-2120, September 1976.

COSTS AND COST ALGORITHMS FOR DRY COOLING TOWER SYSTEMS. P. A. Ard, C. H. Henager, D. R. Pratt and L. E. Wiles, BNWL-2123, September 1976.

A USER'S MANUAL FOR THE BNW-I OPTIMIZATION CODE FOR DRYCOOLED POWER PLANTS. David J. Braun, Daniel J. Braun, Warren V. De Mier, D. W. Faletti and L. E. Wiles, BNWL-2180, January 1977.

AN OVERVIEW OF ECONOMIC, LEGAL, AND WATER AVAILABILITY FACTORS AFFECTING THE DEMAND FOR DRY AND WET/DRY COOL ING OF THERMAL POWER PLANTS. P. L. Hendrickson, BNWL-2268, June 1977 .

ESTIMATION OF BENEFITS FROM DEMONSTRATING ADVANCED DRY COOLING TECHNOLOGY: A FRAMEWORK AND PARTIAL ANALYSIS. J. W. Currie and T. J. Foley, BNWL-2182, Apri1 1977.

ALUMINUM ALLOY PERFORMANCE UNDER DRY COOLING TOWER CONDITIONS. A. B. Johnson, Jr., S. Begaj, M. W. Martini, and R. P. May, PNL-2392, December 1977. 


\section{ACKNOWLEDGMENTS}

This report contains an account of the work sponsored by the Division of Advanced Systems and Materials Production of DOE under the Dry Cooling Enhancement Program at Pacific Northwest Laboratory (PNL). The project was completed under the direction of I. Helms, Project Officer; W. F. Savage, Manager of Advanced Concepts Evaluation Branch, DOE Division of Nuclear Research and Applications; and B. M. Johnson, Manager of the Dry Cooling Enhancement Program at PNL. 
FOREWORD

ACKNOWLEDGMENTS

FIGURES

TABLES

1.0 SUMMARY AND CONCLUSIONS

i i i

vi i

$x i$

$x V$

2.0 INTRODUCTION

1.1

2.1

2.1 BACKGROUND

2.1

2.2 SCOPE OF REPORT

2.3

3.0 PHYSICAL DESCRIPTION OF COOLING SYSTEM .

3.1 GENERAL OVERVIEW

3.2 CONDENSER/REBOILER

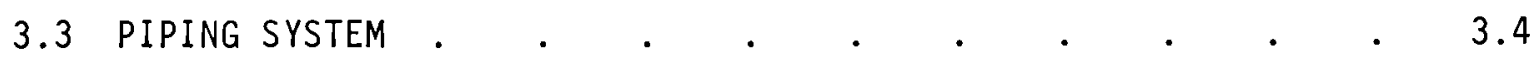

3.4 COOLING TOWERS .

3.4 .1 Tower Configuration . . . . . . . . 3.5

3.4.2 Ammonia Piping . . . . . . . . . . . 3.6

3.4.3 Heat Exchanger Bundles . . . . . . . . 3.8

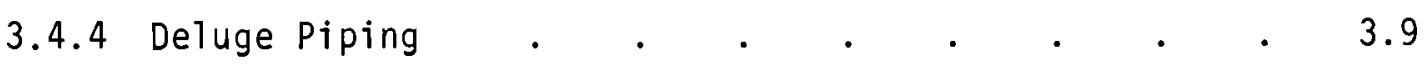

3.4 .5 Fan System . . . . . . . . . . . 3.10

4.0 METHOD OF ANALYSIS .

4.1 COST OPTIMIZATION

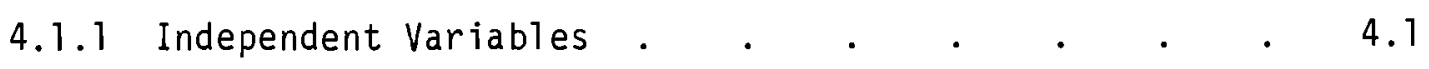

4.1.2 Dependent Parameters/Calculational
Procedure . . . . . . . . . 4.4

4.1 .3 Optimization Technique . . . . . . . . . 4.14

4.2 INCREMENTAL COST . $. \quad . \quad . \quad . \quad . \quad . \quad . \quad . \quad .4 .15$

4.2.1 Capital Costs . . . . . . . . . . . 4.16

4.2.2 Operating Costs . . . . . . . . . . . 4.16

4.3 POWER-PLANT/UTILITY-SYSTEM INTERFACE $. * . \quad \cdot \quad \cdot \quad \cdot 4.17$

4.3.1 Excess Capacity . . . . . . . . . . 4.18

4.3.2 Replacement of Lost Capacity -
Capacity Cost, Energy Cost . . . . . . 4.20

4.3.3 Steam Supply Scaling . . . . . . . . . 4.21 
4.3.4 Scaling for Heat Rate . . . . . . . 4.22

4.3.5 Scaling for Auxiliary Power . . . . . . . 4.23

4.3 .6 Base Plant Fuel . . . . . . . . . . 4.24

4.4 ANNUAL OPERATION AND TOTAL

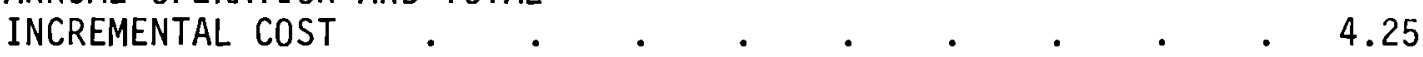

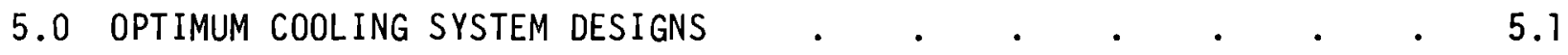

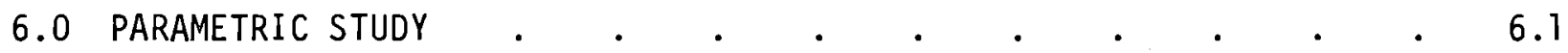

6.1 METHOD OF ANALYSIS . . . . . . . . . . . . . 6.1

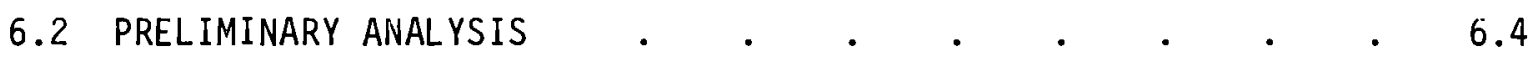

6.2 .1 Subroutine SHOT . . . . . . . . . . . 6.4

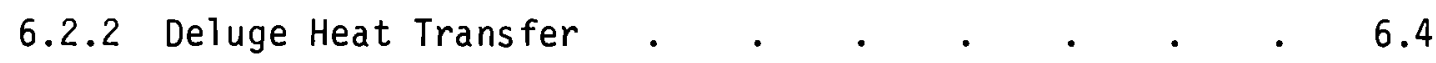

6.3 PARAMETRIC ANALYSIS OF THE DELUGE PARAMETERS . . . . . 6.6

6.3.1 Water Availability and Water Cost . . . . . 6.6

6.3.2 Design Ambient Air Temperature . . . . . . 6.16



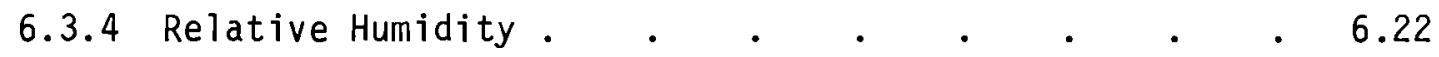

6.3.5 Air Velocity Through the Deluged
Heat Exchanger . . . . . . . . . 6.22

6.4 PARAMETRIC ANALYSIS OF DRY MODE PARAMETERS . $\quad . \quad$. $\quad$. 6.25

6.4 .1 Tube Length/Tower Diameter . . . . . . . 6.25

6.4.2 Number of Tube Rows in Depth . . . . . . 6.29

6.4 .3 Number of Towers . . . . . . . . . . . 6.31

6.4 .4 Fan System $. \quad . \quad . \quad . \quad . \quad . \quad . \quad . \quad . \quad . \quad 6.35$

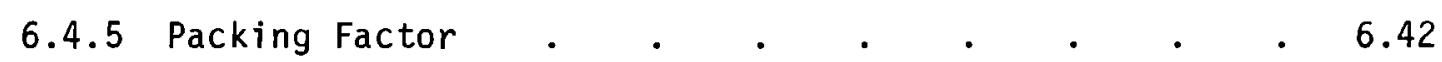

6.4 .6 Frontal Air Velocity . . . . . . . . . 6.45

6.4 .7 Turbine Type . . . . . . . . . . . . . 6.48

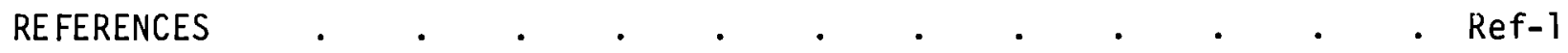

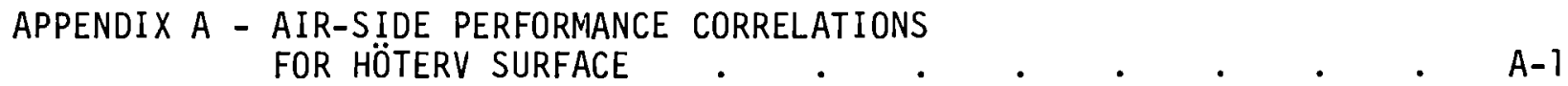

APPENDIX B - FIN EFFICIENCY OF PLATE FIN HEAT

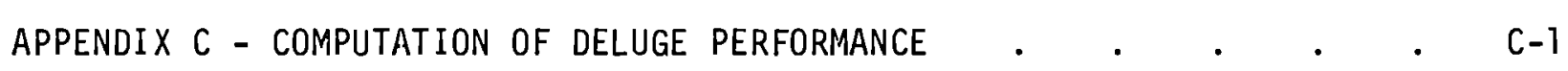

APPENDIX D - METEOROLOGY METHODOLOGY . . • . . . . . . . . D-1

APPENDIX E - COMPARISON OF AIR VELOCITY THROUGH

DELUGE AND DRY SECTIONS FOR HÖTERV

SURFACES 


\section{FIGURES}

1.1 The Incremental Cost of Electricity Attributable to a Cooling System with a Deluged HOTERV Heat Exchanger as a Function of Annual Water Availability to a 100-MWe Fossil-Fuel Power Plant

1.2 Optimized Heat Transfer Area and Maximum Turbine Back Pressure as a Function of Annual Water Availability for a 1000-MWe Fossil-Fueled Power Plant

3.1 Indirect Dry/Wet Cooling System with Ammonia as the Intermediate Coolant.

3.2 Temperature Relationships for Steam, Ammonia, and Air (Dry-Bulb) for the Indirect Cooling System with Ammonia as the Intermediate Coolant

3.3 Ammonia Circulation System for the Vapor Supply and Liquid Return

3.4 Ammonia Distribution Piping in an 8-Sided Tower

3.5 Ammonia Distribution Piping in a 16-Sided Tower

3.6 Ammonia Distribution and Collection to the Heat Exchanger Bundles for an 8-Sided Tower

3.7 Ammonia Distribution and Collection to the Heat Exchanger Bundles for a 16-Sided Tower . . . . . . . . . 3.9

3.8 The HÖTERV Heat Exchanger Plate Fin and Tube Arrangement . . 3.10

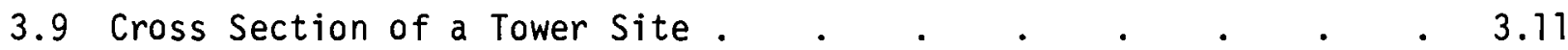

4.1 Pictorial Definition of Overall Heat Exchanger Dimensions . $\quad 4.7$

4.2 Operating Regimes for a Power Plant with a Deluged Cooling System . . . . . . . . . . . . 4.11

4.3 Power Plant Performance Versus Ambient Temperature to Compare Excess Capacity, Lost Capacity, and Gas

Turbine Requirements for Two Different Design Temperatures

5.1 Optimized HOTERV Cooling System with 3000 Acre-ft of Water Available.

5.2 Optimized HÖTERV Cooling System for All-Dry Operation • • • 5.3

5.3 Optimized Cooling System with Spiral-Wrapped Finned-Tube Heat Exchanger for A11-Dry Operation

5.4 Turbine Exhaust Pressure as a Function of Ambient Temperature for Three Systems 
6.1 Heat Transfer Area and Maximum Turbine Exhaust Pressure as a Function of Water Availability.

6.2 Normalized Heat Rate Versus Turbine Exhaust Pressure . . . 6.13

6.3 Incremental cost Versus Water Availability . . . . . . 6.14

6.4 Incremental cost Versus Water Availability for Various Water Costs . . . . . . . . . 6.15

6.5 Incremental cost and Components of the Incremental Cost Versus Design Temperature . . . . . 6.18

6.6 Optimized Airflow Rate and Heat Transfer Area Versus Tube Rows in Depth

6.7 Effect of Air Velocity on the Heat Transfer Area, Fan Power and the Incremental cost of Cooling

6.8 Normalized Heat Rate Versus Turbine Back Pressure - Fossil

6.9 Normalized Heat Rate Versus Turbine Back Pressure - Nuclear

6.10 Incremental Cost Versus Water Availability for Nuclear and Fossil Turbine-Generators . . . . . 6.53

B.l Unit Geometry of Plate Fin Studied . . . . . . . . B.2

B.2 Annular Fin Equivalent of Plate Fin . . . . . . B.3

D.1 Cumulative Dry-Bulb and Wet-Bulb Temperature Distribution Taken from an Eleven-Year Average for Bakersfield, CA. . . D.2

D.2 Cumulative Dry-Bulb and Wet-Bulb Temperature Distribution Taken from a Twenty-Year Average for Boston, MA . . . . D.2

D.3 Cumulative Dry-Bulb and Wet-Bulb Temperature Distribution Taken from a Nineteen-Year Average for Chicago, IL . . . D.3

D.4 Cumulative Dry-Bulb and Wet-Bulb Temperature Distribution Taken from a Twenty-Year Average for Miami, FL . .

D.5 Cumulative Dry-Bulb and Wet-Bulb Temperature Distribution Taken from a Twenty-Six Year Average for Phoenix, AZ . . . 0.4

D.6 Cumulative Dry-Bulb and Wet-Bulb Temperature Distribution Taken from a Seventeen-Year Average for San Francisco, CA

D.7 Cumulative Dry-Bulb and Wet-Bulb Temperature Distribution Taken from a Five-Year Average for San Juan, NM . . . . 0.5

D.8 Cumulative Dry-Bulb and Wet-Bulb Temperature Distribution Taken from a Thirty-Three Year Average for Washington, DC 
D.9 Cumulative Comparison of Dry-Bulb Temperature

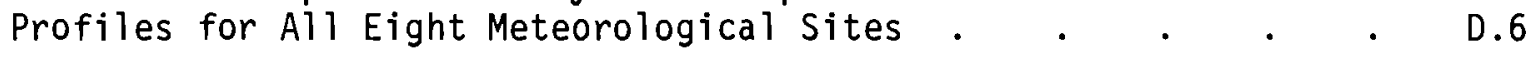

\section{D.10 Cumulative Comparison of Wet-Bulb Temperature} Profiles for All Eight Meteorological Sites . . . . . . . . D.6

D.11 Minimum Allowable Load at Condenser Pressures Above $5.5 \mathrm{in.} \mathrm{Hga} . \quad$. . . . . . . . . D.8

D.12 Operating Regimes for a Power Plant with a Deluged Cooling System . . . . . . . . . . D.8

E.1 Pressure Versus Airflow for a 27-ft Diameter Fan with a 16 Degree Blade Pitch Angle.

E.3 


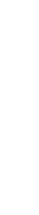

$-$ 


\section{$\underline{\text { TABLES }}$}

5.1 Optimized Design, Performance and Cost Parameters

for Three Comparative Designs . $\quad$. $\quad$. $\quad$. $\quad$. 5.2

5.2 Cooling System Cost Summary for Deluge-Enhanced HÖTERV

Surface with an Annual Water Consumption of 3000 Acre-ft . 5.6

5.3 Cooling System Cost Summary for HÖTERV Surface

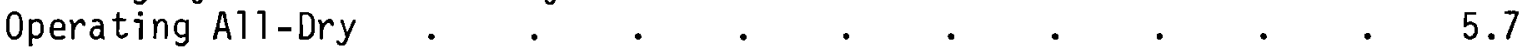

5.4 Cooling System Cost Summary for Vertical Spiral-Wrapped

6.1 Design Basis Parameters .

6.2 Reference Values of the Variables $\quad .6 .3$

6.3 Comparison of Optimized Design, Performance and Cost

Parameters for the Two Optimization Methods . . . . $\quad$. 6.5

6.4 Comparison of Optimized Design, Performance and Cost

Parameters for the Two Methods of Deluge Heat Transfer

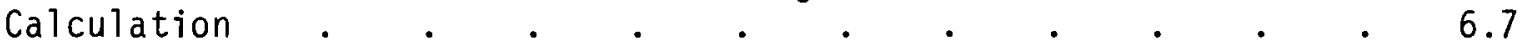

6.5 Comparison of Optimized Design, Performance, and Cost

6.6 Comparison of Optimized Design, Performance and Cost

6.7 Meteorological Site Characteristics . . . . . . . . . 6.20

6.8 Comparison of Optimized Design, Performance and Cost

6.9 Comparison of Optimized Design, Performance, and Cost

Parameters for Various Exit Relative Humidities . . . . 6.23

6.10 Comparison of Optimized Design, Performance, and Cost Parameters for Various Assumed Values of the Ratio of Air Velocity Through the Dry Section to the Air Velocity Through the Wet Section . . . . . . . $\quad$. 6.24

6.11 Comparison of Optimized Design, Performance, and Cost Parameters for Various Tube Lengths for Eight-Sided

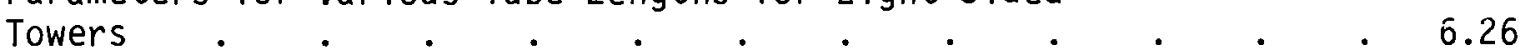

6.12 Comparison of Optimized Design, Performance, and Cost Parameters for Various Tube Lengths for Sixteen-Sided Towers

6.13 Comparison of Optimized Design, Performance, and Cost Parameters for Various Numbers of Tube Rows in Depth . . . 6.30

6.14 Comparison of Optimized Design, Performance, and Cost Parameters for a Specified Number of Towers . . . . . 6.32 
6.15 Design Parameters for Specified Number of Towers . . . . $\quad 6.34$

6.16 Results of Fan Diameter Study . . . . . . . . . . . . 6.37

6.17 Comparison of Optimized Design, Performance, and Cost Parameters for Fixed Fan Diameters . . . . . . . . 6.38

6.18 Comparison of Optimized Design, Performance, and Cost
Parameters With and Without Louvers . . . . . . . . 6.39

6.19 Comparison of Optimized Design, Performance, and Cost
Parameters with and Without Velocity Recovery.
.

6.20 Comparison of Optimized Design, Performance, and Cost
Parameters of Various Packing Factors

6.21 Comparison of Optimized Design, Performance, and Cost
Parameters of Various Values of Frontal Air Velocity . . . . 6.46

6.22 Differences in Fossil and Nuclear . . . . . . . . . . . 6.52

6.23 Comparison of Optimized Design and Cost Data for 3000 Acre-ft of Water Using the Three Turbine Types (Fossil) .

6.24 Comparison of Optimized Design and Cost Data for 3000 Acre-ft of Water Using the Three Turbine Types (Nuclear)

D.1 Meteorological Data for Each Site . . . . . . . . . D.10

D.2 Summary of Daily Maximum Temperatures for San Juan, NM . • . D.11

D.3 Meteorological Data for San Juan, NM, 8 and 16 Temperature Intervals . . . . . . . . . . . . D.13

D.4 Meteorological Data for Bakersfield, CA, 8 and 16
Temperature Intervals

D.5 Meteorological Data for Boston, MA, 8 and 14

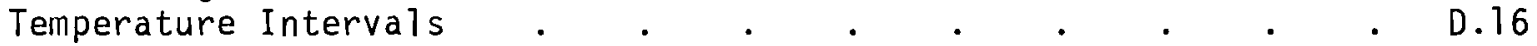

D.6 Meteorological Data for Chicago, IL, 8 and 14

D.7 Meteorological Data for Miami, FL, 8 and $15 \quad 0.18$

D.8 Meteorological Data for Phoenix, AZ, 8 and 16

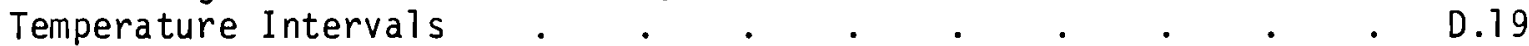

D.9 Meteorological Data for San Francisco, CA, 8 and 13 Temperature Intervals . . . . . . . . . . . D.20

D.10 Meteorological Data for Washington, DC, 8 and 16
Temperature Intervals $. \quad . \quad . \quad . \quad . \quad . \quad . \quad . \quad . \quad 0.21$

E.l Air Characteristics for a Deluged Cooling Tower . . . . E.8

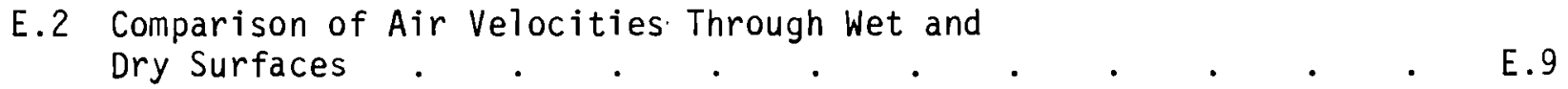




\subsection{SUMMARY AND CONCLUSIONS}

The use of dry cooling for large base-load power plants has generally been precluded in the U.S., due to the inherent high costs. However, the need to conserve both the quantity and quality of remaining water resources is becoming increasingly important. The use of combined dry/wet cooling systems offers the potential for significant water savings as compared to evaporatively cooled power plants and significant cost savings in comparison to dry cooled power plants. This report describes the results of a detailed engineering and cost study of one type of dry/wet cooling system.

The method of dry/wet cooling described in this report is termed "deluge." A finned-tube heat exchanger is designed to operate in the dry mode up to a given ambient temperature. To avoid the degradation of performance for higher ambient temperatures, water (the delugeate) is distributed over a portion of the heat exchanger surface to enhance the cooling process by evaporation. The deluge system used in this study is termed the HÖTERV system. The technology is being developed by the HÖTERV Institute, Budapest, Hungary, and is licensed in the U.S. through Babcock and Wilcox. The HÖTERV deluge system uses a horizontal-tube, vertical-plate-finned heat exchanger. The delugeate is distributed at the top of the heat exchanger and is allowed to fall by gravity in a thin film on the face of the plate fin. While the HÖTERV surface is projected to be somewhat more expensive than the spiralwrapped finned-tube surface, we did not believe it was feasible to deluge the latter.

The cooling system described in this report uses ammonia as the indirect heat transfer medium between the turbine exhaust steam and the ambient air. Steam is condensed by boiling ammonia in a condenser/reboiler. The ammonia is condensed in the heat exchanger by inducing airflow over the plate fins.

Various design parameters of the cooling system have been studied to evaluate their impact on the optimum cooling system design and the powerplant/utility-system interface. The power-plant/utility-system model requires the power plant to provide a prescribed electrical load to the utility grid during all hours of operation. Gas turbines are used to make up lost capacity 
on hot days. The incremental cost is the additional cost of electricity directly attributable to the physical cooling system components and indirectly attributable to the cooling system due to its impact on the remainder of the power plant.

The design parameter most significant to this study was the amount of water available for evaporation on an annual basis. Optimum cooling system designs were developed for a 1000-MWe power plant with water allotments from zero to 5000 acre-ft per year. An evaporatively cooled power plant subject to the same design conditions would require about 9000 acre-ft of water annually. Figure 1.1 shows the results for the case of zero cost water. Important points are listed below.

- A water allotment of only 100 acre-ft offsets the added cost of the more expensive HÖTERV surface.

- Further significant cost savings are made by increasing the water available for evaporation.

- Cost savings with increasing water availability result primarily from the specification of a smaller heat exchanger and lower operating turbine exhaust pressures (see Figure 1.2).

- The low turbine exhaust pressures permit the use of the conventional turbine, thereby avoiding heat rate penalties of high back pressure turbines.

- The low exhaust pressures also result in reduced costs to make up lost capacity for ambient temperatures above the design temperature. In the context of this report, this implies a decrease in the dependence upon and consumption of primary gas turbine fuel.

In addition to the annual water availability, several other parameters were evaluated to determine their impact on the design, performance, and cost of the deluged dry/wet cooling system. These parameters include

- design temperature,

- site meteorology, 


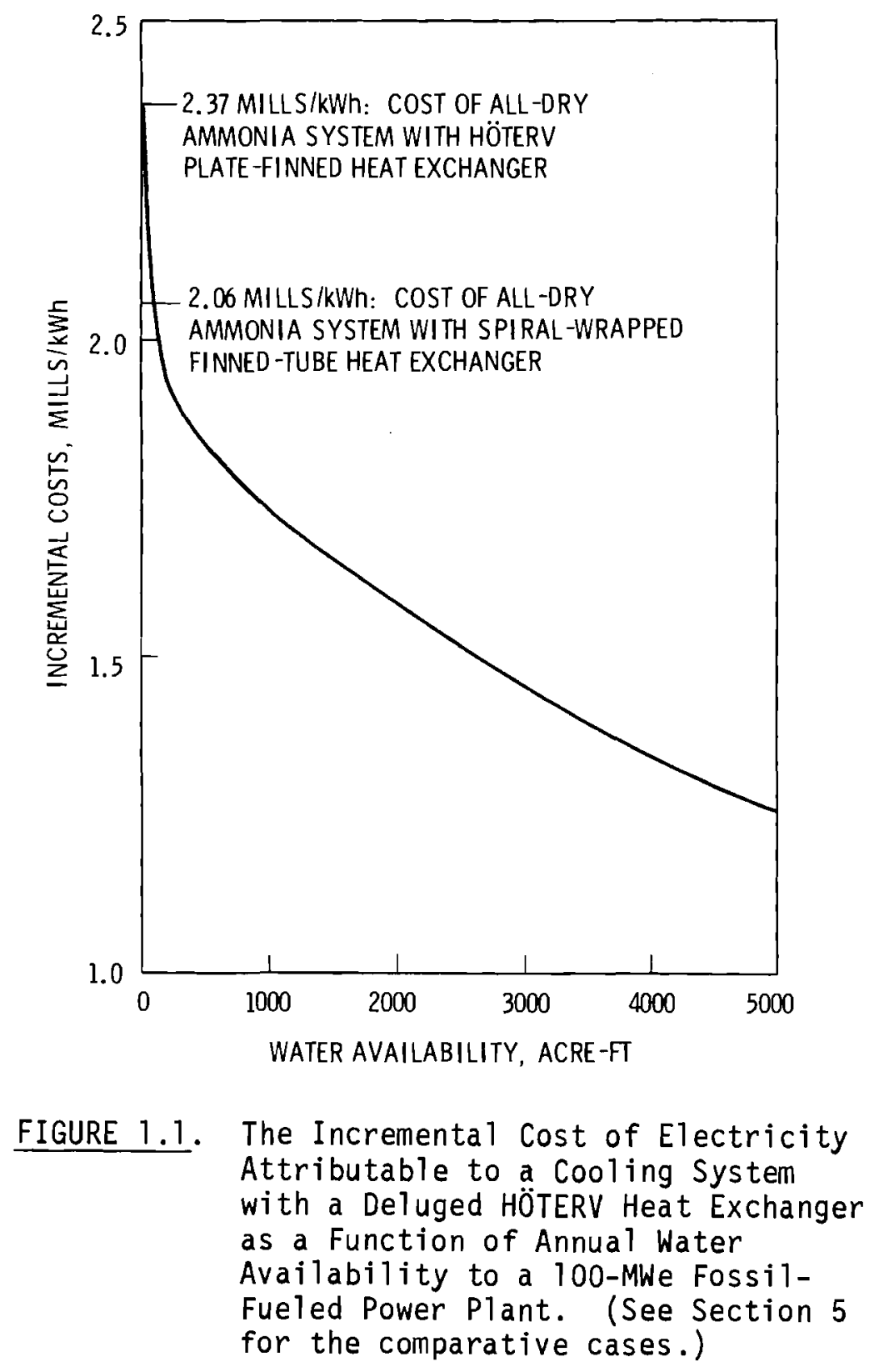

- assumed relative humidity of the air exiting the heat exchanger,

- ratio of air velocity during deluge operation to air velocity during dry operation,

- heat exchanger tube length,

- number of towers, 


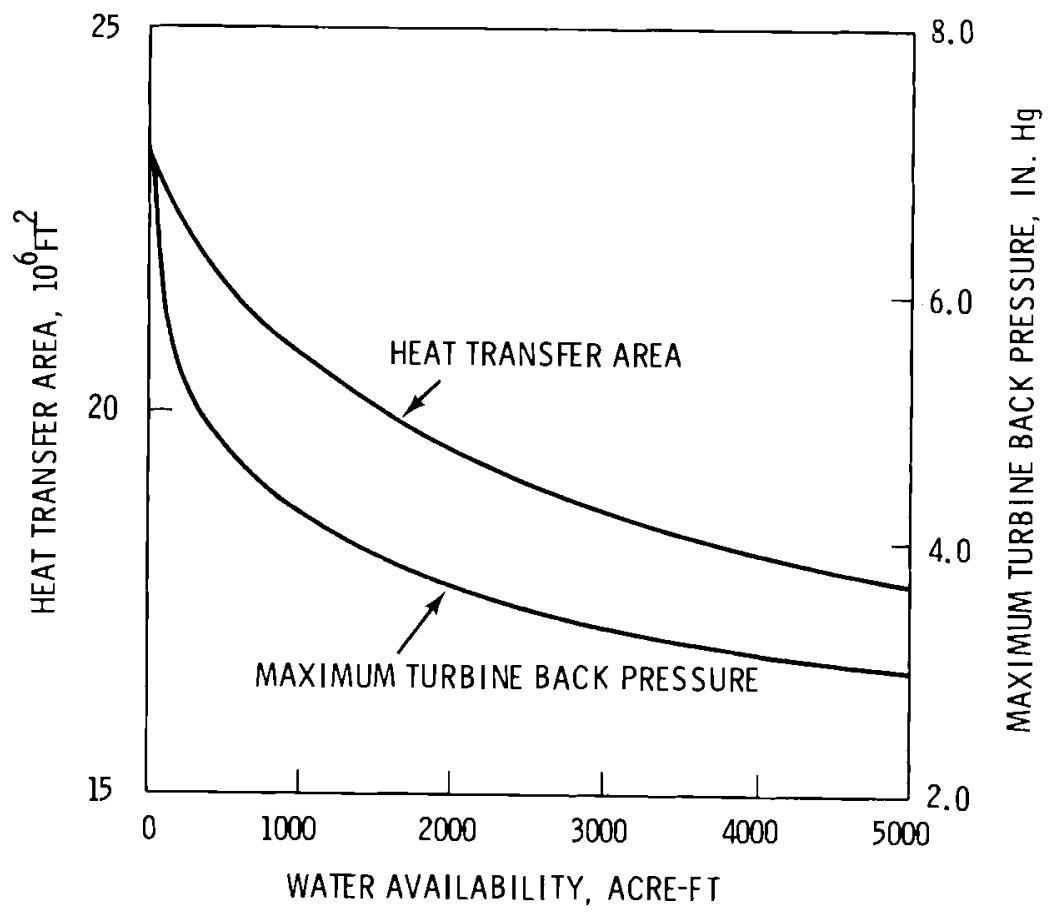

FIGURE 1.2. Optimized Heat Transfer Area and Maximum Turbine Back Pressure as a Function of Annual Water Availability for a 1000-MWe FossilFueled Power Plant

- fan system design (including louvers and velocity recovery),

- ratio of tower roof area to fan-swept area,

- air velocity, and

- turbine models.

The parameters having significant impact on the design, performance, and cost were design temperature, air velocity, and the turbine models. The other parameters were found to have varying degrees of influence on the optimized design of the cooling system, but had relatively little effect on the performance and cost of the cooling system. 
Thus, the most important conclusion from this study is that the HÖTERV deluge system of dry/wet cooling, using ammonia as an intermediate heat transfer medium, offers the potential for significant cost savings compared with a11-dry cooling, while achieving substantially reduced water consumption as compared to an evaporatively cooled power plant. 


\subsection{INTRODUCTION}

The study described in this report was performed as part of the Dry Cooling Enhancement (DCE) program at Batte1le, Pacific Northwest Laboratories (PNL). This work was sponsored by the U.S. Department of Energy (DOE). The objective of this study was to evaluate the potential of the deluged dry/wet method for reducing both the high costs associated with a11-dry cooling and for reducing the water consumption associated with evaporative (a11-wet) cooling.

The deluge surface described in detail here could be replaced by equivalent alternative surfaces or approaches if such should become available. It is not the purpose of this analysis to limit future considerations to the HÖTERV surface. However, at the present time this surface is in a more advanced state of development, having been used in large-scale demonstrations in Europe. It would be the intent of the DOE program in this area to provide opportunity for competitive approaches to this problem of providing some wet or evaporative cooling to reduce the size of dry cooling towers and the quantity of replacement peaking power occasioned by the lower performance of ordinary dry cooling on hot days.

\subsection{BACKGROUND}

The subject of both dry and dry/wet cooling for large electric power generating plants has received significant attention in the last decade due to the realization that, like most natural resources, the nation's water resources are 1 imited.

Dry cooling offers a great potential for reducing consumptive water use by the electric power industry. However, the inherent high costs of dry cooling make it quite undesirable. Because of this, only one large steam electric power plant in the U.S. uses dry cooling, that one being at Wyodak, Wyoming. 
In an effort to reduce the high cost of dry cooling, several studies have been done. A review of these studies is available. (1) Another study (2) concludes that a dry cooling system, using ammonia as an intermediate heat transfer medium between the turbine exhaust steam and the ambient air, and using a conventional spiral-wrapped finned-tube heat exchanger, offers the potential for significant cost savings compared to state-of-the-art dry cooling systems using water as the heat transfer medium.

Dry/wet cooling offers a compromise between a11-dry cooling and evaporative cooling. It can reduce the cooling system costs considerably below the costs of all-dry cooling while providing significant water savings relative to an evaporatively cooled plant.

Several methods of dry/wet cooling are potentially available. The fundamental combinations of dry and wet cooling are discussed in an earlier report. (3) The combinations are classified according to the flow patterns of water and air (i.e., series or parallel flow of the water and series or parallel flow of the air). The dry portion of the dry/wet cooling system would likely consist of an extended surface heat exchanger. The wet portion may be a conventional wet tower, spray pond, etc. A power plant with a series water flow and parallel airflow dry/wet cooling system is being built by the Public Service of New Mexico.

Since the ammonia dry cooling system showed a potential for reducing the cost of conventional dry cooling, it was speculated that it could also improve the costs of dry/wet cooling. One method by which the ammonia cooling system could be augmented by evaporative cooling is termed "deluge." The deluge heat transfer method requires a thin film of water (the delugeate) to flow over an extended fin surface. Lab scale experiments at PNL showed that this was not feasible with the conventional spiral-wrapped finned tube. A new candidate surface was chosen, this being the HÖTERV surface, named for its developers at the Hungarian Institute for Power Plant Design (HÖTERV), Budapest, Hungary. 
The HÖTERV surface is a horizontal-tube, vertical-plate-finned tube arrangement. The delugeate is distributed to the top of the heat exchanger. It is allowed to fall by gravity in a thin film on the surface of the plate fins. In this way, the heat transfer area of the finned surface is not diminished during deluge operation. However, the deluge method of wet/dry cooling will likely use more water than conventional dry/wet cooling methods, because as the deluge is engaged, the dry portion of the heat exchanger becomes smaller and thereby contributes less to the heat transfer. The cost advantage of deluge augmentation is that only one cooling surface needs to be provided.

The expected merits of deluge augmentation suggested that an optimization design code was needed to help study the deluge configuration for dry/wet cooling of power plants. That is the subject of this investigation.

\subsection{SCOPE OF REPORT}

This report:

- defines the physical components of the cooling system from the outlet of the low pressure turbine exhaust flange;

- describes the model upon which the analysis of the cooling system is based (This includes the description of the cooling system interaction with the remainder of the power plant and the utility system.);

- defines and compares three optimum cooling system designs: the all-dry spiral-wrapped finned tube, the all-dry HÖTERV surface, and the HÖTERV surface with a water allotment of 3000 acre-ft. Each system is designed for a 1000-MWe power plant having a capacity factor of 75.8 percent; and

- presents the results and discussion of the parametric study of the significant cooling system design parameters. 



\subsection{PHYSICAL DESCRIPTION OF COOLING SYSTEM}

This section provides a physical description of the cooling system modeled in this study. No attempt is made in this section to justify the model, the features of the associated algorithms, or the results.

The cooling system is described in a general sense, i.e., specific design and performance parameters are not discussed.

\subsection{GENERAL OVERVIEW}

The power plant cooling system is defined herein to include all of the plant components that are connected by, or directly associated with, the primary coolant medium of the heat rejection system. In general, this includes the plant components beyond the low-pressure turbine exhaust flange in the thermodynamic cycle.

The cooling system that has been the object of this study is shown schematically in Figure 3.1. The primary coolant medium is ammonia, which indirectly transfers the low availability energy from the low-pressure exhaust steam to the atmosphere. The principal components of the cooling system are the condenser/reboiler, the ammonia distribution piping, and the cooling towers.

The temperature relationship between the steam, ammonia, and air for the heat rejection cycle is shown in Figure 3.2 .

The heat rejection process begins as low-pressure steam enters the condenser/reboiler. Heat is transferred from the steam in the shell to the ammonia in the tubes while both fluids experience a phase change. That is, the steam condenses at constant temperature and the liquid ammonia vaporizes at constant temperature after being heated from a slightly subcooled state. The condensed steam is returned to the feedwater circuit. At the condenser/ reboiler outlet the ammonia vapor is separated from the ammonia liquid which is collected for recirculation to the condenser/reboiler. The nearly saturated ammonia vapor is distributed to the cooling towers. Pressure losses 


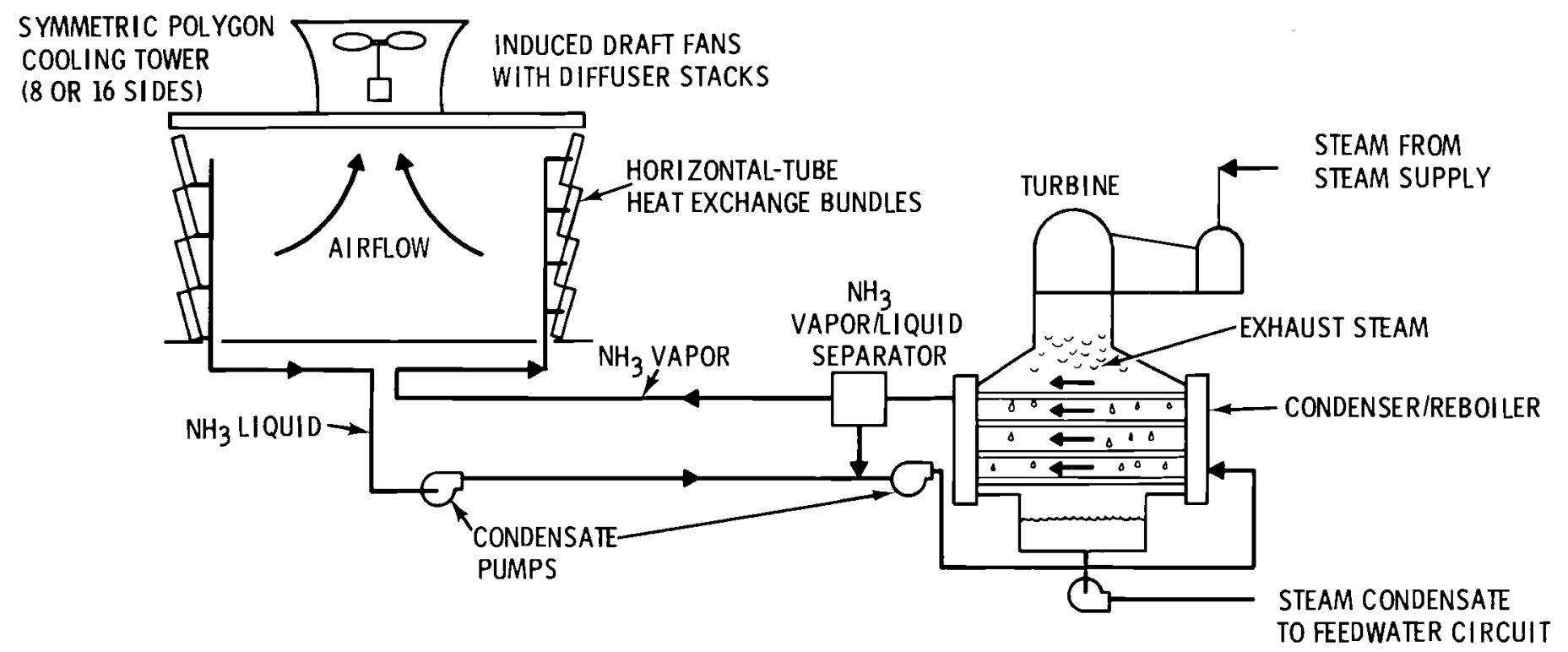

FIGURE 3.1. Indirect Dry/Wet Cooling System with Ammonia as the Intermediate Coolant 


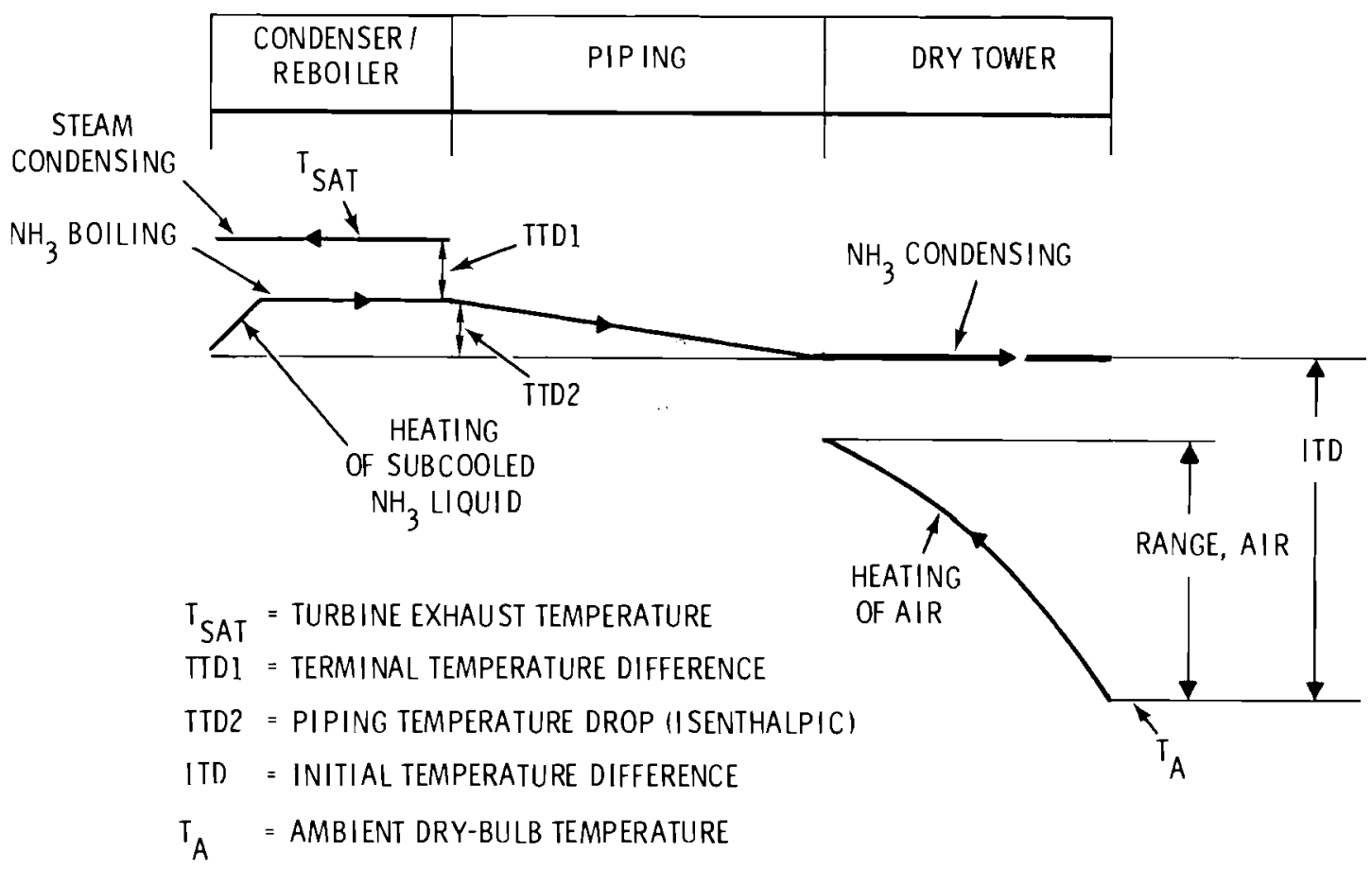

FIGURE 3.2. Temperature Relationships for Steam, Ammonia, and Air (Dry-Bulb) for the Indirect Cooling System with Ammonia as the Intermediate Coolant

in the distribution piping cause the temperature of the saturated vapor to decrease slightly. The vapor is passed through horizontal tubes in the platefinned heat exchanger bundles where it condenses at constant temperature. The ammonia liquid is returned to the condenser/reboiler.

Condensation of the ammonia vapor occurs as heat is transferred to air that is passed over the finned surface of the heat exchanger. The airflow is induced by fans on the roof of the cooling tower.

To enhance the cooling capacity of the finned surface when the air drybulb temperature is high, water is distributed to the top of the cooling tower. The water forms a film over the plate fins and is allowed to flow to the base of the tower where it is collected and recirculated. This form of enhanced cooling has been termed "deluge" cooling. The water is specifically referred to as the deluge water or delugeate. 


\subsection{CONDENSER/REBOILER}

The condenser/reboiler is similar in appearance to the conventional single pass shell and tube surface condenser. The most significant modification employed in this study has been the use of enhanced heat transfer surfaces on both the ammonia side and steam side of the horizontal tubes. The aluminum tubing requires that stainless steel impingement shields be provided to protect against steam erosion. The water boxes of a conventional condenser are replaced with tube headers. The headers, tubes and tube sheets are specified to accommodate ammonia pressures up to $400 \mathrm{psi}$.

Design specifications of the condenser/reboiler include:

- nominal tube OD of 1 in.,

- tube length of $50 \mathrm{ft}$,

- tube depth in the direction of steam flow of $10 \mathrm{ft}$,

- 2 shells, and

- $\mathrm{NH}_{3}$ exit quality of 0.8 .

\subsection{PIPING SYSTEM}

The ammonia distribution piping system is divided into the supply piping, which transports the ammonia vapor from the condenser/reboiler to the heat exchanger bundles, and the return piping, which transports the ammonia liquid from the heat exchanger bundles to the condenser/reboiler. Both the supply and return piping have been further divided into the main circulation piping and the tower distribution piping. The tower distribution piping is described in the next section on cooling towers.

The main circulation supply and return piping is shown in Figure 3.3. The supply and return piping are modeled as having nearly identical plan views. The pipe diameters are different, however, because of dramatically different densities and design velocities between the ammonia vapor and liquid. In addition to the pipe, the design includes specification of valves, tees, elbows, reducers, and flanges, as required. The pipe, valves, and 
fittings are designed for 350 psi. Al1 pipe components are assumed to be available in sizes from 6- to 144-in. diameters in 6-in. increments. Pipe sizing is based on the mass flow rate and design velocity. The distance from the condenser/reboiler outlet to the first tower is $500 \mathrm{ft}$. The lengths of pipe are otherwise based on the tower spacing, which is $3 / 2$ of the equivalent tower diameter. Further details of the circulation piping design are available. $(4,5)$

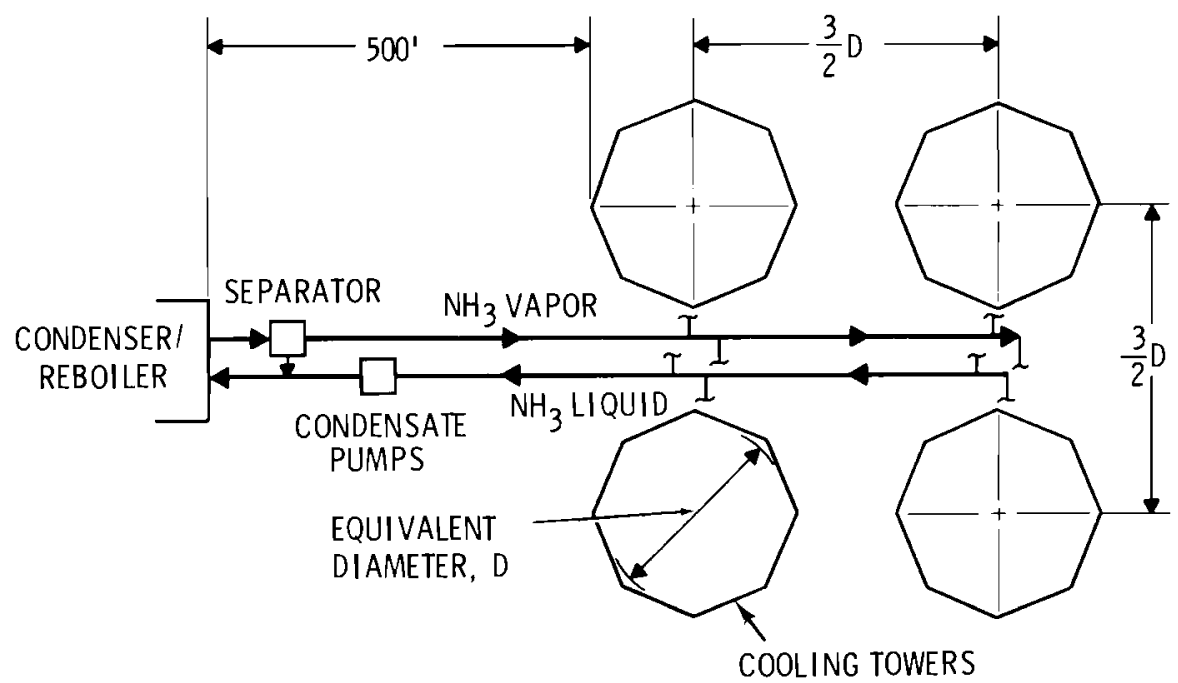

FIGURE 3.3. Ammonia Circulation System for the Vapor Supply and Liquid Return

\subsection{COOLING TOWERS}

The principal components of the cooling towers are the ammonia and deluge piping, the heat exchanger bundles and the fan system. While other design features (such as tower structures) are required, they play only a supportive role in the heat rejection process and are, therefore, not discussed here.

\subsubsection{Tower Configuration}

The cooling towers are modeled as symmetric polygons having either 8 or 16 sides. As shown in Figure 3.3, the towers are spaced on a square grid with the distance between adjacent towers being $3 / 2$ of the equivalent tower diameter. The diameter is based on the roof area of each tower. It should 
not be implied from Figure 3.3 that only four towers are allowed. Designs may have any number of towers. Towers are evenly spaced in the direction of the main circulation piping. All towers are opposed by a tower on the opposite side of the main circulation piping unless the total number of towers is odd, in which case one of the corner positions on the grid would be vacant.

\subsubsection{Ammonia Piping}

The ammonia distribution piping in the towers is shown in Figure 3.4 for an 8-sided tower and Figure 3.5 for a 16-sided tower. In addition to the pipe, the design includes specification of valves, tees, elbows, reducers and flanges, as required. Al1 pipe, valves, and fittings are designed for 350 psi. All pipe components are assumed to be available in sizes from 6to 144-inch diameters in 6-inch increments. Pipe sizing is based on mass

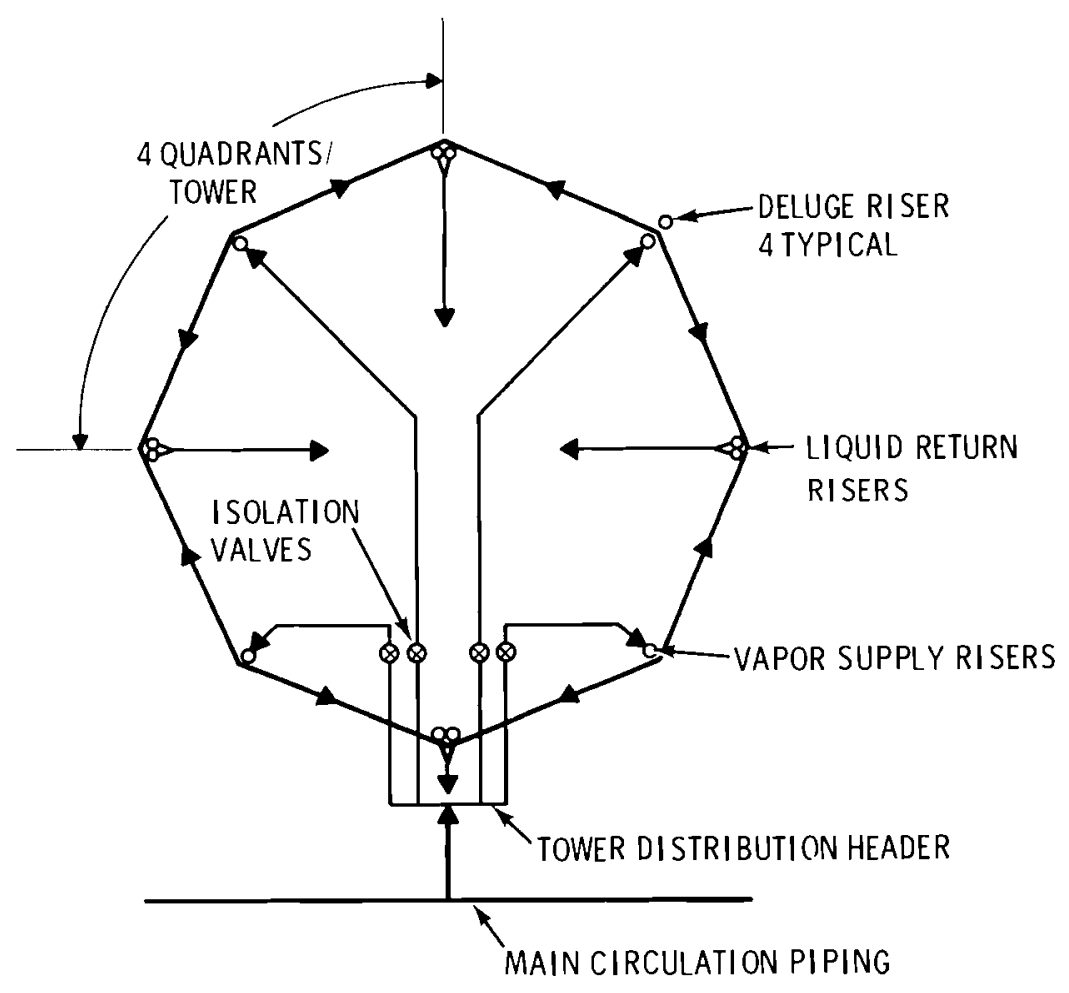

FIGURE 3.4. Ammonia Distribution Piping in an 8-Sided Tower 


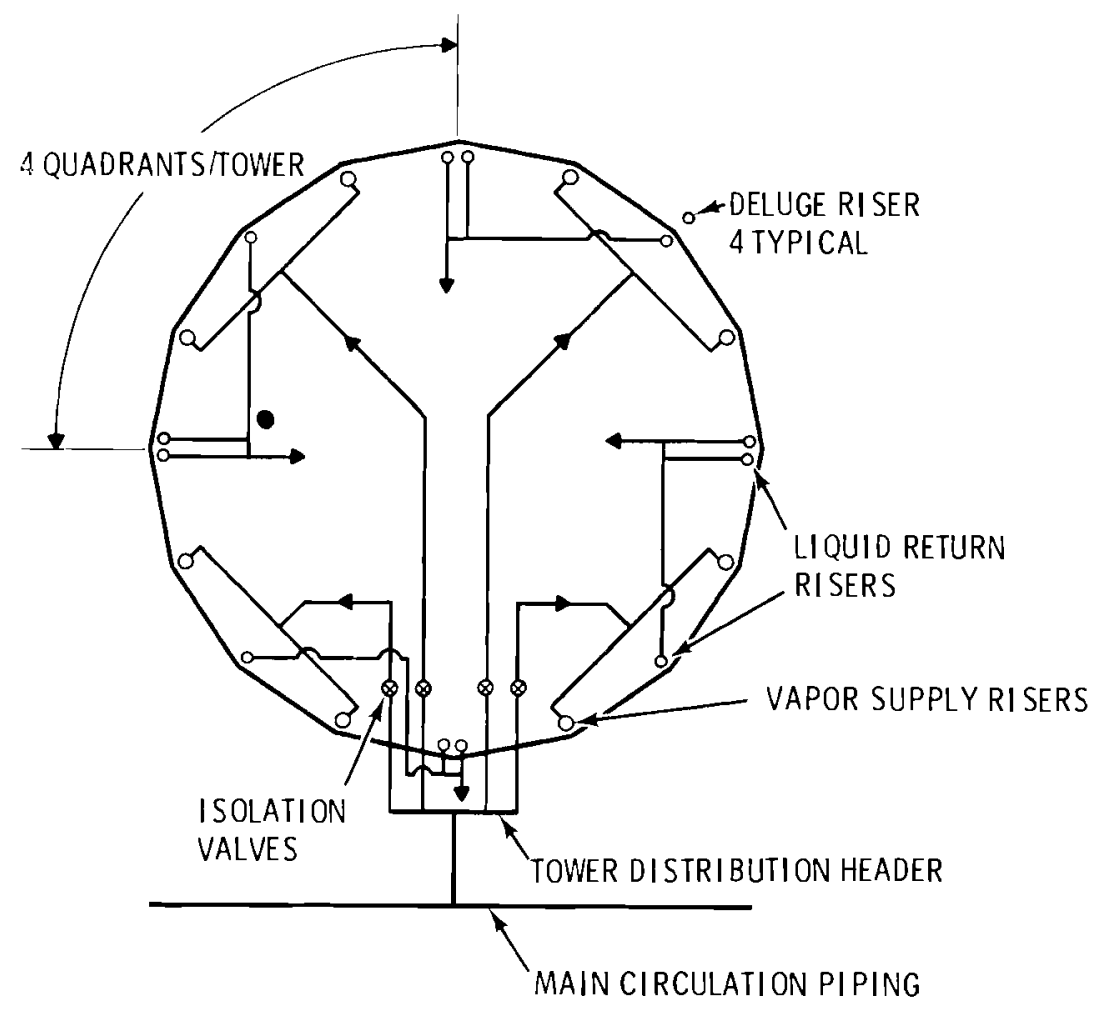

FIGURE 3.5. Ammonia Distribution Piping in a 16-Sided Tower

flow rate and design velocity. The supply and return systems follow nearly identical routes. However, pipe diameters are different because of dramatically different densities and design velocities between the ammonia liquid and vapor. The ammonia vapor from the main circulation piping is distributed to the four tower quadrants through the tower distribution header. Isolation valves are provided for each quadrant for the purpose of safety and operational control. The vapor is distributed to the headers of the horizontal-tube heat exchanger bundles by a riser. The ammonia is distributed to headers on either side of the riser. This is shown in Figures 3.6 and 3.7 for the 8-sided and 16-sided towers, respectively.

The features of the tower piping for the vertical-tube circular-tower a17-dry ammonia cooling system ${ }^{(4,5)}$ formed the starting point for this design. 

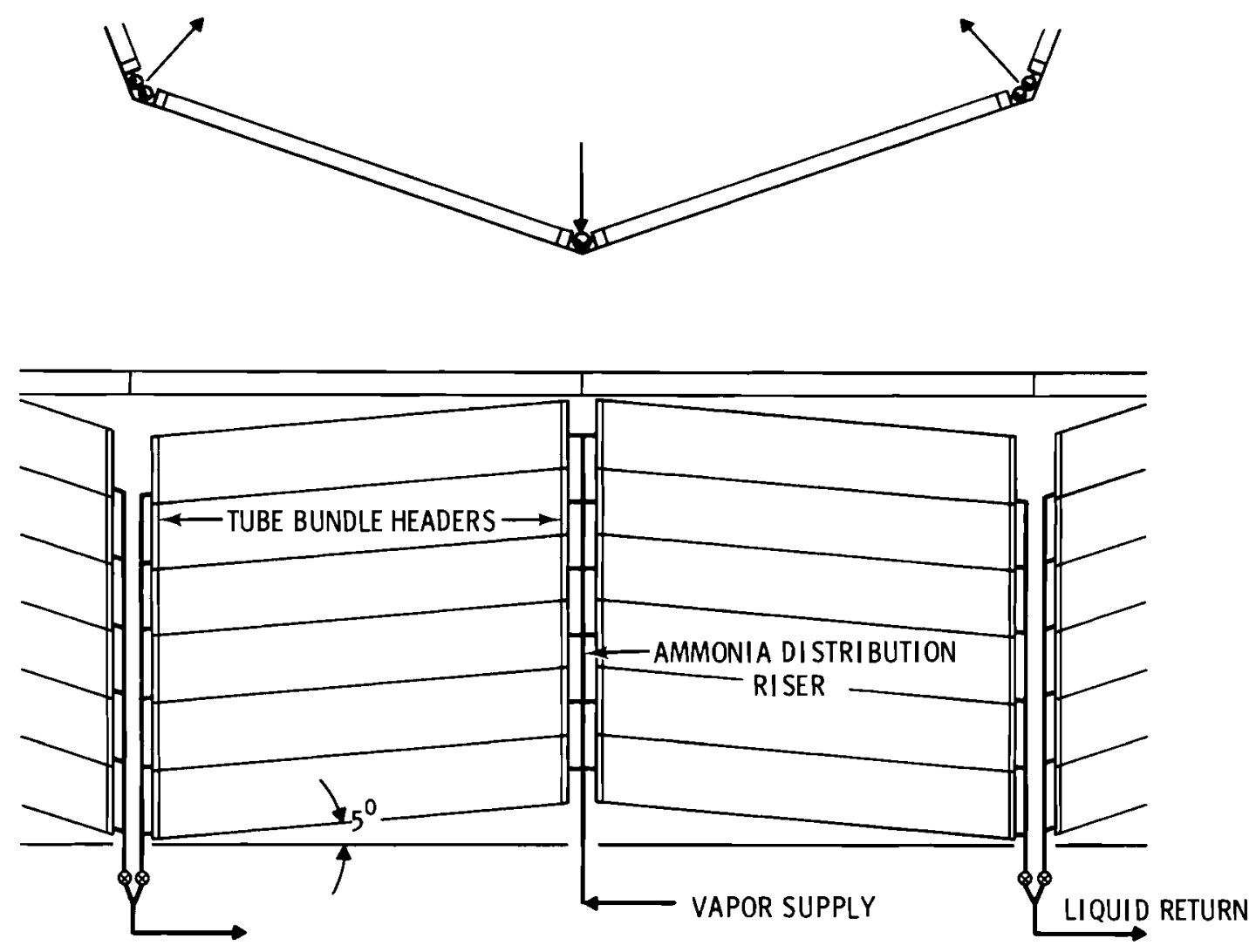

FIGURE 3.6. Ammonia Distribution and Collection to the Heat Exchanger Bundles for a 8-Sided Tower

\subsubsection{Heat Exchanger Bundles}

The guts of the cooling system are the heat exchanger bundles. The bundles are comprised of a staggered arrangement of circular, parallel tubes. The tubes are tied together by continuous plate fins that are perpendicular to the tubes in two directions; i.e., both the face and the leading edge of the plate fin are perpendicular to the axis of each tube. This HÖTERV surface is shown in Figure 3.8. Headers on either end of the tube and plate fin assembly distribute and collect the ammonia coolant in the tubes.

The bundle width is limited to $12 \mathrm{ft}$ (Figure 3.9). The total bundle length is not limited by manufacturing or shipping constraints since any number of bundle segments can be bolted end-to-end. The bundles are arranged 

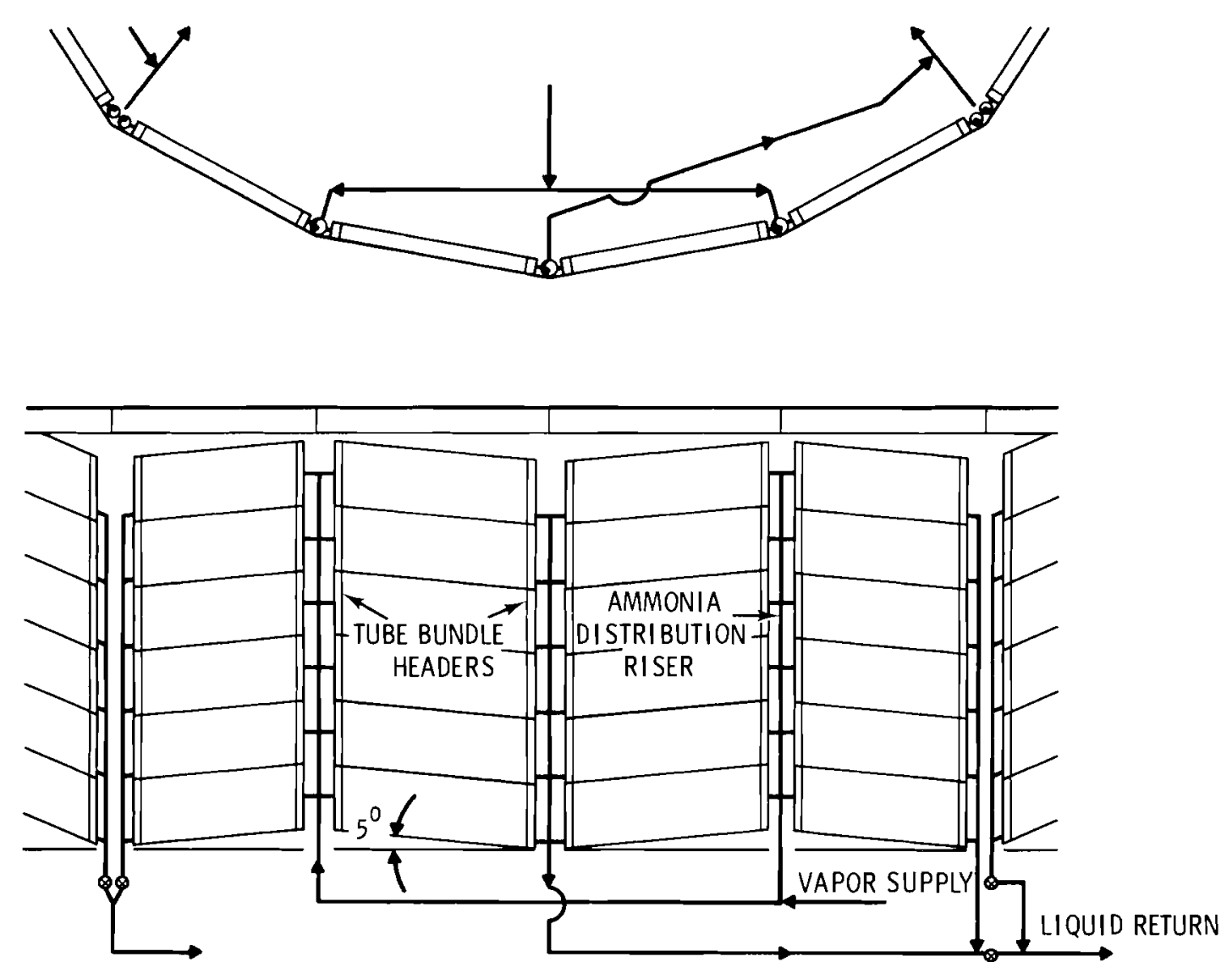

FIGURE 3.7. Ammonia Distribution and Collection to the Heat Exchanger Bundles for a 16-Sided Tower

on the sides of the towers as shown in Figures $3.6,3.7$ and 3.8 . The bundles are tilted 5 degrees from horizontal (Figures 3.6 and 3.7 ) to assist in the collection of the ammonia liquid. The face of each bundle is tilted 15 degrees from vertical (Figure 3.9) so that the effects of gravity and air friction will balance to prevent the leading edge of the plate fins from drying out during deluge operation.

\subsubsection{Deluge Piping}

The deluge water is pumped to the top of the tower via a riser at the center of each tower quadrant (see Figures 3.4, 3.5, and 3.9). The bulk of the deluge water is distributed to the deluge distribution plate at the top of the tower by a pipe that extends from the riser to the ends of the quadrant. At the top of each subsequent lower tube bundle, deluge water is 
6 TUBE ROWS IN DIRECTION

OF AIRFLOW

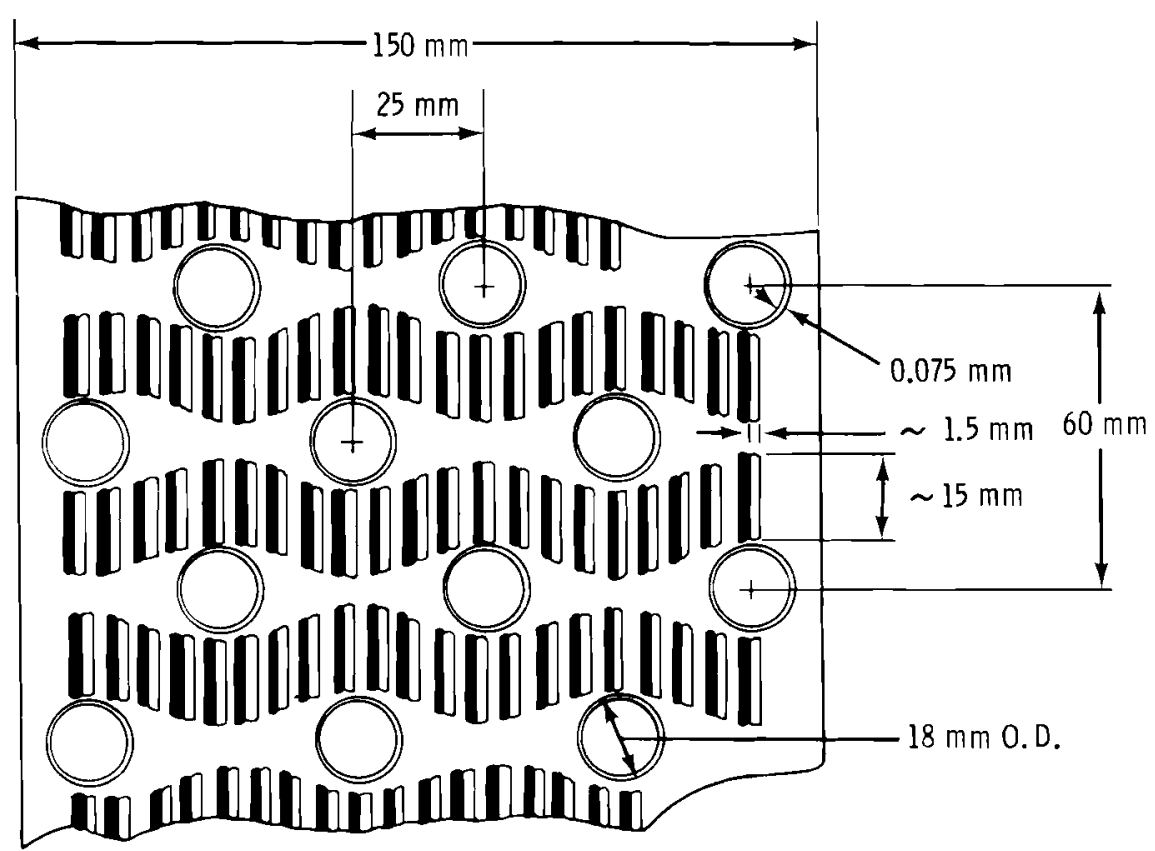

FIGURE 3.8. The HÖTERV Heat Exchanger Plate Fin and Tube Arrangement

supplied by a smaller pipe which also extends from the riser to the end of the quadrant. This secondary deluge water is provided to make up the water that has evaporated from the adjacent upper bundle.

The deluge distribution plates catch the deluge water that is not evaporated, and redistributes this water, along with the make-up water to the bundle below. At the base of each tower a gravity drain returns the deluge water to a sump. Water is treated and the appropriate amount of make-up water is provided.

\subsubsection{Fan System}

Airflow through the heat exchanger is induced by single-speed, singlepitch fans that rest on the roof of the cooling tower. Fans are assumed to be available with blade diameters of $24,26,28,30,40$, or $60 \mathrm{ft}$. 


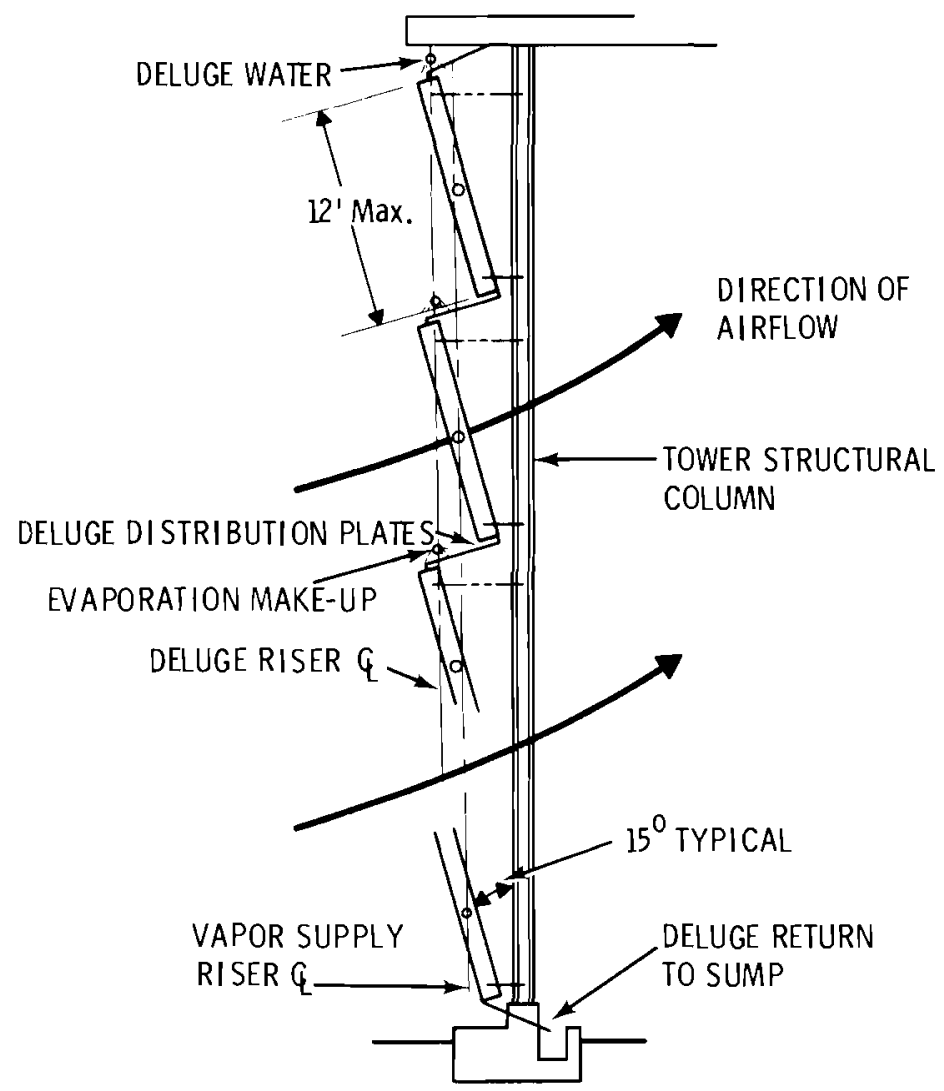

FIGURE 3.9. Cross Section of a Tower Side 


\section{-

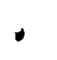

• 


\subsection{METHOD OF ANALYSIS}

The method for determining the optimum design, performance and cost of the cooling system is presented in this section.

\subsection{COST OPTIMIZATION}

The foremost consideration in the evaluation of the cooling system is the consideration of cost. The cost attributed to the cooling system is found by considering the cost impact of the cooling system on the remainder of the power plant and the entire utility system, as well as determing the costs directly associated with the physical components. Assuming that the models (design, performance, cost) used to describe the cooling system and the power-plant/utility-system interface are reasonable, then the optimum system, based on these models, is that which incurs the least cost.

To establish the design, performance, and cost of the optimum system, a computer program has been developed. The ground work for the optimization logic was developed by Andeen and Glicksman. (6) The code developed at PNL for the study of all-dry cooling systems is described in an earlier report. The code has been further developed for evaluation of dry/wet cooling systems; ${ }^{(7)}$ i.e., the subject of this report.

\subsubsection{Independent Variables}

Four equations define the heat rejection of a power plant using an indirect ammonia system with dry/wet cooling. These are:

$$
\begin{aligned}
\text { QREJ } & =f(T S, \text { turbine }) \\
\text { QREJ } & =U A \text { LMTD } \\
& =U A\left[\frac{\text { RANGE }}{\ln \left(\frac{I T D}{\text { ITD }- \text { RANGE }}\right)}\right] \\
\text { QREJ } & =\text { WAIR } \cdot \text { CPAIR - RANGE }
\end{aligned}
$$




$$
\text { QREJ }=\text { WNH3 } \cdot H F G
$$

Equation 4.1 defines the heat rejection based on the efficiency; i.e., the heat rate of the turbine-generator. The heat rate is also a function of exhaust steam temperature, TS.

Equation 4.2 defines the heat rejection from the ammonia to the air based on the driving force for heat rejection and the thermal conductance. This equation is written for heat transfer in the dry mode. The driving force for heat rejection is the log mean temperature difference, LMTD. The LMTD is further defined according to the range of the air, RANGE, and the initial temperature difference, ITD. By definition,

$$
\text { ITD = TS - TTD1 - TTD2 - TA }
$$

where TTDI is the terminal temperature difference of the condenser/reboiler (steam temperature - ammonia temperature), TTD2 is the temperature drop of the ammonia due to frictional pressure losses in the piping from the condenser/reboiler to the heat exchange inlet, and TA is the ambient drybulb air temperature (see Figure 3.2). The thermal conductance is the product of the overall heat transfer coefficient, $U$, and the heat transfer area, A, upon which $U$ is based.

Equation 4.3 defines the heat transferred to the air where WAIR is the mass flow rate of air, CPAIR is the constant pressure-specific heat of air, and RANGE is the temperature rise of the air as it passes through the heat exchanger.

Equation 4.4 defines the heat transferred from the ammonia where WNH3 is the mass flow rate of ammonia and HFG is the heat of vaporization of ammonia for the ammonia temperature in the heat exchanger.

These four equations are interrelated because the heat rejection requirements of the power plant must match the performance of the cooling system and the heat transfer mediums. To specify the cooling system design, each of 
these equations must be represented. Furthermore, it is observed that independent specification of a total of six variables will provide a basis for establishing all the remaining variables. Given that one of these variables is the temperature of the air. TA, then the necessary set of variables is reduced to five. Specifying the five variables and TA establishes the cooling system design when the design and performance models are also provided. These include specification of such details as heat exchanger unit geometry, correlations for heat transfer coefficients and friction factors, turbine heat rate curves, fan performance curves, etc.

The five selected variables are the exhaust steam temperature, the heat exchanger tube length, the number of heat exchanger tube rows in the direction of airflow, the terminal temperature difference of the condenser/reboiler, and the frontal velocity of the air at the heat exchanger. The steam temperature represents Equation 4.1. The tube length and the tube rows in the direction of airflow represent Equation 4.2 where the heat transfer area is a function of these two parameters as well as the heat exchanger width and the heat exchanger unit geometry. The frontal velocity of the air represents Equation 4.3 where the mass flow rate of air can be evaluated in terms of frontal area and frontal velocity. The terminal temperature difference of the condenser/reboiler represents Equation 4.4 where the specification of TS and TTDI and the calculation of TTD2 provides the ammonia temperature at the heat exchanger inlet. The heat of vaporization is a function of this temperature.

The five variables are not a unique set. Other variables and combinations of variables could also be used to generate independent sets of variables that could lead to legitimate cooling system designs. However, the selected set of five variables has the advantage that each of the variables is independent of the power plant size. For example, the range of the air is known to be some percentage of the ITD. Therefore, the mass flow rate of the air depends on the required heat rejection, i.e., the power plant size. In contrast, the frontal velocity of the air is a typical value, when once established, for any size power plant. Thus, the frontal velocity of the 
air was considered to be a more appropriate independent variable than the mass flow rate of air. In addition, the significance of the frontal velocity of the air as well as each of the other variables is most easily understood.

The optimization process within the computer code is based on the five independent variables. It must be realized that the design specifications which are input to the code are also independent. Thus, while the code optimizes the five variables based on a given set of input conditions, a thorough optimization requires that a matrix of input conditions also be evaluated. The delineation of the independent variables into the internal independent variables (the five variable sets) and the external independent variables (the input conditions) is discussed in an earlier report. (2)

\subsubsection{Dependent Parameters/Calculational Procedure}

When a set of the five internal independent variables is defined the remaining cooling system design, performance and cost parameters must be subsequently determined. In this section the procedure used by the computer code is outlined according to the approximate sequential steps that are taken. The procedure is basically divided into two parts. In the first part the plant parameters are evaluated on the basis that the cooling system is in the alldry mode. In the second part the performance is evaluated with deluge water added to the cooling surface.

The steam supply scaling is computed as a separate calculation prior to the calculations done in this outline. Steam supply scaling, as discussed in Section 4.3.3, depends only on the rated heat rate of the turbine being used in the design calculations. As such, it is not a function of cooling system design or performance.

\subsubsection{Dry Mode Design}

The dry mode design procedure is quite lengthy. To avoid excessive discussion, the steps of the analysis are presented in a sequential manner using necessary comments and program nomenclature. 
1. Fix values of five independent variables.

$$
\mathrm{TS}=\text { exhaust steam temperature (saturated) }
$$

TTD1 = condenser/reboiler terminal temperature

$L=$ heat exchanger tube length

$D=$ heat exchanger depth, tube rows in the direction of airflow VAF = frontal velocity of air.

A11 subsequent calculations involve the definition of the dependent variables. All variables used but not calculated are assumed to be input.

2. Turbine back pressure,

$$
T B P=f(T S)
$$

3. Turbine heat rate factor,

$$
\text { HRFAC2 }=f(T B P)
$$

The heat rate factor, HRFAC2, is the ratio of the heat rate of the turbine at the design back pressure, TBP, to the heat rate of a conventional turbine at $3.5 \mathrm{in}$. Hg. The significance and implications of the heat rate factor are magnified in Section 4.3.

4. Thermal efficiency,

$$
T E F F 2=f(\text { HRFAC2 })
$$

5. Required plant heat rejection,

$$
Q R E J=f(T E F F 2)
$$

6. Heat of vaporization of ammonia,

$$
H F G=f(T S-T T D 1)
$$


7. Ammonia flow rate,

$$
W N H 3=Q R E J / H F G
$$

8. Air-side heat transfer coefficient,

$$
H O=f(V A M)
$$

The heat exchanger unit geometry input to the computer code defines the ratio of the minimum free flow area, AMIN, to the frontal area, AFRON, as SIGMA. The maximum air velocity, VAM, is

$$
V A M=V A F / S I G M A
$$

where SIGMA = AMIN/AFRON. The calculation of air-side heat transfer coefficient is given in Appendix $A$.

9. Guess the temperature drop of the ammonia in the piping system, TTD2G.

10. Guess heat exchanger width, WG. See Figure 4.1 for the heat exchanger dimensions.

11. Total number of heat exchanger tubes,

$$
N T=f(W G, D)
$$

12. Ammonia-side heat transfer coefficient,

$$
H I=f(N T, W N H 3)
$$

13. Overall heat transfer coefficient,

$$
U=f(H I, H O \text {, Tube Resistance) }
$$

The overall heat transfer coefficient depends on the fin efficiency which is discussed in Appendix $B$. 


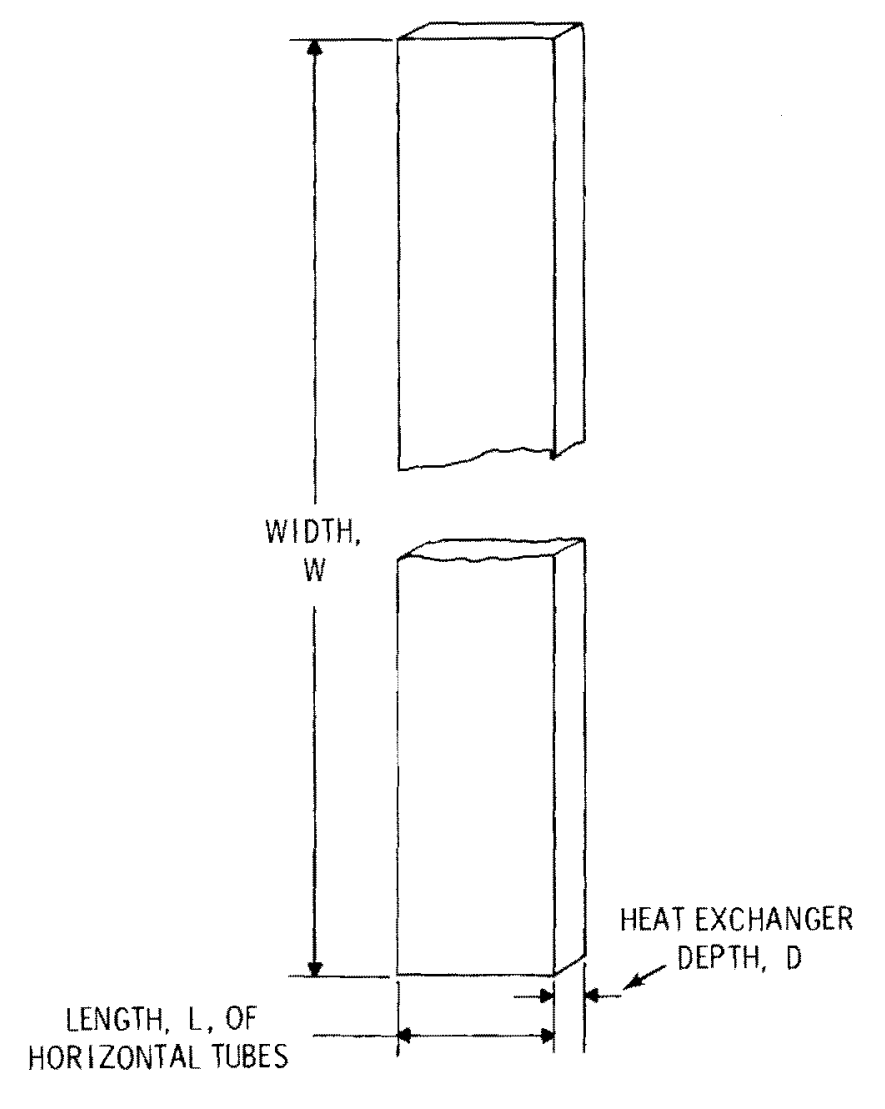

FIGURE 4.1. Pictorial Definition of Overall Heat Exchanger Dimensions

14. Total mass flow rate of air,

$$
W A I R=R H O A(W G \cdot L) \text { VAF }
$$

where RHOA is the air density and $W G$. $L$ is frontal area.

15. Temperature rise of the air through the heat exchanger,

$$
\text { RANGE }=\text { QREJ } /(\text { WAIR } \cdot \text { CPAIR })
$$

where CPAIR is the constant pressure specific heat of air. 
16. Effectiveness of the heat exchanger,

$$
E F F=R A N G E /(T S-T T D 1-T T D 2-T A)
$$

where TA is the ambient design air temperature.

17. Number of transfer units of heat exchanger,

$$
\text { ANTU }=-\ln (1-E F F)
$$

18. Total air-side heat transfer area,

$$
A A I R=A N T U \cdot \text { WAIR } \cdot \text { CPAIR/U }
$$

19. Determine width from the area, length, depth, and unit geometry,

$$
W=f(\text { AAIR, } L, D \text {, unit geometry })
$$

20. Compare $W$ to $W G$. I terate to Step 10 as required.

21. Pressure drop of air through heat exchanger,

$$
D E L P A=f(V A M)
$$

The correlation for the pressure drop is given in Appendix A.

22. Define the fan system, number of towers, tower height, and combined fan system, structures and foundation cost.

a. For a fan-blade diameter, FAND, determine the operating point, i.e., flow rate per fan,

$$
W F A N=f(D E L P A)
$$

b. Number of fans,

$$
\text { NOF }=\text { WAIR/WFAN }
$$


c. Fan power,

$$
\mathrm{FPOW}=\mathrm{HPPF} \cdot \mathrm{NOF}
$$

where HPPF is the horse power per fan.

d. Number of towers,

$$
\text { NTOW }=F^{2} \cdot N O F \cdot P F A C T / T O W D^{2}
$$

where PFACT is the packing factor, i.e., the ratio of the tower roof area to fan swept area, and TOWD is the tower diameter based on the tube length, $L$, and the number of tower sides.

e. Tower height,

$$
\text { HTOW }=W /(\text { NSIDES } \cdot \text { NTOW })
$$

where NSIDES is either 8 or 16 sides.

f. Determined combined fan system, structures, and foundation costs.

23. Design and cost ammonia vapor supply piping,

$$
\text { Design }=f(\text { WNH3, DESVELV })
$$

where DESVELV is the nominal design velocity of the ammonia vapor.

a. Define ammonia vapor pressure drop, DELPS.

b. Define ammonia temperature, TIN, at heat exchanger inlet by virtue of saturation pressure.

c. TTD2 $=$ TCONOUT - TIN

where TCONOUT is the ammonia temperature at the outlet of the condenser/reboiler. 
24. Compare TTD2 with TTD2G. Iterate to Step 9 as required.

25. Design and cost ammonia liquid return piping.

$$
\text { Design }=f(\text { WNH3, DESVELL })
$$

where DESVELL is the nominal design velocity of the ammonia liquid. Define the pressure drop of the ammonia liquid, DELPR.

26. Design and cost condenser/reboiler.

$$
\text { Design }=f(T S, T T D 1, \text { QREJ, XQUALY })
$$

where XQUALY is the exit quality of the ammonia vapor. Define the ammonia pressure drop, DELPC.

27. Define the ammonia pressure drop through the heat exchanger, DELPHX.

28. Design and cost ammonia pumps,

$$
\text { Ammonia power pump }=f\left(\sum \text { Pressure drops, } W N H 3\right)
$$

29. Deluge pump power $=f$ (total deluge water, HTOW).

30. Pump power,

$$
\text { PPOW }=\text { (ammonia + deluge }) \text { pump power } \text {. }
$$

31. Base plant scaling for heat rate, HRFAC2, and auxiliary power, FPOW (Step 22.C) + PPOW (Step 30). Steam supply and base plant scaling determine the fuel cost differential.

32. Determine turbine back pressure for each ambient temperature in the meteorological profile. 


\subsubsection{Deluge Enhancement}

Two methods have been built into the computer code to evaluate deluge heat transfer. One method employs an experimentally derived correlation developed for the HÖTERV surface. This correlation was made available through Babcock and Wilcox. The correlation is given in Appendix $A$. A second method employs fundamental theory of the evaporative heat transfer process to evaluate deluge enhancement. This is discussed in Appendix $C$.

The calculation of the deluge enhancement is dominated by the requirement that the cooling system, defined by the dry mode calculations, consume all of the available water. Secondly, the turbine model used in the design will have a prescribed turbine exhaust pressure limit curve that is a function of ambient temperature. The first step in the calculations is, therefore, to bracket the problem to assure that all of the available water can be consumed while maintaining the turbine exhaust pressure at or below the limit for all ambient temperatures.

To determine if the dry mode design will satisfy the water consumption and turbine exhaust pressure requirements, three calculational zones were established. These are shown in Figure 4.2. The following sequential steps are taken in the code to bracket and define the deluge enhancement.

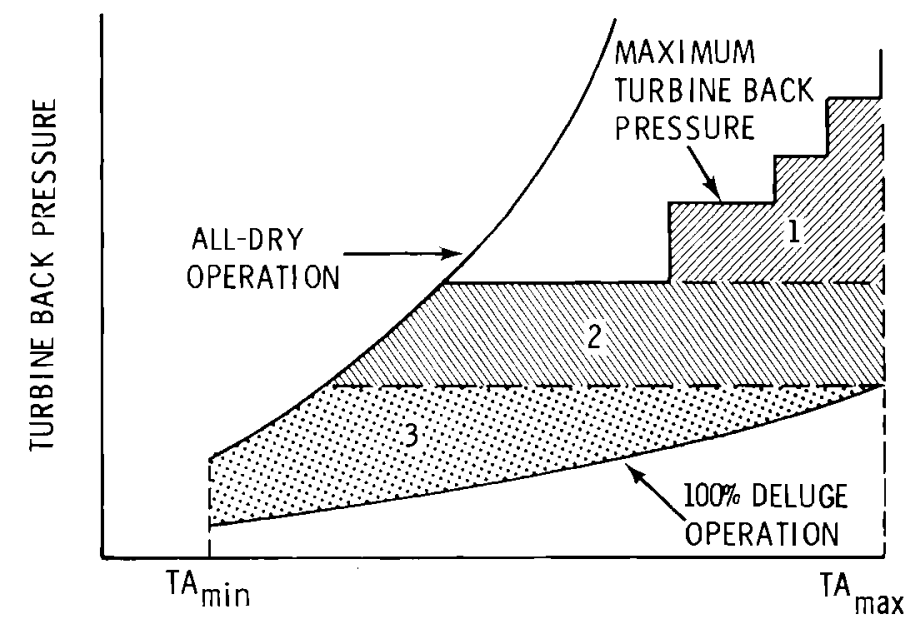

AMBIENT TEMPERATURE

FIGURE 4.2. Operating Regimes for a Power Plant with a Deluged Cooling System 
1. The entire heat exchanger surface is deluged during all operating hours of the year. The total water consumption is evaluated. If the water consumed is less than the water available, then the entire design is rejected, i.e., the prescribed set of the five independent variables is replaced. If all available water can be consumed, then the turbine back pressures for each ambient temperature are stored. However, if any of these back pressures are greater than the limit back pressure at the same ambient temperature, then the design requirements cannot be satisfied and the entire design is rejected.

2. The lowest ambient temperature is determined for which the dry mode exhaust pressure is greater than the turbine exhaust pressure limit at that ambient temperature. This makes use of the results of Step 32 of the dry mode analysis. For this temperature and each higher temperature, evaluate the consumption of deluge water necessary to bring the exhaust pressure down to the exhaust pressure limit. The subsequent total deluge consumption is determined. If the water consumed is greater than the water available then the design is rejected.

3. If the design passes the tests in Steps 1 and 2 then a solution is known to exist. The next step is to determine which calculational zone should be investigated. This is done by bracketing Zone 2 in a fashion similar to Steps 1 and 2 .

a. The exhaust pressure for $100 \%$ deluge when the ambient temperature is $T A_{\max }$ defines the bottom of Zone 2. The lowest ambient temperature is determined for which the dry mode exhaust pressure is greater than the back pressure defining the bottom of Zone 2. The deluge consumption required to maintain this exhaust pressure for ambient temperatures at and above the defined value is determined. If the water consumed is greater than the water available then the solution lies above Zone 3 .

b. The lowest exhaust pressure specified by the maximum turbine back pressure curve defines the top of Zone 2 . The lowest ambient temperature is determined for which the dry mode exhaust pressure is 
greater than the back pressure defining the top of Zone 2. The water consumption required to maintain the exhaust pressure for ambient temperatures at and above the defined value is determined. If the water consumed is less than the water available then the solution lies below Zone 1 .

4. If the design satisfied both $3 a$ and $3 b$, then the solution is in Zone 2 . An iterative procedure is used to determine the operating back pressure for which all of the water available is consumed. This exhaust pressure is assumed to be the same value for each ambient temperature for which deluge enhancement is used. The dry/wet split, i.e., the percent of the heat exchanger surface that is dry and that which is wet, is determined for each ambient temperature.

5. In Zone 3 the exhaust pressure is assumed to be the same value for each ambient temperature for which deluge enhancement is used. However, when the ambient temperature is reached for which the back pressure with $100 \%$ deluge is greater than the constant back pressure, the exhaust pressure corresponding to $100 \%$ deluge is used. The dry/wet split at each ambient temperature is evaluated.

6. The calculations in Zone 1 first determine under which exhaust pressure step the solution exists. The steps are bracketed for water consumption until the subzone is found in which all of the deluge water will be consumed. Thus, the turbine exhaust pressure will follow the maximum exhaust pressure curve until the back pressure is reached for which, if maintained for all higher ambient temperatures, all the available water will be consumed.

When the deluge enhancement calculations are concluded, the operating exhaust pressure is known for each ambient temperature. Using the turbine heat rate factors to determine the electrical output of the power plant on the hottest day, the gas turbine capital cost is determined. The integration of the base plant lost capacity for temperatures above the design temperature leads to the energy cost of the gas turbines.

At this point the calculations are completed for one set of the internal independent variables. 


\subsubsection{Optimization Technique}

The requirements for establishing the cooling system design include the specification of the appropriate independent parameters and the design and performance models. With inclusion of the cost models, the cost optimization can proceed.

The optimization technique begins by appointing values to the initial set of five independent variables. The cooling system design and performance is evaluated. The cost of electricity attributed to the cooling system is evaluated based on capital expenditures, operating expenses, and the costs associated with the power-plant/utility-system interface. In brief, the optimization is then performed by selecting sets of variables and comparing the subsequent costs. The variable set associated with the least cost system is considered to be the optimum.

In the computer code the optimization process is performed in two steps. The subroutines involved are called "SHOT" and "SERCH."

In subroutine SHOT an extensive grid is established with each grid point being a set of values for the five internal independent variables. The values of the variables in each set are determined by the input starting point on the basis of a programmed incremental step size for each variable. For each set of five variables in the matrix, a cooling system is designed and costed. The set of variables associated with the lowest incremental cost is used as the starting point for the second step.

In subroutine SERCH a single variable is adjusted to find the optimum value, i.e., the value associated with the lowest cost, while the four remaining variables are fixed. The optimization is a hill-climbing technique with programmed reduction of step size. If the incremental cost increases, the value of the variable being adjusted is then readjusted in the opposite direction. All five variables are singly optimized in this fashion to determine an optimum set. The process is repeated at least four times. If the result of the fifth optimization is within one percent of the fourth, then the optimization is complete. Otherwise, successive optimizations are developed until the improvement in cost is less than one percent. 
A certain amount of discretion should be used when reviewing the results of this optimization process. One cannot guarantee that the true optimum has been found for any particular design. The design and performance models are believed to cover a range broad enough to include the optimum point. The optimization code has the capability to surround the optimum. However, to secure the true optimum an infinitely tight grid of internal independent variable sets would have to be evaluated for each optimization. This is due to discontinuities in the design and performance parameters associated with the reality of available pipe diameters, fan types, etc.

For the results to be useful it is not necessary that the exact optimum be found. Given the assumptions and constraints of the models, it is believed that the optimization technique provides designs that are at least very near the optimum. Therefore, incentives to further evaluate certain design parameters can be established by consideration of trends that are defined by parametrically studying the external independent parameters.

The computer program is not intended to be an engineering design code. Except for the cost, the code places no merit on comparable designs. Also, some details have been omitted because it was felt that the added complexity would not add to a knowledge of the cooling system. For example, the code may very well specify 103 fans for a cooling system having five towers. Obviously, a single tower cannot include 20.6 fans. However, an engineering design may begin by consideration of 20 or 21 fans per tower.

The computer code is, therefore, dual in purpose. It can establish trends in cost by parametric evaluation of the input variables. It can provide a starting point for the engineering design of a cooling system.

\subsection{INCREMENTAL COST}

Within the context of this report the incremental cost refers to the total of all the costs attributable to the power plant cooling system. The components of the incremental cost include both capital costs and operating costs. These costs are incurred directly by the cooling system or through the cost impact that the cooling system has on the remainder of the power plant and the utility system. 
It is important to note that the incremental cost is referenced to a power plant with a conventional turbine operating at $3.5 \mathrm{in}$. Hg. Steam supply scaling, heat rate scaling and the fuel cost differential are each based on this reference value. That is, if the power plant operated at $3.5 \mathrm{in}$. $\mathrm{Hg}$ throughout the year then both of the scaling components would be zero and the fuel cost differential would only reflect the scaling for auxiliary power.

\subsubsection{Capital Costs}

The cooling system components that require capital expenditures are the condenser/reboiler (including separator), the piping system (including pumps and the deluge supply system), and the cooling tower. Within the cooling tower, costs are provided for the heat exchanger tube bundles (including headers), fan system (including fans, fan motors, electrical components and diffuser stacks), fan plenums, louvers, hail screens, tower structures and tower foundation. In addition, the cost of land can be included. All of these cooling system capital costs are included in the cost variable cCOS.

The utility system model described in Section 4.3 leads to capital costs that are grouped under the headings of steam supply scaling, heat rate scaling, auxiliary power scaling and capacity cost.

\subsubsection{Operating Costs}

The operating costs directly associated with the cooling system are the cost of operation and maintenance and the cost of deluge water.

The operation and maintenance cost is based on a fixed percentage of the cooling system capital costs. The corresponding unit energy cost is calculated according to

$$
\operatorname{COSM}=\frac{\mathrm{CCOS} \cdot \mathrm{PER}}{\mathrm{PSIZE} \cdot \mathrm{CAPF} \cdot 8760}
$$

where

CCOS = total cooling system capital cost,

PER = a fixed percentage (The value used in this study was 1 percent.), PSIZE = base-load power output, 


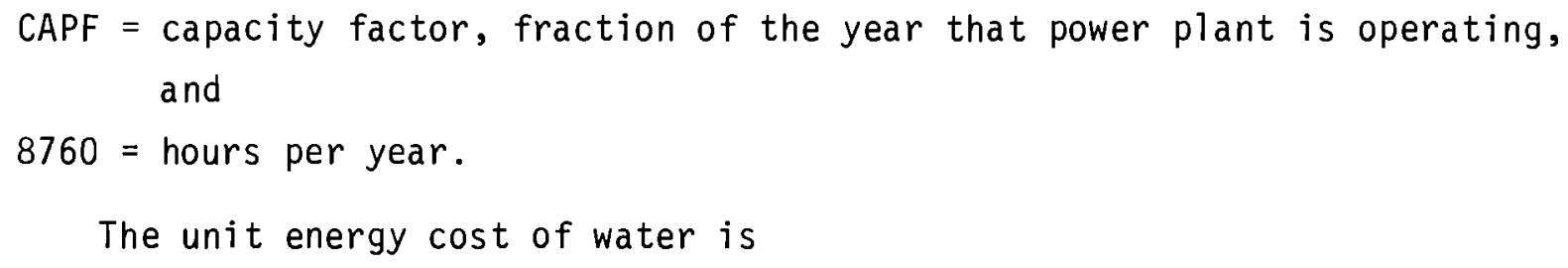

The unit energy cost of water is

$$
\text { WATCST }=\frac{\text { WATCOST } \cdot \text { WATCONA }}{\text { PSIZE } \cdot \text { CAPF } \cdot 8760}
$$

where, additionally,

$$
\begin{aligned}
\text { WATCOST } & =\text { cost of water } / 1000 \text { gal, and } \\
\text { WATCONA } & =\text { total water consumed in thousands of gal. }
\end{aligned}
$$

The utility system model leads to operating costs that are discussed in Sections 4.3.2 and 4.3.6.

\subsection{POWER-PLANT/UTILITY-SYSTEM INTERFACE}

The question of the interface of the dry/wet cooling system with the remainder of the plant and the utility system arises because the power output of the base plant can be strongly dependent upon ambient temperature. It is, therefore, necessary to define the characteristics of the interface and how these conditions are evaluated. Many possibilities exist for the utility system model and methods of supplying replacement power. (1) Rather than discussing all the potential models, however, only that model chosen for this work will be defined.

The backbone of the power-plant/utility-system interface model is that the power plant is defined to be a base-load plant. In this study, the power plant provides a net 1000 MWe to the utility grid during all operating hours. The percent of time the plant is operating is the capacity factor. When the power plant is not operating it provides no power. That is, the plant provides its base load or it provides nothing.

The operating strategy inherent in the utility system model is displayed in the calculational procedure for deluge enhancement, Section 4.1.2.2. The exhaust pressure is defined as some constant value for all ambient temperatures 
at and above which the deluge enhancement is initiated. (a) This was done with the a priori belief that allowing the exhaust pressure to climb on the hottest days of the year would dramatically increase the gas turbine capital and energy costs without actually benefitting other costs. In addition, it is not expected that the exhaust pressure would be maintained at a constant value throughout the daily temperature fluctuations. Instead, the exhaust pressure would fluctuate as unit sections if the heat exchanger surface were engaged with deluge water. It is believed that the constant exhaust pressure model is a good and reasonable approximation of the sawtooth exhaust pressure curve likely to occur in an operating power plant as a result of the diurnal temperature variations.

A term that is used throughout the following discussion is heat rate factor (HRFAC). It is important that this term be clearly understood. The heat rate factor is the ratio of the heat rate of the turbine-generator at the actual operating exhaust pressure to the heat rate of a conventional turbine operating at $3.5 \mathrm{in}$. Hg exhaust pressure. The variations on the heat rate factor are:

- HRFACl - the heat rate factor of the turbine when the turbine is operating at its rated back pressure (The HRFACl of a conventional turbine is unity.),

- HRFAC2 - the heat rate factor of the turbine when the turbine is being operated at the back pressure corresponding to the design point of the turbine, and

- HRFAC4 - the heat rate factor of the turbine when the turbine is being operated at a back pressure corresponding to an ambient temperature other than the design point ambient temperature.

\subsubsection{Excess Capacity}

The design temperature of the power plant/cooling system is the ambient dry-bulb temperature for which the base plant can provide a net base load output. For lower ambient temperatures the base plant thermal efficiency is

(a) This is exactly true in Zone 2 for which most of the situations encountered in this study apply. It is the basis of the calculations in Zones 1 and 3 . 
increased by virtue of a decrease in turbine exhaust pressure. This allows the power plant to have a net electrical production capacity in excess of its design power. The utility system model provides no market for the excess power, however. Instead of producing and selling the excess power, the steam flow to the turbine is cut back by reducing the fuel consumption. While there is a small savings in fuel cost (an operating expense), there can be tremendous cost penalties (a capital expense) due to having the idle capacity. Figure 4.3 compares the performance of two cooling systems; one designed for a high ambient temperature, $T D_{H}$, and the other for a low ambient temperature, $T D_{L}$. The power output of the base plant is 1000 MWe at the design temperature. As shown, the power production capacity of the base plant varies between the extremes of ambient temperature, $\mathrm{TA}_{\min }$ to $\mathrm{TA}_{\max }$. The area between the power capacity curve and the design power level for temperatures below the design temperature represents excess idle capacity.

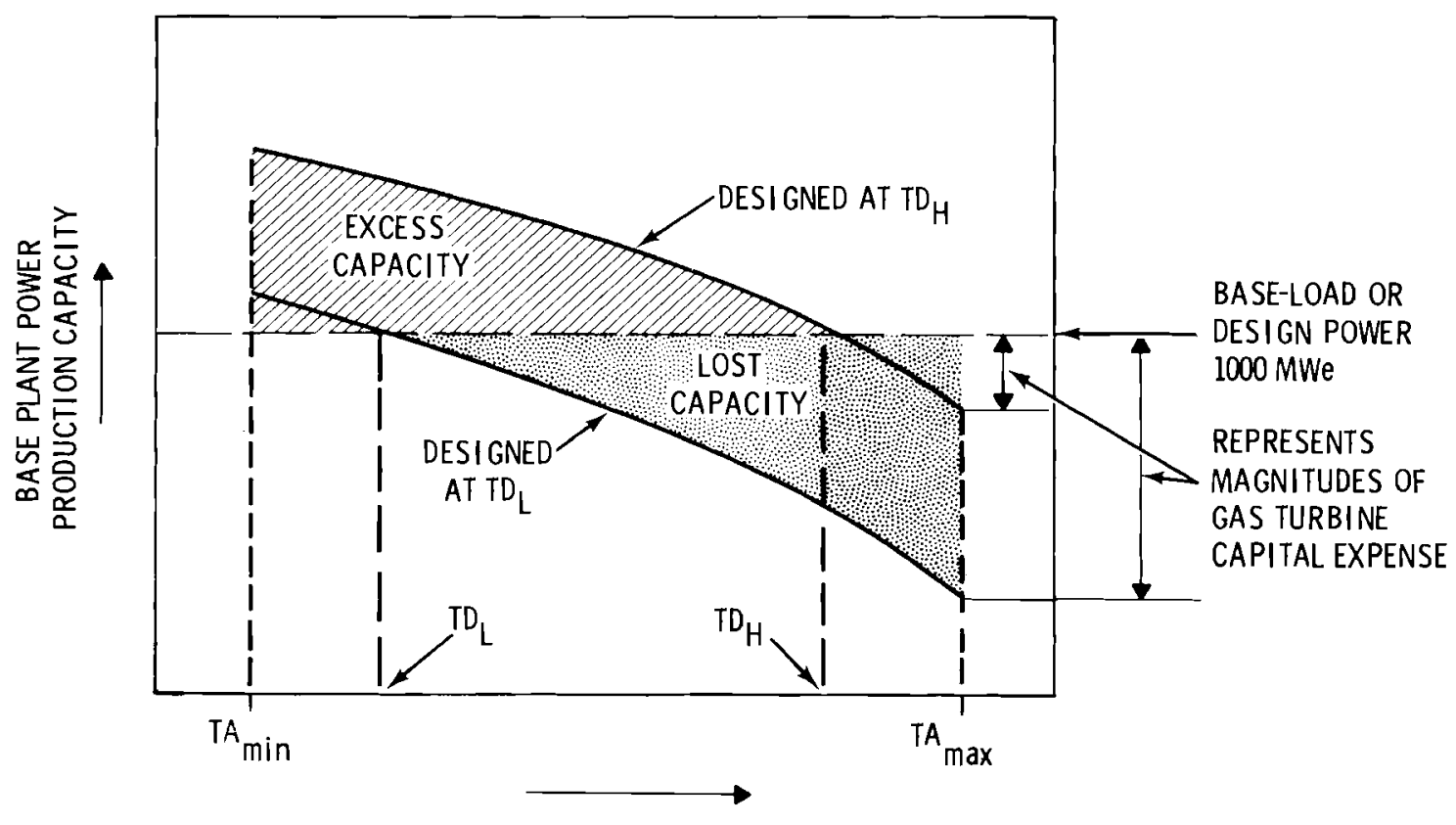

AMBIENT TEMPERATURE

FIGURE 4.3. Power Plant Performance Versus Ambient Temperature to Compare Excess Capacity, Lost Capacity, and Gast Turbine Requirements for Two Different Design Temperatures (The performance curves assume the cooling system operates all dry between $T A_{\min }$ and $T A_{\max } \cdot$ ) 


\subsubsection{Replacement of Lost Capacity - Capacity Cost, Energy Cost}

For ambient temperatures in excess of the design temperature, the electrical production capability of the base plant degrades due to an increase in turbine exhaust pressure. To continue to provide design power to the electrical grid system a secondary power source must be defined. In this model the replacement power for lost capacity is provided by gas turbines. The size of the gas turbine plant required is based on the difference between the power capacity on the hottest day and the base-load power. The capital cost of the gas turbines is termed the capacity cost. It is calculated by

$$
\text { CAPCST }=\left[\text { PSIZE }-P G E N\left(T A_{\max }\right)\right] C A P C H G
$$

where

$$
\begin{aligned}
\text { PSIZE = } & \text { base-load power output, } \\
\operatorname{PGEN}\left(\mathrm{TA}_{\max }\right)= & \text { base plant net output at the maximum ambient temperature, } \\
& \text { TA } A_{\text {max }} \text {, and } \\
\text { CAPCHG = } & \text { capacity charge, unit capital cost to provide gas turbine } \\
& \text { capability. }
\end{aligned}
$$

From Figure 4.3 one can observe that the higher design temperature results in a reduced gas turbine requirement. In addition, the integrated amount of power required from the gas turbines on an annual basis is lower. The total cost of providing the replacement power using the gas turbine is calculated by

$$
\mathrm{CSTCL}=\sum_{i}\left\{\left[\frac{\operatorname{PSIZE}-\operatorname{PGEN}\left(\operatorname{TA}_{i}\right)}{\operatorname{PSIZE}}\right] \operatorname{PWCOS}\right\}
$$

where, additionally, $\operatorname{PGEN}\left(T A_{j}\right)=$ base plant net output at ambient temperature, $T A_{j}$, and PWCOS = unit energy cost of producing power with the gas turbines.

The production cost to replace lost capacity, CSTLC, is represented by the area between the design power level and the power capacity curve for temperatures above the design temperatures in Figure 4.3. Thus, in the equation for CSTCL, if PGEN(TA $\left.{ }_{j}\right)$ is greater than PSIZE, then the component $\mathrm{CSTCL}_{j}$ is zero. 
The capital cost of gas turbines is significantly less than the capital cost of the base power plant on a per kWe basis. However, the prime fuels used by gas turbines are more expensive than either coal or nuclear power. In view of this, the only way that high design temperatures could possibly be advantageous is if the utility model provides a market for the excess power. This is not the case, however.

\subsubsection{Steam Supply Scaling}

In the analysis of all-dry cooling systems it was shown that there is some cost incentive for investigating the use of new turbine designs that will be able to withstand continuous operation at back pressures previously considered to be exceedingly high. (2) The new turbines would be less efficient than the conventional turbine because of aerodynamic constraints at the low pressure end. Therefore, to achieve a prescribed rated power level, a greater steam flow to the turbine would be required. Steam supply scaling is an adjustment made to the power plant construction cost that accounts for the required increase in the size of the steam supply system such that the turbine-generator can provide a prescribed power level at the rated back pressure. A conventional turbine, of course, requires no steam supply scaling.

The cost model assumes that $1 / 3$ of the nominal power plant construction cost, PLANC, is due to the steam supply system. The percent of increase in the size of the steam supply system is based on the ratio of the rated heat rate of the turbine in question to the rated heat rate of a conventional turbine. This normalized heat rate ratio is called the heat rate factor, HRFAC. The scaled steam supply cost differential, SSCD, is calculated by

$$
\operatorname{SSCD}=\left(\frac{\text { PLANC }}{3}\right) \cdot(\text { HRFAC1 }-1) \cdot \text { PSIZE }
$$

where

PLANC = nominal power plant construction cost, HRFAC1 = heat rate factor of turbine at the rated exhaust pressure, and PSIZE = base-load power output. 
The power plant construction cost adjusted for steam supply scaling is

$$
\text { PLANC } 1=(P L A N C \cdot P S I Z E+S S C D) / P S I Z E
$$

\subsubsection{Scaling for Heat Rate}

When the cooling system design is developed for a prescribed design temperature, the turbine exhaust pressure is not generally equal to the rated exhaust pressure. If the design exhaust pressure is below the rated exhaust pressure then the power plant will have more capacity at the design point than at the rated condition. Therefore, the cost of the power plant is reduced. This is best explained by example. At the design point a power plant generates a base-load 1000 MWe at $2.0 \mathrm{in}$. $\mathrm{Hg}$. When the ambient temperature increases such that the exhaust pressure rises to the rated value of $3.5 \mathrm{in}$. $\mathrm{Hg}$ the power plant generates $980 \mathrm{MWe}$. This is the size of the power plant that must be purchased. Heat rate scaling is the adjustment of the power plant construction cost to account for this difference in required capital cost. That is, a 1000-MWe power plant is designed by purchasing a 980-Mwe power plant and improving its performance. In this way, heat rate scaling is computed as a negative number. Of course, if the design exhaust pressure were above the rated exhaust pressure, the opposite would be true.

The cost attributed to heat rate scaling is calculated by

$$
\text { HRSC }=\left(\frac{\text { HRFAC2 }}{\text { HRFAC1 }}-1\right) \cdot \text { PLANC1 } \cdot \text { PSIZE }
$$

where

HRFAC2 = heat rate factor of the turbine at the design exhaust pressure, $\mathrm{HRFACl}$ = heat rate factor of the turbine at the rated exhaust pressure, PLANCI = power plant construction cost adjusted for steam supply scaling, and

PSIZE = base-load power output.

The power plant unit construction cost adjusted for heat rate scaling is

$$
\text { PLANC2 = PLANC1 } \cdot \text { HRFAC2 } / \text { HRFAC1 }
$$




\subsubsection{Scaling for Auxiliary Power}

The auxiliary power is the electrical power required by the cooling system for the fans and pump. Since the utility model requires that the net plant output be some prescribed value, the auxiliary power must be produced in excess of this amount. One could view this as though an adjacent power plant were producing enough electrical power to provide for the fans and pumps of the base plant. This second power plant also requires a cooling system, which also includes power for fans and pumps. Thus, a third adjacent power plant could supply this power, and so on. When the power plant is scaled for auxiliary power, it is scaled according to the infinite sum of the power required from these adjacent plants. The scaling factor is thereby defined as

$$
S F=\frac{P S I Z E}{P S I Z E-(\text { FPOW }+ \text { PPOW })}-1
$$

where

$$
\text { PSIZE = base-load power output, and }
$$

FPOW + PPOW $=$ auxiliary power for fans and pumps.

The implication of the scaling factor is that selected design features are increased in size or magnitude by $(1+S F)$. The heat transfer area and airflow rate are examples of parameters that are scaled. The air velocity, heat exchanger depth, and tube length are not scaled.

The actual power generation of the plant at the design temperature is given by

$$
\text { PTOT = PSIZE } \cdot(1+S F)
$$

The power plant construction cost adjusted for auxiliary power scaling is

$$
\text { PLANC3 }=\text { PLANC2 } \cdot(1+S F)
$$

where PLANC2 is the power plant construction cost adjusted for heat rate scaling. 
The increase in the power plant cost attribured to auxiliary power scaling is

$$
A P S C=(P L A N C 3-P L A N C 2) \cdot P S I Z E
$$

The nominal plant cost is adjusted for scaling by three steps: steam supply scaling, heat rate scaling, and auxiliary power scaling. The total cost of the base plant scaling is calculated by

$$
S P C D=(P L A N C 3-P L A N C) \cdot P S I Z E
$$

where PLANC is the nominal power plant construction cost. The power plant size is adjusted so that the power plant output will satisfy the utility system load requirement at the design temperature. The corresponding cost represents the capital investment in the power plant that is attributed to the cooling system.

\subsubsection{Base Plant Fuel}

At the design point the power plant typically operates at a different thermal efficiency than that of a conventional turbine at its rated back pressure. This can be due to either the use of a nonconventional turbine having a different heat rate than the conventional turbine and/or the design back pressure being different than the rated back pressure of the conventional turbine. The difference in efficiency implies that a difference will exist in the fuel consumption between the power plant being designed and a power plant with a conventional turbine being operated at its rated back pressure. In addition, the fuel consumption will be increased due to the auxiliary power required by the cooling system.

For ambient temperatures above the design temperature, the fuel cost differential for ambient temperature $T A_{i}$ is a constant and is calculated by

$$
\mathrm{DELFC}_{i}=\frac{\mathrm{FCOS}}{\mathrm{TEFF}}([(1+\mathrm{SF}) \cdot \mathrm{HRFAC2}]-1)
$$


where

FCOS = fuel cost per Btu,

TEFF = base thermal efficiency of the power plant with a conventional turbine operating at $3.5 \mathrm{in}$. Hg exhaust pressure,

SF = auxiliary power scaling factor, and

HRFAC2 = heat rate factor of the turbine at the design exhaust pressure.

For ambient temperatures below the design temperature, the base power plant net output is greater than the design power output. The fuel cost differential is calculated according to the improved heat rate by

$$
\operatorname{DELFC}_{i}=\frac{\mathrm{FCOS}}{\operatorname{TEFF}}([(1+\mathrm{SF}) \cdot \operatorname{HRFAC} 4]-1)
$$

where HRFAC4 is the heat rate factor of the turbine at ambient temperature $T A_{i}$.

\subsection{ANNUAL OPERATION AND TOTAL INCREMENTAL COST}

Although the performance of the base power plant is known to depend on ambient temperature, the utility model requires that the net power output be some fixed value. For ambient temperatures above the design temperature, gas turbines are used to supply the power to replace lost capacity. For ambient temperatures below the design temperature, steam flow is cut back to avoid excess capacity.

In the computer program the meteorology of a particular site is represented by as many as 16 dry-bulb temperatures and the corresponding wet-bulb temperatures. The meteorological data is reduced to determine the total number of hours per year that each of the temperatures can be expected to occur. The incremental cost of the dry/wet cooling system is computed for each temperature. The only costs that actually vary with temperature, however, are the fuel cost and the energy cost to replace lost capacity.

Two important assumptions have been made that simplify the annual performance and cost problem. The first is that the capacity factor is distributed uniformly to each ambient temperature. That is, of the total hours at 
each ambient temperature, the plant operates during a percentage of those hours which is equal to the capacity factor. Secondly, the fan and pump power, determined at the design point, is assumed to be fixed during a 11 operating hours.

With the above discussion in mind and with consideration of the discussion and definitions provided in Sections 4.2 and 4.3 , the incremental cost of electricity attributed to the cooling system for the temperature $\mathrm{TA}_{\mathbf{j}}$, can be calculated by

$$
\begin{aligned}
\operatorname{PCST}\left(\mathrm{TA}_{i}\right)= & (\mathrm{CCOS}+\operatorname{SPCD}+\mathrm{CAPCST}) \cdot \frac{\mathrm{FCR}}{\operatorname{PSIZE} \cdot \operatorname{CAPF} \cdot 8760} \\
& + \text { WATCST }+\operatorname{COSM}+\text { DELFC }_{i}+\text { CSTCL }_{i}
\end{aligned}
$$

where

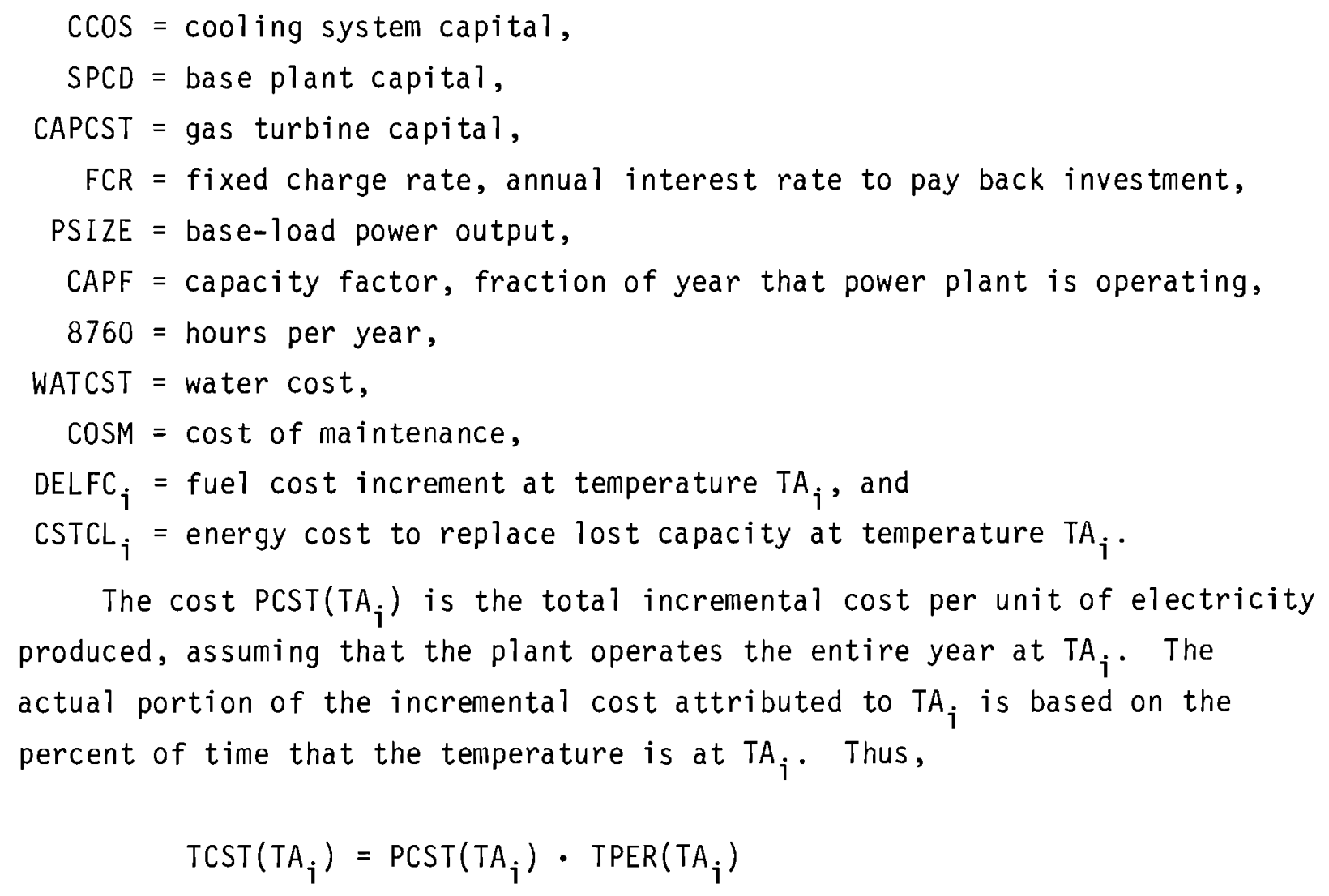

The cost PCST(TA $)_{j}$ is the total incremental cost per unit of electricity produced, assuming that the plant operates the entire year at $T A_{i}$. The actual portion of the incremental cost attributed to $T A_{i}$ is based on the percent of time that the temperature is at $\mathrm{TA}_{i}$. Thus,

$$
\operatorname{TCST}\left(T A_{\mathbf{i}}\right)=\operatorname{PCST}\left(T A_{\mathbf{i}}\right) \cdot \operatorname{TPER}\left(T A_{\mathbf{i}}\right)
$$

where $\operatorname{TPER}\left(T A_{j}\right)$ is the fraction of the year that the ambient temperature is at $T A_{i}$. 
The total incremental cost, ACOS, is obtained by summing the incremental costs for each ambient temperature, i.e.,

$$
A \operatorname{COS}=\sum_{i} \operatorname{TCST}\left(T A_{i}\right)
$$


- 


\subsection{OPTIMUM COOLING SYSTEM DESIGNS}

In this section three cooling system designs are compared. The purpose is to provide an indication of continuity from previous work and to show the impact on the design when deluge enhancement is used. The three designs are:

- a deluge-enhanced cooling system using the HÖTERV surface with an annual water consumption of 3000 acre-ft,

- an all-dry design using the HÖTERV surface, and

- an al1-dry design using a spiral-wrapped finned-tube surface.

Important design information is given in Table 5.1. In Figures 5.1, 5.2, and 5.3 plan views of the three designs are shown. Design information that is not provided by Table 5.1 or by the figures is discussed below. In Figure 5.4 the turbine exhaust pressure curves are shown. In Tables 5.2, 5.3 , and 5.4 cost summaries are given for the three designs. These summaries provide both the capital dollars and the unit energy cost for the cooling systems.

The deluge-enhanced design was developed from the reference design conditions used in the parametric study. These conditions are defined in Tables 6.1 and 6.2. The optimized design includes a tube length of $94.4 \mathrm{ft}$ corresponding to an equivalent tower diameter of $247 \mathrm{ft}$. In addition, the tower height is $72.5 \mathrm{ft}$ and the heat exchanger depth is 6 tube rows. To facilitate an equitable visual comparison of the designs, the two all-dry designs were developed in adherence to these dimensions. Because of these constraints the HÖTERV all-dry design of Table 5.1 does not match the HÖTERV al1-dry design of Table 6.5. Similarly, the spiral-wrapped finned-tube design of Table 5.1 will not match its counterpart that was reported in a previous study. (2)

The design developed for the vertical spiral-wrapped finned-tube surface was based on the computer code described in Reference 5 . Fundamental differences in unit geometry exist between the spiral-wrapped surface, shown on 


\section{TABLE 5.1. Optimized Design, Performance and Cost Parameters}

for Three Comparative Designs

\begin{tabular}{|c|c|c|c|c|}
\hline & & $\begin{array}{c}\text { HÖTERV, } \\
3000 \text { acre-ft }\end{array}$ & $\begin{array}{l}\text { HÖTERV, } \\
\text { All-Dry }\end{array}$ & $\begin{array}{c}\text { Spiral-Wrapped } \\
\text { Finned-Tube, } \\
\text { All-Dry } \\
\end{array}$ \\
\hline \multicolumn{5}{|l|}{ Airflow Parameters } \\
\hline Airflow Rate & $10^{6} 1 \mathrm{bm} / \mathrm{hr}$ & 401. & 629. & 807. \\
\hline Maximum Air Velocity & $\mathrm{ft} / \mathrm{sec}$ & 13.6 & 13.7 & 15.8 \\
\hline$\Delta P_{\text {air }}, h . x$. & psi & 0.0138 & 0.0142 & 0.0876 \\
\hline$\Delta P_{\text {air }}$, discharge & psi & 0.0048 & 0.0050 & 0.0051 \\
\hline Fan Power & $M W$ & 8.8 & 13.7 & 11.9 \\
\hline Fans & & 93 & 141 & 180 \\
\hline \multicolumn{5}{|l|}{$\mathrm{NH}_{3}$ Parameters } \\
\hline $\mathrm{NH}_{3}$ Flow Rate & $10^{6} 1 \mathrm{bm} / \mathrm{hr}$ & 10.2 & 9.70 & 9.66 \\
\hline$\Delta \mathrm{P}_{\mathrm{NH}_{3}}$ & psi & 19.5 & 30.9 & 26.0 \\
\hline Pump Power & $M W$ & 0.555 & 0.512 & 0.429 \\
\hline \multicolumn{5}{|l|}{ Heat Exchanger Design } \\
\hline Towers & & 4 & 6 & 8 \\
\hline Approximate Tower Diameter & $f t$ & 247. & 247 & 232. \\
\hline Tower Height & $f t$ & 72.5 & 73.9 & 73.0 \\
\hline Frontal Area & $10^{6} \mathrm{ft}^{2}$ & 0.219 & 0.335 & 0.426 \\
\hline Heat Transfer Area & $10^{6} \mathrm{ft}^{2}$ & 19.6 & 30.0 & 40.8 \\
\hline Tube Length & $f t$ & 94.4 & 94.4 & 73.0 \\
\hline Tube Rows in Depth & & 6 & 6 & 3 \\
\hline \multicolumn{5}{|l|}{ Condenser Design } \\
\hline Heat Transfer Area & $10^{6} \mathrm{ft}^{2}$ & 0.454 & 0.519 & 0.532 \\
\hline TTD & ${ }^{\circ} \mathrm{F}$ & 4.00 & 3.40 & 3.28 \\
\hline \multicolumn{5}{|l|}{ Performance Parameters } \\
\hline Design TBP & in. $\mathrm{Hg}$ & 2.18 & 1.10 & 1.06 \\
\hline Maximum TBP & in. $\mathrm{Hg}$ & 3.20 & 7.35 & 6.96 \\
\hline Power at Maximum TBP & $\mathrm{MW}$ & 991.9 & 904.5 & 915.3 \\
\hline Maximum \% Deluge & & 43.0 & 0.00 & 0.00 \\
\hline Maximum Evaporation Rate & $10^{3} \mathrm{gpm}$ & 9.54 & 0.00 & 0.00 \\
\hline \multicolumn{5}{|l|}{ Cost Summary } \\
\hline Cooling System & $\mathrm{mills} / \mathrm{kWh}$ & 1.26 & 1.73 & 1.59 \\
\hline Capacity & $m i l l s / k w h$ & 0.03 & 0.31 & 0.28 \\
\hline Steam Supply Scaling & $\mathrm{mills} / \mathrm{kwh}$ & 0.00 & 0.00 & 0.00 \\
\hline Heat Rate Scaling & $\mathrm{mills} / \mathrm{kWh}$ & -0.18 & -0.21 & -0.21 \\
\hline Auxiliary Power Scaling & mills/kwh & 0.12 & 0.22 & 0.18 \\
\hline Energy & $\mathrm{mills} / \mathrm{kwh}$ & 0.13 & 0.15 & 0.14 \\
\hline Base Fuel & mills/kwh & -0.01 & 0.00 & -0.01 \\
\hline $0 \& M$ & $\mathrm{mills} / \mathrm{kwh}$ & 0.07 & 0.10 & 0.09 \\
\hline Incremental cost of Cooling & $\mathrm{mills} / \mathrm{kWh}$ & 1.44 & 2.30 & 2.06 \\
\hline
\end{tabular}




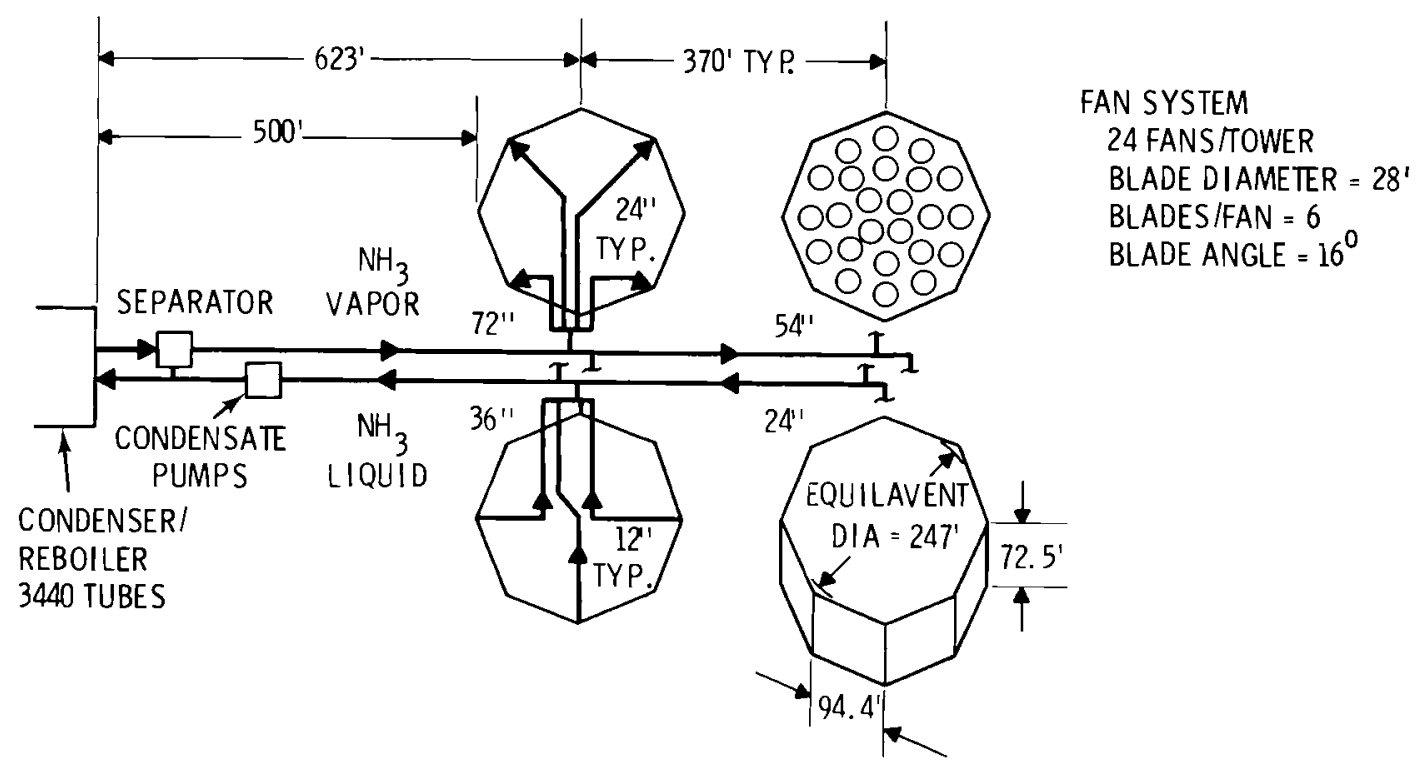

FIGURE 5.1. Optimized HÖTERV Cooling System with 3000 Acre-ft of Water Available. (Deluge piping is required for two towers.)

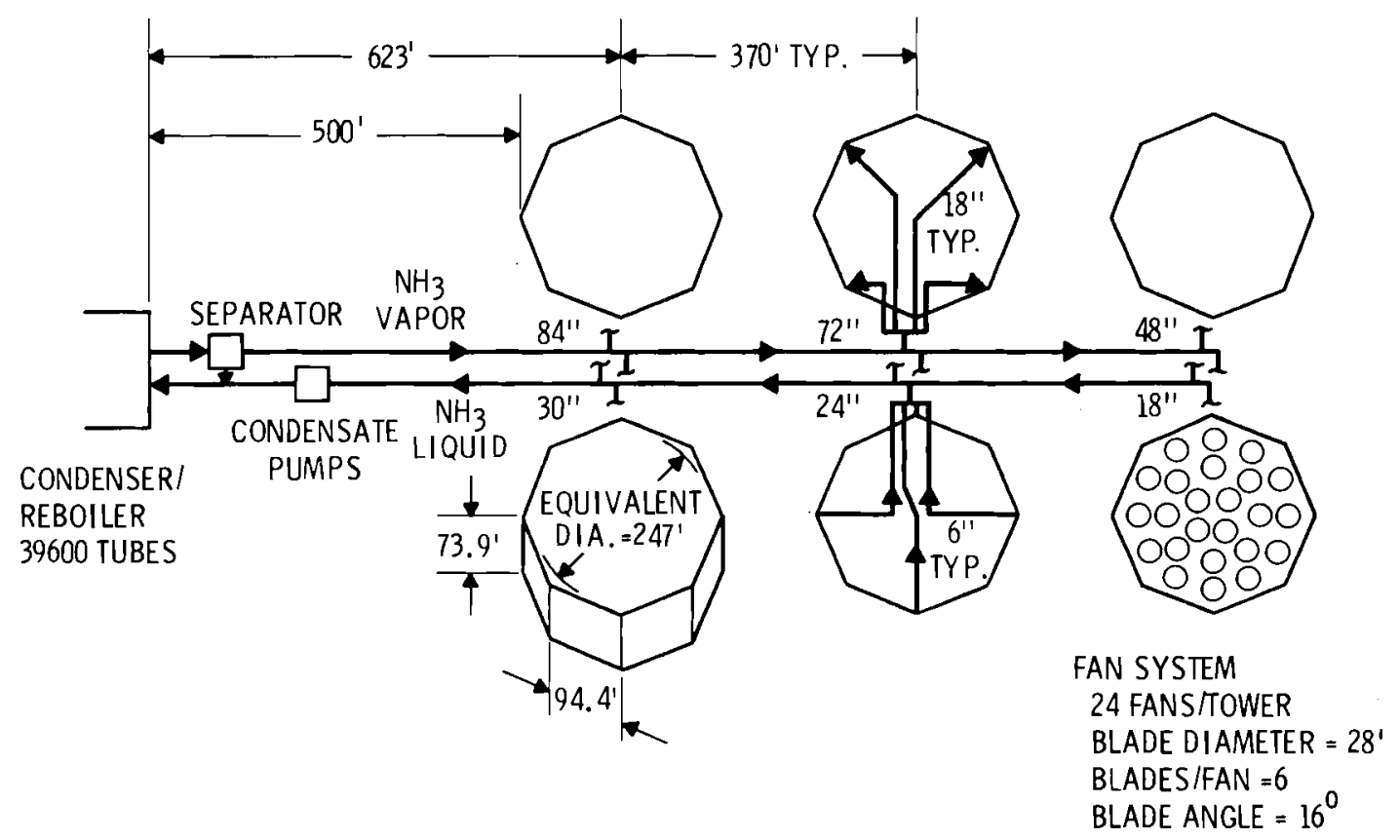

FIGURE 5.2. Optimized HÖTERV Cooling System for A11-Dry Operation 


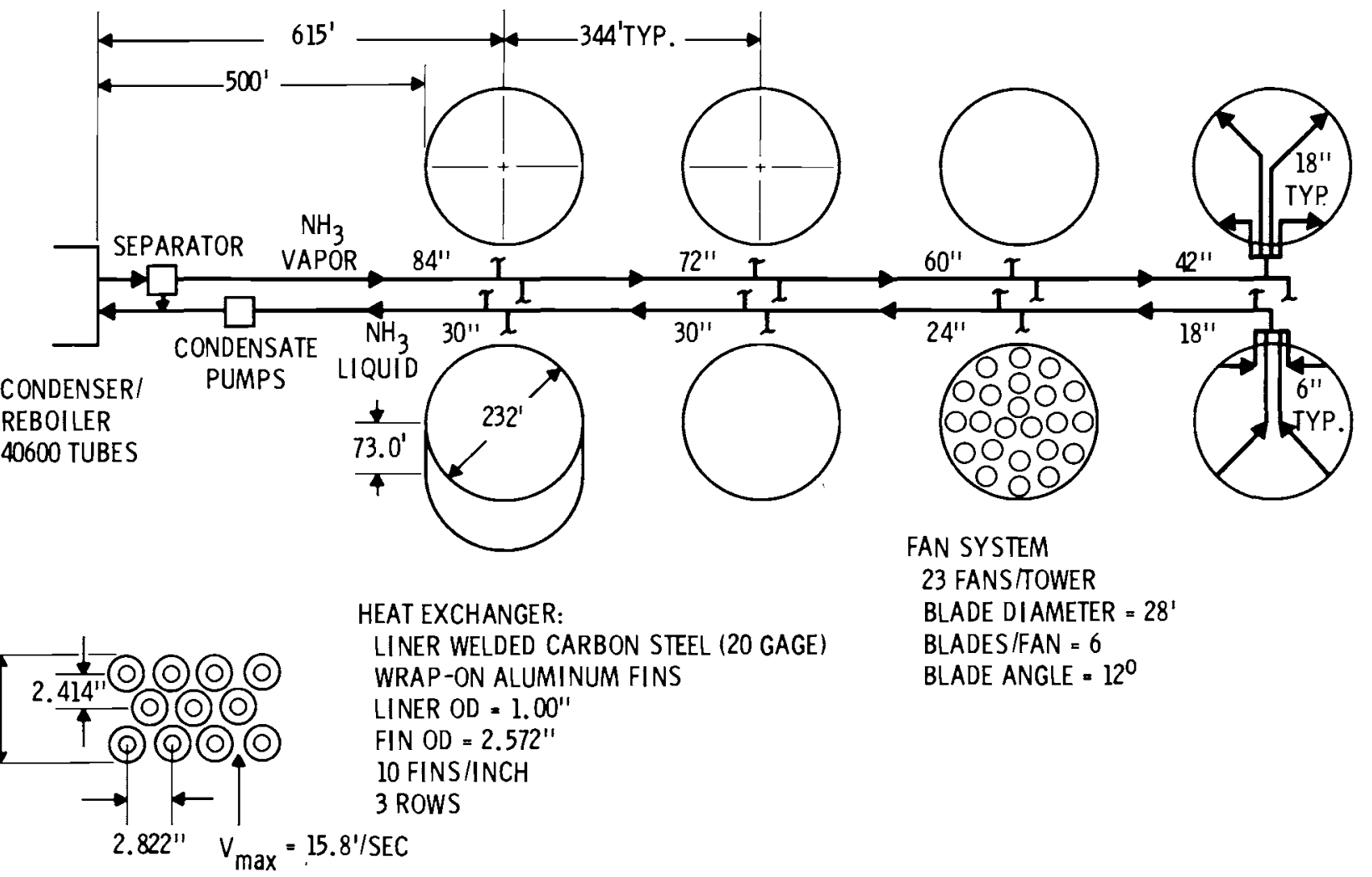

FIGURE 5.3. Optimized Cooling System with Spiral-Wrapped Finned-Tube Heat Exchanger for A11-Dry Operation 


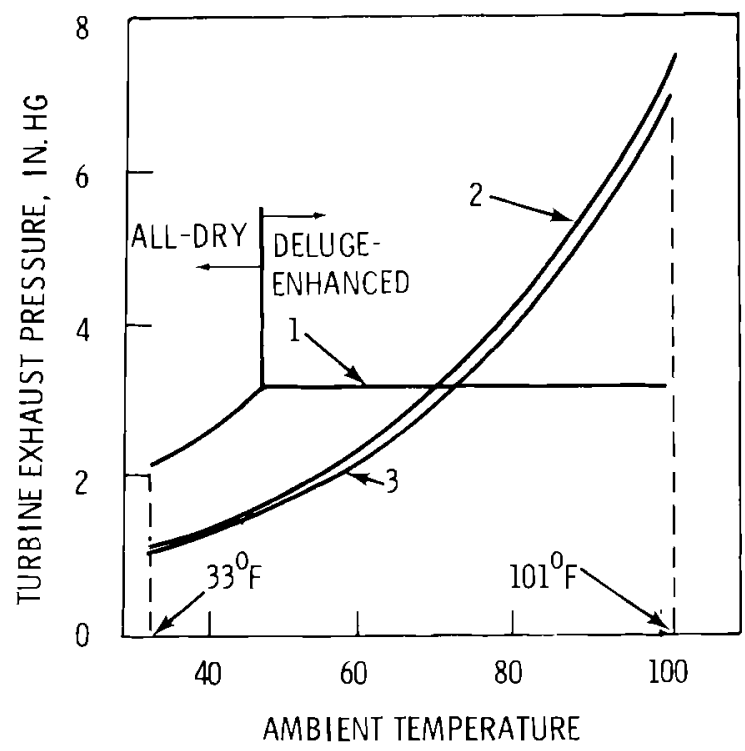

FIGURE 5.4. Turbine Exhaust Pressure as a Function of Ambient Temperature for Three Systems. The three systems are: 1) HÖTERV, 3000 acre-ft; 2) HÖTERV, al1-dry; and 3) spiralwrapped finned tube all-dry.

Figure 5.3, and the HÖTERV surface, defined in Figure 3.8. The spiralwrapped finned-tube design was restricted to three tube rows in depth to compensate for these differences. By this means, the density of the heat exchanger surface area per $\mathrm{ft}^{2}$ of frontal area is nearly equal for all three designs.

The investigation of all-dry cooling systems, described by Fryer et al., leads to the belief that the vertical tube design is a good reference point with which the HÖTERV designs can be compared. The all-dry ammonia system was shown to have significant potential for reducing the costs attributable to the cooling system as compared to state-of-the-art designs. However, the vertical spiral-wrapped finned tube was not considered to be a feasible candidate for deluge enhancement because of the poor distribution of the flow of water down the shallow gradient in the narrow passage between the fins. In this respect the HÖTERV surface was shown to be feasible. (a) However, the HÖTERV surface was also known to be more expensive than the conventional

(a) This information was provided by B. M. Johnson of PNL in an internal communication. 
TABLE 5.2. Cooling System Cost Summary for Deluge-Enhanced HÖTERV Surface with an Annual Water Consumption of 3000 Acre-ft

\begin{tabular}{|c|c|c|c|}
\hline Item & Caprta & $\begin{array}{l}\text { Cost Si } \\
10^{6} \$\end{array}$ & mmary, \\
\hline Cooling System Capital & & & 46.46 \\
\hline Tower & & 28.8 & \\
\hline $\begin{array}{l}\text { Heat Exchanger } \\
\text { Plenum } \\
\text { Louvers } \\
\text { Hail Screens } \\
\text { Fan System } \\
\text { Structure } \\
\text { Foundation }\end{array}$ & $\begin{array}{c}17.33 \\
0.21 \\
0.00 \\
0.58 \\
6.52 \\
3.78 \\
0.41\end{array}$ & & \\
\hline Piping & & 9.98 & \\
\hline Condenser/Reboiler & & 7.67 & \\
\hline Capacity (Gas Turbines) & & & 0.98 \\
\hline Plant Scaling & & & -1.26 \\
\hline Steam Supply & & 0.00 & \\
\hline Base Plant & & -1.26 & \\
\hline Water & & & 0.0 \\
\hline TOTAL CAPITAL COST & & & 46.18 \\
\hline \multicolumn{4}{|l|}{ Energy (Gas Turbines) } \\
\hline \multicolumn{4}{|l|}{ Additional Base Plant Fuel } \\
\hline Operation and Maintenance & & & \\
\hline TOTAL INCREMENTAL COST & & & \\
\hline
\end{tabular}

Unit Energy Cost Summary mills/kWh

\begin{tabular}{rrr}
\hline & & 1.259 \\
0.470 & & \\
0.006 & & \\
0.000 & & \\
0.016 & & \\
0.177 & & \\
0.102 & & \\
0.011 & & \\
& 0.271 & \\
& 0.208 & \\
& & 0.026 \\
& & -0.034 \\
& 0.000 & \\
& -0.034 & \\
& & 0.0 \\
& & 1.252 \\
& & 0.130 \\
& & -0.012 \\
& & 0.069 \\
& & 1.438
\end{tabular}


TABLE 5.3. Cooling System Cost Summary for HÖTERV Surface Operating Al1-Dry

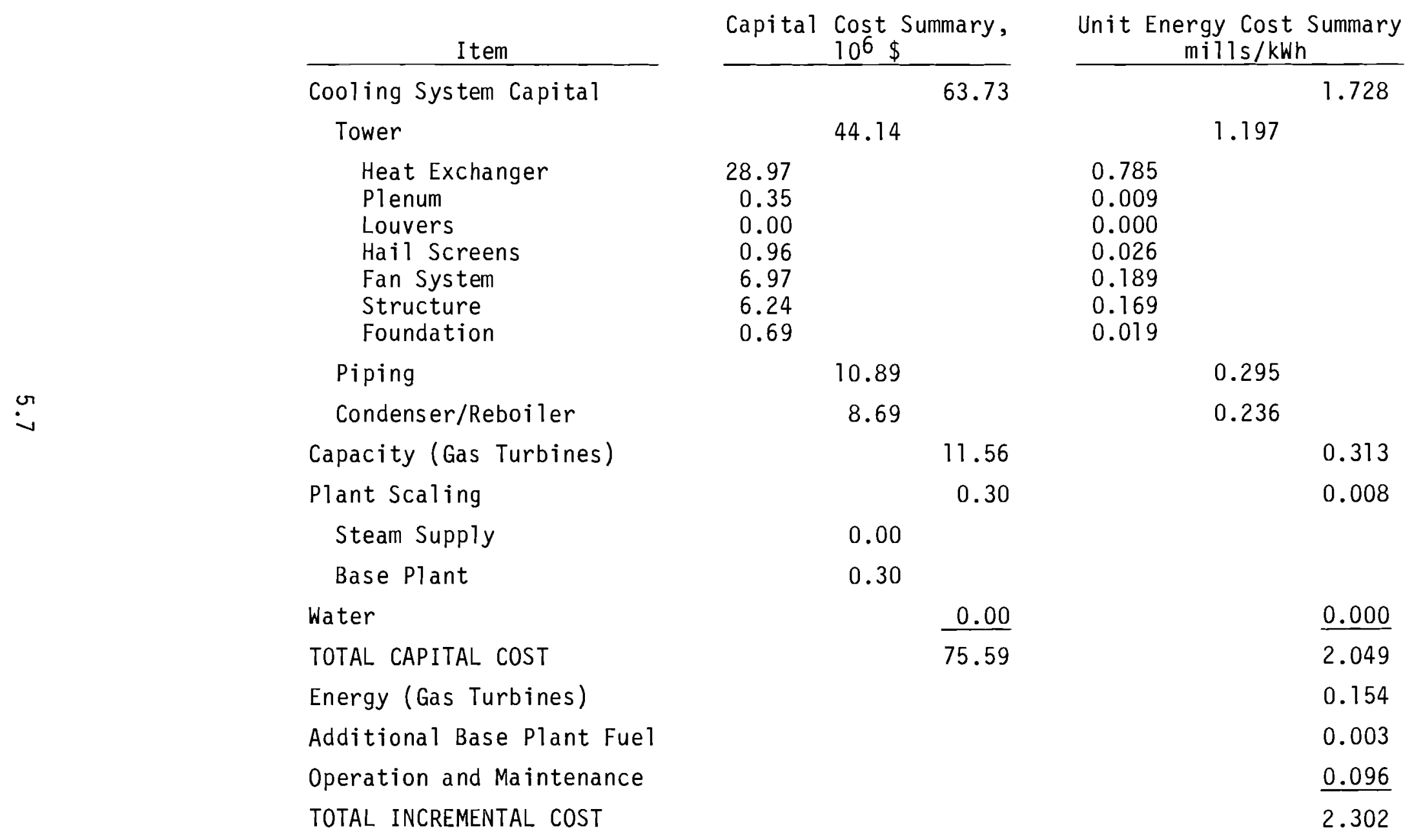


TABLE 5.4. Cooling System Cost Summary for Vertical Spiral-Wrapped Finned-Tube Operating A11-Dry

\begin{tabular}{|c|c|c|c|c|c|}
\hline Item & Capital & $\begin{array}{l}\text { Cost Summary, } \\
10^{6} \$\end{array}$ & Unit En & $\begin{array}{l}\text { rgy Cost } \\
\text { mil1 } 1 \mathrm{~s} / \mathrm{kw}\end{array}$ & Summary \\
\hline Cooling System Capital & & 58.68 & & & 1.591 \\
\hline Tower & & 36.96 & & 1.002 & \\
\hline $\begin{array}{l}\text { Heat Exchanger } \\
\text { Plenum } \\
\text { Louvers } \\
\text { Hail Screens } \\
\text { Fan System } \\
\text { Structure } \\
\text { Foundation }\end{array}$ & $\begin{array}{r}16.95 \\
0.42 \\
0.00 \\
1.13 \\
10.64 \\
7.34 \\
0.52\end{array}$ & & $\begin{array}{l}0.459 \\
0.011 \\
0.000 \\
0.031 \\
0.289 \\
0.199 \\
0.014\end{array}$ & & \\
\hline Piping & & 12.82 & & 0.347 & \\
\hline Condenser/Reboiler & & 8.90 & & 0.241 & \\
\hline Capacity (Gas Turbines) & & 10.24 & & & 0.278 \\
\hline Plant Scaling & & -0.80 & & & -0.022 \\
\hline Steam Supply & & 0.00 & & 0.000 & \\
\hline Base Plant & & -0.80 & & -0.022 & \\
\hline Water & & 0.00 & & & 0.000 \\
\hline TOTAL CAPITAL COST & & 68.13 & & & 1.847 \\
\hline Energy (Gas Turbines) & & & & & 0.136 \\
\hline Additional Base Plant Fuel & & & & & -0.008 \\
\hline Operation and Maintenance & & & & & 0.088 \\
\hline TOTAL INCREMENTAL COST & & & & & 2.063 \\
\hline
\end{tabular}


finned tube surface. In spite of this the optimized all-dry design developed for the HÖTERV surface showed it to be competitive with other all-dry designs. The subsequent development of the deluge theory for the HÖTERV analysis was, therefore, deemed a worthwhile venture.

The primary difference in going from the vertical tube design to the al1-dry horizontal tube HÖTERV design is the unit cost of the heat exchanger surface. Cost models used in the analysis indicate the HÖTERV surface to be roughly 2-1/2 times greater in cost per unit of heat transfer area than the spiral-wrapped finned tube. As such, the optimization procedure minimizes the surface area specified for the all-dry HÖTERV design. The extent to which the surface area can be reduced is enhanced by the fact that for comparable air velocities through the heat exchanger, the overall heat transfer coefficient for the HÖTERV surface exceeds that of the conventional surface by more than $60 \%$. This, in part, is a result of the serrated design of the HÖTERV surface. The built-in surface irregularities improve the heat transfer at the expense of air pressure drop through the heat exchanger. The pressure loss difference is severe enough that even though the HÖTERV all-dry design has a lower velocity and much lower airflow rate, the total fan power required is greater than that for the spiral-wrapped finned-tube design. This shows up as a difference in the auxiliary power scaling costs. The net impact of airflow conditions, heat transfer surface area, heat transfer coefficients, etc., is that the HÖTERV all-dry design has a slightly higher turbine exhaust pressure curve compared to that of the conventional spiral-wrapped finnedtube surface (Figure 5.4). This is reflected as small differences in the capacity and energy costs. Finally, it is important to note that even though the surface costs are dramatically different for the two all-dry designs, the optimization process enables the total cost of the HÖTERV design to be competitive by adjusting the fundamental design parameters.

Design studies carried on simultaneously with these computer-optimized designs have led to the conclusion that the cost-effectiveness of the HÖTERV surface could be improved by arranging the heat exchangers horizontally under the fans rather than around the periphery of round towers. This arrangement 
results in significantly lower structure and piping costs but would not markedly reduce the cost of the heat exchangers. Algorithms to estimate the cost of a system using this configuration are being developed.

Since the HÖTERV surface appears to be a viable candidate for deluge enhancement, it is of perhaps greater interest to point out the impact that the evaporative heat transfer can have on the optimized design. For comparative purposes the deluge design was developed with 3000 acre-ft of water available annually for evaporative consumption. The primary difference between the deluged and all-dry designs is that the size of the cooling system is about $1 / 3$ smaller for the deluged design. This is reflected in the cooling system capital costs. As seen in Figure 5.4 the turbine exhaust pressure curve for the deluged design is slightly higher at the low ambient temperatures, while it is significantly lower for the hottest ambient temperatures. The behavior at the low ambient temperatures is due to the smaller heat exchanger size, which, in the all-dry mode, requires a larger ITD to reject the required heat load. Thus, the heat rate scaling cost is slightly higher, i.e., less negative, for the deluge design. This penalty is more than compensated for by the improved performance on the hottest day. The base power plant with the deluged cooling system generates a net 991.9 MWe on the hottest day, thereby requiring a gas turbine plant of only 8.1 MWe. Meanwhile, the all-dry plant requires 95.5 MWe of gas turbine capability. This difference is reflected in the capacity charge. The final cost difference to be pointed out is the one for auxiliary power scaling. This is a direct result of the reduced airflow requirement for the deluged design. 


\subsection{PARAMETRIC STUDY}

The computer code described in Section 4 has been used to provide fundamental information regarding the design, performance, and cost parameters of deluge-enhanced cooling systems. In this section the basis of the analysis and the results of the parametric study are provided.

\subsection{METHOD OF ANALYSIS}

The parametric analysis was performed by establishing a set of design, performance, and cost input parameters for the computer code. This set of input parameters will be referred to as the reference conditions. The variables chosen for parametric study were singly adjusted over a range of values that, unless otherwise constrained, bounded the optimum. Many variables that play important roles in the cooling system design, some of which are defined in Table 6.1, have not been studied parametrically. Such variables as piping system design velocities, unit geometry, etc., were thoroughly evaluated in a previous study. (2) It was believed that the conclusions, with regard to these variables, would not be affected by deluge augmentation.

The reference conditions include two groups of parameters; those that were varied and those that were fixed throughout the study. This second group formed what could be called the design basis. These parameters and the values given them are defined in Table 6.1. The parameters that were varied and their reference values are given in Table 6.2. This group of studied parameters was further divided into two subgroups; one being the parameters associated with the deluge performance and the other comprising the dry mode parameters that are established as part of the cooling system design prior to the computation of the deluge enhancement.

It should be emphasized that many important parameters in the set of reference conditions are specific to the San Juan site. These include:

- capacity factor,

- fixed charge rate,

- fuel cost, 
TABLE 6.1. Design Basis Parameters

Parameters

Plant Parameters
Plant Type
Design Net Power
Conventional Turbine (a)
Nominal Heat Rejection
Capacity Factor
Cost Parameters
Fixed Charge Rate
Fuel
Base Plant Capital
Base Plant Steam Supply System
Gas Turbine Capital
Power Cost for Gas Turbines
Design Parameters
Cooling System Type
HötERV Plate-Fin Heat Exchanger
Tower Configuration
Velocity Recovery Stacks
Intermediate Heat Transfer Fluid
Ammonia Vapor Design Velocity
Ammonia Liquid Design Velocity
Deluge Water Design Velocity
Deluge Flow/Evaporation
Distance from Condenser to Tower
Condenser Type
Condenser Tubes

Values

Fossil

1000 MWe

$4.92 \times 10^{9}$ Btu/hr
0.758

0.180

$66.9 \phi / 10^{6}$ Btu

$\$ 571 / \mathrm{kWe}$

$\$ 190 / \mathrm{kWe}$

$\$ 121 / \mathrm{kWe}$

$24.0 \mathrm{mills} / \mathrm{kWh}$

Indirect mechanical draft

Yes

Symmetric polygon ( 8 or 16 sides), horizontal tube

Yes

Ammonia

$150 \mathrm{ft} / \mathrm{sec}$

$15 \mathrm{ft} / \mathrm{sec}$

$10 \mathrm{ft} / \mathrm{sec}$

5

$500 \mathrm{ft}$

Single-pressure, one-pass, 2-shell surface condenser

Linde AL12, 1.00-in. OD, 50-ft length

(a) The heat rate versus exhaust pressure curve is given in Figure 6.2 . 
TABLE 6.2. Reference Values of the Variables Studied Parametrically

\begin{tabular}{|c|c|}
\hline Parameters & Values \\
\hline \multicolumn{2}{|l|}{ Deluge Parameters } \\
\hline Water Availability & 3000 acre-ft/yr \\
\hline Water Cost & $\$ 0 / 1000 \mathrm{gal}$ \\
\hline Design Temperature & $33^{\circ} \mathrm{F}$ \\
\hline Meteorology Site & San Juan, New Mexico \\
\hline $\begin{array}{l}\text { Relative Humidity of Air at Heat } \\
\text { Exchanger Exit }\end{array}$ & 1.00 \\
\hline $\begin{array}{l}\text { Air Velocity through Deluge Section/ } \\
\text { Air Velocity through Dry Section }\end{array}$ & 0.77 \\
\hline \multicolumn{2}{|l|}{ Dry Parameters } \\
\hline Tube Length & Optimized \\
\hline Tube Rows in Direction of Airflow & Optimized \\
\hline Number of Towers & Optimized \\
\hline Number of Tower Sides & 8 \\
\hline Tower Roof Area/Fan-Swept Area & 3.0 \\
\hline Fan Diameter & $28 \mathrm{ft}$ \\
\hline Air Velocity & Optimized \\
\hline Turbine & Conventional \\
\hline
\end{tabular}

- thermal efficiency (nominal heat rejection),

- base plant capital cost,

- base plant steam supply system cost,

- meteorology, and

- elevation.

This has been done because the Public Service of New Mexico No. 3 unit at San Juan is one of a limited number of dry/wet cooling systems in the U.S., although it is a parallel air series water system employing conventional dry and evaporative cooling rather than deluge enhancement. The values given these variables were developed from information provided by Public Service of New Mexico. 


\subsection{PRELIMINARY ANALYSIS}

Prior to the parametric study, analyses were performed to determine near optimum values for each of the reference conditions. These values, presented in Table 6.2, comprised the reference case for the parametric study. Initial studies were also conducted to justify certain computer-time-saving assumptions.

\subsubsection{Subroutine SHOT}

One of the most important assumptions that had to be validated was that optimum solutions could be obtained while skipping subroutine SHOT in the optimization process. There was an incentive to by-pass subroutine SHOT because the computer cost of operating without the SHOT by-pass was five times greater than the cost obtained by skipping this subroutine. As discussed in the section on the optimization technique, subroutine SHOT conducts a grid search to determine the values of the five internally independent variables which are in close proximity to the minimum incremental cost. To skip SHOT requires that the initial input values of the five independent parameters be reasonably near the optimum that the SHOT subroutine would have selected. This is done using experience and some trial and error.

Running the code with SHOT and without SHOT verifed that it was possible to locate an optimum solution without the SHOT subroutine. Optimized designs for each case are presented in Table 6.3. The incremental costs of the resultant designs were within $1 \%$ of each other. The optimized designs reflected the fact that local optimums have been found. However, the differences in the designs could be readily explained on the basis of known cost trade-offs between various components.

\subsubsection{Deluge Heat Transfer}

The accuracy of the deluge heat transfer calculations is another important consideration with regard to the validity of the BNW-II computer code. To evaluate the accuracy of the deluge heat transfer, two calculational techniques were developed. One method was developed from the fundamental theory 
TABLE 6.3. Comparison of Optimized Design, Performance, and Cost Parameters for the Two Optimization Methods

\begin{tabular}{|c|c|c|c|}
\hline \multirow{2}{*}{ Airflow Parameters } & & \multirow[t]{2}{*}{ SHOT } & \multirow[t]{2}{*}{ SKIPSHOT } \\
\hline & & & \\
\hline Airflow Rate & $10^{6} \mathrm{lbm} / \mathrm{hr}$ & 450 & 401. \\
\hline Maximum Air Velocity & $\mathrm{ft} / \mathrm{sec}$ & 14.9 & 13.6 \\
\hline$\Delta P_{\text {air }}$, h.x. & psi & 0.0135 & 0.0138 \\
\hline$\Delta P_{\text {air }}$, discharge & psi & 0.0061 & 0.0048 \\
\hline Fan Power & MW & 10.2 & 8.75 \\
\hline Fans & & 93 & 93 \\
\hline \multicolumn{4}{|l|}{$\mathrm{NH}_{3}$ Parameters } \\
\hline $\mathrm{NH}_{3}$ Flow Rate & $10^{6} 1 \mathrm{bm} / \mathrm{hr}$ & 10.1 & 10.1 \\
\hline$\Delta \mathrm{P}_{\mathrm{NH}_{3}}$ & psi & 18.9 & 19.6 \\
\hline Pump Power & MW & 0.498 & 0.555 \\
\hline \multicolumn{4}{|l|}{ Heat Exchanger Design } \\
\hline Towers & & 4 & 4 \\
\hline Approximate Tower Diameter & $\mathrm{ft}$ & 247 & 247. \\
\hline Tower Height & $\mathrm{ft}$ & 73.9 & 72.5 \\
\hline Frontal Area & $10^{6} \mathrm{ft}^{2}$ & 0.223 & 0.219 \\
\hline Heat Transfer Area & $10^{6} \mathrm{ft}^{2}$ & 16.7 & 19.6 \\
\hline Tube Length & $\mathrm{ft}$ & 94.4 & 94.4 \\
\hline Tube Rows in Depth & & 5 & 6 \\
\hline \multicolumn{4}{|l|}{ Condenser Design } \\
\hline Heat Transfer Area & $10^{6} \mathrm{ft}^{2}$ & 0.400 & 0.454 \\
\hline TTD & ${ }^{\circ} \mathrm{F}$ & 4.92 & 4.00 \\
\hline \multicolumn{4}{|l|}{ Performance Parameters } \\
\hline Design TBP & in. $\mathrm{Hg}$ & 2.18 & 2.18 \\
\hline Maximum TBP & in. $\mathrm{Hg}$ & 3.33 & 3.20 \\
\hline Power at Maximum TBP & MW & 990.4 & 991.9 \\
\hline Maximum \% Deluge & & 45.1 & 43.0 \\
\hline Maximum Evaporation Rate & $10^{3} \mathrm{gpm}$ & 9.93 & 9.54 \\
\hline \multicolumn{4}{|l|}{ Cost Summary } \\
\hline Cooling System & $\mathrm{mills} / \mathrm{kWh}$ & 1.19 & 1.26 \\
\hline Capacity & $\mathrm{mills} / \mathrm{kWh}$ & 0.03 & 0.03 \\
\hline Steam Supply Scaling & mills/kWh & 0.00 & 0.00 \\
\hline Heat Rate Scaling & $\mathrm{mills} / \mathrm{kWh}$ & -0.18 & -0.18 \\
\hline Auxiliary Power Scaling & $\mathrm{mills} / \mathrm{kWh}$ & 0.16 & 0.12 \\
\hline Energy & mills/kWh & 0.15 & 0.13 \\
\hline Base Fuel & $\mathrm{mills} / \mathrm{kWh}$ & -0.00 & -0.01 \\
\hline $0 \& M$ & $\mathrm{mills} / \mathrm{kWh}$ & 0.06 & 0.07 \\
\hline Incremental Cost of Cooling & mills $/ \mathrm{kWh}$ & 1.42 & 1.44 \\
\hline
\end{tabular}


of evaporative heat transfer. This is discussed in Appendix $C$. The second method was based on experimentally derived correlations provided by Babcock and Wilcox. The experimental correlations were developed for the HÖTERV heat transfer surface. The optimized designs based on these methods are compared in Table 6.4. The design based on fundamental theory was developed first. It was found to have an optimized depth of four tube rows. The design based on the HÖTERV data was subsequently constrained to four heat exchanger tube rows in depth. Thus, the heat transfer computation schemes can be compared without having to sort out design differences which are due to the selection of local optimums. Significant design parameters such as airflow rate, heat transfer surface area and frontal area are nearly identical; the exhaust pressure on the hottest day is $3.29 \mathrm{in.} \mathrm{Hg}$ for the theoretical prediction and $3.47 \mathrm{in.} \mathrm{Hg}$ for the optimized design based on experimental data. The incremental costs for the two designs are witbin $3 \%$ of each other. These results indicate that the design and performance of an optimized cool: ing system are similar for the two methods of calculating deluge heat transfer. The HÖTERV data provided by Babcock and wilcox were used for the remainder of the parametric study because the algorithm required less computing time and was believed to give better accuracy because it was based on experimental data.

\subsection{PARAMETRIC ANALYSIS OF THE DELUGE PARAMETERS}

In this section the optimized designs are presented and discussed for the various parameters that might have an impact on the performance of a deluged heat exchanger. These parameters, which are 1 isted in Table 6.2 along with their reference values, are water availability, water cost, design temperature, meteorology, relative humidity of the air at the heat exchanger exit, and the ratio of the air velocity through the deluged sections to the air velocity through the dry sections.

\subsubsection{Water Availability and Water Cost}

One of the most important parameters that must be considered in the design and performance evaluation of a dry/wet heat exchanger is the quantity of water that is available for evaporation on a yearly basis. 
TABLE 6.4. Comparison of Optimized Design, Performance, and Cost Parameters for the Two Methods of

Deluge Heat Transfer Calculation

\begin{tabular}{|c|c|c|c|}
\hline & & HÖTERV Data & $\begin{array}{c}\text { Fundamental } \\
\text { Theory }\end{array}$ \\
\hline \multicolumn{4}{|l|}{ Airflow Parameters } \\
\hline Airflow Rate & $10^{6} 1 \mathrm{bm} / \mathrm{hr}$ & 490. & 489. \\
\hline Maximum Air Velocity & $\mathrm{ft} / \mathrm{sec}$ & 13.4 & 13.4 \\
\hline$\Delta P_{a i r}$, h.x. & psi & 0.0090 & 0.0090 \\
\hline$\Delta P_{\text {air }}$, discharge & psi & 0.0055 & 0.0055 \\
\hline Fan Power & MW & 8.42 & 8.40 \\
\hline Fans & & 106 & 106 \\
\hline \multicolumn{4}{|l|}{$\mathrm{NH}_{3}$ Parameters } \\
\hline $\mathrm{NH}_{3}$ Flow Rate & $10^{6} 1 \mathrm{bm} / \mathrm{hr}$ & 10.2 & 10.1 \\
\hline$\Delta \mathrm{P}_{\mathrm{NH}_{3}}$ & psi & 22.2 & 22.2 \\
\hline Pump Power & MW & 0.559 & 0.557 \\
\hline \multicolumn{4}{|l|}{ Heat Exchanger Design } \\
\hline Towers & & 5 & 5 \\
\hline Approximate Tower Diameter & $\mathrm{ft}$ & 235. & 235. \\
\hline Tower He ight & $\mathrm{ft}$ & 74.8 & 74.6 \\
\hline Frontal Area & $10^{6} \mathrm{ft}^{2}$ & 0.269 & 0.269 \\
\hline Heat Transfer Area & $10^{6} \mathrm{ft}^{2}$ & 16.1 & 16.0 \\
\hline Tube Length & $\mathrm{ft}$ & 90.0 & 90.0 \\
\hline Tube Rows in Depth & & 4 & 4 \\
\hline \multicolumn{4}{|l|}{ Condenser Design } \\
\hline Heat Transfer Area & $10^{6} \mathrm{ft}^{2}$ & 0.405 & 0.412 \\
\hline TTD & ${ }^{\circ} \mathrm{F}$ & 4.80 & 4.68 \\
\hline \multicolumn{4}{|l|}{ Performance Parameters } \\
\hline Design TBP & in. $\mathrm{Hg}$ & 2.24 & 2.24 \\
\hline Maximum TBP & in. $\mathrm{Hg}$ & 3.47 & 3.29 \\
\hline Power at Maximum TBP & MW & 989.1 & 991.3 \\
\hline Maximum \% Deluge & & 46.0 & 41.6 \\
\hline Maximum Evaporation Rate & $10^{3} \mathrm{gpm}$ & 10.3 & 9.12 \\
\hline \multicolumn{4}{|l|}{ Cost Summary } \\
\hline Cooling System & mills/kWh & 1.23 & 1.23 \\
\hline Capacity & $\mathrm{mills} / \mathrm{kWh}$ & 0.04 & 0.03 \\
\hline Steam Supply Scaling & mills/kwh & 0.00 & 0.00 \\
\hline Heat Rate Scaling & $\mathrm{mills} / \mathrm{kWh}$ & -0.17 & -0.17 \\
\hline Auxiliary Power Scaling & mills/kwh & 0.14 & 0.14 \\
\hline Energy & mills/kwh & 0.17 & 0.14 \\
\hline Base Fuel & $\mathrm{mills} / \mathrm{kWh}$ & -0.01 & -0.01 \\
\hline $0 \& M$ & mills/kwh & 0.07 & 0.07 \\
\hline Incremental cost of Cooling & $\mathrm{mills} / \mathrm{kWh}$ & 1.46 & 1.42 \\
\hline
\end{tabular}


The reference value for water availability is based on an estimate of the total water required by a 1000-MWe power plant if it were completely evaporatively cooled. This estimate assumed that $75 \%$ of the heat rejection was done by latent cooling and $25 \%$ by sensible cooling. The nominal heat rejection used in the estimate was $5.12 \times 10^{9} \mathrm{Btu} / \mathrm{hr}$. The result is that approximately 9000 acre-ft of water would be required on an annual basis. Thus, if 9000 acre-ft were available to a particular site then the total potential power generation at that site could be increased by a factor of three if enhanced cooling were employed at the rate of 3000 acre-ft/year to the component plants. The expansion of the electrical generating capability at a site is a prime incentive for the utilization of dry/wet cooling. On this basis 3000 acre-ft seemed a reasonable estimate.

Generaliy, addition of water enhances the heat transfer and allows for smaller heat exchangers to be built. The heat exchanger and associated tower components (fan system, tower, structure, etc.) comprise $40 \%$ of the total incremental cost of electricity when optimized for the reference design conditions. Because of this, it was expected that the optimization process would converge to a solution having the smallest possible heat exchanger, with the size being constrained by the turbine back pressure limitations. (If the back pressure, i.e., steam temperature, is maximized, then the thermal driving force for heat transfer, the ITD, is also maximized. Thus, heat exchanger size would be as small as possible.) However, there are other variables that constrain the extent to which the size of the heat exchanger can be reduced by increasing turbine back pressure.

Listed in Table 6.5 are the optimized designs for various water allotments. The heat transfer area (size of the heat exchanger) is reduced as water availability increases (see Figure 6.1). Regardless of the availability of water, the maximum turbine back pressures are below the limiting values, (a) thereby indicating a potential for reducing the size of the heat exchanger. The maximum turbine exhaust pressure for different water availabilities is

(a) The reference condition model used for the turbine required that the back pressure not exceed 5.5 in. Hga, except for a few hours per year during which the exhaust pressure may be as high as $8.0 \mathrm{in}$. Hga. 
TABLE 6.5. Comparison of Optimized Design, Performance, and Cost Parameters for Various Annual Water Availabilities

\begin{tabular}{|c|c|c|c|c|c|}
\hline & 0 & $\begin{array}{l}\text { Water } \\
400\end{array}$ & $\frac{11 a b i l i t y}{1000}$ & $\frac{\mathrm{e}-\mathrm{ft}}{3000}$ & 5000 \\
\hline $10^{6} 1 \mathrm{bm} / \mathrm{sec}$ & 822. & 560. & 540. & 401. & 354. \\
\hline $\mathrm{ft} / \mathrm{sec}$ & 11.4 & 13.9 & 14.6 & 13.6 & 14.1 \\
\hline psi & 0.0051 & 0.0122 & 0.0132 & 0.0138 & 0.0147 \\
\hline psi & 0.0048 & 0.0057 & 0.0053 & 0.0048 & 0.0054 \\
\hline \multirow[t]{2}{*}{ MW } & 8.80 & 11.4 & 11.4 & 8.75 & 8.41 \\
\hline & 188 & 119 & 119 & 93 & 79 \\
\hline $10^{6} \mathrm{lbm} / \mathrm{hr}$ & 9.76 & 9.88 & 9.94 & 10.2 & 10.5 \\
\hline psi & 27.9 & 23.7 & 24.0 & 19.6 & 23.8 \\
\hline \multirow[t]{2}{*}{ MW } & 0.465 & 0.432 & 0.476 & 0.555 & 0.683 \\
\hline & 12 & 5 & 5 & 4 & 4 \\
\hline $\mathrm{ft}$ & 203. & 256. & 251. & 247. & 230. \\
\hline $\mathrm{ft}$ & 70.4 & 75.0 & 70.7 & 72.5 & 66.6 \\
\hline $10^{6} \mathrm{ft}^{2}$ & 0.524 & 0.294 & 0.271 & 0.219 & 0.188 \\
\hline $10^{6} \mathrm{ft}^{2}$ & 23.5 & 21.9 & 20.2 & 19.6 & 16.8 \\
\hline \multirow[t]{2}{*}{$\mathrm{ft}$} & 77.6 & 98.0 & 96.0 & 94.4 & 88.0 \\
\hline & 3 & 5 & 5 & 6 & 6 \\
\hline $10^{6} \mathrm{ft}^{2}$ & 0.532 & 0.520 & 0.438 & 0.454 & 0.406 \\
\hline${ }^{\circ} \mathrm{F}$ & 3.24 & 3.32 & 4.28 & 4.00 & 4.80 \\
\hline in. $\mathrm{Hg}$ & 1.22 & 1.48 & 1.63 & 2.18 & 2.98 \\
\hline in. $\mathrm{Hg}$ & 7.89 & 4.70 & 4.06 & 3.20 & 2.99 \\
\hline MW & 888.9 & 967.9 & 978.9 & 991.9 & 999.9 \\
\hline & 0.0 & 14.0 & 23.0 & 43.0 & 63.7 \\
\hline $10^{3} \mathrm{gpm}$ & 0.0 & 5.53 & 7.32 & 9.54 & 10.8 \\
\hline mill s/kWh & 1.81 & 1.46 & 1.38 & 1.26 & 1.12 \\
\hline mills/kwh & 0.36 & 0.11 & 0.07 & 0.03 & 0.00 \\
\hline mill s/kwh & 0.00 & 0.00 & 0.00 & 0.00 & 0.00 \\
\hline mills/kwh & -0.21 & -0.21 & -0.21 & -0.18 & -0.09 \\
\hline$m i l l s / k w h$ & 0.14 & 0.18 & 0.18 & 0.12 & 0.14 \\
\hline mill s/kwh & 0.19 & 0.24 & 0.22 & 0.13 & 0.00 \\
\hline mills/kwh & -0.02 & -0.01 & -0.01 & -0.01 & 0.02 \\
\hline $\mathrm{mi} 11 \mathrm{~s} / \mathrm{kWh}$ & 0.10 & 0.08 & 0.08 & 0.07 & 0.06 \\
\hline mill $/ \mathrm{s} / \mathrm{kWh}$ & 2.37 & 1.85 & 1.72 & 1.44 & 1.25 \\
\hline
\end{tabular}




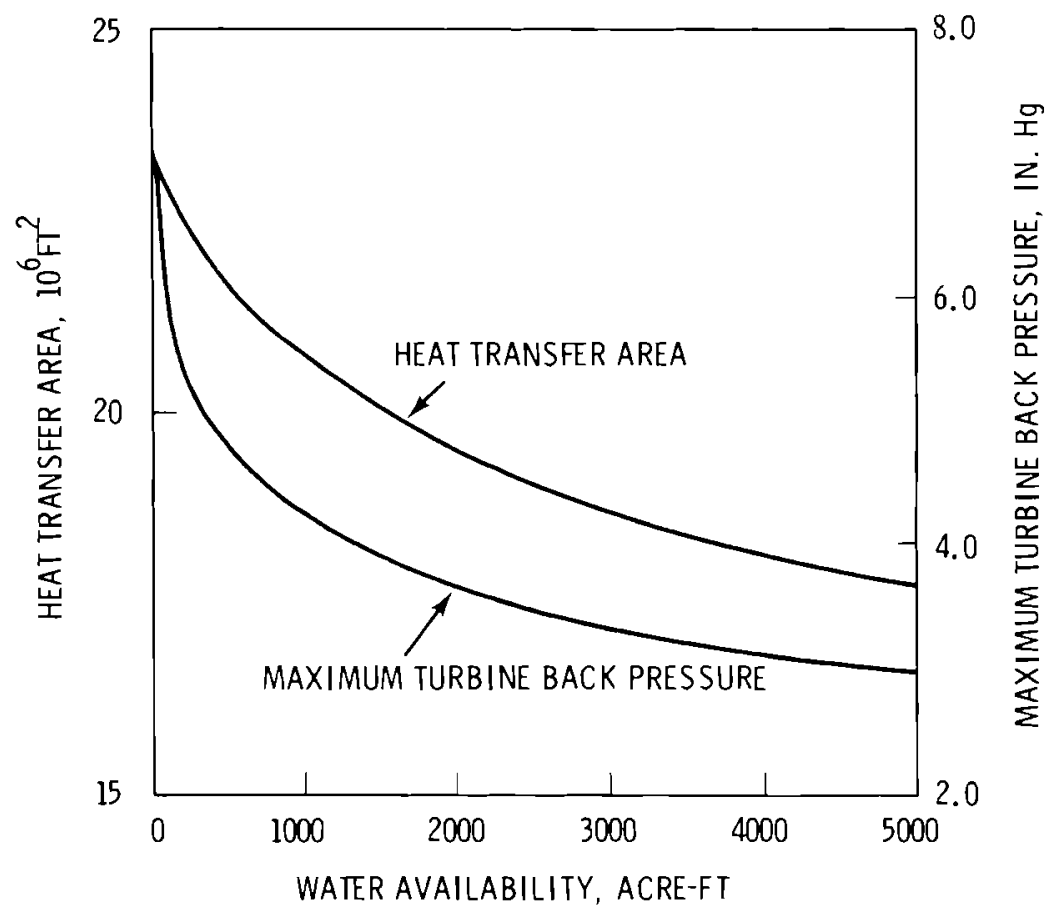

FIGURE 6.1. Heat Transfer Area and Maximum

Turbine Exhaust Pressure as a

Function of Water Availability

also shown in Figure 6.1. The fact that the turbine back pressures are not maximized is based on a trade-off between heat rate scaling and heat exchanger size.

As an example, consider the reference case which is based on a design temperature of $33^{\circ} \mathrm{F}$ with 3000 acre-ft of water available. Since the maximum operating turbine exhaust back pressure for the optimized reference design is $3.20 \mathrm{in.} \mathrm{Hg}$, it appears that a smaller heat exchanger could be specified if the back pressure were increased. The potential effects on costs are examined below.

The heat rejection in the dry mode can be given by

$$
\text { QREJ }=U A \frac{\text { RANGE }}{\ln \left(\frac{I T D}{I T D-R A N G E}\right)}
$$


Since the temperature range of the air, RANGE, usually optimizes at about half the initial temperature difference, ITD, and since the overall heat transfer coefficient, $U$, can be taken as a constant to facilitate comparison of designs, then the above equation becomes

$$
Q R E J=C A I T D
$$

Since QREJ is approximately a fixed value for a given size power plant, two designs can be compared according to the relation

$$
A_{1} \operatorname{ITD}_{1}=A_{2} \operatorname{ITD}_{2}
$$

For the reference design conditions the heat exchanger cost is $\$ 22.0 \times 10^{6}$. Since cost is approximately proportional to area, this value can be used for $A_{1}$. The optimized ITD is $63.3^{\circ} \mathrm{F}$. The optimized design steam temperature is $103.8^{\circ} \mathrm{F}$, and the corresponding heat rate is 0.9886 . The heat exchanger area and, therefore, the cost of the heat exchanger can be reduced by increasing the ITD. If the ITD is increased by $5^{\circ} \mathrm{F}$ to $68.3^{\circ} \mathrm{F}$, the cost of the heat exchanger could be reduced by about $\$ 1.6 \times 10^{6}$ since

$$
\begin{aligned}
& A_{2}=A_{1}\left(\frac{I T D_{1}}{I T D_{2}}\right)=22.0 \times 10^{6}\left(\frac{63.3}{68.3}\right)=20.4 \times 10^{6} \\
& A_{2}-A_{1}=(22.0-20.4) \times 10^{6}=1.6 \times 10^{6}
\end{aligned}
$$

To increase the ITD by $5^{\circ} \mathrm{F}$ the design steam temperature would increase to about $108.8^{\circ} \mathrm{F}$ with a corresponding heat rate of 0.9918 . This would result in an increase in the heat rate scaling cost of about $\$ 1.8 \times 10^{6}$ (i.e., $\left.0.9918-0.9886=0.0032 ; 0.0032 \times \$ 571 / \mathrm{kWe} \times 10^{6} \mathrm{kWe}=1.8 \times 10^{6}\right)$. Therefore, the total costs would actually increase if the ITD were increased. Because of this trade-off, the maximum turbine back pressure should not be expected to be at or near the limit values. 
The trade-off between heat exchanger size and heat rate scaling is a result of the steepness of the heat rate curve for the conventional turbine, shown in Figure 6.2. That is, the increase in heat rate due to small increases in back pressure result in large increases in heat rate scaling. It was suggested $^{(a)}$ that another reasonable model for the turbine performance characteristics would be to subtract $1 \%$ from the heat rate of the modified conventional turbine. Although the resultant curve, also shown in figure 6.2 , has a shallower slope and a lower heat rate at the upper end, use of this model did not change the trend of the results. Apparently, the slightly higher heat rate between $1-$ and $3-i n$. Hg exhaust pressure, as compared to the conventional turbine model, counteracts the shallower slope.

So far only one result of the analysis of water availability has been discussed, this being the decrease in heat exchanger size as water availability increases. A second observation that merits some discussion is the relationship between ambient design temperature and the lowest temperature that deluge enhancement is used. By definition, the design temperature is the ambient temperature for which the power plant will produce rated power. The base plant scaling required to achieve this is determined by calculations that assume the cooling system is in the all-dry mode at the design temperature. If deluge water is subsequently added at or below the design temperature, which may be necessary in order to comply with the requirement that all the available water be consumed, the performance would be improved and the net plant output would exceed rated power during all operating hours of the year rather than just for ambient temperatures below the design temperature. This would represent an increase in the excess power production capability as discussed in reference to Figure 4.3. This superfluous capability is a result of the plant being effectively over-scaled. At a cost of $\$ 571,000 / \mathrm{MW}$ the excess base plant scaling could be significant. Thus, it is generally not reasonable to compare different designs for which the power at the maximum turbine back pressure exceeds the plant-rated power. This is effectively a calculational limitation of the optimization code. Results obtained outside this limitation should be used with caution. The parametric study has been

(a) This information was provided by G. J. Sylvestri of the Steam Turbine Division, Westinghouse Electric Corporation, Lester, PA, in a private communication to PNL. 


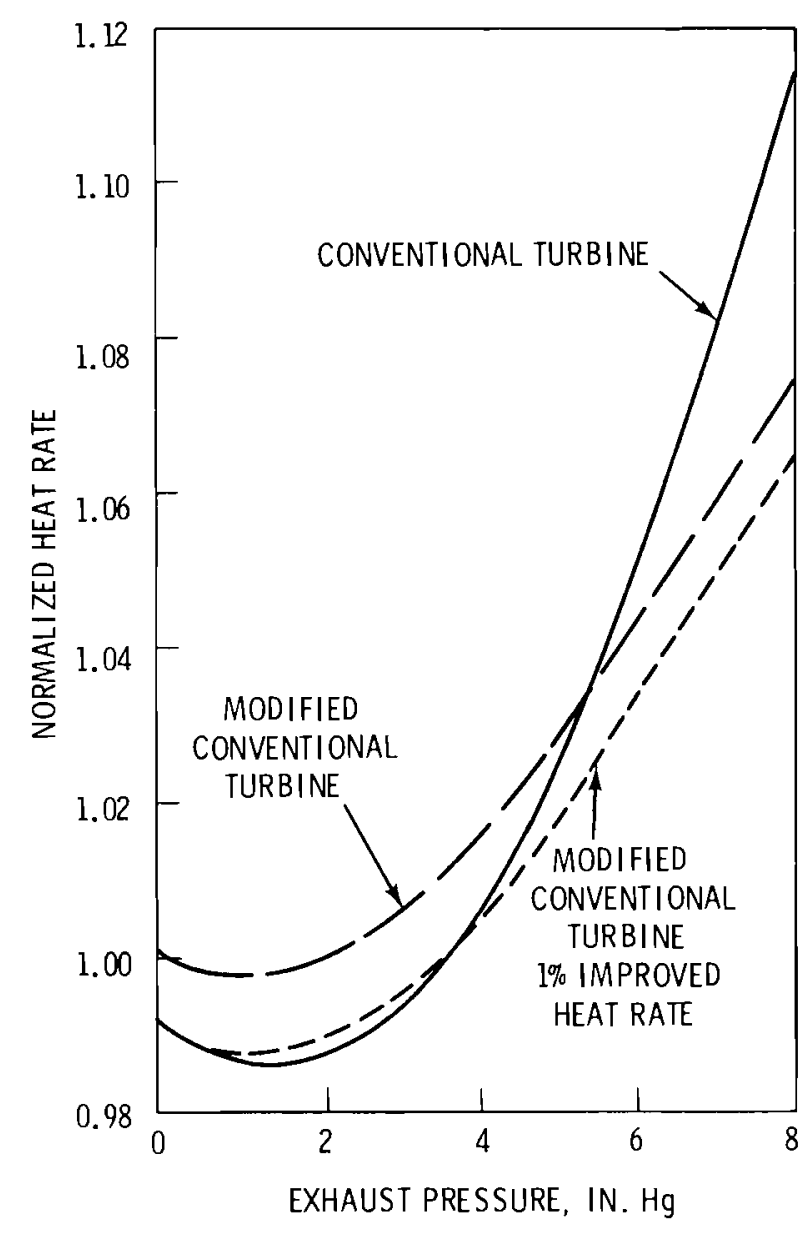

FIGURE 6.2. Normalized Heat Rate Versus Turbine Exhaust Pressure. Heat rates are normalized to heat rate of conventional turbine at $3.5 \mathrm{in}$. Hg.

done in adherence to this limitation. Excessive scaling occurs for high design temperatures or large amounts of water or a combination of the two. For a design temperature of $33^{\circ} \mathrm{F}$, excess scaling occurs when slightly more than 5000 acre-ft of water are available. At $52^{\circ} \mathrm{F}$ it occurs for 3000 acre-ft.

Optimized designs obtained for various water availabilities are given in Table 6.5. The incremental costs decrease for increasing water availabilities (see Figure 6.3). This trend is observed up to the point where there is enough available water that the onset of deluge occurs at the design temperature. This point is at about 5000 acre-ft for the design temperature of $33^{\circ} \mathrm{F}$. 


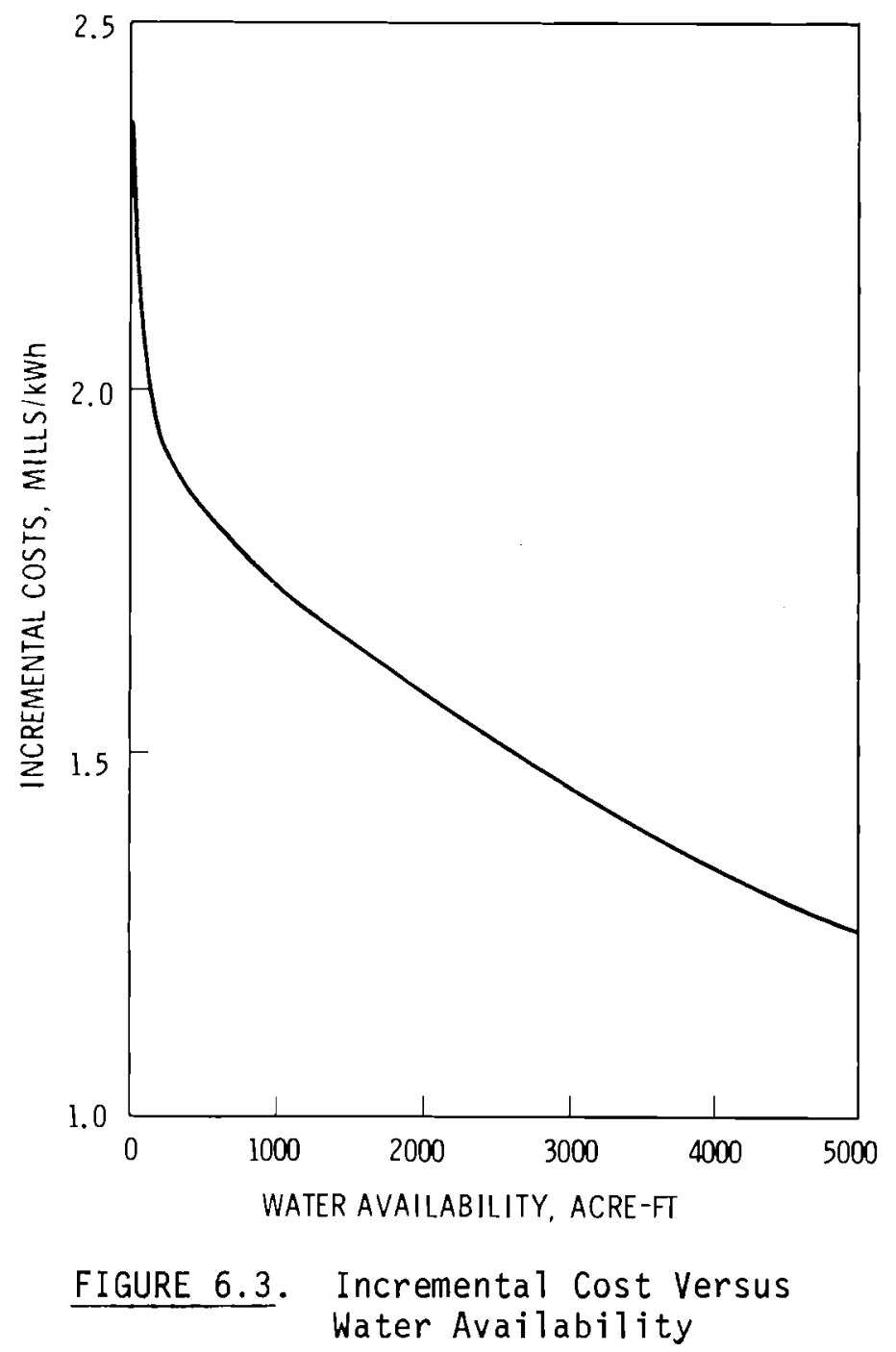

For water availabilities up to 5000 acre-ft, excess scaling is not encountered as indicated by the fact that the net power at the maximum turbine back pressure does not exceed $1000 \mathrm{MW}$.

A water cost subroutine was incorporated into the dry/wet code so that the effects of costing water usage can be seen. Five water cost values were used for this optimization: $\$ 1.00, \$ 3.00, \$ 6.00, \$ 10.00$, and $\$ 14.00 / 1000$ gal. The results of these optimizations can be seen in Figure 6.4 . 


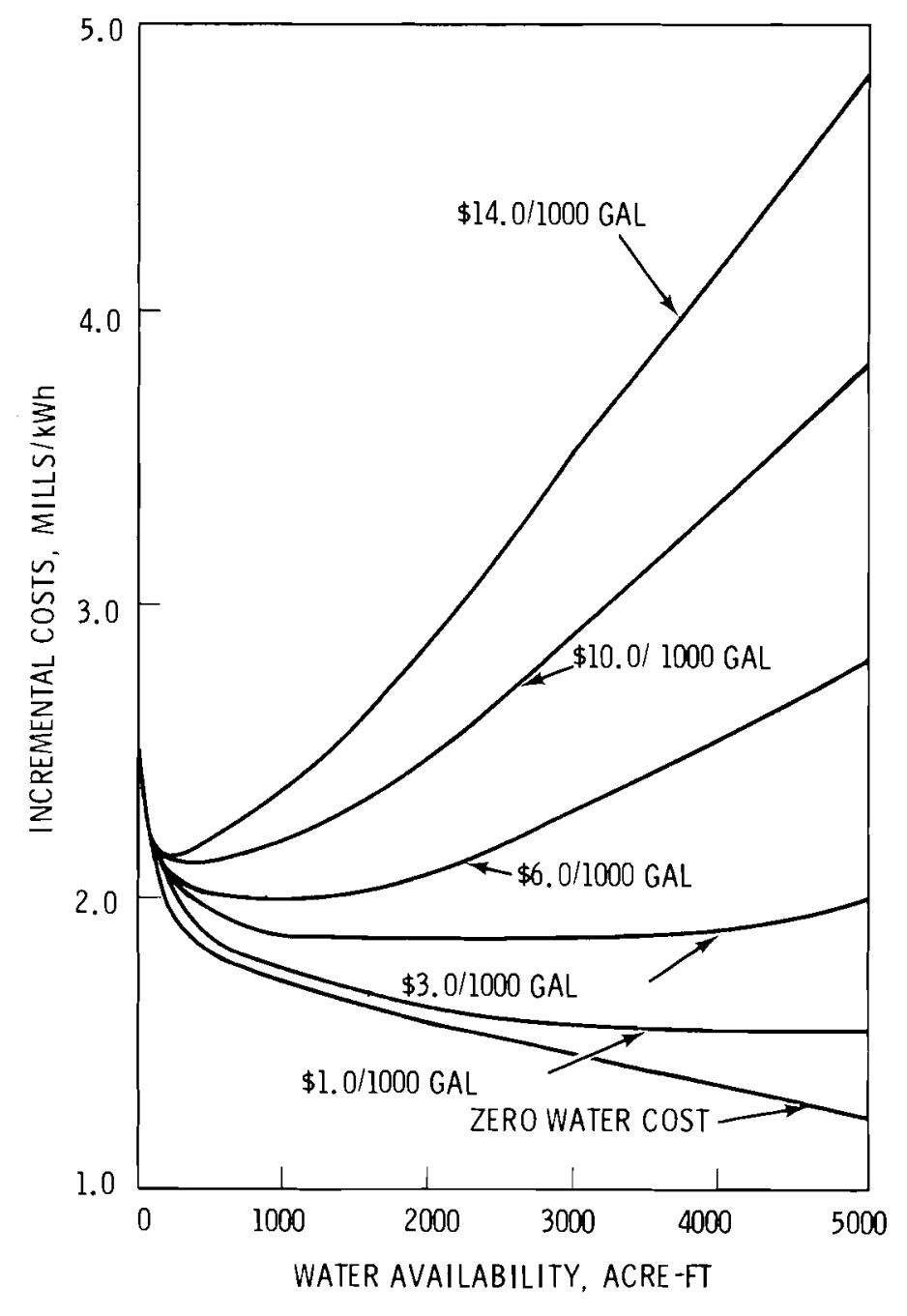

\section{FIGURE 6.4. Incremental cost Versus Water Availability for} Various Water Costs

The optimized design and the performance parameters are identical to those presented in Table 6.5 for the case of zero water cost. Since the code requires that all of the available water be used, the optimization process will converge to a solution according to the amount of water specified. Thus the optimized designs for a specific water allotment are identical regardless of water cost. However, the incremental costs associated with the cooling system reflect the cost and quantity of water used. 
For zero cost water the incremental cost decreases as more deluge water becomes available. For water costs somewhat above $\$ 1.00 / 1000$ gal, however, the price of the water will dictate the optimum amount of water that should actually be consumed.

\subsubsection{Design Ambient Air Temperature}

The design temperature is the temperature at which the power plant net output equals the base-load power required by the utility system. Optimized designs have been developed for design temperatures from $0^{\circ}$ to $47^{\circ} \mathrm{F}$. Design, performance, and cost data are given in Table 6.6. A close examination of the results reveals that the optimization process involving design temperature affects nearly every aspect of the cooling system power-plant/utility-system interface. Cost trade-offs involve heat exchanger size, capacity cost, energy cost, heat rate scaling, auxiliary power scaling, and fuel cost. (a) These costs are shown graphically in Figure 6.5. The cooling system capital reflects the heat exchanger size. Heat rate scaling is based on the difference between the design turbine exhaust pressure and the rated turbine exhaust pressure of $3.5 \mathrm{in.} \mathrm{Hg}$. The capacity penalty is the capital expense for the contingent of gas turbines required to maintain base-load plant output on the hottest day. The capacity charge used in this study was $\$ 121,000 / \mathrm{MW}$. The energy penalty is the integrated cost over one year of making up lost capacity by operation of the gas turbines. This power replacement cost was set at $24.0 \mathrm{mi} 11 \mathrm{~s} / \mathrm{kWh}$.

The combined capacity and energy costs are generally higher for low design temperatures. The design exhaust back pressure decreases with decreasing design temperature. Coupled with the fact that heat exchanger size also follows this trend, there is a great potential for lost capacity on the hottest day. Thus, the capacity penalty is large. Correspondingly, because the computer model maintains a constant exhaust pressure from the onset of deluge to the hottest day, the energy cost of operating the gas turbines is large where the capacity penalty is most severe.

(a) The relationship between these parameters is discussed in some detail by Fryer et al.,(2) as well as in Section 4. 
TABLE 6.6. Comparison of Optimized Design, Performance, and Cost Parameters for Various Design Temperatures

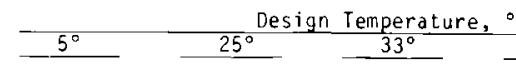

\begin{tabular}{|c|c|c|c|c|c|c|}
\hline \multicolumn{7}{|l|}{ Airflow Parameters } \\
\hline Airflow Rate & $10^{6} \mathrm{lbm} / \mathrm{hr}$ & 393. & 412 . & 401. & 399. & 403. \\
\hline Maximum Air Velocity & $\mathrm{ft} / \mathrm{sec}$ & 13.8 & 13.6 & 13.6 & 13.6 & 13.8 \\
\hline${ }_{\Delta} P_{a i r}$, h.x. & ps $i$ & 0.0147 & 0.0141 & 0.0138 & 0.0138 & 0.0141 \\
\hline$\Delta P_{a i r}$, discharge & psi & 0.0067 & 0.0049 & 0.0048 & 0.0046 & 0.0055 \\
\hline Fan Power & MW & 9.0 & 9.0 & 8.8 & 8.8 & 9.4 \\
\hline Fans & & 79 & 94 & 93 & 95 & 89 \\
\hline \multicolumn{7}{|l|}{$\mathrm{NH}_{3}$ Parameters } \\
\hline $\mathrm{NH}_{3}$ Flow Rate & $10^{6} \mathrm{lbm} / \mathrm{hr}$ & 9.5 & 9.8 & 10.1 & 10.5 & 10.6 \\
\hline$\Delta \mathrm{P}_{\mathrm{NH}_{3}}$ & psi & 15.7 & 18.2 & 19.5 & 24.1 & 23.6 \\
\hline Pump Power & MW & 0.409 & 0.546 & 0.555 & 0.659 & 0.614 \\
\hline \multicolumn{7}{|l|}{ Heat Exchanger Design } \\
\hline Towers & & 4 & 4 & 4 & 4 & 4 \\
\hline Approximate Tower 0 iameter & $\mathrm{ft}$ & 228. & 249. & 247. & 251. & 241. \\
\hline Tower Height & $\mathrm{ft}$ & 71.4 & 72.4 & 72.5 & 71.8 & 75.0 \\
\hline Frontal Area & $10^{6} \mathrm{ft}^{2}$ & 0.199 & 0.220 & 0.219 & 0.221 & 0.222 \\
\hline Heat Iransfer Area & $10^{6} \mathrm{ft}^{2}$ & 17.8 & 19.7 & 19.6 & 19.7 & 19.8 \\
\hline Tube Length & $\mathrm{ft}$ & 87.2 & 95.2 & 94.4 & 96.0 & 92.4 \\
\hline Tube Rows in Depth & & 6 & 6 & 6 & 6 & 6 \\
\hline \multicolumn{7}{|l|}{ Condenser Design } \\
\hline Heat Transfer Area & $10^{6} \mathrm{ft}^{2}$ & 0.458 & 0.399 & 0.454 & 0.413 & 0.519 \\
\hline TTD & ${ }^{\circ} \mathrm{F}$ & 4.08 & 4.96 & 4.00 & 4.68 & 3.28 \\
\hline \multicolumn{7}{|l|}{ Performance Parameters } \\
\hline Design TBP & $\mathrm{in.} \mathrm{Hg}$ & 0.99 & 1.68 & 2.18 & 2.98 & 3.26 \\
\hline Maximum TBP & in. $\mathrm{Hg}$ & 3.24 & 3.16 & 3.20 & 3.42 & 3.30 \\
\hline Power at Maximum TBP & MW & 989.6 & 990.6 & 991.9 & 995.3 & 999.5 \\
\hline Maximum \% Deluge & & 40.7 & 43.3 & 43.0 & 42.7 & 43.1 \\
\hline Maximum Evaporation Rate & $10^{3} \mathrm{gpm}$ & 9.12 & 9.60 & 9.54 & 9.44 & 9.53 \\
\hline \multicolumn{7}{|l|}{ Cost Summary } \\
\hline Cooling System & mills/kwh & 1.21 & 1.25 & 1.26 & 1.23 & 1.27 \\
\hline Capacity & $\mathrm{mills} / \mathrm{kwh}$ & 0.03 & 0.03 & 0.03 & 0.02 & 0.00 \\
\hline Steam Supply Scaling & $\mathrm{mills} / \mathrm{kWh}$ & 0.00 & 0.00 & 0.00 & 0.00 & 0.00 \\
\hline Heat Rate Scaling & mills/kwh & -0.20 & -0.20 & -0.18 & -0.09 & -0.05 \\
\hline Auxiliary Power Scaling & mills/kwh & 0.14 & 0.15 & 0.12 & 0.15 & 0.15 \\
\hline Energy & mills/kwh & 0.18 & 0.16 & 0.13 & 0.07 & 0.01 \\
\hline Base Fuel & mills/kwh & -0.02 & -0.02 & -0.01 & 0.01 & 0.03 \\
\hline OSM & $\mathrm{mills} / \mathrm{kWh}$ & 0.07 & 0.07 & 0.07 & 0.07 & 0.07 \\
\hline Incremental cost of & in & 1.47 & 1.43 & 1.44 & 1.45 & 1.47 \\
\hline
\end{tabular}




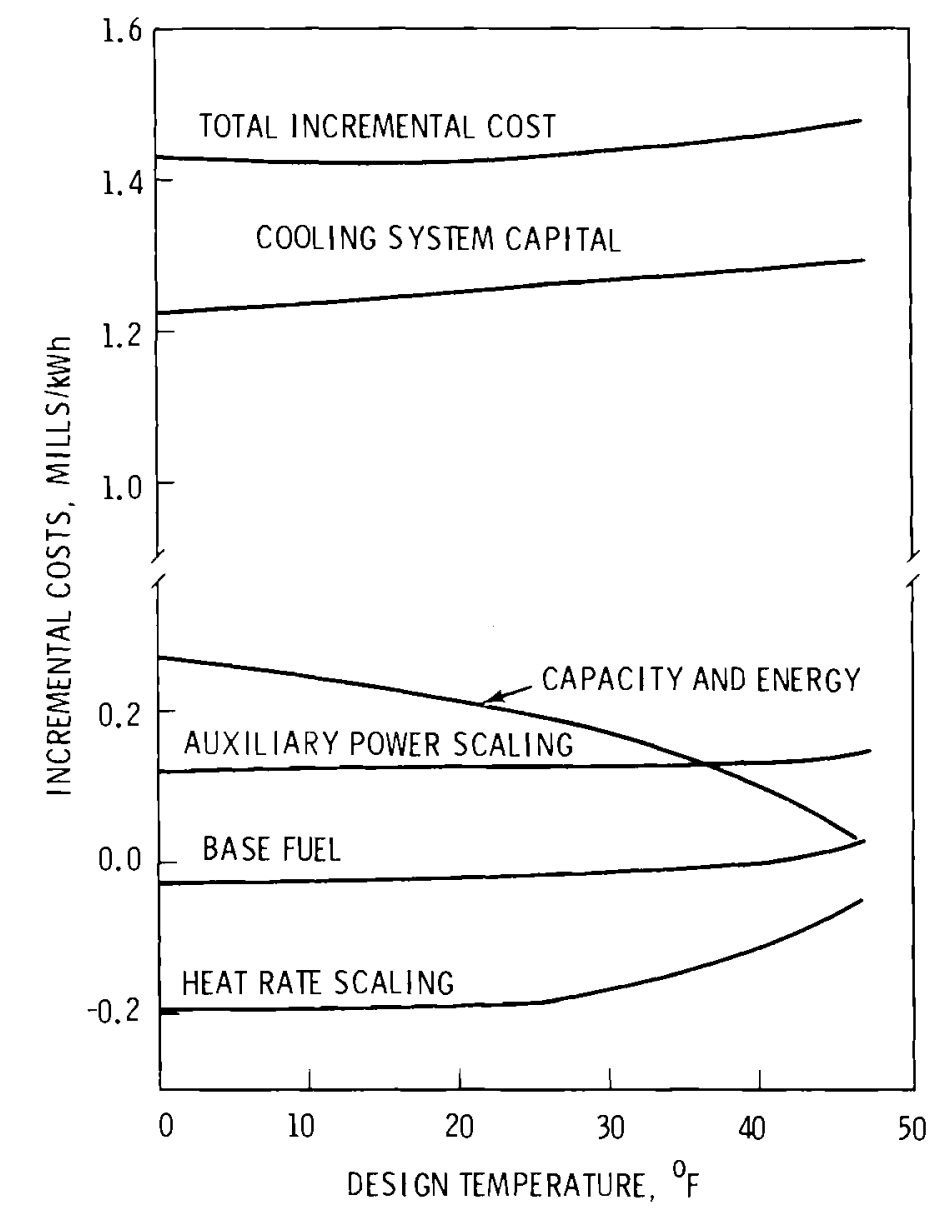

FIGURE 6.5. Incremental Cost and Components of the Incremental cost Versus Design Temperature

The heat rate and auxiliary power scaling, fuel, and cooling system capital costs are generally lower for the lower design temperatures. The basis for these results are outlined below.

- Lower design temperatures will have lower design steam temperatures, i.e., lower design heat rates, for a given ITD. The lower the design heat rate, the lower the heat rate scaling.

- The power plant producing rated power with a lower heat rate will have a lower heat rejection requirement at the design conditions. Since the heat rejection depends on the airflow, as well as the heat transfer area 
and ITD, the fan power to produce the airflow can generally be lower for a lower design temperature. In this way the auxiliary power scaling would be lower. While the influence of auxiliary power scaling appears to be small (Figure 6.5), the impact is certainly present in the tradeoff between airflow, heat transfer area, and ITD.

- The base plant fuel consumption charged to the cooling system is due to heat rate effects and auxiliary power requirements. Thus, it is expected that the fuel cost penalty would follow the trends discussed in the two preceding paragraphs.

- The cooling system capital cost is lower for the low design temperatures for two reasons. As discussed in the second paragraph a lower heat rejection requirement at the design point allows a smaller heat exchanger to be specified. In addition, the trade-off between heat rate and ITD makes a smaller heat exchanger cost effective for lower design temperatures. For example, an ITD of $70^{\circ} \mathrm{F}$ would result in a heat rate of 0.9907 with a $33^{\circ} \mathrm{F}$ design temperature but the same $70^{\circ} \mathrm{F}$ ITD would result in a heat rate of 1.0013 with a design temperature of $52^{\circ} \mathrm{F}$. The heat exchanger size for both cases would be nearly the same because the ITDs are the same. (The heat exchanger size would also reflect the heat rejection requirements.) However, the difference in heat rates would make the design at $52^{\circ} \mathrm{F}$ about $\$ 12 \times 10^{6}$ more costly $[(1.0113-0.9907) \times$ $571 \times 10^{6}$ ] excluding the influence of other trade-offs which contribute significantly to reducing this impact.

The net result of all the trade-offs is that low design temperatures are generally more cost effective. However, it must be kept in mind that this is related to the utility model which does not provide a market for excess capacity for ambient temperatures below the design point.

\subsubsection{Meteorology}

The meteorology data for each site were represented by sixteen dry-bulb temperatures and the associated wet-bulb temperatures. The temperatures selected to represent the hottest days of the year were determined by exhaust 
pressure limitations of the turbine as well as the accumulative distribution of temperatures. The turbine was modeled in the code as being capable of withstanding an exhaust pressure of $8 \mathrm{in}$. Hg for a total of about 44 hours/year at the San Juan site. (The total time allowed at a given exhaust pressure is based on the number of separate occurrences of the ambient temperature for which that pressure would occur. For example, the turbine was allowed to attain a back pressure of $8 \mathrm{in}$. Hg for 36 different occurrences regardless of the total duration of each occurrence. The 36 hottest occurrences of the year had a total duration of 44 hours at San Juan.) The exhaust pressure could reach $7 \mathrm{in}$. Hg for an additional 52 hours and $6 \mathrm{in}$. Hg for another 87 hours. For the remaining 8577 hours of the year the maximum exhaust pressure was limited to $5.5 \mathrm{in}$. Hg. The development of the meteorology is further discussed in Appendix $D$.

Perhaps the most important temperatures for a particular site are the maximum dry-bulb and associated wet-bulb temperatures. The sites for which optimized designs were developed are given in Table 6.7 with the elevation and maximum temperatures. A summary of the optimized designs for the eight sites that were studied is given in Table 6.8 .

TABLE 6.7. Meteorological Site Characteristics

\begin{tabular}{lrrrr}
\multicolumn{1}{c}{ Site } & $\begin{array}{c}\text { Elevation, } \\
\mathrm{ft}\end{array}$ & $\begin{array}{c}\text { Maximum } \\
\text { Dry-Bulb, }{ }^{\circ} \mathrm{F}\end{array}$ & $\begin{array}{c}\text { Maximum } \\
\text { Wet-Bulb, }{ }^{\circ} \mathrm{F}\end{array}$ \\
San Juan, NM & 5509. & & 101. & 71. \\
Miami, FL & 0. & 96. & 82. \\
Chicago, IL & 614. & 98. & 81. \\
San Francisco, CA & 0. & 93. & 70. \\
Washington, DC & 0. & 95. & 80. \\
Boston, MA & 0. & 95. & 78. \\
Bakersfield, CA & 475. & 109. & 77. \\
Phoenix, AZ & 1064. & 112. & 79.
\end{tabular}


TABLE 6.8. Comparison of Optimized Design, Performance, and Cost Parameters for Eight Site Meteorologies

Airflow Parameters

Airflow Rate

Maximum Air Velocity

$\Delta P$ a ir, h.x.

$\Delta P_{a i r}$, discharge

Fan Power

Fans

$\mathrm{NH}_{3}$ Parameters

$\mathrm{NH}_{3}$ Flow Rate

$\therefore \mathrm{P}_{\mathrm{NH}_{3}}$

Pump Power

Heat Exchanger Design

Towers

Approximate Tower Diameter

Tower Height

Frontal Area

$\stackrel{a}{i}$

Tube Length

Tube Rows in Depth

Condenser Design

Heat Transfer Area

TTD

Performance Parameters

Design TBP

Maximum TBP

Power at Maximum TBP

Maximum \% 0eluge

Maximum Evaporation Rate

Cost Summary

Cooling System

Capacity

Steam Supply Scaling

Heat Rate Scaling

Auxiliary Power Scaling

Energy

Base Fue 1

$08 M$

Incremental cost of Cooling mills/kwh

Farmington, NM Miami, FL Chicago, IL San Francisco, CA Washington, DC Bost

$\begin{array}{lcccc}10^{6} \mathrm{Ibm} / \mathrm{sec} & 401 . & 602 . & 442 . & 516 . \\ \mathrm{ft} / \mathrm{sec} & 13.6 & 12.3 & 11.9 & 13.8 \\ \mathrm{psi} & 0.0138 & 0.0115 & 0.0106 & 0.0112 \\ \mathrm{psi} & 0.0048 & 0.0043 & 0.0042 & 0.0043 \\ \mathrm{MW} & 8.75 & 8.50 & 6.10 & 7.20 \\ & 93 & 131 & 100 & 113\end{array}$

$10^{6} 1 \mathrm{bm} / \mathrm{hr}$

psi

MW

10.2

19.6
0.555

9.85

20.8
0.558

70.2

79.2

10.2
31.6

0.715

$\mathrm{ft}$
$\mathrm{ft}$
$10^{6} \mathrm{ft}^{2}$
$10^{6} \mathrm{ft}^{2}$
$\mathrm{ft}$

$10^{6} \mathrm{ft}^{2}$

${ }^{\circ} \mathrm{F}$

in. $\mathrm{Hg}$

in. $\mathrm{Hg}$

$M W$

$10^{3} \mathrm{gPm}$

$\mathrm{mills} / \mathrm{kwh}$

$\mathrm{mills} / \mathrm{kwh}$

mills/kwh

$\mathrm{mill} / \mathrm{kwh}$

$\mathrm{mitis/kwh}$

mills/ kwh

mills/kwh

mills/kwh

4
247.
72.5
0.219
19.6
94.4
6

0.454
4.00

2.18
3.20
991.9
43.0
9.54

1.26
0.03
0.00
-0.18
0.12
0.13
-0.01
0.07
1.44

64

$\begin{array}{cc}4 & 7 \\ 256 . & 208 \\ 72.4 & 50.0 \\ 0.227 & 0.223 \\ 16.9 & 13.3 \\ 98.0 & 79.6\end{array}$

0.526

3.2

2.26

$\begin{array}{ll}1.37 & 2.27\end{array}$

3.61

984.9

3.09
993.2

73.0

6.77

9.97

1.17

0.02

0.00

$-0.18$

0.10

0.10

$-0.03$

0.06

453.
12.0
0.0110
0.0043
6.31
100

10.1
18.8
0.537
4
255.
71.9
0.225
16.7
97.6
5

0.429
4.36

2.10
3.38
989.6
56.6
8.53
1.18
0.03
0.00
-0.18
0.11
0.18
-0.03
0.06
1.35

3.16
992.8

70.1

1.19

0.02

0.00

$-0.17$

0.17

$-0.02$

0.06

1.38
Boston, MA

Bakersfield. CA Phoenix, $A Z$

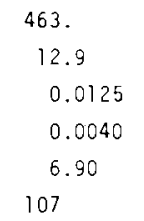

487.

487.

0.0176

0.0057

9.80

103

$\begin{array}{ccc}10.2 & 10.0 & 9.85 \\ 29.5 & 27.3 & 18.3 \\ 0.765 & 0.568 & 0.513\end{array}$

3
310.
75.0
0.214
15.9
178.8
5

0.386
5.20

2.24
3.16
992.7
69.5
9.65

1.15
0.02
0.00
-0.17
0.12
0.12
-0.02
0.06
1.28

5
233.
73.8
0.263
19.6
89.2
5

0.413
4.68

7.86
3.58
986.7
42.4
10.6

1.33
0.05
0.00
-0.20
0.18
0.24
-0.01
0.07
1.64

4

554.

71.9
0.224

23.3

97.2

7

0.454

4.08

1.42

3.84

981.8

32.9

39

0.06

0.00

$-0.21$

0.18

0.31

$-0.01$

0.08

1.79 
For the San Juan site the dominating characteristic is the elevation $(5509 \mathrm{ft})$. The lower air density at this elevation results in a lower overall heat transfer coefficient. To counteract this, the heat exchanger is generally larger than for the sites that are at sea level and have the same peak temperatures.

While the maximum temperature at Miami is not excessive, the optimized design for the Miami meteorology reflects the fact that the temperatures remain warm throughout the year. The large energy penalty indicates that the gas turbines supply power to make up lost capacity over a significant portion of the year.

\subsubsection{Relative Humidity}

The method used to calculate the heat rejection of the deluged portion of the heat exchanger does not compute the relative humidity of the air leaving the heat exchanger. Therefore, the relative humidity of the exiting air must be specified in order to compute its temperature. This situation commonly occurs with the design of wet towers where, in general, the exiting air is assumed saturated since the computational effort to obtain the relative humidity is usually not worth the additional effort. Where this is the case, the exiting air is assumed saturated (normally, a good approximation).

The results of four optimization runs made at exiting air relative humidities of 0.5 to $1.0(50 \%$ to $100 \%)$ are shown in Table 6.9 . The effects on incremental costs are small over the expected range of exiting relative humidity of 0.9 to 1.0 .

\subsubsection{Air Velocity Through The Deluged Heat Exchanger}

Table 6.10 presents the results of the effect of FACTOR (the ratio of air velocity during deluging to air velocity during all-dry operation) on the optimized design, performance, and cost parameters.

FACTOR had very little effect on the incremental costs. A reference value of 0.77 was chosen for FACTOR. The value of FACTOR was determined by finding the FACTOR value that gives the same pressure drop through the wet 
TABLE 6.9. Comparison of Optimized Design, Performance, and Cost Parameters for Various Exit Relative Humidities

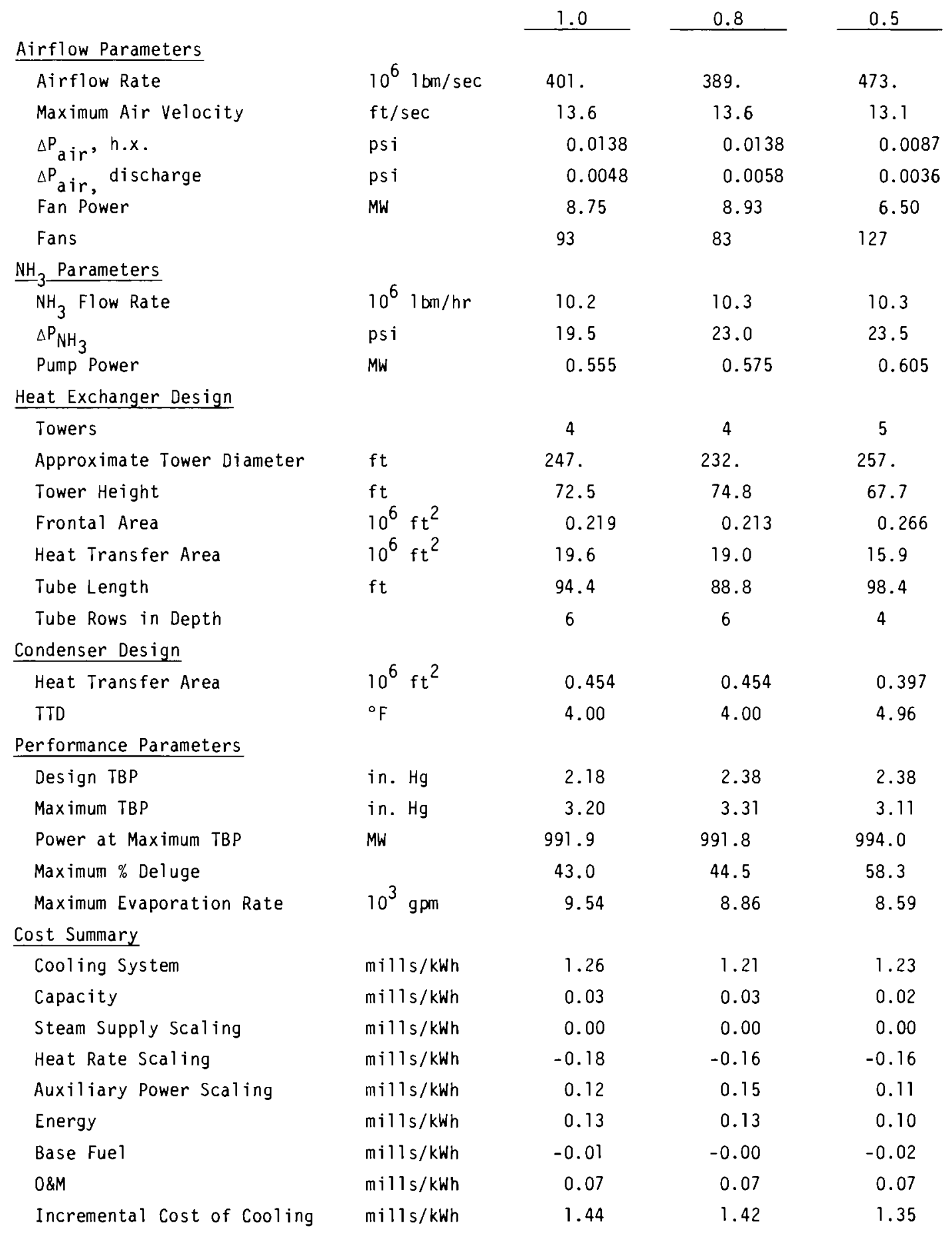


TABLE 6.10. Comparison of Optimized Design, Performance, and Cost Parameters for Various Assumed Values of the Ratio of Air Velocity Through the Dry Section to the Air Velocity Through the Wet Section

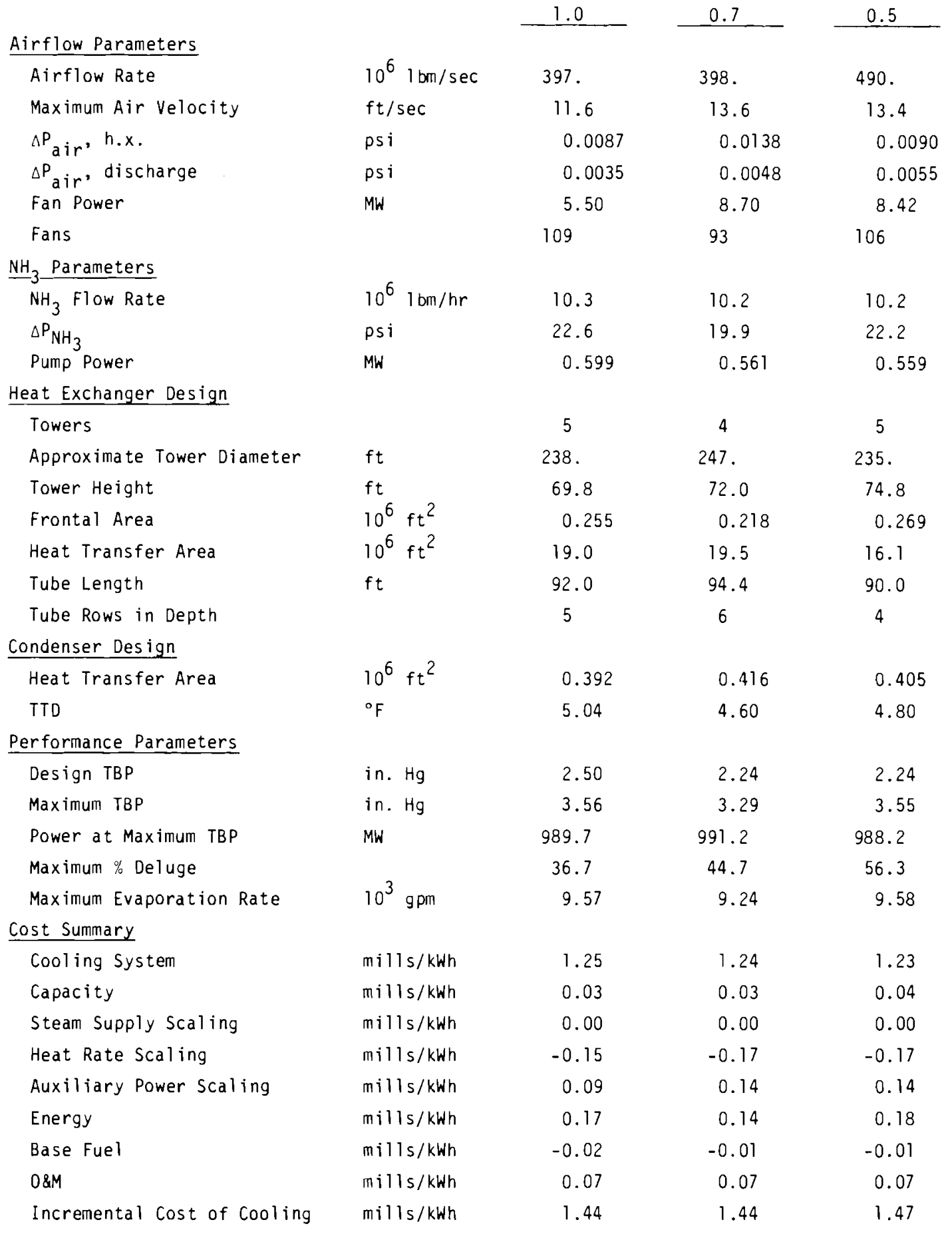


and through the dry sections of a given tower. Appendix $E$ presents the engineering considerations that were used to determine the proper value for FACTOR. The major effect of reducing the value of FACTOR from 1.0 to 0.5 is to increase the maximum percent of heat exchanger deluged from $36.7 \%$ to $56.3 \%$.

\subsection{PARAMETRIC ANALYSIS OF THE DRY MODE PARAMETERS}

The dry mode parameters are those established as a part of the cooling system design prior to the deluge enhancement computations. This section includes parametric evaluations of the following:

- the length of the heat exchanger tubes,

- the number of heat exchanger tube rows in depth,

- the number of towers,

- the fan packing factor,

- the fan system,

- the air velacity through the heat exchanger, and

- the type of turbine.

Their reference values are 1isted in Table 6.2. In addition to these parameters, the use of louvers and velocity recovery stacks is also considered. The optimized designs for these parameters are presented and discussed in this section.

\subsubsection{Tube Length/Tower Diameter}

The tube length is one of the five internally optimized independent variables. However, the tube length can be constrained to a prescribed value by using an input option of the computer code. By this means, optimized designs were developed for tube lengths from 60 to $120 \mathrm{ft}$ for towers having eight sides and from 30 to $60 \mathrm{ft}$ for towers having sixteen sides. The resultant optimized design information is given in Tables 6.11 and 6.12 . A tower with a 60-ft tube length and eight sides will have essentially the same diameter as a tower with a 30-ft tube length and sixteen sides. Since the tube length and number of sides establishes the equivalent tower diameter, 
TABLE 6.11. Comparison of Optimized Design, Performance, and Cost Parameters for Various Tube Lengths for Eight-Sided Towers

\section{Airflow Parameters}

Airflow Rate

Maximum Air Velocity

$\Delta P_{\text {a ir }}, h . x$.

$\Delta P_{\text {a ir }}$, discharge

Fan Power

Fans

$\mathrm{NH}_{3}$ Parameters

$\mathrm{NH}_{3}$ Flow Rate

$\triangle \mathrm{P}_{\mathrm{NH}_{3}}$

Pump Power

Heat Exchanger Design

Towers

Approximate Tower Diameter

Tower Height

Frontal Area

Heat Transfer Area

Tube Length

Tube Rows in Depth

\section{Condenser Design}

Heat Transfer Area

TTD

Performance Parameters

Design TBP

Maximum TBP

Power at Maximum TEP

Maximum \% Deluge

Maximum Evaporation Rate

Cost Summary

Cooling System

Capacity

Steam Supply Scaling

Heat Rate Scaling

Auxiliary Power Scaling

Energy

Base Fuel

O\&M

Incremental cost of Cooling

$10^{6} 1 \mathrm{bm} / \mathrm{hr}$
$\mathrm{ft} / \mathrm{sec}$
psi
psi
$\mathrm{MW}$

$10^{6} 1 \mathrm{bm} / \mathrm{hr}$

psi

$\mathrm{MW}$

$\mathrm{ft}$

$\mathrm{ft}$

$10^{6} \mathrm{ft}^{2}$

$10^{6} \mathrm{ft}^{2}$

$\mathrm{ft}$

$10^{6} \mathrm{ft}^{2}$

${ }^{\circ} \mathrm{F}$

in. $\mathrm{Hg}$

in. $\mathrm{Hg}$

$\mathrm{MW}$

$10^{3} \mathrm{gpm}$

mills/kwh

mills/kWh

mills/kWh

mills/kWh

$\mathrm{mills} / \mathrm{kWh}$

$\mathrm{mills} / \mathrm{kWh}$

mills/kwh

mills/kwh

mills/kwh

\begin{tabular}{llll} 
Tube Length, $\mathrm{ft}$ & \\
\hline 60 & 90 & 100 & 120 \\
\hline
\end{tabular}

436.

13.9

0.0120

481.

13.8

402 .

486.

0.0055

0.0095

13.6

12.8

8.90

0.0034

0.0139

0.0084

6.91

94

133

0.0048

0.0037

8.82

6.53

94

129

10.2
26.7
0.609

10.2

10.2

10.2

26.3

19.2

21.8

0.614

0.540

0.593

11
157.
48.4
0.232
17.3
60.0
5

8
209.
50.0
0.256
15.3
80.0
4

0.502

0.505

3.40

4
261.

4

66.3

314.

$0.219 \quad 0.278$

19.6

16.6

100.0

120.0

6

4

3.44

0.361

0.411

5.84

4.68

$$
\begin{array}{r}
2.26 \\
3.41
\end{array}
$$

2.26

2.26

2.17

989.9

3.45

989.5

45.5

9.81

46.0

10.1

3.32

3.34

991.0

990.3

42.7

9.45

44.9

10.1

1.29
0.03
0.00
-0.17
0.15
0.16
-0.01
0.07
1.51

1.31

1.25

1.29

0.03

0.03

0.03

0.00

0.00

0.00

$-0.17$

$-0.17$

$-0.18$

0.12

0.14

0.11

0.16

0.15

0.15

$-0.02$

$-0.01$

$-0.02$

0.07

0.07

0.07

1.51

1.46

1.45 
TABLE 6.12. Comparison of Optimized Design, Performance, and Cost Parameters for Various Tube Lengths for Sixteen-Sided Towers

\begin{tabular}{|c|c|c|c|}
\hline & \multicolumn{2}{|c|}{ Tube Length, ft } & \\
\hline 30 & 40 & 50 & 60 \\
\hline 447. & 397. & 401. & 401. \\
\hline 14.2 & 14.2 & 13.6 & 14.2 \\
\hline 0.0125 & 0.0150 & 0.0138 & 0.0150 \\
\hline 0.0054 & 0.0054 & 0.0048 & 0.0044 \\
\hline 9.30 & 9.40 & 8.75 & 9.13 \\
\hline 98 & 87 & 93 & 98 \\
\hline 10.2 & 10.2 & 10.2 & 10.2 \\
\hline 26.4 & 20.3 & 16.9 & 24.8 \\
\hline 0.604 & 0.540 & 0.499 & 0.677 \\
\hline 11 & 7 & 4 & 3 \\
\hline 154. & 205. & 256. & 308. \\
\hline 48.4 & 64.8 & 68.4 & 72.7 \\
\hline 0.232 & 0.207 & 0.219 & 0.209 \\
\hline 17.3 & 18.5 & 19.6 & 18.7 \\
\hline 30.0 & 40.0 & 50.0 & 60.0 \\
\hline 5 & 6 & 6 & 6 \\
\hline 0.410 & 0.443 & 0.376 & 0.416 \\
\hline 4.72 & 4.16 & 5.44 & 4.60 \\
\hline 2.26 & 2.31 & 2.23 & 2.31 \\
\hline 3.48 & 3.41 & 3.35 & 3.42 \\
\hline 989.2 & 990.2 & 990.5 & 990.1 \\
\hline 45.9 & 43.1 & 43.1 & 43.4 \\
\hline 9.96 & 9.36 & 9.43 & 9.44 . \\
\hline 1.32 & 1.31 & 1.30 & 1.29 \\
\hline 0.04 & 0.03 & 0.03 & 0.03 \\
\hline 0.00 & 0.00 & 0.00 & 0.00 \\
\hline-0.17 & -0.17 & -0.17 & -0.17 \\
\hline 0.15 & 0.15 & 0.14 & 0.16 \\
\hline 0.17 & 0.16 & 0.15 & -0.01 \\
\hline-0.01 & -0.00 & -0.01 & -0.01 \\
\hline 0.07 & 0.07 & 0.07 & 0.07 \\
\hline 1.57 & 1.56 & 1.51 & 1.53 \\
\hline
\end{tabular}


the range of tube lengths provides tower diameters from 154 to $314 \mathrm{ft}$. A discussion of the tower diameter is more relevant than a discussion of the tube length, since the tower diameter impacts the optimization of the cooling system. The tower diameter and number of towers are related. Thus, the reader may find that the discussion in Section 6.4.3 (regarding the specification of the number of towers) will parallel portions of the following discussion. In fact, the reader may find this characteristic somewhat typical of the discussions in this section through Section 6.4.5, since each of the parameters impacts all the others.

When the tower diameter is specified the roof area per tower is thereby established. With a given packing factor (Section 6.4.5) the area available for fans is also established. For the small diameter tower a small number of fans can fit on the tower roof. Thus, the tower height must be kept small. This, in turn, reduces frontal area and, for a given frontal air velocity, reduces the airflow through the fans. In this way the discharge losses encountered by the fan system are not excessive. By similar reasoning, the large diameter tower affords a greater tower height. Since more fans can be fit to the tower roof it is appropriate to specify a taller tower so that the total airflow to the fans is sufficient to meet a balance between the cost of the fans and the fan power consumed. That is, the fan system is optimized as discussed in Section 6.4.4.

It is seen that the tube length has only a small impact on incremental cost. This results because the optimum heat exchanger design and the optimum fan system can be combined by manipulation of the number of towers and the tower height. As discussed in Section 6.4.3, the heat exchanger design and the airflow requirements essentially dictate the optimum design because these components represent a large portion (about two-thirds) of the total incremental cost. Thus, the impact that tube length has on the cost is related to such cost items as structures and piping, which are both functions of the number and size of the towers. 


\subsubsection{Number of Tube Rows in Depth}

The number of heat exchanger tube rows in the direction of airflow is the number of tube rows in depth. Although this parameter is one of the five internally optimized independent variables, it could be constrained to any given integer value by using an input option of the computer code.

Restricting the number of tubes in depth affects the cooling tower configuration in the following manner. A deeper heat exchanger has a greater air-side pressure drop for a given air velocity than does a shallow heat exchanger. This is evident from the results shown in Table 6.13 where, as the number of tube rows in depth increases, the pressure drop across the heat exchanger increases. This results because the optimized air velocities are nearly identical for each design. With nearly identical air velocities the air traveling through a deeper heat exchanger will have a higher RANGE and, therefore, a lower LMTD. The overall heat transfer coefficient in the dry mode is dominated by the air-side coefficient which is determined by air velocity. Since the optimized air velocities are similar, the overall heat transfer coefficients are comparatively equal. To reject the required amount of heat the deeper heat exchanger must have a larger heat transfer area to compensate for the lower LMTD $(Q R E J=U A$ LMTD). Furthermore, the greater temperature rise of the air in the deeper heat exchanger permits a reduced airflow rate (QREJ = CPAIR . WAIR - RANGE). In spite of the high pressure drop in the deeper heat exchanger, the low airflow requirements keep the fan power at a reasonable level.

The primary trade-off involving a shallow versus a deep heat exchanger is airflow rate and fan power versus heat exchanger area (see Figure 6.6). For the deep heat exchanger to require less area the LMTD would have to be increased. This would require an increase in airflow rate with the associated increase in fan power. The opposite is true, of course, for the shallow heat exchanger. As one can observe in Table 6.13, the optimization process finds a balance in cost over a relatively broad range of heat exchanger depth. 
TABLE 6.13. Comparison of Optimized Design, Performance, and Cost Parameters for Various Numbers of Tube Rows in Depth



Heat Exchanger Design

Towers
Approximate Tower
Tower Height
Frontal Area
Heat Transfer Area
Tube Length
Tube Rows in Depth

Condenser Design

Heat Transfer Area

TTD

Performance Parameters

Design TBP

Maximum TBP

Power at Maximum TBP

Maximum \% Deluge

Maximum Evaporation Rate

Cost Summary

Cooling System
Capacity
Steam Supply Scaling
Heat Rate Scaling
Auxiliary Power Scaling
Energy
Base Fuel
O\&M

Incremental cost of Cooling

$10^{6} 1 \mathrm{bm} / \mathrm{hr}$
$\mathrm{ft} / \mathrm{sec}$
$\mathrm{psi}$
$\mathrm{psi}$
$\mathrm{MW}$

$10^{6} 1 \mathrm{bm} / \mathrm{hr}$ psi

$\mathrm{MW}$

$f t$

$\mathrm{ft}$

$10^{6} \mathrm{ft}^{2}$

$10^{6} \mathrm{ft}^{2}$

$\mathrm{ft}$

$10^{6} \mathrm{ft}^{2}$

${ }^{\circ} \mathrm{F}$

in. $\mathrm{Hg}$

in. $\mathrm{Hg}$

$\mathrm{MW}$

$10^{3} \mathrm{gpm}$

$\mathrm{mills} / \mathrm{kWh}$

$\mathrm{mi} 11 \mathrm{~s} / \mathrm{kWh}$

mills/ kwh

$\mathrm{mills} / \mathrm{kwh}$

mills/kwh

$\mathrm{mills} / \mathrm{kWh}$

$\mathrm{mills} / \mathrm{kWh}$

mills/kwh

$\mathrm{mills} / \mathrm{kWh}$
Number of Tube Rows

\begin{tabular}{l} 
Number of Tube Rows \\
\hline 4 \\
\hline
\end{tabular}

490.

395.

360.

13.4

13.9

12.9

0.0090

0.0145

0.0167

0.0055

0.0046

0.0045

8.42

8.84

9.11

106

95

87

10.2
22.2
0.559

10.2

10.2

26.2

18.2

0.638

0.522

\section{5}

235.

74.8

0.269

16.1

90.0

4

$$
5
$$

287.

79.7

4

249.

0.210
18.8

68.3

0.208

110.0

24.8

95.2

6

8

$\begin{array}{lll}0.405 & 0.536 & 0.373 \\ 4.80 & 3.12 & 5.52\end{array}$

2.24

2.26

2.24

3.47

989.1

46.0

3.26

3.21

- 991.7

992.1

41.4

38.5

10.3

9.22

8.97

1.23

1.27

1.33

0.04

0.03

0.03

0.00

0.00

$-0.17$

0.00

$-0.17$

0.14

$-0.17$

0.15

0.17

0.14

0.13

$-0.01$

0.13

$-0.01$

0.07

$-0.01$

0.07

1.46

0.07

1.52 


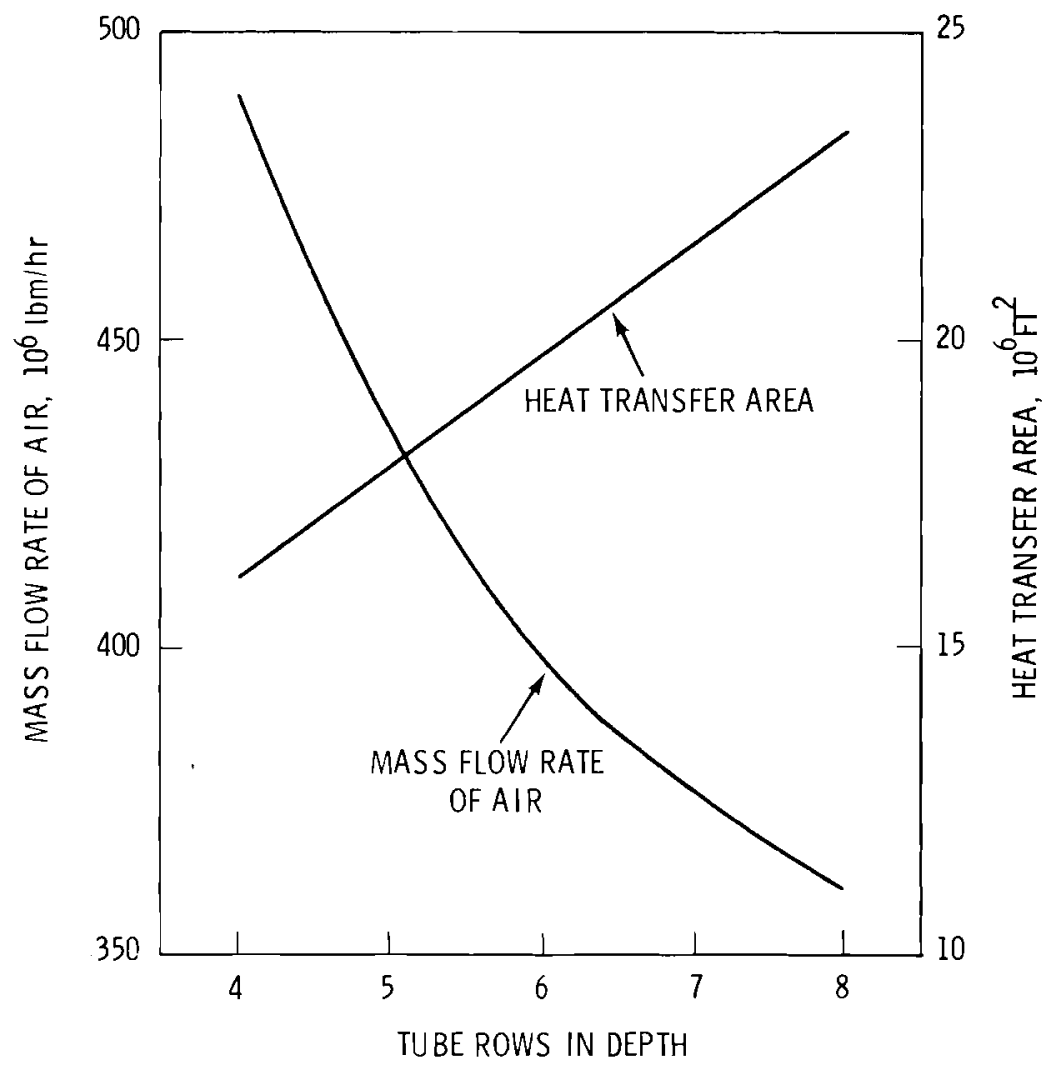

FIGURE 6.6. Optimized Airflow Rate and Heat Transfer Area Versus Tube Rows in Depth

\subsubsection{Number of Towers}

An option exists in the computer code input to specify the number of towers. This option was used to evaluate the effect of the number of towers upon the design and cost of the cooling system. The results are presented in Table 6.14.

The number of towers is strictly a dependent variable within the computer code. For each set of the five internal independent parameters a cooling system will be defined. If the number of towers in that design does not equal the number specified by the code input, then the design is rejected. Thus, the optimization proceeds in a normal fashion except that it is guided by the restriction that the specified number of towers must be satisfied. 
TABLE 6.14. Comparison of Optimized Design, Performance, and Cost Parameters for a Specified Number of Towers

\begin{tabular}{|c|c|c|c|c|}
\hline \multirow{2}{*}{\multicolumn{5}{|c|}{$\underline{\text { Airflow Parameters }}$}} \\
\hline & & & & \\
\hline Airflow Rate & $10^{6} 1 \mathrm{bm} / \mathrm{hr}$ & 436 & 429 & 426 \\
\hline Maximum Air Velocity & $\mathrm{ft} / \mathrm{sec}$ & 13.5 & 12.5 & 13.7 \\
\hline$\Delta P_{\text {air }}, h . x$. & psi & 0.0115 & 0.0100 & 0.0118 \\
\hline$\Delta P_{a i r}$, discharge & psi & 0.0057 & 0.0051 & 0.0036 \\
\hline Fan Power & $M W$ & 8.75 & 7.7 & 7.83 \\
\hline Fans & & 93 & 97 & 114 \\
\hline \multicolumn{5}{|l|}{$\underline{\mathrm{NH}}_{3}$ Parameters } \\
\hline $\mathrm{NH}_{3}$ Flow Rate & $10^{6} 1 \mathrm{bm} / \mathrm{hr}$ & 10.2 & 10.2 & 10.2 \\
\hline$\Delta \mathrm{P}_{\mathrm{NH}}$ & psi & 26.7 & 21.4 & 21.5 \\
\hline Pump Power & $M W$ & 0.673 & 0.529 & 0.557 \\
\hline \multicolumn{5}{|l|}{ Heat Exchanger Design } \\
\hline Towers & & 3 & 6 & 8 \\
\hline Approximate Tower Diameter & $\mathrm{ft}$ & 284 & 205 & 193. \\
\hline Tower Height & $\mathrm{ft}$ & 91.2 & 67.4 & 48.4 \\
\hline Frontal Area & $10^{6} \mathrm{ft}^{2}$ & 0.238 & 0.254 & 0.229 \\
\hline Heat Transfer Area & $10^{6} \mathrm{ft}^{2}$ & 17.8 & 18.9 & 17.1 \\
\hline Tube Length & $\mathrm{ft}$ & 108.8 & 78.4 & 74.0 \\
\hline Tube Rows in Depth & & 5 & 5 & 5 \\
\hline \multicolumn{5}{|l|}{ Condenser Design } \\
\hline Heat Transfer Area & $10^{6} \mathrm{ft}^{2}$ & 0.405 & 0.399 & 0.423 \\
\hline TTD & ${ }^{\circ} \mathrm{F}$ & 4.80 & 4.92 & 4.48 \\
\hline \multicolumn{5}{|l|}{ Performance Parameters } \\
\hline Design TBP & in. $\mathrm{Hg}$ & 2.27 & 2.24 & 2.31 \\
\hline Maximum TBP & in. $\mathrm{Hg}$ & 3.39 & 3.38 & 3.45 \\
\hline Power at Maximum TBP & MW & 990.2 & 990.3 & 989.7 \\
\hline Maximum $\%$ Deluge & & 43.6 & 45.1 & 44.8 \\
\hline Maximum Evaporation Rate & $10^{3} \mathrm{gpm}$ & 9.72 & 9.79 & 9.68 \\
\hline \multicolumn{5}{|l|}{ Cost Summary } \\
\hline Cooling System & $\mathrm{mill} \mathrm{s} / \mathrm{kwh}$ & 1.21 & 1.25 & 1.25 \\
\hline Capacity & $\mathrm{mil1s} / \mathrm{kWh}$ & 0.03 & 0.03 & 0.03 \\
\hline Steam Supply Scaling & $\mathrm{mi} 1 \mathrm{~s} / \mathrm{kwh}$ & 0.00 & 0.00 & 0.00 \\
\hline Heat Rate Scaling & $\mathrm{mill} \mathrm{s} / \mathrm{kwh}$ & -0.17 & -0.17 & -0.17 \\
\hline Auxiliary Power Scaling & $\mathrm{mills} / \mathrm{kWh}$ & 0.14 & 0.13 & 0.13 \\
\hline Energy & mills/kWh & 0.15 & 0.15 & 0.16 \\
\hline Base Fuel & $\mathrm{mills} / \mathrm{kWh}$ & -0.01 & -0.02 & -0.01 \\
\hline O\&M & $\mathrm{mills} / \mathrm{kwh}$ & 0.07 & 0.07 & 0.07 \\
\hline Incremental Cost of Cooling & $\mathrm{mills} / \mathrm{kWh}$ & 1.43 & 1.44 & 1.46 \\
\hline
\end{tabular}


The heat exchanger is the single most costly item in the cooling system. The airflow requirement results in a fan system, base plant scaling for fan power and additional fuel consumption for fan power. The combination of these costs associated with airflow are nearly equal to the heat exchanger cost. The variables that dictate the heat transfer area and the airflow rate will, therefore, dominate the selection of the optimum cooling system. of the five internal independent variables the heat exchanger depth and air velocity are most significant in determining the optimum airflow rate and heat transfer area.

If the computer code is allowed to optimize without restriction on the number of towers, it will arrive at some optimum airflow and heat exchanger specifications. Because the number of towers is a dependent parameter it is logical to expect that the same set of optimum specifications will be encountered when the number of towers is restricted as long as the conditions of the restriction can be satisfied. This reduces to the fact that the total airflow must pass through the swept area of the fans on the tower roofs. The fan-swept area is a prescribed fraction of the roof area. The ratio of roof area to fan area is the packing factor. The number of towers is calculated by the equation provided in Section 6.4.5. If a fan system cannot be found to satisfy the required number of towers, then the set of independent variables which led to this condition is rejected.

The tube length (correspondingly, the tower diameter), tower height, heat exchanger depth, and the number of towers will define the heat transfer area. If the heat exchanger depth and heat transfer area are optimized and the number of towers is specified, then the tower roof area is manipulated by the selection of tube length and tower height.

At this point the behavior of the results given in Table 6.14 should be explainable. If the number of towers is increased while maintaining the same total circumference, the total roof area will decrease. This would reduce the total area for fans, thus making each available fan operate at a higher volumetric flow rate with correspondingly higher discharge losses at the fan 
stack exit. It may be that, among the fan models available in the code, the fan requirements under these conditions cannot be satisfied. Thus when the number of towers is increased, the total circumference, and therefore, the total roof area, is increased by reducing the height of the tower. One may calculate that the total roof areas for the designs in Table 6.14 are comparatively equal (see Table 6.15). Thus, regardless of the number of towers imposed as a restriction on the optimization, the tube length (tower diameter), and tower height can be defined such that the optimum in flow and heat transfer area conditions can be satisfied by the selection of an appropriate fan system.

Because the restriction to a given number of towers does not block the specification of the optimum values of the major cost items of the cooling system, the restriction to a given number of towers is observed to have almost no impact on the incremental cost. One logical source of influence on the cost is the tower structures, since the gross dimensions of the towers differ dramatically. In Table 6.15, the tower structure costs are shown to be related to tower volume. The magnitude of the structures costs imply that these costs will have only a small impact on cooling system design. However, for a small number of towers the optimization process will attempt to minimize the impact of the cost of the structures by minimizing the tower volume.

TABLE 6.15. Design Parameters for Specified Number of Towers

\begin{tabular}{|c|c|c|c|}
\hline $\begin{array}{c}\text { Number of } \\
\text { Towers }\end{array}$ & $\begin{array}{c}\text { Total Roof } \\
\text { Area, } \\
10^{5} \mathrm{ft}^{2} \\
\end{array}$ & $\begin{array}{c}\text { Total Tower } \\
\text { Volume } \\
10^{7} \mathrm{ft}^{3} \\
\end{array}$ & $\begin{array}{c}\text { Structures } \\
\text { Cost, } \\
\text { mill } / \mathrm{swh} \\
\end{array}$ \\
\hline 3 & 1.90 & 1.73 & 0.124 \\
\hline 4 & 1.96 & 1.64 & 0.125 \\
\hline 5 & 2.30 & 1.55 & 0.119 \\
\hline 6 & 1.98 & 1.33 & 0.106 \\
\hline 7 & 1.80 & 1.06 & 0.097 \\
\hline 8 & 2.34 & 1.13 & 0.094 \\
\hline
\end{tabular}


For a given frontal area the tower volume is reduced by decreasing the tower diameter and increasing the height. The extent to which this path is taken is dominated, however, by the overriding need to provide tower roof area. The resulting net impact of the structures costs is, thus, quite small.

\subsubsection{Fan System}

The fan system includes the specification of the following items:

- fan assemblies,

- fan plenums,

- fan rings and diffuser stacks,

- fan drive motors,

- speed reducers, and

- electrical system and controls.

The fan assembly includes the hub and blades. The blade diameter, blade pitch angle and number of blades per fan define the fan type. There are 153 different fan types modeled in the code. The blade diameters available are $24,26,28,30,40$ and $60 \mathrm{ft}$. There may be an even number of 6 to 16 blades per fan. The blade pitch angle may be selected from discrete values between 2 and 22 degrees.

Each fan type is modeled in the optimization code by a performance curve fit relating both the pressure drop and the fan power requirements to the volumetric flow rate per fan. The pressure drop includes the pressure drop across the heat exchanger plus any discharge losses at the fan exit. The discharge loss is the nonrecoverable velocity head. Each fan type and the items listed above are modeled in terms of cost. (4)

The number of fans required for a cooling system design depends, in part, on the total airflow rate and the flow rate per fan. The flow rate per fan is determined from the intersection of the fan performance curve with the fan pressure curve, i.e., the operating point. In general, the larger the blade diameter, number of blades per fan, and blade pitch angle, the higher the flow rate per fan. For a given total airflow fewer of these fans are required. However, the cost per fan is generally greater. Thus, the selection of a 
particular fan type in the design of the cooling system is not a strong function of cost but rather it is dominated by the need to find a fan for which the operating point will satisfy the design airflow requirements. For each set of the five internal independent parameters it is possible to search through all of the 153 fan models to determine operating points and, therefore, the fan system requirements.

The cost model for the fan assembly does not consider blade pitch. Blade diameter and the number of blades determine the total blade cost while an additional cost accounts for the hub components. In the model the hub costs are not dependent on the number of blades. For a given fan diameter and number of blades, the flow rate per fan depends on the blade pitch. A higher pitch angle will generally provide a higher flow rate per fan. Coinciding with the high flow rate, however, will be a high discharge loss. The air exiting the fan ring or diffuser stack will have a higher velocity; discharge loss being a function of the square of velocity. Thus, while a high pitch angle reduces the total number of fans required, the cost is traded off against fan power costs involving power plant scaling and fuel consumption that account for the higher discharge losses. In addition, greater fan power requirements generally imply increased costs for fan motors.

The optimization code can be restricted to consider any particular fan type. This option was employed to evaluate the available fan diameters. Table 6.16 presents the important results. For all of these cases, the optimized airflow rate, fan power, heat transfer area and other design parameters were comparatively equal (see Table 6.17). As expected, the incremental cost is not strongly dependent on fan diameter. The difference in fan system costs are reflected in the incremental cost, however. The cost trade-off between the number of fans and the fan power is dominated by the blade pitch angle. The net result is that moderately high pitch angles are preferred. It should be noted that these results were obtained with diffuser stacks. Without velocity recovery the fan power requirements would be higher, thus pushing the optimization to select a fan with a lower blade angle (see Section 6.4.4.2). 
TABLE 6.16. Results of Fan Diameter Study

\begin{tabular}{|c|c|c|c|c|c|}
\hline $\begin{array}{c}\text { Blade } \\
\text { Diameter, } \\
\mathrm{ft}\end{array}$ & $\begin{array}{c}\text { Number of } \\
\text { Blades/ } \\
\text { Fan } \\
\end{array}$ & $\begin{array}{r}\text { Blade } \\
\text { Angle, } \\
\text { degrees } \\
\end{array}$ & $\begin{array}{l}\text { Number } \\
\text { of Fans }\end{array}$ & $\begin{array}{c}\text { Fan System } \\
\text { Cost, } \\
\text { mills } / \mathrm{kWh} \\
\end{array}$ & $\begin{array}{c}\text { Incremental } \\
\text { Cost, } \\
\mathrm{mills} / \mathrm{kWh}\end{array}$ \\
\hline 24 & 10 & 18 & 89 & 0.179 & 1.44 \\
\hline 26 & 6 & 14 & 114 & 0.186 & 1.45 \\
\hline 28 & 6 & 16 & 93 & 0.177 & 1.44 \\
\hline 30 & 8 & 18 & 67 & 0.177 & 1.44 \\
\hline 40 & 8 & 14 & 45 & 0.158 & 1.43 \\
\hline 60 & 12 & 18 & 18 & 0.154 & 1.40 \\
\hline
\end{tabular}

As is observed in Table 6.16, the larger the fan diameter, the fewer fans required, although fan performance must also be considered $(24 \mathrm{ft})$. Each fan with motor, gearbox, etc., must receive routine maintenance. For this reason, the utility industry may prefer to deal with a fewer number of large diameter fans since there appears to be no significant capital cost penalty in doing so. Certainly, a more thorough evaluation of the maintenance costs related to the number and size of fans is necessary.

\subsubsection{Louvers}

Under certain circumstances it may be necessary to provide louvers to control airflow through the heat exchanger during high winds and during deluge operation. It may be necessary to adjust the airflow during deluge operation if only a portion of the tower is being deluged. This will maintain appropriate air velocities through the wet and dry sections of the tower. The cost of louvers, as modeled in the cost code, is strictly a function of the frontal area of the cooling tower. To reduce the effect of the cost of louvers on the incremental cost, the optimized frontal area decreased when louvers were included in the design. However, this trade-off could not completely compensate for the additional costs. The incremental cost of cooling increased $0.09 \mathrm{mi} 1 \mathrm{~s} / \mathrm{kWh}$ when louvers were required. These results are shown in Table 6.18. 
TABLE 6.17. Comparison of Optimized Design, Performance, and Cost Parameters for Fixed Fan Diameters

\section{Airflow Parameter}

Airflow Rate

Maximum Air Velocity

$A_{a}{ }_{a}$ ir, h.x.

$\therefore P$ air, discharge

Fan Power

Fans

$\mathrm{NH}_{3}$ Parameters

$\mathrm{NH}_{3}$ Flow Ra

$\therefore \mathrm{P}_{\mathrm{NH}}$

Pump Power

Heat Exchanger Design

Towers

Approxinate Tower Oiameter

Tower Height

Frontal Area

Heat Transfer Area

Tube Length

Tube Rows in Depth

Condenser Design

Heat Transfer Area

TTD

Performance Parameters

Design TBP

Maximum TBP

Power at Maximum TBP

Maximum \% Deluge

Maximum Evaporation Rate

\section{Cost Summary}

Cooling System

Capacity

Steam Supply Scaling

Heat Rate Scaling

Auxiliary Power Scaling

Energy

Base Fue 1

O\&M

Incremental cost of Cooling

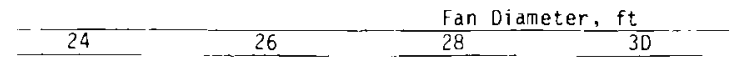

$10^{6} 1 \mathrm{bm} / \mathrm{hr}$
$\mathrm{ft} / \mathrm{sec}$
psi
psi
MW

$10^{6} 1 \mathrm{bm} / \mathrm{hr}$

psi

MW

$f t$

$\mathrm{ft}$

$10^{6} \mathrm{ft}^{2}$

$10^{6} \mathrm{ft}^{2}$

$f t$

$10^{6} \mathrm{ft}^{2}$

${ }^{\circ} \mathrm{F}$

in. $\mathrm{Hg}$

in. $\mathrm{Hg}$

MW

$10^{3} \mathrm{gpm}$

$\mathrm{mi} 1 \mathrm{~s} / \mathrm{kwh}$

$\mathrm{mills} / \mathrm{kwh}$

mi11s/kwh

$\mathrm{mills} / \mathrm{kwh}$

$\mathrm{mills} / \mathrm{kwh}$

mills/kwh

mills/kwh

mills/kwh

mi11s/kwh

$\begin{array}{ll}398 . & 432 . \\ 13.9 & 13.7 \\ 0.0143 & 0.0118 \\ 0.0097 & 0.0051 \\ 9.83 & 8.90 \\ 89 & 113\end{array}$

401.
13.6

0.0138

0.0048

433.

0.0121

0.0084

9.91

67

93

10.2

10.2

23.3

10.2

23.1

0.625

19.6
0.555

10.2

20.0

0.493

$\begin{array}{rrr}4 & 4 & 4 \\ 238 . & 253 . & 247 .\end{array}$

0.213

19.1

75.0

0.232

17.3

72.5

0.219

0.229

17.1

76.8

$6 \quad 5$

6

$\begin{array}{ll}0.458 & 0.506\end{array}$

3.96

3.40

4.00

3.84

2.26

3.29

2.26

991.3

42.5

3.35

990.7
43.8

2.18

2.24

3.38

991.9

43.0

990.3

44.9

$\begin{array}{ll}1.22 & 1.24\end{array}$

0.03

0.00

$-0.17$

0.16

0.14

$-0.00$

1.24

0.03

0.00

$-0.17$

0.15

0.15

$-0.01$

0.07

1.26

0.03

9.75

-0.18
0.12

$-0.01$

0.07

1.44

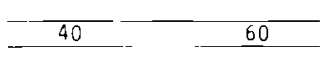

$429 . \quad 439$.

$12.9-13.1$

$\begin{array}{ll}0.0106 & 0.0109\end{array}$

$0.0061 \quad 0.0073$

$9.00 \quad 9.01$

$44 \quad 18$

$10.2 \quad 10.2$

$\begin{array}{ll}10.2 & 18.5\end{array}$

$0.665 \quad 0.511$

$\begin{array}{llrrr}4 & 4 & 4 & 5 & 4\end{array}$

280.

95.5

83.9

$0.246 \quad 0.247$

$18.3 \quad 18.4$

107.292 .0

5

$\begin{array}{lll}0.467 & 0.454 & 0.397\end{array}$

4.00

5.04

$2.23 \quad 2.15$

$3.32 \quad 3.28$

990.9
43.3

$43.3 \quad 44.9$

0.07
1.44

9.59

1.22

0.03

0.00

$-0.17$

0.15 
TABLE 6.18. Comparison of Optimized Design, Performance, and cost Parameters with and Without Louvers

\begin{tabular}{|c|c|c|c|}
\hline \multirow{2}{*}{\multicolumn{4}{|c|}{ Airflow Parameters }} \\
\hline & & & \\
\hline Airflow Rate & $10^{6} \mathrm{ibm} / \mathrm{hr}$ & 401 & 377. \\
\hline Maximum Air Velocity & $\mathrm{ft} / \mathrm{sec}$ & 13.6 & 13.2 \\
\hline$\Delta P_{a i r}, h . x$. & psi & 0.0138 & 0.0153 \\
\hline$\Delta P_{a i r}$, discharge & psi & 0.0048 & 0.0052 \\
\hline Fan Power & MW & 8.75 & 9.04 \\
\hline Fans & & 93 & 85 \\
\hline \multicolumn{4}{|l|}{$\underline{\mathrm{NH}}_{3}$ Parameters } \\
\hline $\mathrm{NH}_{3} \mathrm{Flow}_{\text {Rate }}$ & $10^{6} 1 \mathrm{bm} / \mathrm{hr}$ & 10.2 & 10.2 \\
\hline$\Delta \mathrm{P}_{\mathrm{NH}_{3}}$ & psi & 19.6 & 18.3 \\
\hline Pump Power & MW & 0.555 & 0.488 \\
\hline \multicolumn{4}{|l|}{ Heat Exchanger Design } \\
\hline Towers & & 4 & 4 \\
\hline Approximate Tower Diameter & $\mathrm{ft}$ & 247. & 235 \\
\hline Tower Height & $\mathrm{ft}$ & 72.5 & 73.7 \\
\hline Frontal Area & $10^{6} \mathrm{ft}^{2}$ & 0.219 & 0.212 \\
\hline Heat Transfer Area & $10^{6} \mathrm{ft}^{2}$ & 19.6 & 22.2 \\
\hline Tube Length & $\mathrm{ft}$ & 94.4 & 90.0 \\
\hline Tube Rows in Depth & & 6 & 7 \\
\hline \multicolumn{4}{|l|}{ Condenser Design } \\
\hline Heat Transfer Area & $10^{6} \mathrm{ft}^{2}$ & 0.454 & 0.371 \\
\hline TTD & ${ }^{\circ} \mathrm{F}$ & 4.00 & 5.56 \\
\hline \multicolumn{4}{|l|}{ Performance Parameters } \\
\hline Design TBP & in. $\mathrm{Hg}$ & 2.18 & 2.24 \\
\hline Maximum TBP & in. $\mathrm{Hg}$ & 3.20 & 3.26 \\
\hline Power at Maximum TBP & MW & 991.9 & 991.6 \\
\hline Maximum \% Deluge & & 43.0 & 40.9 \\
\hline Maximum Evaporation Rate & $10^{3} \mathrm{gpm}$ & 9.54 & 9.20 \\
\hline \multicolumn{4}{|l|}{ Cost Summary } \\
\hline Cooling System & milis/kwh & 1.26 & 1.33 \\
\hline Capacity & $\mathrm{milis} / \mathrm{kWh}$ & 0.03 & 0.03 \\
\hline Steam Supply Scaling & $\mathrm{mi} 11 \mathrm{~s} / \mathrm{kWh}$ & 0.00 & 0.00 \\
\hline Heat Rate Scaling & mills/kwh & -0.18 & -0.17 \\
\hline Auxiliary Power Scaling & $\mathrm{mills} / \mathrm{kWh}$ & 0.12 & 0.15 \\
\hline Energy & $\mathrm{mills} / \mathrm{kWh}$ & 0.13 & 0.14 \\
\hline Base Fuet & $\mathrm{mills} / \mathrm{kWh}$ & -0.01 & -0.01 \\
\hline O\&M & $\mathrm{mills} / \mathrm{kWh}$ & 0.07 & 0.07 \\
\hline Incremental cost of Cooling & $\mathrm{mills} / \mathrm{kwh}$ & 1.44 & 1.53 \\
\hline
\end{tabular}




\subsubsection{Velocity Recovery}

Optimized designs have been developed for the reference conditions with and without velocity recovery. The two designs are compared in Table 6.19.

Diffuser stacks help to recover some of the velocity pressure at the fan exit, thereby reducing the required fan power and the associated capital and operating costs. However, the benefit of the diffuser stacks is partially offset by the capital cost of the stacks. Thus, it is reasonable to expect that the design without velocity recovery would require more fan power and would have a lower cooling system capital cost. The tabulated results do not support this hypothesis.

The optimization procedure effectively over-compensates for the expected high fan power requirements of the design without diffusers by specifying a shallower heat exchanger and a fan system with a lower blade pitch angle than for the design with velocity recovery. The shallower heat exchanger reduces the air pressure drop through the heat exchanger. The slightly lower air velocity is also a benefit in this respect. The fan specified for the design with diffusers has a blade angle of 16 degrees (the 28-ft diameter fan of Table 6.16). In contrast, the fan specified for the design without diffusers is the same fan except that the blade pitch angle is 10 degrees. As discussed with regard to Table 6.16, the lower blade pitch results in less flow per fan with a correspondingly lower exit loss. Thus the design without velocity recovery has a lower total pressure drop and a lower fan power requirement.

The reduced fan power requirement is obtained at the price of the fan system. The lower flow per fan and the greater total airflow results in a significantly greater number of fans for the design without diffusers. The increased cost of the fans offsets the capital cost savings made by not having the diffuser stacks. Thus, the cooling system capital cost is higher. 
TABLE 6.19. Comparison of Optimized Design, Performance and Cost Parameters With and Without Velocity Recovery

\begin{tabular}{|c|c|c|c|}
\hline & & $\begin{array}{l}\text { Velocity } \\
\text { Recovery }\end{array}$ & $\begin{array}{l}\text { No Velocity } \\
\text { Recovery }\end{array}$ \\
\hline \multicolumn{4}{|l|}{ Airflow Parameters } \\
\hline Airflow Rate & $10^{6} \mathrm{lbm} / \mathrm{hr}$ & 401 & 457 \\
\hline Maximum Air Velocity & $\mathrm{ft} / \mathrm{sec}$ & 13.6 & 13.2 \\
\hline$\Delta P_{a i r}, h \cdot x$. & psi & 0.0138 & 0.0109 \\
\hline$\Delta P_{a i r}$, discharge & psi & 0.0048 & 0.0041 \\
\hline Fan Power & MW & 8.75 & 7.68 \\
\hline Fans & & 93 & 143 \\
\hline \multicolumn{4}{|l|}{$\underline{\mathrm{NH}}_{3}$ Parameters } \\
\hline $\mathrm{NH}_{3}$ Flow Rate & $10^{6} 1 \mathrm{bm} / \mathrm{hr}$ & 10.2 & 10.0 \\
\hline$\Delta \mathrm{P}_{\mathrm{NH}_{3}}$ & psi & 19.5 & 33.0 \\
\hline Pump Power & MW & 0.555 & 0.551 \\
\hline \multicolumn{4}{|l|}{ Heat Exchanger Design } \\
\hline Towers & & 4 & 6 \\
\hline Approximate Tower Diameter & $\mathrm{ft}$ & 247. & 250. \\
\hline Tower Height & $\mathrm{ft}$ & 72.5 & 55.9 \\
\hline Frontal Area & $10^{6} \mathrm{ft}^{2}$ & 0.219 & 0.256 \\
\hline Heat Transfer Area & $10^{6} \mathrm{ft}^{2}$ & 19.6 & 19.1 \\
\hline Tube Length & $\mathrm{ft}$ & 94.4 & 95.6 \\
\hline Tube Rows in Depth & & 6 & 5 \\
\hline \multicolumn{4}{|l|}{ Condenser Design } \\
\hline Heat Transfer Area & $10^{6} \mathrm{ft}^{2}$ & 0.454 & 0.397 \\
\hline TTD & ${ }^{\circ} \mathrm{F}$ & 4.00 & 4.96 \\
\hline \multicolumn{4}{|l|}{ Performance Parameters } \\
\hline Design TBP & in. $\mathrm{Hg}$ & 2.18 & 2.02 \\
\hline Maximum TBP & in. $\mathrm{Hg}$ & 3.20 & 3.15 \\
\hline Power at Maximum TBP & MW & 991.9 & 991.7 \\
\hline Maximum \% Deluge & & 43.0 & 46.3 \\
\hline Maximum Evaporation Rate & $10^{3} \mathrm{gpm}$ & 9.54 & 10.2 \\
\hline \multicolumn{4}{|l|}{ Cost Summary } \\
\hline Cooling System & $\mathrm{mills} / \mathrm{kWh}$ & 1.26 & 1.33 \\
\hline Capacity & $\mathrm{mills} / \mathrm{kWh}$ & 0.03 & 0.03 \\
\hline Steam Supply Scaling & $\mathrm{mills} / \mathrm{kWh}$ & 0.00 & 0.00 \\
\hline Heat Rate Scaling & $\mathrm{mills} / \mathrm{kWh}$ & -0.18 & -0.19 \\
\hline Auxiliary Power Scaling & mills/kwh & 0.12 & 0.13 \\
\hline Energy & $\mathrm{mills} / \mathrm{kWh}$ & 0.13 & 0.13 \\
\hline Base Fuel & $\mathrm{mills} / \mathrm{kWh}$ & -0.01 & -0.02 \\
\hline O\&M & $\mathrm{mills} / \mathrm{kWh}$ & 0.07 & 0.07 \\
\hline Incremental cost of Cooling & $\mathrm{mills} / \mathrm{kWh}$ & 1.44 & 1.47 \\
\hline
\end{tabular}




\subsubsection{Packing Factor}

The packing factor, $P F$, is the ratio of the total roof area of the towers, $\pi D_{T}^{2} N_{T} / 4$, to the total swept area of the fans, $\pi D_{T}^{2} N_{F} / 4$, where $D_{T}$ and $D_{F}$ are the diameters of the towers and fan blades, and $N_{T}$ and $N_{F}$ are the number of towers and fans, respectively. Therefore,

$$
P F=\frac{D_{T}^{2} N_{T}}{D_{F}^{2} N_{F}}
$$

By examining the geometry of the fans with diffuser stacks the minimum possible packing factor is about 2.0. While no physical upper limit exists, the costs dictate an adherence to a relatively tight packing arrangement. Optimized designs were developed for packing factors from 2.0 to 4.0 . The results are shown in Table 6.20.

The relationship for the packing factor is used to obtain the number of towers:

$$
N_{T}=\frac{D_{F}^{2} N_{F} P F}{D_{T}^{2}}
$$

For a given fan system and tower diameter, the smaller the packing factor the fewer the number of towers. Additionally, for a given tower diameter and total frontal area, the fewer the number of towers the greater the tower height. While these trends are observable in Table 6.20, the optimization process has lessened the exactness of the description. This is primarily influenced by the airflow requirements. The description of the fan systems indicated the importance of the blade pitch angle in interpreting the results with regard to airflow per fan, fan power and number of fans. The blade pitch angles are also given in Table 6.20 .

For a given packing factor, tower diameter, and fan blade diameter the number of fans per tower roof is fixed. The air entering the heat exchanger must pass through the fan-swept area. For a given frontal air velocity the total airflow per tower is dependent on the tower height. Thus, a tight fan packing arrangement permits higher towers to be specified. The greater 
TABLE 6.20. Comparison of Optimized Design, Performance and Cost Parameters of Various Packing Factors

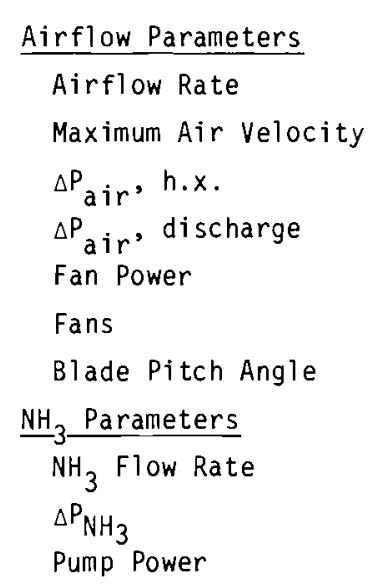

Heat Exchanger Design

Towers

Approximate Tower Diameter

Tower Height

Frontal Area

Heat Transfer Area

Tube Length

Tube Rows in Depth

Condenser Design

Heat Transfer Area

TTD

Performance Parameters

Design TBP

Maximum TBP

Power at Maximum TBP

Maximum \% Deluge

Maximum Evaporation Rate

Cost Summary

Cooling System

Capacity

Steam Supply Scaling

Heat Rate Scaling

Auxiliary Power Scaling

Energy

Base Fuel

0\&M

Incremental cost of Cooling
$10^{6} 1 \mathrm{bm} / \mathrm{hr}$

$\mathrm{ft} / \mathrm{sec}$

psi

psi

$\mathrm{MW}$

degrees

$10^{6} 1 \mathrm{bm} / \mathrm{hr}$

ps $i$

$\mathrm{MW}$

$f t$

$\mathrm{ft}$

$10^{6} \mathrm{ft}^{2}$

$10^{6} \mathrm{ft}^{2}$

$\mathrm{ft}$

$10^{6} \mathrm{ft}^{2}$

${ }^{\circ} \mathrm{F}$

in. $\mathrm{Hg}$

in. $\mathrm{Hg}$

MW

$10^{3} \mathrm{gpm}$

mills/kwh

mi11s/kwh

mills/kWh

mills/kWh

$\mathrm{mills} / \mathrm{kWh}$

milis/kWh

$\mathrm{mills} / \mathrm{kWh}$

$\mathrm{milis/kWh}$

milis/kWh

\begin{tabular}{c} 
Packing Factor \\
\hline 2.0 \\
\hline
\end{tabular}

499.

401.

394.

14.1

13.6

13.9

0.0100

0.0138

0.0145

0.0033

0.0048

0.0056

7.32

140

10

8.75

9.20

93

85

16

18

10.2

10.2

10.2

27.8

19.6

30.4

0.802

0.555

0.567

\section{3}

292.

96.7

0.259

15.5

111.6

4

0.411

4.68

6

247.

7

72.5

206.

0.219

47.5

19.6

0.210

94.4

18.8

6

78.8

6

$\begin{array}{ll}0.454 & 0.438 \\ 4.00 & 4.24\end{array}$

\subsection{6}

3.47

2.18

2.32

3.20

3.38

989.2

991.9

990.7

45.4

10.31

43.0

42.8

9.54

9.35

1.26

1.25

1.22

0.04

0.03

0.03

0.00

0.00

0.00

$-0.17$

$-0.18$

$-0.17$

0.13

0.12

0.15

0.17

0.13

0.15

$-0.02$

$-0.01$

$-0.00$

0.07

0.07

0.07

1.43

1.44

1.48 
airflow through the tower is acceptable because more fans are available. High discharge losses and associated fan power requirements are not encountered. The tall towers also tend to reduce the total roof area which is necessary to specify a fan system that operates at the optimum balance between fan system capital cost, due to the number of fans, and fan power requirements. The design with a packing factor of 2.0 has the highest towers with the lowest total fan power required. Even though this design has the highest total airflow, the fan power is lower because of the shallow, four-tube-row heat exchanger and a fan system with a 10-degree blade pitch.

The conditions with a packing factor of 4.0 are quite different. The optimization leads to a larger number of shorter towers to keep the airflow through the fans at a reasonable level. The short towers tend to increase the total roof area which is necessary to optimize the fan system. In spite of this the fan system required a blade pitch angle of 18 degrees to get enough flow per fan. The result is high fan power requirements. The discharge losses could have been lower had the design specified a fan system with a lower blade pitch angle. More fans would be required which would result in the calculation of more towers which would be shorter. Since the optimization does not do this, it is likely that increased piping system costs become excessive due to spreading out the cooling system. It is observed that the optimization of the fan system itself must be approached from opposite ends of the spectrum by the designs for low and high packing factors. The low packing factor has many fans operating at low power while the high packing factor reveals the opposing characteristics. The optimum fan system balances the number of fans and the fan power.

The other possibilities for reducing the fan power for the high packing factor design are more involved. A shallower heat exchanger would reduce the air pressure drop through the heat exchanger. Reducing the temperature range of the air would require more total airflow but would allow less heat transfer area. The combination of a shallower heat exchanger and less heat transfer area would probably result in a relatively unaffected frontal area. 
Thus, the same seven towers could be specified. However, the greater airflow would cause an increase in fan discharge losses. The optimization process is, therefore, finding a balance between the air pressure losses through the heat exchanger and at the fan exit.

The airflow conditions are seen to dominate the optimization involving packing factor because of the impact on the fan system, fan power and heat exchanger costs.

Although costs are not a strong function of packing factor, the packing factor has a noticeable effect on the appearance of the cooling system and the trade-offs determining the cooling system design. If the packing factor is increased, then more tower roof area is required for each fan. The tower roof area can be increased using a smaller number of larger diameter towers. In this way the frontal area of the heat exchanger, the fan system specifications, and the air velocities through the heat exchanger and fan exits can be maintained. However, because the structure costs go up as the square of the tower diameter, the optimization process does not allow tower diameter to increase, nor the number of towers to decrease, as much as it would have if it were not for this cost relationship. If the frontal area is fixed, the result of going to a higher packing factor is to have a fewer number of fans that will operate at higher flow velocities; thus, high discharge losses. Therefore, the cooling system design resulting from an increase in packing factor is influenced by the cost trade-off between structures and scaling for fan power. The capital cost of fans is also a part of the cost trade-offs.

\subsubsection{Frontal Air Velocity}

The frontal air velocity of the heat exchanger is one of the five internally optimized independent variables. However, the air velocity can be constrained to a prescribed value by using an input option of the computer code. By this means frontal air velocities from 5 to $12 \mathrm{ft} / \mathrm{sec}$ were examined. Three optimized designs are reported in Table 6.21. In Figure 6.7 the fan power and heat transfer area are shown with incremental cost as functions of velocity. The reported air velocities are the maximum air velocity in the heat exchanger. These are calculated by 
TABLE 6.21. Comparison of Optimized Design, Performance and Cost Parameters for Various Values of Frontal Air Velocity

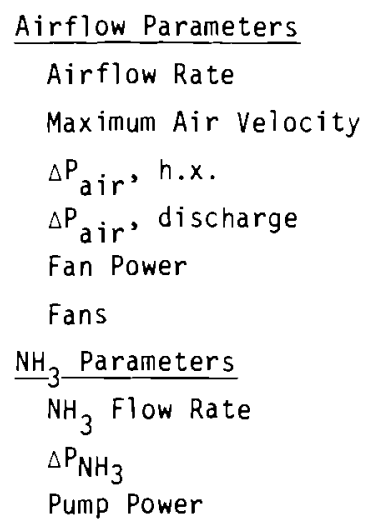

Heat Exchanger Design

Towers

Approximate Tower Diameter

Tower Height

Frontal Area

Heat Transfer Area

Tube Length

Tube Rows in Depth

Condenser Design

Heat Transfer Area

TTD

Performance Parameters

Design TBP

Maximum TBP

Power at Maximum TBP

Maximum \% Deluge

Maximum Evaporation Rate

Cost Summary

Cooling System

Capacity

Steam Supply Scaling

Heat Rate Scaling

Auxiliary Power Scaling

Energy

Base Fuel

O\&M

Incremental Cost of Cooling

$10^{6} \mathrm{lbm} / \mathrm{hr}$
$\mathrm{ft} / \mathrm{sec}$
$\mathrm{psi}$
$\mathrm{psi}$
$\mathrm{MW}$

$10^{6} \mathrm{lbm} / \mathrm{hr}$

psi

MW

$\mathrm{ft}$

$\mathrm{ft}$

$10^{6} \mathrm{ft}^{2}$

$10^{6} \mathrm{ft}^{2}$

$\mathrm{ft}$

$10^{6} \mathrm{ft}^{2}$

${ }^{\circ} \mathrm{F}$

in. $\mathrm{Hg}$

in. $\mathrm{Hg}$

MW

$10^{3} \mathrm{gpm}$

mills/kwh

$\mathrm{mil1s} / \mathrm{kWh}$

$\mathrm{mills} / \mathrm{kWh}$

milis/kwh

mills/kwh

mi11s/kWh

$\mathrm{mills} / \mathrm{kWh}$

mills/kWh

mills/kWh

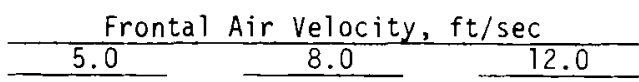

421.

481.

555.

8.7

13.8

20.6

0.0042

0.0095

0.0194

0.0047

0.0053

0.0047

4.30

8.50

16.0

99

106

129

10.3

16.8

0.602

\section{5}

236.

99.3

0.359

21.4

90.4

4

0.481

3.64

2. 30

3.36

990.8

43.4

9.50

1.40

0.03

0.00

$-0.17$

0.07

0.15

$-0.03$

0.08

1.52
10.2

10.2

19.9

24.6

0.541

0.578

\section{5}

235.

71.1

0.256

15.3

90.0

4

0.531

0.555

3.16

3.00

\subsection{6}

2.26

3.43

3.55

989.7

45.3

988.1

46.0

10.1

10.6

\subsection{6}

1.26

0.03

0.04

0.06

0.00

$-0.17$

$-0.17$

0.14

0.25

0.16

0.18

$-0.01$

0.03

0.07

0.07

1.47

1.67 


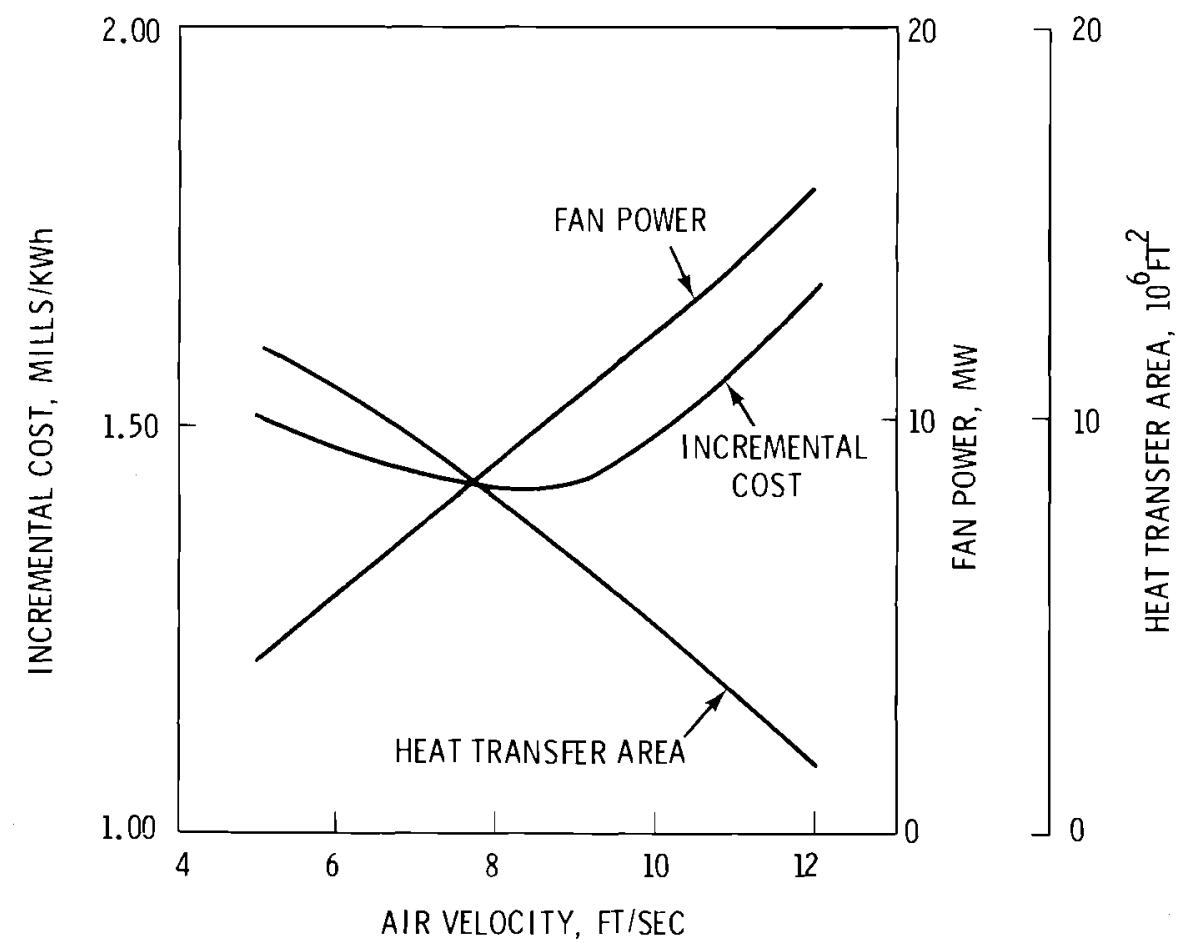

FIGURE 6.7. Effect of Air Velocity on the Heat Transfer Area, Fan Power and the Incremental cost of cooling

$$
V A M=V A F \frac{A F R O N}{\text { AMIN }}
$$

where VAF is the frontal air velocity, AFRON is the heat exchanger frontal area and AMIN is the minimum free flow area through the heat exchanger. The area ratio depends only on the unit geometry of the HÖTERV surface. It has a constant value of 0.602 . The maximum air velocities shown in Table 6.21 are also corrected for the change in air density across the heat exchanger.

The effect of varying the air velocity can be deduced by studying the components of the cooling system heat balance equation:

$$
\text { QREJ }=U A \text { LMTD }=\text { WAIR } \cdot \text { CPAIR } \cdot \text { RANGE }
$$


As the velocity of the air increases, so does the overall heat transfer coefficient, $U$. For a given heat exchanger depth, the temperature range of the air, RANGE, decreases because the air has less residence time in the heat exchanger. As a result, the log mean temperature difference, LMTD, increases. Thus, the heat rejection can be satisfied with a reduced heat exchanger area. On the other side of the equation, the lower RANGE implies a greater air mass flow rate. Increasing the air velocity and air mass flow rate saves heat exchanger surface costs but comes at the expense of increased fan system costs and fan power requirements.

A design with a low frontal air velocity (see $5.0 \mathrm{ft} / \mathrm{sec}$ in Table 6.21) is penalized by a large heat exchanger requirement. Since the heat transfer coefficient is essentially fixed by the air velocity and unit geometry, then the only way to decrease the required heat exchanger area is to decrease the heat exchanger depth. This would decrease the range of the air and increase the LMTD. The extent to which the depth can be decreased in the optimization is probably tied to the resultant increase in the total airflow rate necessary to balance the heat rejection when the range of the air decreases.

A design with a high frontal air velocity (see $12.0 \mathrm{ft} / \mathrm{sec}$ in Table 6.21) is penalized by a large auxiliary power scaling requirement for fan power. The large pressure drop that results in the large fan power could be reduced by considering a shallower heat exchanger. However, fan power depends on total airflow as well as the pressure drop. To satisfy the heat load a shallower heat exchanger would require more airflow, as discussed in the preceding paragraph. It appears that the high air velocities leave the optimization with no options; the fan power is effectively fixed at an excessive value.

\subsubsection{Turbine Type}

Economic studies of all-dry cooling systems indicated a definite incentive to provide large turbine generators capable of operating at back pressures well in excess of $5 \mathrm{in.} \mathrm{Hga.} \mathrm{(2)} \mathrm{A} \mathrm{similar} \mathrm{study} \mathrm{is} \mathrm{reported} \mathrm{here} \mathrm{which}$ evaluates the cost incentives for high exhaust pressure operation when various amounts of water are available for evaporation. 
Three basic turbines--conventional, modified conventional, and high back pressure--were considered in this analysis. Normalized heat rate as a function of back pressure is shown in Figures 6.8 and 6.9 for fossil and nuclear turbine-generators, respectively. The curves were adapted from Reference 8 and are presented here for illustrative purposes only. The reader should consult the turbine vendor for actual data. Vendors include General Electric; Westinghouse, Allis-Chalmers, Brown Boveri, DeLaval, MAN, and Turbodyne. The normalized heat rate for a turbine is the heat rate of the turbine at the given exhaust pressure divided by the heat rate of the conventional turbine at $3.5 \mathrm{in.} \mathrm{Hga.}$

As can be seen in Figures 6.8 and 6.9 the performance of the proposed modified conventional and high back pressure turbines is characterized by significantly higher heat rates. Because of this, to achieve a given amount of electric power output at a given ambient temperature, a plant with either of the increased back pressure turbines will consume more fuel. In general this will be true only when the cooling systems have been optimized for equal design ambient temperatures. In addition to the increased fuel consumption, the increased heat rates result in a requirement for a larger steam supply system.

\subsubsection{Turbine Descriptions}

In this section, the three turbines considered in this analysis will be described in greater detail.

6.4.7.1.1 Conventional Turbine. The technology of the conventional turbine is relatively well established. These turbines are available to the power industry in sizes up to and exceeding 1000 MWe for both fossil and nuclear power stations. The operating back pressure range is typically 2 to 5 in. Hga, although some turbines are designed for slightly higher back pressures. Westinghouse has established guidelines for conventional turbine operation from 5.5 to $8.0 \mathrm{in}$. Hga. The guidelines are presented in Appendix D. Power output for the conventional turbine is usually rated at 3.5 in. Hga with $3 \%$ makeup, but this may also vary with the manufacturer. 


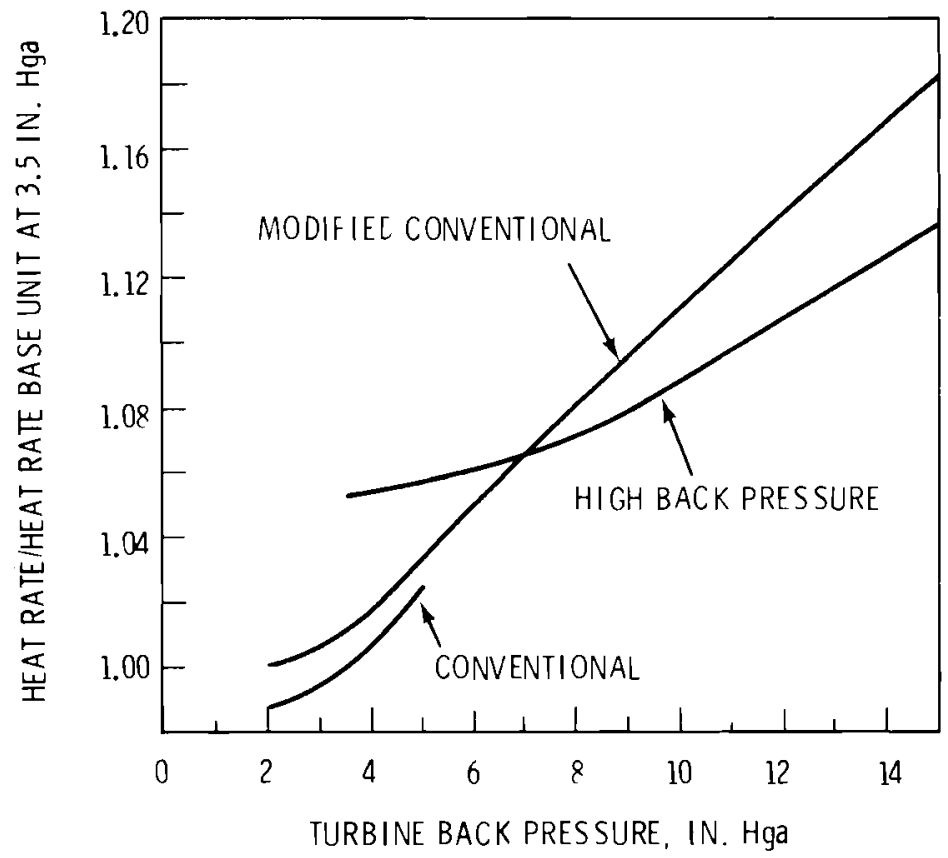

FIGURE 6.8. Normalized Heat Rate Versus Turbine Back Pressure - Fossil

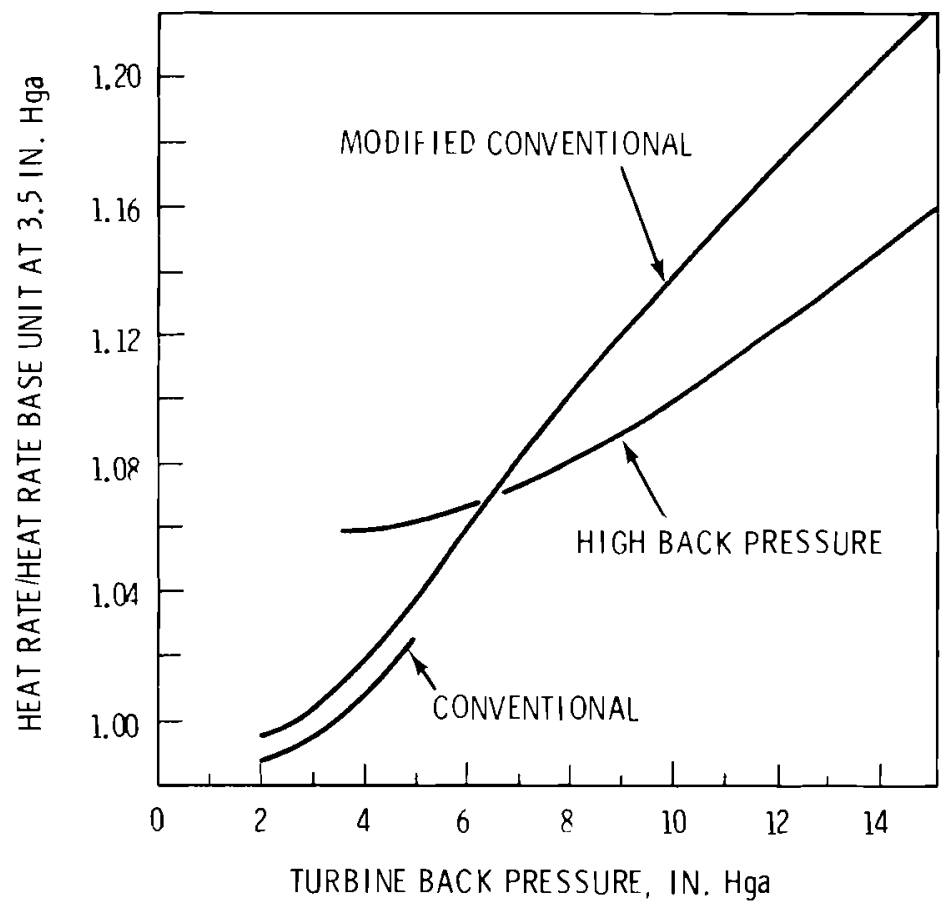

FIGURE 6.9. Normalized Heat Rate Versus Turbine Back Pressure - Nuclear 
As can be seen from the performance curves, the conventional turbine has the lowest heat rate. Conventional turbines have typically been used where sufficient water is available for once-through or completely evaporative cooling. Under this condition, the back pressure can be maintained reasonably constant at low values. Because the steam is allowed to expand as completely as is practicable, the maximum energy will have been extracted from the steam. Thus, the heat rate is as low as is feasible.

\subsection{Modified Conventional Turbine. It was initially proposed} that modifications could be made to existing conventional turbines to allow the back pressure to vary from 2 to $14 \mathrm{in.} \mathrm{Hga.} \mathrm{The} \mathrm{modified} \mathrm{conventional}$ turbine would have a heat rate approximately $1 \%$ higher than the conventional turbine at the rating back pressure of $3.5 \mathrm{in}$. Hga. However, potentially destructive problems with off-design aerodynamics at the low pressure end of the turbine have caused vendors to suggest that upper limits of about

$8.0 \mathrm{in.} \mathrm{Hga} \mathrm{be} \mathrm{imposed} \mathrm{on} \mathrm{the} \mathrm{operation} \mathrm{of} \mathrm{this} \mathrm{hypothetical} \mathrm{machine.} \mathrm{The}$ 8.0-in. Hga limit is not a serious constraint, however, when deluge augmentation is an option.

No modified conventional turbines are currently in operation or planned for delivery in the U.S. However, Westinghouse has indicated that they expect to market a modified conventional turbine for limited operation at $8.0 \mathrm{in}$. Hga. This would be suitable for nuclear plants or very large fossil plants (1000to $1100-$ MWe range).

6.4.7.1.3 High Back Pressure Turbine. Of the proposed new turbines, only one has been declared available for delivery in the U.S. This is a high back pressure turbine for a fossil-fueled power station capable of generating 330 MWe at a rating condition of $8.0 \mathrm{in.} \mathrm{Hga} \mathrm{with} 3 \%$ makeup required. This power plant at Wyodak, Wyoming is all-dry cooled. Its operating back pressure range is about 5.0 to $15.0 \mathrm{in.} \mathrm{Hga.} \mathrm{Larger} \mathrm{turbine-generators} \mathrm{for} \mathrm{fossil-}$ fueled applications would likely be available upon demand. For nuclear applications, additional problems have yet to be solved. Vendors have not stated when (or if) these nuclear tubines will be available. 


\subsubsection{Turbine Optimization Analysis}

The optimization analysis was performed for the three turbine types for fossil and nuclear fuel. Basic differences between the two fuels involve, of course, the different heat rate curves for the corresponding fossil and nuclear turbine-generators. In addition, significant differences occur in the parameters that are listed in Table 6.22. As discussed in the introduction to the parametric study, the design numbers for the fossil plant are specific to the San Juan site. For the nuclear application the efficiency and fuel cost are national average numbers. ${ }^{(2)}$ The power plant construction cost is based on the cost of the fossil plant at San Juan. It was believed that the same site-specific cost escalators would apply to fossil and nuclear power plants. The unit cost of a large nuclear power plant is assumed to be $20 \%$ greater than that of a fossil power plant. The steam supply system cost is evaluated as one-third of the power plant construction cost. It has been assumed that the modified conventional and high back pressure fossil-fueled turbine-generators will cost the same as a conventional fossil unit with the same rating. However, the cost of the proposed modified conventional or high back pressure turbines for nuclear applications is expected to be about $15 \%$ higher than a similarly rated nuclear-fueled conventional turbine. ${ }^{(8)}$ This is the basis for the cost adder of $34.3 \$ / \mathrm{kW}$ for nonconventional nuclear turbines. The turbine generator cost is one-third of the power plant construction cost. The turbine cost adder is $15 \%$ of this, i.e., $(685 / 3) \times 0.15=$ $34.3 \$ / \mathrm{kW}$.

TABLE 6.22. Differences in Fossil and Nuclear

$\begin{array}{lccc} & \text { Fossil } & & \text { Nuclear } \\ \text { Overall thermal efficiency, percent } & 41.0 & 33.0 \\ \text { Fuel cost, } \$ / 10^{6} \text { Btu } & 66.9 & 43.0 \\ \text { Power plant construction costs, } \$ / \mathrm{kW} & 571 . & 685 . \\ \text { Costs of steam supply, } \$ / \mathrm{kW} & 190 . & 228 . \\ \begin{array}{l}\text { Additional cost for nonconventional } \\ \text { nuclear turbines, } \$ / \mathrm{kW}\end{array} & 0.00 & 34.3\end{array}$


To evaluate the economic incentive for high exhaust pressure operation, water availability was varied from 0 to 5000 acre-ft for both fossil and nuclear turbines. Maximum turbine back pressure imposed on each turbine type was $15.0 \mathrm{in}$. $\mathrm{Hg}$ for the high back pressure turbine and $8.0 \mathrm{in.} \mathrm{Hg}$ for the modified conventional turbine. The conventional turbine was restricted to $5.5 \mathrm{in.} \mathrm{Hg}$ for most of the year; nowever, a specified number of excursions ranging from 5.5 to $8.0 \mathrm{in}$. $\mathrm{Hg}$ were also allowed, as discussed in the section on meteorology and in Appendix D. A plot of incremental cost versus water availability is shown in Figure 6.10. Optimized designs are shown in Table 6.23 for fossil turbines and Table 6.24 for nuclear turbines. The

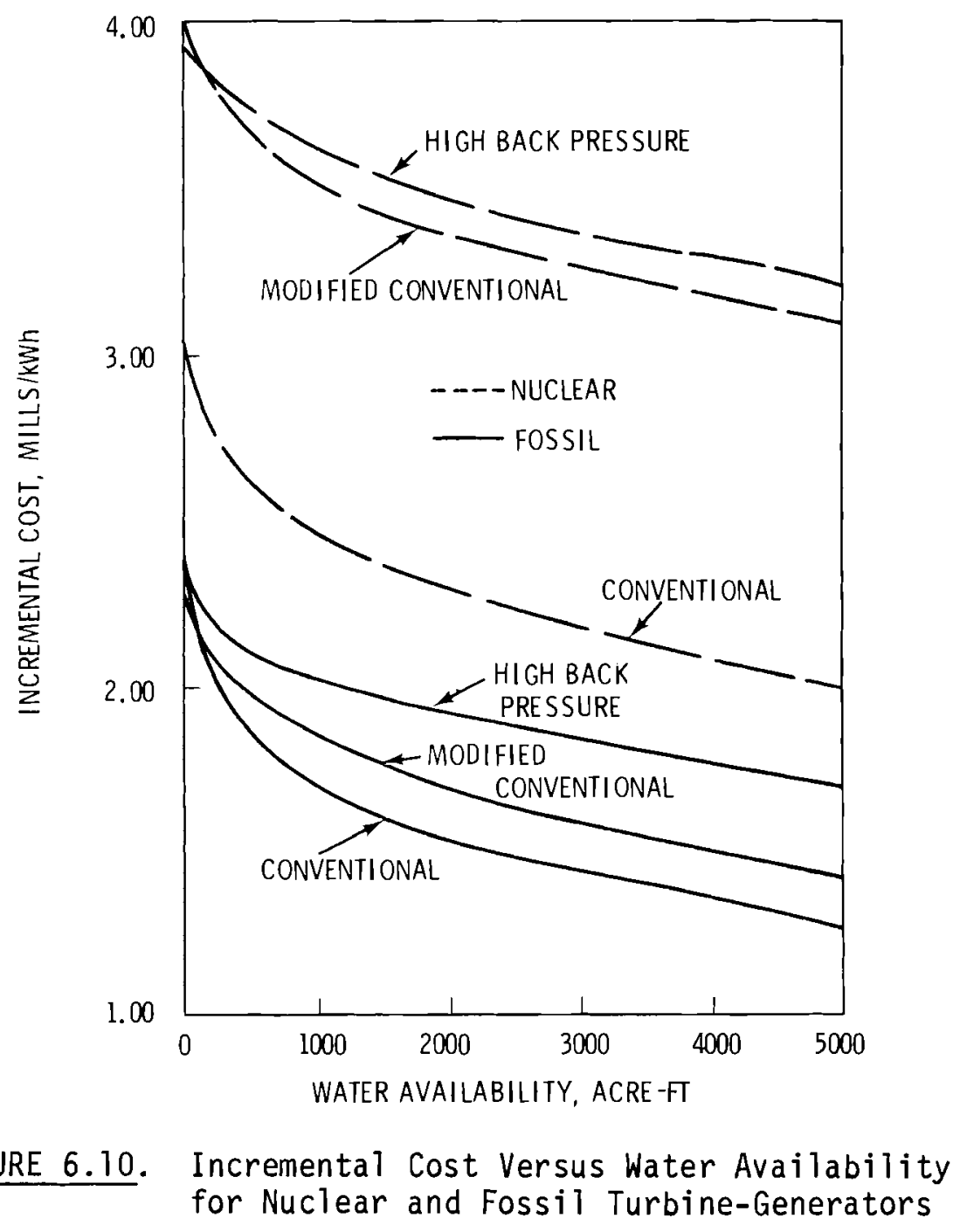




\section{TABLE 6.23. Comparison of Optimized Design and Cost Data for 3000 Acre-ft of Water Using the Three Turbine Types (Fossil)}

Airflow Parameters

Airflow Rate

Maximum Air Velocity

$\Delta P_{\text {air, h.x. }}$.

$\Delta P_{\text {a ir }}$, discharge

Fan Power

Fans

$\mathrm{NH}_{3}$ Parameters

$\mathrm{NH}_{3}$ Flow Rate

$\triangle \mathrm{P}_{\mathrm{NH}}$

Pump Power

Heat Exchanger Design

Towers

Approximate Tower Diameter

Tower Height

Frontal Area

Heat Transfer Area

Tube Length

Tube Rows in Depth

Condenser Design

Heat Transfer Area

TTO

Performance Parameters

Design TBP

Maximum TBP

Power at Maximum TBP

Maximum \% Deluge

Maximum Evaporation Rate

Cost Summary

Cooling System

Capacity

Steam Supply Scaling

Heat Rate Scaling

Auxiliary Power Scaling

Energy

Base Fuel

O\&M

Incremental Cost of Cooling

Conventional \begin{tabular}{cc}
$\begin{array}{c}\text { Modified } \\
\text { Conventional }\end{array}$ & $\begin{array}{r}\text { High Back } \\
\text { Pressure }\end{array}$ \\
\hline
\end{tabular}

$10^{6} 1 \mathrm{bm} / \mathrm{hr}$
$\mathrm{ft} / \mathrm{sec}$
$\mathrm{psi}$
$\mathrm{psi}$
$\mathrm{MW}$

$10^{6} \mathrm{lbm} / \mathrm{hr}$

psi

MW

401.
13.6
0.0138
0.0048
8.75

403.

13.6

0.0138

330.

13.9

0.0143

0.0048

0.0053

8.81

7.80

94

74

10.2
19.6
0.555

10.4

12.1

18.9

28.9

0.555

0.553

0.782

4

247.

72.5

0.219

4

250.

4

$\mathrm{ft}$

$10^{6} \mathrm{ft}^{2}$

$10^{6} \mathrm{ft}^{2}$

19.6

71.9

0.220

223.

65.5

0.179

$\mathrm{ft}$

94.4

6

19.7

16.0

95.6

85.2

6

6

$10^{6} \mathrm{ft}^{2}$

0.454

0.402

0.355

${ }^{\circ} \mathrm{F}$

4.00

5.04

7.12

in. $\mathrm{Hg}$

2.18

2.28

4.54

in. $\mathrm{Hg}$

3.20

3.36

5.63

991.9

992.0

996.8

43.0

$10^{3} \mathrm{gpm}$

9.54

41.5

29.4

9.43

7.94

mills/kWh

1.26

1.25

1.06

mills/kWh

0.03

0.03

0.01

$\mathrm{mills} / \mathrm{kWh}$

0.00

0.06

0.37

$-0.18$

$-0.14$

$-0.24$

0.12

0.14

0.13

0.13

0.13

0.06

$-0.01$

$-0.06$

0.36

0.07

0.07

0.06

1.44

1.59

1.80 


\section{TABLE 6.24. Comparison of Optimized Design and Cost Data for 3000 Acre-ft of Water Using the Three Turbine Types (Nuclear)}

Airflow Parameters

Airflow Rate

Maximum Air Velocity

$\Delta P_{\text {a ir, }}$ h.x.

$\Delta P_{\text {a ir }}$, discharge

Fan Power

Fans

$\mathrm{NH}_{3}$ Parameters

$\mathrm{NH}_{3}$ Flow Rate

$\triangle \mathrm{P}_{\mathrm{NH}_{3}}$

Pump Power

Heat Exchanger Design

Towers

Approximate Tower Diameter

Tower Height

Frontal Area

Heat Transfer Area

Tube Length

Tube Rows in Depth

Condenser Design

Heat Transfer Area

TTD

Performance Parameters

Design TBP

Maximum TBP

Power at Maximum TBP

Maximum \% Deluge

Maximum Evaporation Rate

Cost Summary

Cooling System

Capacity

Steam Supply Scaling

Heat Rate Scaling

Auxiliary Power Scaling

Energy

Base Fuel

0\&M

Incremental Cost of Cooling

\begin{tabular}{lcc} 
& Turbine Type & \\
\hline Conventional & Modified & High Back \\
Conventional & Pressure
\end{tabular}

$10^{6} 1 \mathrm{bm} / \mathrm{hr}$
$\mathrm{ft} / \mathrm{sec}$
$\mathrm{psi}$
$\mathrm{psi}$
$\mathrm{MW}$

555.

605.

564.

14.2

13.8

12.1

0.0150

0.0143

0.0075

0.0054

0.0057

0.0037

13.2

14.0

7.3

123

129

150

$10^{6} 1 \mathrm{bm} / \mathrm{hr}$

14.3

14.2

16.6

psi

23.3

23.8

29.3

MW

0.797

0.797

1.081

\section{5}

$\mathrm{ft}$

253.

74.8

$10^{6} \mathrm{ft}^{2}$

$10^{6} \mathrm{ft}^{2}$

0.290

25.9

96.8

6

$10^{6} \mathrm{ft}^{2}$

${ }^{\circ} \mathrm{F}$

0.647

4.72

0.535

3.96

2.09

4.14

in. $\mathrm{Hg}$

2.34

3.73

6.30

MW

981.2

975.5

992.4

30.5

11.2

32.7

25.0

$10^{3} \mathrm{gpm}$

1.71

1.82

1.63

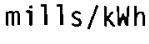

0.06

0.08

0.02

mills/kwh

0.00

0.08

0.02

$-0.22$

$-0.38$

$-0.35$

0.26

0.27

0.15

0.28

0.36

0.11

0.01

0.03

0.30

0.09

0.10

0.09

2.19

3.37 
results show that the conventional turbine-generator is preferable for both fossil-and nuclear-fueled power plants when water is available for deluge augmentation. This becomes apparent when as little as 500 acre-ft of water is available to the 1000-MWe power plant. To a large extent, the gap between the incremental cost of the conventional and the other two nuclear turbines is due to the turbine cost adder included in the modified conventional and high back pressure turbine models.

An increase in the maximum turbine back pressure affects the cooling system design in the following manner. Turbine operation at a higher back pressure for a given ambient temperature results in a higher initial temperature difference (ITD) for the heat exchanger. The ITD is the difference between the inlet ammonia temperature and the inlet air temperature at the heat exchanger. The size of the heat exchanger generaliy decreases as the ITD increases. Therefore, a high ITD resuits in a lower cost cooling system in terms of initial capital investment. However, it is obvious that the advantages of reduced cooling system capital cost for high back pressure operation are over-shadowed by the impact of the high heat rate. 


\section{REFERENCES}

1. B. C. Fryer, A Review and Assessment of Engineering Economic Studies of Dry Cooled Electrical Generating Plants. BNWL-1976, Battelle, Pacific Northwest Laboratories, Richland, WA, March 1976.

2. B. C. Fryer, Daniel J. Braun, David J. Braun, D. W. Faletti, and L. E. Wiles, An Engineering and Cost Comparison of Three Different AllDry Cooling Systems. BNWL-2121, Battelle, Pacific Northwest Laboratories, Richland, WA, September 1976.

3. W. V. Loscutoff, Prel iminary Evaluation of Wet/Dry Cooling Concepts for Power Plants. BNWL-1969, Battelle, Pacific Northwest Laboratories, Richland, WA, January 1976.

4. P. A. Ard, C. H. Henager, D. R. Pratt, and L. E. Wiles, Costs and Cost Algorithms for Dry Cooling Tower Systems, BNWL-2123, Battelle, Pacific Northwest Laboratories, Richland, WA, September 1976.

5. David J. Braun, Daniel J. Braun, W. V. DeMier, D. W. Faletti, and L. E. Wiles, A Users Manual for the BNW-1 Optimization Code for DryCooled Power Plants. BNWL-2180, Battelle, Pacific Northwest Laboratories, Richland, $W A$, September 1976.

6. B. R. Andeen and L. R. Glicksman, Dry Cooling Towers for Power Plants. DSR 73047-1, Massachusetts Institute of Technology, Cambridge, MA, February 1972 .

7. J. A. Bamberger, Daniel J. Braun, David J. Braun, D. W. Faletti, and L. E. Wiles, A Users Manual for the BNW-II Optimization Code for Power Plants Using Deluge Dry/Wet Cooling. Battelle, Pacific Northwest Laboratories, Richland, WA, to be published.

8. J. P. Rossie, R. D. Mitchel1, and R. 0. Young, Economics of the Use of Surface Condensers with Dry Cooling Systems for Fossil-Fueled and Nuclear Generating Plants. R. W. Beck and Associates, Denver, CO, December 1973.

9. Heat Transfer and Pressure Drop Characteristics of Dry Tower Extended Surfaces. Part II: Data Analysis and Correlation. PFR Engineering Systems, Inc., Marina del Rey, CA, June 15, 1976. 


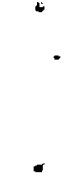

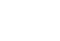

- 
APPENDIX A

AIR-SIDE PERFORMANCE CORRELATIONS FOR HÖTERV SURFACE 


\section{APPENDIX A}

\section{AIR-SIDE PERFORMANCE CORRELATIONS FOR HÖTERV SURFACE}

The PNL method of predicting the performance of the deluged HÖTERV heat exchanger bundle is based on the air-side heat transfer coefficient, $h_{s}$, whereas the B\&W approach to determining the heat transfer performance is based on a delugeate water mass transfer coefficient, $\sigma_{S}$ (Appendix $C$ ).

There are two different options by which the heat transfer performance of the HÖTERV heat exchanger bundle can be predicted. The correlations that are the basis for each option are given below. The pressure drop through the heat exchanger bundle is calculated using a correlation for the friction factor, $f$. Correlations for $h_{S}, \sigma_{S}$, and friction factor used in the BNW-II code are given below.

\section{HEAT TRANSFER COEFFICIENT}

The PNL method for predicting the performance of the HÖTERV heat exchanger bundle is based on using the all-dry mode heat transfer coefficient correlation in conjunction with the enthalpy driving force in predicting the amount of water evaporated.

The heat transfer coefficient correlation was developed from a correlation provided by Babcock and Wilcox. (a) The correlation is

$$
h_{0}=0.12518\left(\operatorname{Re}_{\text {air }}\right)^{0.515} \operatorname{Pr}^{1 / 3}\left(k_{a} / D_{H}\right)
$$

where

$$
\begin{aligned}
h_{0} & =\text { overall air-side heat transfer coefficient } \\
\operatorname{Re}_{\text {air }} & =\text { Reynolds number at the minimum flow area of the heat exchanger }
\end{aligned}
$$

(a) This information was provided by $W$. W. Sowa, New Products, Power Generation Group, Babcock and Wilcox, Barberton, $\mathrm{OH}$, in a private communication to PNL on February 4, 1977. 


$$
\begin{aligned}
& \operatorname{Pr}=\text { Prandtl number of the air } \\
& k_{a}=\text { thermal conductivity of the air } \\
& D_{H}=\text { hydraulic diameter of the heat exchanger. }
\end{aligned}
$$

Since this is in terms of an overall heat transfer coefficient, the effect of fin efficiency of the surface is built into the correlation. The local heat transfer coefficient is given by the following:

$$
h_{s}=h_{0}\left(A_{b}+A_{f}\right) /\left(A_{b}+n_{f} A_{f}\right)
$$

where

$$
h_{s}=\text { local heat transfer coefficient }
$$

$h_{0}=$ overall heat transfer coefficient

$A_{b}=$ air-side tube area excluding the fin

$A_{f}=$ air-side fin area

$n_{f}=$ fin effectiveness.

With the fin effectiveness, $n_{f}$, a function of the local heat transfer coefficient, $h_{s}$, the solution for the local heat transfer coefficient in terms of the overall heat transfer coefficient is an iterative process. For various Reynolds numbers the overall heat transfer coefficient is calculated using Equation A.1. Using Equation A.2 the local heat transfer coefficient is determined by a simple iterative process for each Reynolds number. A curve fit is then made for the local heat transfer coefficient as a function of Reynolds number resulting in the following:

$$
h_{c}=0.18534\left(\operatorname{Re}_{\text {air }}\right)^{0.577} \mathrm{Pr}^{1 / 3}\left(\mathrm{k}_{\mathrm{a}} / \mathrm{D}_{H}\right)
$$

The range of Reynolds numbers over which the correlation is applicable is 500 to 1500 . 


\section{MASS TRANSFER COEFFICIENT}

The Hungarian method of predicting the amount of water being evaporated from the surface of the heat exchanger is based on a mass transfer correlation. The correlation was provided by Babcock and Wilcox. (a) The correlation is provided here in the form in which it was used.

$$
\sigma_{S}=0.0250\left(\operatorname{Re}_{\text {air }}\right)_{\min }^{0.615}
$$

where

$\sigma_{S}=$ mass transfer coefficient

$\operatorname{Re}_{\text {air }}=$ Reynolds number at the minimum flow area of the heat exchanger

The range of Reynolds numbers over which this correlation is applicable is 500 to 1500 .

\section{PRESSURE DROP}

The pressure drop through the heat exchanger bundles was calculated using a friction factor correlation derived from information provided by Babcock and Wilcox. (a) The pressure drop equation is of the following form:

$$
\Delta p=\left(\rho v^{2} / g_{C}\right) N_{D} f
$$

where

$$
\begin{aligned}
\Delta p & =\text { pressure drop } \\
p & =\text { average density of air in the heat exchanger } \\
V & =\text { maximum velocity of air in the heat exchanger } \\
g_{C} & =\text { gravitational constant } \\
N_{D} & =\text { number of tubes in depth } \\
f & =\text { friction factor }
\end{aligned}
$$

(a) This information was provided by $W$. W. Sowa, New Products, Power Generation Group, Babcock and Wilcox, Barberton, $\mathrm{OH}$, in a private communication to PNL on February 4, 1977. 
The friction factor is given by the following correlation:

$$
f=4.781\left(\operatorname{Re}_{\text {air }}\right)^{-0.24}
$$

where

$$
\begin{aligned}
\mathrm{Re}_{\text {air }}= & \text { Reynolds number of the airflow at the minimum cross-sectional } \\
& \text { flow area of the heat exchanger. }
\end{aligned}
$$

The range of Reynolds numbers over which the correlation is applicable is 500 to 1500 . 
APPENDIX B

FIN EFFICIENCY OF PLATE FIN HEAT EXCHANGERS 


\section{APPENDIX B}

FIN EFFICIENCY OF PLATE FIN HEAT EXCHANGERS

The temperature difference between a fin and the bulk fluid decreases with distance from the base of the fin because of heat transfer resistance of the fin material. As a result the heat transfer does not increase in direct proportion to the fin area and a correction, the fin efficiency, $r_{i}$, must be applied. Thus the heat transfer rate, $Q$, is given by Equation $B .1$

$$
Q=h_{s}\left(A_{b}+n_{f} A_{f}\right)\left(T_{b}-T_{\infty}\right)
$$

where

$h_{S}=$ the air-side transfer coefficient, Btu/hr-ft ${ }^{2}-{ }^{\circ} \mathrm{F}$

$A_{b}=$ tube area between the fins which is exposed to the air, $\mathrm{ft}^{2}$

$A_{f}=$ area of the fins, $f t^{2}$

$\eta_{f}=$ fin efficiency, dimensionless

$T_{b}=$ temperature at the fin base, ${ }^{\circ} \mathrm{F}$

$T_{\infty}=$ temperature of the bulk air, ${ }^{\circ} \mathrm{F}$

For example, a fin will have a fin efficiency of 0.5 if the mean temperature difference between the fin and the bulk air (averaged over the entire fin area) is $1 / 2$ of the telimperature difference between the fin root and the bulk air. In effect, a fin with a fin efficiency of 0.5 behaves (in regard to heat transfer) as if it had only half the area of a fin having an infinite thermal conductivity.

The accuracy of the PNL method (see Appendix A) for computing the performance of deluged heat exchangers depends upon a sufficiently accurate method for determining the fin efficiency of the plate fin surface studied in this report. The purpose of this appendix is to describe the method used to compute the fin efficiency (both in dry operation and in deluged operation) of the plate fin heat exchanger surface studied. We begin by describing how the plate fin heat exchanger was treated for the purpose of computing the fin efficiency as an annular fin heat exchanger. 


\section{TRANSFORMATION OF THE PLATE FIN INTO AN ANNULAR FIN EQUIVALENT}

The heat exchanger configuration studied was one developed by the HÖTERV Institute. As shown in Figure B.l it is a plate fin configuration with 18.5-mm OD tubes located in a staggered isosceles triangular arrangement with a $60-\mathrm{mm}$ transverse (to the direction of flow) pitch and a 50-mm longitudinal pitch. The plate fins are $0.33-\mathrm{mm}$ thick and are located at a center to center spacing of $2.88 \mathrm{~mm}$, giving an interfin gap of $2.5 \mathrm{~mm}$.



FIGURE B.1. Unit Geometry of Plate Fin Studied 
The approximation was used that the plate fin heat exchanger's fin effectiveness could be computed with sufficient accuracy by assuming that the piate fin was replaced by annular fins with the same cross section per tube. A 43.7-mm fin OD results (Figure B.2). Fin thickness and spacing were left unchanged. The shaded areas of Figure B.2 show where the equivalent annular fins overlap and the regions which they "miss." Though the annular fin approximation'introduces some error, it is probably a reasonable approximation which should be adequate for the present purpose.

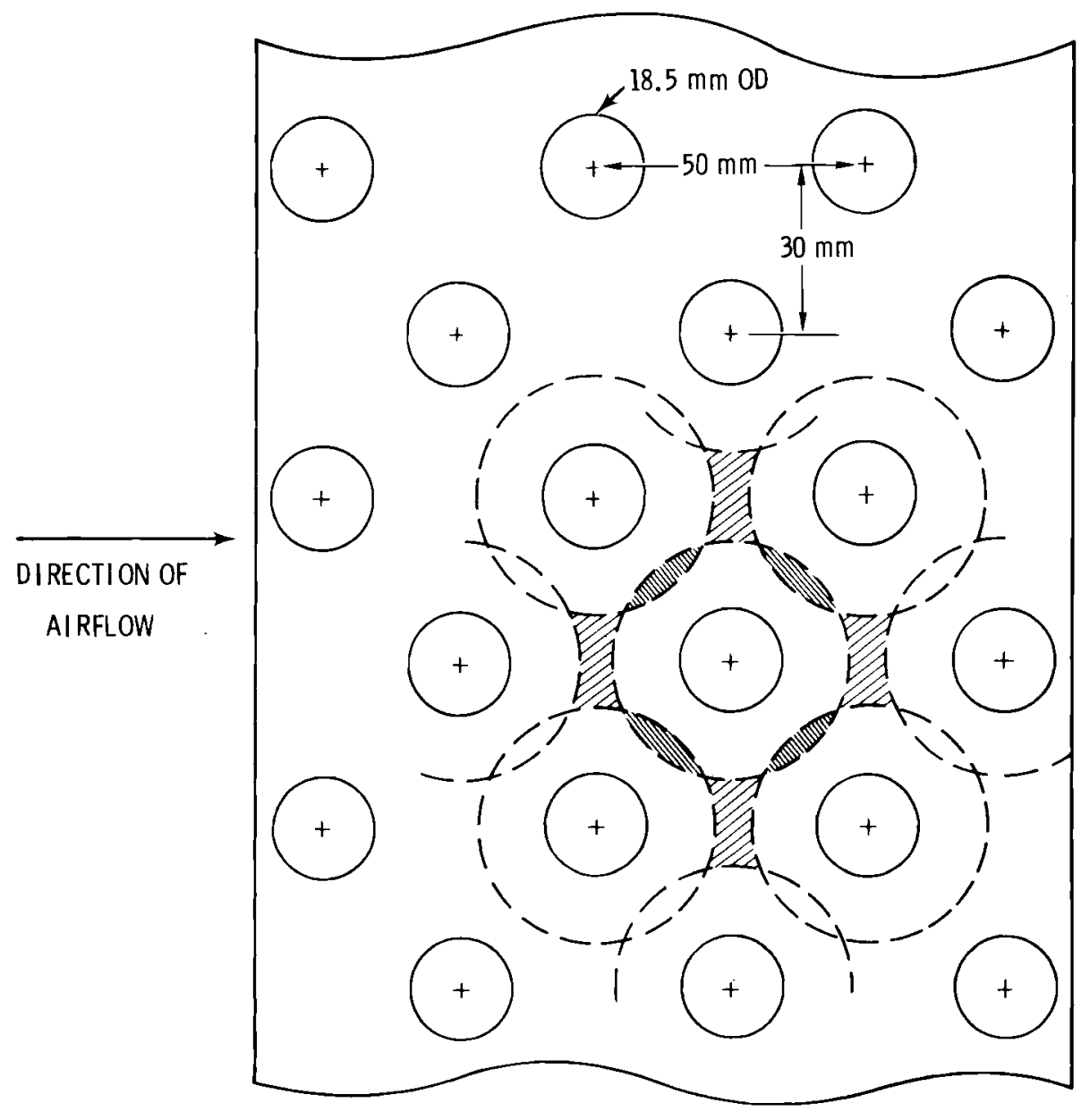

FIGURE B.2. Annular Fin Equivalent of Plate Fin (The shaded areas show where the annular fins overlap and where they "miss.") 
The heat transfer data provided PNL by Babcock and Wilcox gave values of the lumped air-side heat transfer coefficient, $h^{\prime}$, which includes the effect of fin efficiency such that Equation B.2 applies.

$$
Q=h^{\prime}\left(A_{b}+A_{f}\right)\left(T_{b}-T_{\infty}\right)
$$

The relationship between $h^{\prime}$ and $h_{s}$ can be derived by equating Equations $B .1$ and B.2 giving Equation B.3.

$$
h_{s}=h^{\prime}\left(A_{b}+A_{f}\right) /\left(A_{b}+n_{f} A_{f}\right)
$$

The heat transfer of dry surfaces can be computed from $h^{\prime}$; however, values of $h_{s}$ are required for deluge computations. Thus both the dry and the wet performance of the heat exchangers were computed from correlations for $h_{s}$ derived from the experimental values of $h^{\prime}$ (See Appendix $A$ ). These values of $h_{s}$ were obtained by iterative solutions involving Equation $B .3$ and the equation for fin effectiveness (Equation B.4).

\section{COMPUTATION OF FIN EFFICIENCY}

\section{DRY OPERATION}

Gardner (B.1) derived Equation B.4 for the fin efficiency of annular fins of constant thickness with the following assumptions:

1. The heat flow and temperature distribution throughout the fin are independent of time, i.e., the heat flow is steady.

2. The fin material is homogeneous and isotropic.

3. There are no heat sources in the fin itself.

4. The heat flow to or from the fin surface at any point is directly proportional to the temperature difference between the surface at that point and the surrounding fluid.

5. The thermal conductivity of the fin is constant. 
6. The heat-transfer coefficient is the same over all the fin surface.

7. The temperature of the surrounding fluid is uniform.

8. The temperature of the base of the fin is uniform.

9. The fin thickness is so small compared to its height that temperature gradients normal to the surface may be neglected.

10. The heat transferred through the outermost edge of the fin is negligible compared to that passing through the sides.

$$
n_{f}=\frac{2}{U_{b}\left[1-\left(\frac{U_{e}}{U_{b}}\right)^{2}\right]} \frac{I_{1}\left(U_{b}\right)-\beta_{1} k_{1}\left(U_{b}\right)}{I_{0}\left(U_{b}\right)+\beta_{1} k_{0}\left(U_{b}\right)}
$$

where

$$
\begin{aligned}
& \beta_{1}=\frac{I_{1}\left(U_{e}\right)}{K_{1}\left(U_{e}\right)} \\
& U_{b}=\frac{\left(r_{e}-r_{b}\right)\left[h_{s} /\left(k y_{b}\right)\right]^{1 / 2}}{\left(\frac{r_{e}}{r_{b}}-1\right)} \\
& U_{e}=U_{b}\left(\frac{r_{e}}{r_{b}}\right)
\end{aligned}
$$

$I_{n}$ and $K_{n}$ are Bessel functions of order $n$ of the first and second kind, respectively. Other terms are:

$$
\begin{aligned}
h_{s} & =\text { air-side heat transfer coefficient } \\
k & =\text { thermal conductivity of the fin material } \\
r_{e} & =\text { fin outside radius } \\
r_{b} & =\text { fin root radius } \\
y_{b} & =1 / 2 \text { of the fin thickness. }
\end{aligned}
$$

Thus, the fin efficiency is a function of the fin geometry, the thermal conductivity of the fin material and the local heat transfer coefficient. 


\section{DELUGE OPERATION}

The fin efficiency relationship for deluge operation will now be derived. This relationship is identical to Equation B.4 except that the quantity $h_{s}$ is replaced by the quantity

$$
U^{*} r_{\infty} /\left(C_{a} \frac{d T}{d i^{\top}}\right)
$$

where

$U^{\star}{ }_{r_{\infty}}=$ the overall heat transfer coefficient (enthalpic driving force) between the fin root and the bulk air, Btu/ft ${ }^{2}-\mathrm{hr}-{ }^{\circ} \mathrm{F}$

$C_{a}=$ the heat capacity of humid air, Btu/ ${ }^{\circ} \mathrm{F}-1 \mathrm{~b}$ of dry air

$\mathrm{dT} / \mathrm{di}=$ the derivative of temperature with respect to the enthalpy of dry air, ${ }^{\circ} \mathrm{F}-1 \mathrm{~b}$ of dry air/Btu.

These terms are defined in Appendix $C$.

Equation B.4 is the solution for the equation

$$
\frac{d^{2} \theta}{d r^{2}}+\left(\frac{1}{a_{r}} \frac{d a_{r}}{d r}\right) \frac{d \theta}{d r}-\left(\frac{h_{s}}{k a_{r}} \frac{d A}{d r}\right) \theta=0
$$

with the boundary conditions

$$
\begin{aligned}
& \theta=\theta_{b} \text { when } r=r_{b} \\
& \frac{d \theta}{d r}=0 \text { when } r=r_{e}
\end{aligned}
$$

where

$$
\begin{aligned}
\theta & =T_{r}-T_{\infty} \\
T_{r} & =\text { fin temperature at distance } r \text { from the centerline } \\
T_{\infty} & =\text { temperature of the bulk air }
\end{aligned}
$$

$a_{r}=$ the cross sectional area of the fin at distance $r$ from the centerline.

The method of solution to arrive at Equation B. 4 from Equation B. 8 is the same for both the dry and the deluge applications. The reader is 
referred to References B.1 and B.2 for the details. We shall derive the equation analogous to Equation B.8 for deluge operation and show that it has the same form and boundary conditions.

The driving force used in the BNW method for computing deluge performance is $\Delta i / C_{a}$ where $\Delta i$ is the enthalpy difference, Btu/lb of dry air. Thus the heat transfer between the fin root and the air immediately adjoining it is given by

$$
Q=U^{*}{ }_{r_{\infty}} A \frac{\Delta i}{C_{a}}
$$

where

$U^{*}{ }_{r_{\infty}}=$ the overall heat transfer coefficient between the fin root and the air, Btu/ft ${ }^{2}-h r-{ }^{\circ} \mathrm{F}$, and

$A=$ the heat transfer area under consideration.

Since our driving force is $\Delta i / C_{a}$, the quantity analogous to $\theta$, is $\theta^{\prime}$, where

$$
\theta^{\prime}=\frac{i^{\prime}-i_{\infty}}{C_{a}}
$$

and $i^{\prime}$ ' is the enthalpy of saturated air at the fin temperature at any distance from the centerline.

Consider the case where $\left(i-i_{\infty}\right)$ is positive (i.e., the case where heat is being transferred to the air). Let $Q$ be the amount of heat transferred to the air between the edge of the fin and radius $r$. Let $A$ be the total surface area between the edge of the fin and radius $r$, and let $a_{r}$ be the cross. sectional area of the fin at radius $r$. Then

$$
d Q=U^{*} r_{\infty} \theta^{\prime} d A
$$

Differentiating Equation B.11 gives

$$
\frac{d Q}{d r}=U^{*}{ }_{r_{\infty}} \theta^{\prime} \frac{d A}{d r}
$$


The conduction equation gives

$$
Q=-k a_{r} \frac{d \theta}{d r}=-k a_{r} \frac{d \theta}{d \theta^{\prime}} \frac{d \theta^{\prime}}{d r}
$$

Differentiating Equation B.13 gives

$$
\frac{d Q}{d r}=-k a_{r} \frac{d \theta}{d \theta^{\prime}} \frac{d^{2} \theta^{\prime}}{d r^{2}}-k \frac{d a}{d r} \frac{d \theta}{d \theta^{\prime}} \frac{d \theta^{\prime}}{d r}
$$

Equating Equations B.12 and B.14 gives

$$
\frac{d^{2} \theta^{\prime}}{d r^{2}}+\left(\frac{1}{a_{r}} \frac{d a_{r}}{d r}\right) \frac{d \theta^{\prime}}{d r}+\left(\frac{U^{*} r_{\infty}}{k a_{r} \frac{d \theta}{d \theta^{\prime}}} \frac{d A}{d r}\right) \theta^{\prime}=0
$$

From the definition of $\theta$ and $\theta^{\prime}$

$$
\frac{d \theta}{d \theta^{\top}}=\lim _{\Delta \rightarrow 0} \frac{\left(T+\Delta T-T_{\infty}\right)-\left(T-T_{\infty}\right)}{\frac{\left(i^{\top}+\Delta i^{\top}-i_{\infty}\right)-\left(i^{\top}-i_{\infty}\right)}{C_{a}}}=C_{a} \frac{d T}{d j^{\top}}
$$

Inserting Equation B.16 into Equation B.15 gives

$$
\frac{d^{2} \theta^{\prime}}{d r^{2}}+\left(\frac{1}{a_{r}} \frac{d a_{r}}{d r}\right) \frac{d \theta^{\prime}}{d r}+\left(\frac{U^{*} r_{\infty}}{k a_{r} c_{a} \frac{d T}{d j^{\prime}}} \frac{d A}{d r}\right) \theta^{\prime}=0
$$

The boundary conditions for Equation B.17 are

$$
\theta^{\prime}=\theta^{\prime} \text { bhen } r=r_{b}
$$

and

$$
\frac{d \theta^{\prime}}{d r}=0 \text { when } r=r_{e}
$$


These boundary conditions arise from the same assumptions used to derive Equation B.8. Equation B.17 and its boundary conditions are identical to Equation B.8 except that $\theta^{\prime}$ replaces $\theta$ and that the coefficient of the third term differs. Equating these coefficients gives us the relationship

$$
h_{s}=\frac{U^{*} r_{\infty}}{c_{a} \frac{d T}{d j^{\top}}}
$$

Thus Equation B.4 can be used to compute the fin effectiveness for deluged systems if the right side of Equation B.17 is substituted for $h_{s}$. The discussion here has been 1 imited to annular fins of constant thickness. A study of References B.1 and B.2 shows that the substitution suggested by Equation B.20 is also applicable to other extended surfaces such as spines and straight fins, as well as annular fins of nonconstant thickness. By analogy it is quite possible that Equation B.18 is applicable to most extended surfaces.

The quantity $U^{*}{ }_{r_{\infty}} /\left(C_{a} d T / d i^{\prime}\right)$ must be constant if Equation 4 is to be exact. $U^{*}{ }_{r_{\infty}}$ is as likely to be constant as $h_{s}$. The value of $d T / d i '$ will vary somewhat if there is a large temperature drop across the fin. However, the percentage variation in heat transfer coefficient within the fins is probably just as large as any variation in $\mathrm{dT} / \mathrm{d} \mathrm{i}$ ' when one considers the nature of the flow.

$C_{a}$ is approximately 0.24 . $d T / d i '$ is seldom much greater than unity and is often less than unity. For the same face velocity, $U^{*}{ }_{r_{\infty}}$ is generally within $10 \%$ of $h_{s}$. Therefore, the quantity $U_{r_{\infty}} /\left(c_{a} d T / d i^{\prime}\right)$ is generally four times that of $h_{s}$ and as a result the fin efficiency during deluge is often near 0.7 compared to the $0.9^{+}$found in dry operation. 


\section{APPROXIMATE SOLUTION FOR FIN EFFICIENCY}

In order to reduce computation time, a curve fit of the results predicted by Equation B.4 was used to compute the fin efficiency in the BNW-II computer code. The resulting equation was

$$
\eta_{f}=\frac{1}{1+C h_{s}}+0.06313766\left(1-e^{-0.00745032 h_{s}}\right)
$$

where

$$
c=\left(r_{e}-r_{b}\right)^{2} \frac{\left(r_{e} / r_{b}\right)^{1 / 2}}{3 k y_{b}}
$$

and the units of $h_{s}$ are $B t u / f t^{2}-h r-{ }^{\circ} F$. 


\section{REFERENCES}

B.1. K. A. Gardner, Trans. ASME, 67, 621-632, 1945.

B.2. D. G. Kern, Process Heat Transfer. First Edition, McGraw-Hill Book Co., New York, NY, 1950. 


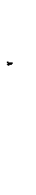


APPENDIX C

COMPUTATION OF DELUGE PERFORMANCE 
APPENDIX C

COMPUTATION OF DELUGE PERFORMANCE

Deluging, as used in this study, refers to a method of augmenting a heat exchanger's performance by distributing water (delugeate) onto the exchanger in such a way that the normally dry exterior surfaces are covered with a thin layer of water. This layer of water is thin compared to the interfin spacing thus permitting air to flow between the fins though at a somewhat larger resistance to airflow due to the somewhat smaller air passages as well as possible bridging of the liquid film.

This type of water augmentation of dry heat transfer surfaces is under intensive development by the HÖTERV Institutue, Budapest Hungary. Babcock and Wilcox (B\&W) is the U.S. licensee for this technology.

The mechanism for transport of heat between the surface of the delugeate and the air is the same in a deluged heat exchanger as that in an evaporative tower--combined mass and heat transfer. However, in an evaporative tower the primary fluid (water) is in direct contact with the air. Thus the resistance to heat transfer from the bulk of the primary fluid to the air-water surface is relatively small in contrast to the situation found in a deluged heat exchanger where the heat must pass from the primary fluid (in this study, $\mathrm{NH}_{3}$ ) through several resistances to heat transfer before reaching the delugeate-air interface. Evaporative towers are designed by use of the enthalpy driving force. ( C.1, p.356) The design methods given here for deluged towers also use the enthalpy driving force; the heat transfer terms arising from the heat transfer resistance between the tube side fluid and the surface of the delugeate are transformed from use of the temperature driving force to use of the enthalpy driving force.

Two computational methods were used in this study. The first method was that recommended by $B \& W$ which was used in conjunction with experimental data obtained by the HÖTERV group. Since it was the most accurate it was used in all but a few cases. 
The second method was developed by PNL. (C.2) The PNL inethod, though less accurate, predicts the performance of a deluged heat exchanger given only its dry heat transfer data. Because of its potential utility for evaluating the performance of candidate surfaces for which experimental deluged data is not available, a description of the PNL method is also presented.

Both the $B \& W$ and the PNL methods take into account all resistances to heat transfer between the tube-side fluid and the bulk air. The B\&W method makes use of the enthalpy driving force used routinely in evaporative tower design. Thus all heat transfer resistance terms which are expressed in terms of a temperature driving force are converted to an enthalpy driving force. An analogous approach is used by the PNL method.

The remainder of this appendix is divided into four sections:

- basics and definitions,

- B\&W method for determining the overall heat transfer coefficient,

- PNL method for determining the overall heat transfer coefficient,

- computation of overall heat transfer and water evaporation rate of a deluged heat exchanger, and

- nomenclature.

\section{BASICS AND DEFINITIONS}

The purpose of this section is to introduce the reader to the quantities which are used in the sections which follow.

The absolute humidity, the ratio of the weight of water to the weight of air in moist air, is given by

$$
H=\frac{18.02 p}{(28.97)\left(29.92 P_{a}-p\right)}
$$

where

$$
\begin{aligned}
& p=\text { the partial pressure of water, in. } \mathrm{Hg} \\
& P_{a}=\text { atmospheric pressure, in. } \mathrm{Hg} .
\end{aligned}
$$


The heat capacity of moist air, expressed as Btu/1b of dry air $-{ }^{\circ} \mathrm{F}$ (also known as the humid heat capacity), is given by

$$
c_{a}=0.24+0.45 H
$$

The contribution of the water vapor to the humid heat capacity is given by the second term of Equation 2.

The enthalpy of moist air, $i$, expressed as Btu/lb of dry air is given by

$$
i=C_{a} T+1094 H
$$

where

$$
\mathrm{T}=\text { dry-bulb temperature, }{ }^{\circ} \mathrm{F} \text {. }
$$

The reference condition is $0^{\circ} \mathrm{F}$ for both the air and the steam. The constant 1094 is the extrapolated heat of vaporization of water at $0^{\circ} \mathrm{F} .(\mathrm{C} .1, \mathrm{p} .358)$

Before proceeding further, it is worthwhile to digress and present some background information on how $\mathrm{H}, \mathrm{i}$ and $\mathrm{T}$ are interrelated and to describe several methods of computing these quantities which are used in BNW-II code.

First, the value of $i$ for a moist air mixture can be determined from a knowledge of $i$ ts dry-bulb temperature, relative humidity and the atmospheric pressure. This follows since $\mathrm{H}$ can be determined from Equation $\mathrm{C}_{1} 1, \mathrm{C}_{\mathrm{a}}$ from Equation C.2 and finally $i$ from Equation C.3. However, an alternate, extremely useful way of determining $i$ is from a knowledge of the moist air mixture's dry-bulb temperature, wet-bulb temperature and the atmospheric pressure. This is possible because the enthalpy of air at the wet-bulb temperature is very nearly the same as the enthalpy of the moist air mixture at the drybulb temperature (This can be best visualized by examining a phychometric chart and observing the near parallelism of the constant enthalpy and constant wet-bulb lines.).

The procedure is as follows. Since the air is saturated at the wetbulb temperature the partial pressure of air at the wet-bulb is equal to the vapor pressure of air at the (known) wet-bulb temperature. The absolute 
humidity at the wet-bulb conditions is then calculated from Equation $\mathrm{C} .1$ from which $C_{a}$ is calculated from Equation $C .2$ and finally the enthalpy, $i$, from Equation C.3.

From a knowledge of $i$, the absolute humidity at the actual air condition can be obtained from Equations $C .2$ and $C .3$ by inserting the dry-bulb temperature. This permits the computation of $C_{a}$ at the actual conditions from Equation C.2 and finally a computation of the partial pressure and relative humidity from Equation C. 1 .

Another operation which is conducted frequently in computing the performance of a deluge heat exchanger is the determination of the temperature of a moist air mixture given its enthalpy and relative humidity, and given the atmospheric pressure. This involves using Equations C.1, C.2 and C.3 in an iterative computation. With this background we can now proceed to discuss the use of the enthalpy driving force.

For an evaporative tower the heat transfer is computed by use of an enthalpy driving force as shown in Equation C.4:

$$
Q=\sigma_{S} A_{S}\left(i_{w}^{\prime}-i_{\infty}\right)
$$

where

$$
\begin{aligned}
Q= & \text { the heat transfer rate, Btu/hr, } \\
\sigma_{S}= & \text { the mass transfer coefficient (enthalpic driving force), lb of dry } \\
& \text { air/ft }{ }^{2}-h r,(a) \\
A_{S}= & \text { the surface area, } \\
i_{W}^{\prime}= & \text { the enthalpy of saturated air at the cooling water temperature, } \\
& \text { Btu/lb of dry air, and } \\
i_{\infty}= & \text { the enthalpy of the bulk air, Btu/lb of dry air. }
\end{aligned}
$$

(a) $\sigma_{s}$ is the mass transfer coefficient when absolute humidity is used as the driving force, e.g.,

where

$$
\dot{m}_{w}=\sigma_{s} A\left(H_{S}^{\prime}-H_{\infty}\right)
$$

$\dot{m}_{w}=$ the evaporation rate of water, $1 b_{W} / \mathrm{ft}^{2}-\mathrm{hr}$

$\mathrm{H}_{\mathrm{S}}^{\prime}=$ the absolute humidity of saturated air at the air-water interface, $1 b_{w} / 1 b_{a}$

$H_{\infty}=$ the absolute humdity of the bulk air, $1 b_{W} / 1 b_{a}$. 
Reference C.1 gives a good description of the development of the use of this driving force. The use of an enthalpy driving force is most nearly correct if the convective Lewis number, given by Equation C.5:

$$
\text { Le }=\frac{h_{s}}{\sigma_{s} C_{s}}
$$

is equal to one, ${ }^{(C .2)}$ which is a reasonable approximation for water.

The B\&W approach uses an equation of the form of Equation C.4 for the computation of the heat transfer rate. Values of $\sigma_{s}$ from correlations based on experimentally determined values of $\sigma_{s}$ were used in the computations.

The PNL approach was developed to permit the prediciton of the performance of deluged heat exchangers when dry heat transfer data (but not deluged data) were available. With the assumption that the Lewis number is unity, $\sigma_{s}=h_{s} / C_{s}$, which allows us to arrive at Equation C.6 from Equation C.4,

$$
Q=\left(\frac{h_{s}}{C_{s}}\right) A\left(i_{w}^{\prime}-i_{\infty}\right)=h_{s} A \frac{\left(i_{w}^{\prime}-i_{\infty}\right)}{C_{a}}
$$

Either the enthalpy difference, or the enthalpy difference divided by the humid heat capacity, can be used as the driving force. The latter was selected since we found it convenient to work with heat transfer coefficients; rather than the ratio of the heat transfer coefficient and the humid heat capacity.

Note that no approximations are introduced by use of Equation C.6 that are not used by Equation C.4, if the Lewis number is unity. The approximation used by the PNL approach is to assume that the value of $h$ obtained from dry heat transfer correlations is equal to $h_{s}$, the local value of convective heat transfer at the delugeate-air interface. Corrections for the case when the Lewis number is not equal to unity could be used; however, this was not deemed necessary in this study.

Before one can solve for the overall heat transfer coefficient between tube-side fluid and the bulk air in terms of an enthalpy driving force, all resistances to heat transfer, such as the heat transfer coefficient between tube-side fluid and the tube wall, must be also transformed to an enthalpy driving force. In the next section we shall show how this is done for the B\&W approach. 
As mentioned in the previous section, the $B \& W$ method makes use of the enthalpy difference between tube side fluid and the bulk air as a driving force. Thus the heat transfer rate is given by

$$
Q=\Sigma_{p \infty} A_{t}\left(i_{p}^{\prime}-i_{\infty}\right)
$$

where

$$
\begin{aligned}
Q= & \text { the heat transfer rate, Btu/hr } \\
\Sigma_{p o s}= & \text { the overall tube side to bulk air mass transfer coefficient, } \\
& 1 \text { b of dry air/ft }{ }^{2}-h r \\
A_{t}= & \text { the total transfer area on the air side, } \mathrm{ft}^{2} \text {, and } \\
i_{p}^{\prime}= & \text { the enthalpy of saturated air at the temperature of the tube- } \\
& \text { side fluid, Btu/lb of dry air. }
\end{aligned}
$$

The total air-side heat transfer area, $A_{t}$, is given by

$$
A_{t}=A_{b}+A_{f}
$$

where $A_{b}$ is the area of the tubes between the fins which is exposed to air and $A_{f}$ is the area of the fin.

There are five resistances to heat transfer in series between the tubeside fluid and the bulk air. These are:

- the resistance between the tube-side fluid and the inside of the tube wall (heat transfer coefficient $h_{p}$ ),

- fouling on the inside of the wall (equivalent heat transfer coefficient $\left.\beta_{f p}\right)$,

- conduction through the wall $\left(k_{w} / t_{w}\right)$,

- the resistance between the fins and the delugeate (heat transfer coefficient $h_{d}$ ),

- the resistance between the surface of the delugeate and the bulk air (mass transfer coefficient, $\sigma_{s}$ ). 
The first four of these resistances use temperature as the driving force, the fifth uses enthalpy. In order to arrive at an overall coefficient using enthalpy, the first four coefficients must be lumped together and then converted over to an enthalpic driving force. This is done by first computing the overall heat transfer coefficient between the tube-side fluid and the bulk of the delugeate, $U_{p s}$, by use of Equation C.9:

$$
U_{p s}=\left[\left(A_{b}+A_{f}\right)\left(\frac{1}{h_{p} A_{p}}+\frac{1}{\beta_{f p} A_{p}}+\frac{t_{w}}{k_{w} A_{w}}+\frac{1}{h_{d}\left(A_{b}+A_{f}\right)}\right)\right]^{-1}
$$

where $A_{p}$ and $A_{w}$ are the tube side and average tube wall areas, respectively.

We shall now derive the equation for obtaining the value of the tube side to delugeate overall heat transfer coefficient in enthalpic terms given the tube side to delugeate coefficient $U_{p s}$ and temperature driving force terms. Letting $\Sigma_{p s}$ be the heat transfer coefficient with enthalpic driving force and equating the heat transfer via temperature driving force to heat transfer via enthalpic driving force, we arrive at Equation C.10:

$$
\Sigma_{p s}\left(i_{p}^{\prime}-i_{s}^{\prime}\right)\left(A_{b}+A_{f}\right)=U_{p s}\left(T_{p}-T_{s}\right)\left(A_{b}+A_{f}\right)
$$

where

$$
\begin{aligned}
& T_{S}=\text { bulk temperature of the delugeate }{ }^{(a)} \\
& i_{S}=\text { enthalpy of saturated air at } T_{S} .
\end{aligned}
$$

Dividing out the area terms and rearranging, we arrive at

$$
\Sigma_{p s}=U_{p s} \frac{\left(T_{p}-T_{s}\right)}{\left(i_{p}^{\prime}-i_{s}^{1}\right)}
$$

which is used to give the overall pipe to bulk delugeate heat transfer coefficient in enthalpic terms. We have now reduced the heat transfer problem

(a) The heat transfer resistance between the bulk of the delugeate and the delugeate-air interface is assumed to be negligible. 
to that of having two resistances in series, that between the tube-side fluid and the delugeate and that between the delugeate and the bulk air, both of which are enthalpic driving force equivalents. Therefore, the tube side to bulk air overall coefficient is given by

$$
\Sigma_{p \infty}=\left[\frac{1}{\Sigma_{p s}}+\frac{1}{\sigma_{s}}\right]^{-1}
$$

from which the heat transfer rate can be computed by Equation C.13:

$$
Q=\Sigma_{p \infty o}\left(A_{b}+A_{f}\right)\left(i_{p}^{\prime}-i_{\infty}\right)
$$

The heat transfer rate can be computed via Equations C.8 through C.13 from a knowledge of the tube-side and bulk air temperatures, the five heat transfer coefficients involved and a knowledge of the tube side, average tube wa11, and outside surface areas. However, use of Equation C.11 requires either a knowledge of $T_{S}$ and $i_{S}^{\prime}$ or, as recommended by $B \& W$, an approximation for the quantity $\left(T_{p}-T_{s}\right) /\left(i_{p}^{\prime}-i_{s}^{\prime}\right)$ obtained from the enthalpy-temperature curve over the region of interest. While use of the approximation is satisfactory for hand calculations, it was decided to evaluate $T_{S}$ and $i_{S}^{\prime}$ in the BNW-II code. The resulting computation is of the iterative type; the convergence criteria is a sufficiently small change in $\Sigma_{\text {poo }}$ (generally $0.1 \%$ ).

PNL METHOD FOR COMPUTING THE TUBE SIDE TO BULK AIR ENTHALPY-BASED HEAT

\section{TRANSFER COEFFICIENT}

Equation C.14 gives the heat transfer rate for the PNL method:

$$
Q=U{ }_{p \infty}\left(A_{b}+\eta_{f} A_{f}\right)\left(i_{p}^{\prime}-i_{\infty}\right) / C_{a}
$$

Note as mentioned above that the driving force, instead of being the quantity $\left(i_{p}^{\prime}-i_{\infty}\right)$ is now the quantity $\left(i_{p}^{\prime}-i_{\infty}\right) / c_{a}$. The transformed overall pipe to air heat transfer coefficient is denoted by $U^{*}{ }_{p_{\infty}}$. In addition to the difference in driving force, provisions are made for use of the fin efficiency, $n_{f}$. 
The matter of the inclusion of the fin efficiency bears further comment. The fin efficiency is defined as the ratio of heat actually transferred from a fin to that transferred from a hypothetical fin with a uniform surface temperature the same as that at the fin root. As described in Appendix B, equations exist for predicting the fin efficiency for a number of fin geometries; we have adapted one of these to the prediction of the fin efficiency of plate fins for both dry and deluged operations. The fin efficiency is typically near $90 \%$ during dry operation and $70 \%$ during deluge operation. Thus, corrections for fin effectiveness are large during deluge operation and must be included.

The B\&W approach does not involve the use of fin efficiency because it is based upon experimentally obtained data. It was convenient to lump the effects of fin effectiveness into the value of $\sigma_{s}$. The relationship given between the local value of the mass transfer coeficient, $\sigma_{s}(10 c a 1)$ and $\sigma_{s}$ (lumped) is given by

$$
\sigma_{s(1 \text { umped })}=\sigma_{s(10 c a 1)} \frac{A_{b}+\eta_{f} A_{f}}{A_{b}+A_{f}}
$$

where $n_{f}$ is the (unknown) value of fin effectiveness during deluge operation. A similar situation exists in dry heat transfer where the lumped heat transfer coefficient, $h_{s(l u m p e d)}$ and the local heat transfer coefficient, $h_{s(10 c a l)}$ are related by

$$
h_{s(1 \text { umped })}=h_{s(100 a 1)} \frac{A_{b}+\eta_{f} A_{f}}{A_{b}+A_{f}}
$$

The quantity $h_{s}$ used in the PNL approach is the local value of the convective heat transfer coefficient; the quantity os used in the B\&W method is the lumped mass transfer coefficient.

The resistances to heat transfer (with their equivalent heat transfer coefficients) between the tube-side fluid and the bulk air include the following: 
- tube-side fluid to wall, $h_{p}$,

- tube-side fouling coefficient, ${ }^{\beta} f p$,

- conduction through wall, $k_{w} / t_{w}$,

- conduction along the fin $(a)$,

- fin to delugeate, $h_{d}$, and

- delugeate to air coefficient, $h_{s}$.

All of the above heat transfer coefficients are in terms of temperature driving force. We shall now show how these are transformed into overall coefficients in terms of the enthalpy-heat capacity driving force given in Equation C.14.

The transformed coefficient between tube-side fluid and the base of the fins is computed by use of Equation $C .17$ and $C .18$ below:

$$
\begin{aligned}
& U_{p r}=\left[\left(A_{b}+n_{f} A_{f}\right)\left(\frac{1}{h_{p} A_{p}}+\frac{1}{B_{f p} A_{p}}+\frac{t_{w}}{A_{w} k_{w}}\right)\right]^{-1} \\
& U_{p r}^{*}=U_{p r} c_{a}\left(\frac{T_{p}-T_{r}}{i_{p}^{1}-i_{r}^{\prime}}\right)
\end{aligned}
$$

where $T_{r}$ and $i_{r}^{\prime}$ are the temperature and enthalpy of saturated air at the fin root, respectively.

The heat transfer path between the fin root and the bulk delugeate contains two resistances, the fouling on the air-side surface and the airside surface to bulk delugeate resistance.

Equation C.19 gives the transformed overall coefficient between the fin root and the delugeate, $U^{\star}{ }_{r s}$.

$$
U^{*}{ }_{r s}=\left[\frac{1}{h_{d}}+\frac{1}{\beta_{f f}}\right]^{-1} c_{a}\left[\frac{{ }_{r}-T_{s}}{i_{r}^{1}-i_{s}^{\prime}}\right]
$$

(a) Taken into account by $n_{f}$, the fin efficiency. 
where $\beta_{f f}$ is the air-side fouling coefficient, $T_{s}$ is the temperature of the delugeate and $i_{s}^{\prime}$ is the enthalpy of saturated air at temperature $T_{S}$.

Similar reasoning gives Equation 20 for $U^{*}{ }_{r_{\infty}}$, the transformed overall coefficient between the fin root and the bulk air:

$$
U^{*}{ }_{r_{\infty}}=\left[\frac{1}{U^{*}{ }_{r s}}+\frac{1}{h_{s}}\right]^{-1}
$$

The quantity $h_{s}$ is the air-side heat transfer coefficient based on temperature driving force. Thus, if the effects of the geometric changes caused by the presence of delugeate can be neglected or compensated for, values of $h_{s}$ from dry operation can be used to predict the deluge performance.

In the above manner all of the convective terms except that of the delugeate to air are transformed to enthalpic driving forces by the use of a ratio of a temperature difference to an enthalpy difference at the same temperature as seen in terms used in Equations C.18 and C.19. Examination of the derivation of Equation C.6 from Equation C.5 shows that no such transformation is required for the delugeate to air heat transfer coefficient.

The overall tube side to air transformed heat transfer coefficient is given by Equation C.21,

$$
U^{*}{ }_{p_{\infty}}=\left[\frac{1}{U^{\star}{ }_{p r}}+\frac{1}{U^{*}{ }_{r_{\infty}}}\right]^{-1}
$$

The computation of fin efficiency is described in Appendix $B$. The fin efficiency of a deluged system is computed identically to that of a dry system except the quantity $U^{*}{ }_{r_{\infty}} /\left(C_{a} \frac{d T}{d i}\right)$ is used in place of $h_{s}$. The derivative of temperature with respect to enthalpy, dT/di is evaluated at the average fin temperature $\bar{T}_{f}$.

In order to solve Equations $C .17$ through $C .21$ for $U^{*}{ }_{\text {poo }}$, given values of $A_{p}$, $A_{w}, A_{b}, A_{f}, h_{p}, k_{w}, \beta_{f p}, \beta_{f f}, h_{d}, h_{s}, T_{p}, T_{a}, i_{p}^{\prime}$ and $i_{a}^{\prime}$, values of $T_{r}, T_{s}$, and $\bar{T}_{f}$ must be evaluated. This was done by an iterative process; the convergence criteria was a change in $U^{*}{ }_{\text {pos }}$ of less than $0.1 \%$. Derivations of 
relationships for computing values of enthalpy of saturated air at the fin root $\left(i_{r}^{\prime}\right)$, at the delugeate-air surface $\left(i_{s}^{\prime}\right)$ and at the average condition on the fin surface $\left(\bar{i}_{f}^{\prime}\right)$ are given by Equations $C .22$ through $C .24$.

$$
Q=U^{*}{ }_{r_{\infty}}\left(i_{r}^{\prime}-i_{\infty}\right)\left(A_{b}+\eta_{f} A_{f}\right) / C_{a}=U_{p \infty}^{*}\left(i_{p}^{\prime}-i_{\infty}\right)\left(A_{b}+\eta_{f} A_{f}\right) / C_{a}
$$

Therefore,

$$
\begin{aligned}
i_{r}^{\prime} & =i_{\infty}+\frac{U^{\star} p_{\infty}}{U^{\star}{ }_{r_{\infty}}}\left(i_{p}^{\prime}-i_{\infty}\right) \\
Q & =U_{r_{\infty}}^{\star}\left(A_{b}+\eta_{f} A_{f}\right)\left(i_{r}^{\prime}-i_{\infty}\right) / C_{a} \\
& =h_{s}\left(A_{b}+A_{f}\right)\left(i_{s}^{\prime}-i_{\infty}\right) / C_{a}
\end{aligned}
$$

Therefore,

$$
i_{s}^{\prime}=i_{\infty}+\frac{U^{*} r_{\infty}}{h_{s}} \frac{\left(A_{b}+n_{f} A_{f}\right)}{\left(A_{b}+A_{f}\right)}\left(i_{r}^{\prime}-i_{\infty}\right)
$$

(a) Equation C. 23b gives a value of $i_{s}^{\prime}$ which is the average value over the total outside area $\left(A_{b}+A_{f}\right)$. This choice of the value of $i s$ with its corresponding $T_{S}$ used for the calculation of $U^{*} r s$ is probably the most reasonable. If the value of $i_{s}^{\prime}$ at the fin root is desired, it can be obtained from

$$
i_{s}^{\prime}=\frac{U^{*}}{h_{s}}\left(i_{r}-i_{\infty}\right)+i_{\infty} \text {. }
$$

from

If the average value of $i_{s}^{\prime}$ on the fin is desired, it can be obtained

$$
i_{s}^{\prime}=\frac{U^{*} r_{\infty}}{h_{s}} n_{f}\left(i_{r}^{\prime}-i_{\infty}\right)+i_{\infty}
$$

Note that for

$$
h_{b}=\beta_{f f}=\infty
$$

the equation for the average value of $i_{s}^{\prime}$ on the fin reduces to Equation C. $24 b$ as it should. 
By definition

$$
n_{f}=\frac{h_{s} A_{f}\left(\bar{i}_{f}^{\prime}-i_{\infty}\right) / c_{a}}{h_{s} A_{f}\left(i_{r}^{\prime}-i_{\infty}\right) / C_{a}}
$$

Therefore,

$$
\bar{i}_{f}^{\prime}=i_{\infty}+\eta_{f}\left(i_{r}^{\prime}-i_{\infty}\right)
$$

$T_{r}, T_{s}$ and $\bar{T}_{f}$ are computed from the values of $i_{r}^{\prime}$, $i_{s}^{\prime}$ and $\bar{i}_{f}^{\prime}$ computed from Equations C.21b, C.22b and C.23b, respectively (see "Basics and Definitions," this appendix).

\section{COMPUTATION OF OVERALL HEAT TRANSFER AND WATER EVAPORATION RATE}

Both the B\&W and the PNL methods use the NTU approach for computing heat exchanger performance. This approach is described in detail for temperature driving force by Kaynes and London, (C.3) which we shall now give a brief review. The heat exchanger effectiveness for temperature driving force is defined by

$$
\phi_{T}=\frac{T_{\infty 2}-T_{\infty 1}}{T_{p}-T_{\infty 1}}
$$

where $T_{p}$ is the tube-side temperature, and $T_{\infty 1}$ and $T_{\infty 2}$ are the bulb temperatures of the air entering and exiting the heat exchanger, respectively.

The heat transfer rate is given by

$$
Q=\dot{m}_{a} C_{p a}\left(T_{\infty 2}-T_{\infty l}\right)=\dot{m}_{a} C_{p a} \phi_{T}\left(T_{p}-T_{\infty l}\right)
$$

For the $\mathrm{NH}_{3}$ condenser the relationship for $\phi_{T}$ is

$$
\phi_{T}=1-\mathrm{e}^{-\mathrm{N}_{T}}
$$


where $N_{T}$, the number of NTUs based on the temperature driving force is given by

$$
N_{T}=\frac{A U}{m_{a} C_{p a}}
$$

where

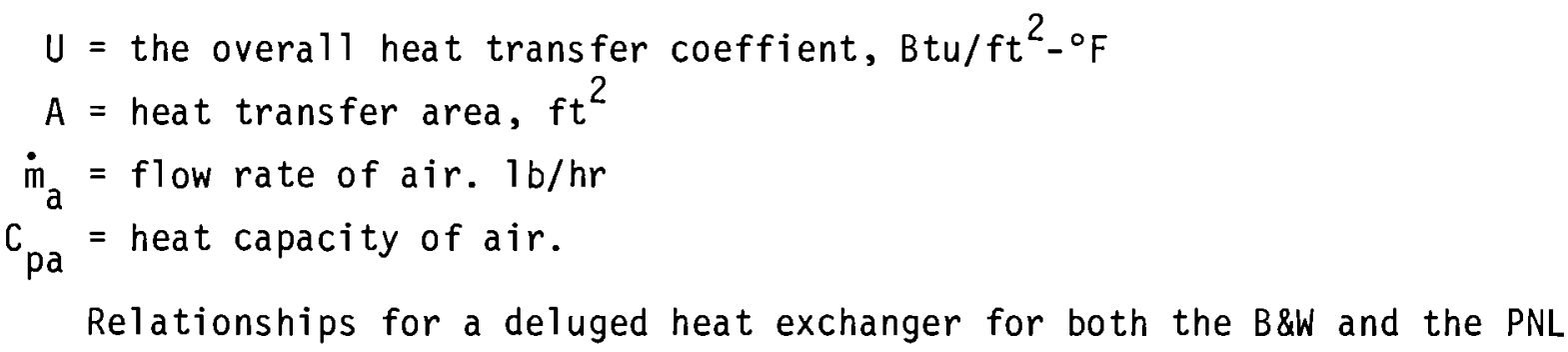
method are

$$
\begin{aligned}
& \phi=\frac{i_{\infty 2}-i_{\infty 1}}{i_{p}^{\prime}-i_{\infty 1}} \\
& Q=\dot{m}_{a} \phi\left(i_{p}^{\prime}-i_{\infty}\right)
\end{aligned}
$$

and

$$
\phi=1-e^{-N}
$$

However, because the B\&W approach uses the enthalpy difference as the driving force

$$
N=\Sigma_{p \infty o}\left(A_{b}+A_{f}\right) / \dot{m}_{a}
$$

for the B\&W approach. For the PNL approach, which uses enthalpy difference divided by the heat capacity as the driving force, and incorporates fin efficiency into Equation C.14,

$$
N=U_{p \infty}^{*}\left(A_{b}+\eta_{f} A_{f}\right) /\left(C_{p a} \dot{m}_{a}\right)
$$


The performance of a deluged heat exchanger was computed in a similar manner no matter whether the B\&W or the PNL method was used. Changes in the mass (or heat) transfer coefficient between the leading and the trailing edge of the heat exchanger were taken into account in the following manner. A value of $\Sigma_{p \infty o}\left(\right.$ or $U_{p \infty o l}$ ) was computed for the leading edge and the number of enthalpy transfer units $N_{1}$ were computed by Equation $C .33$ a for the B\&W method

$$
N_{1}=\Sigma_{p \infty 1}\left(A_{b}+A_{f}\right) / \dot{m}_{a}
$$

and by Equation C.32b for the PNL method.

$$
N_{1}=U *{ }_{p \infty o}\left(A_{b}+n_{f} A_{f}\right) /\left(C_{a} \dot{m}_{a}\right)
$$

where $\dot{m}_{a}$ is the flow rate of the air through the heat exchanger and the subscript 1 refers to the leading edge. In a similar manner, $\mathrm{N}_{2}$, the number of enthalpy transfer units based upon conditions at the trailing edge was computed from Equations C.34a and C.34b for the B\&W and for the PNL methods, respectively.

$$
\begin{aligned}
& N_{2}=\Sigma_{p \infty 22}\left(A_{b}+A_{f}\right) / \dot{m}_{a} \\
& N_{2}=U_{p \infty 02}^{*}\left(A_{b}+n_{f} A_{f}\right) /\left(C_{a 2} \dot{m}_{a}\right)
\end{aligned}
$$

The arithmetic mean of the number of enthalpy transfer units, based upon conditions at the leading and trailing edge, are taken (Equation C.35)

$$
\bar{N}=\left(N_{1}+N_{2}\right) / 2
$$

from which the heat exchanger effectivenss was computed from Equation C.31. The total heat transfer, $Q$, was computed from Equation C.30 and the water evaporation rate, $\dot{\mathrm{m}}_{v}$, from Equation C.36.

$$
\dot{m}_{v}=\dot{m}_{a}\left(H_{2}-H_{1}\right)
$$


where

$\dot{m}_{a}$ is the flow rate of the entering air

$\mathrm{H}_{1}$ is the absolute numidity of the entering air

$\mathrm{H}_{2}$ is the absolute humidity of the exiting air.

As mentioned under "Basics and Definitions" $\mathrm{H}_{1}$ can be computed from a knowledge of the atmospheric pressure, the dry-bulb temperature and either the relative humidity or the wet-bulb temperature of the entering air. The computation of $\mathrm{H}_{2}$ is a little more complicated. First, the enthalpy of the exiting air is computed from Equation C.37.

$$
i_{\infty 2}=i_{\infty 1}+\phi\left(i_{p}^{\prime}-i_{\infty 1}\right)
$$

Then from an assumed relative humidity of the exiting air (generally 100\%), the temperature and absolute humidity of the exiting air was computed from Equations C.1, C.2 and C.3 (and from the known vapor pressure-temperature relationship for water).

The computation of the performance of a deluged heat exchanger was iterative in nature because the value of $\mathrm{N}_{2}$, the number of transfer units at the trailing edge was dependent upon the conditions at the trailing edge. The convergence criterion was a change of less than a specified amount (generally $0.1 \%$ ) in both $Q$ and $\dot{\mathrm{m}}_{\mathrm{v}}$.

\section{NOMENCLATURE}

$$
\begin{aligned}
& A=\text { area, } \mathrm{ft}^{2} \\
& A_{b}=\text { area of the tubes between the fins, } \mathrm{ft}^{2} \\
& A_{f}=\text { surface area of the fins, } \mathrm{ft}^{2} \\
& A_{p}=\text { wetted surface area, primary side } \\
& A_{t}=\text { total air-side surface area, } \mathrm{ft}^{2} \\
& A_{w}=\text { average area of the tube wall, } \mathrm{ft}^{2} \\
& C_{a}=\text { specific heat of moist air, Btu/lb of dry air- }{ }^{\circ} \mathrm{F}
\end{aligned}
$$




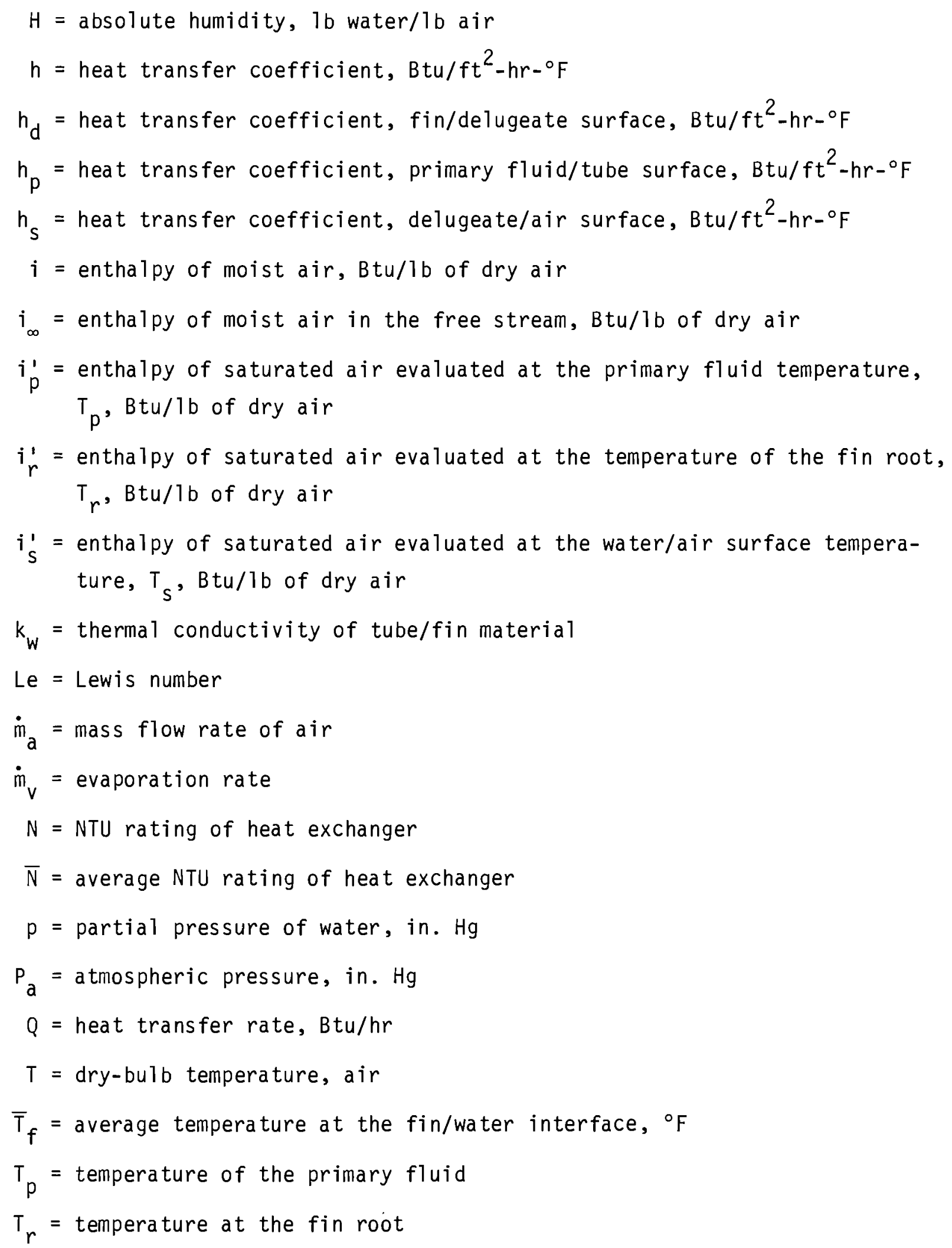




$$
\begin{aligned}
T_{S} & =\text { temperature at the air/water interface } \\
T_{\infty} & =\text { temperature of the free stream moist air } \\
t_{w} & =\text { tube wall thickness, ft } \\
U_{p r} & =\text { overall heat transfer coefficient between the tubeside fluid and the }
\end{aligned}
$$
fin root, Btu/ft ${ }^{2}-h r-{ }^{\circ} \mathrm{F}$

$U{ }_{p r}=$ overall enthalpy-based heat transfer coefficient between the tube-side fluid and the fin root, Btu/hr-ft ${ }^{2}{ }^{\circ} \mathrm{F}$

$U_{p s}=$ overall heat transfer coefficient between the tube-side fluid and the delugeate-air surface, Btu/ft ${ }^{2}-h r-{ }^{\circ} \mathrm{F}$

$U^{*}{ }_{p s}=$ enthalpy-based heat transfer coefficient between the tube-side fluid and the delugeate-air surface, lb of dry air/ft ${ }^{2}-h r$

$U{ }_{\text {poo }}=$ overall enthalpy-based heat transfer coefficient between the tube-side fluid and the bulk air, Btu/hr-ft ${ }^{2}{ }^{\circ} \mathrm{F}$

$U^{*}{ }_{r s}=$ overall enthalpy-based heat transfer coefficient between the fin root and the delugeate-air surface, Btu/hr-ft ${ }^{2}-{ }^{\circ} \mathrm{F}$

$U^{*}{ }_{\text {roo }}=$ overall enthalpy-based heat transfer coefficient between the fin root and the bulk air, Btu/hr-ft ${ }^{2}{ }^{\circ} \mathrm{F}$

$B_{f f}=$ fouling factor at the fin water surface, $B t u / h r-f t^{2}-{ }^{\circ} \mathrm{F}$

$B_{f p}=$ fouling factor on the tube side, $B t u / h r-f t^{2}-{ }^{\circ} F$

$\sigma_{s}=$ delugeate-air mass transfer coefficient, lb of dry air/ft ${ }^{2}-h r$

$\phi=$ heat exchanger effectiveness, dimensionless

$n_{f}=$ fin efficiency

$\Sigma_{p s}=$ overall mass transfer coefficient between the tube-side fluid and the delugeate-air interface, lb of dry air/ft ${ }^{2}-h r$

$\Sigma_{\text {poo }}=$ overall mass transfer coefficient between the tube-side fluid and the bulk air, lb of dry air/ft ${ }^{2}-h r$ 


\section{Superscripts}

()$^{*}=$ denotes transformed or wet parameter

$i^{\prime}=$ denotes saturated air enthalpy

Subscripts

$$
\begin{aligned}
& p=\text { primary fluid } \\
& s=\text { air/water interface } \\
& w=\text { tube/fin material property } \\
& 1=\text { inlet (leading edge) } \\
& 2=\text { outlet (trailing edge) } \\
& \infty=\text { free stream condition }
\end{aligned}
$$




\section{REFERENCES}

C.1. W. H. McAdams, Heat Transmission, 3rd Ed., McGraw-Hill Book Co., New York, NY, 1954.

C.2. W. M. Kays, and A. L. London, Compact Heat Exchangers. McGraw-Hi11 Book Co., New York, NY, 1964.

C.3. D. K. Kreid, B. M. Johnson and D. W. Faletti, Approximation Analysis of Heat Transfer from the Surface of a Wet Finned Heat Exchanger. PNL-SA-6422, Battel1e, Pacific Northwest Laboratories, Richland, WA 99352, February 1977. (Also to be presented at the Second AIAA/ASME Thermophysics and Heat Transfer Conference, Palo Alto, CA, May 24-26, 1978). 
APPENDIX D

METEOROLOGY METHODOLOGY 
APPENDIX D

METEOROLOGY METHODOLOGY

The meteorology of a particular site is characterized by a maximum temperature and a cumulative distribution of wet-bulb and dry-bulb temperatures. Eight sites were selected for this analysis: San Juan, NM; Miami, FL; Chicago, IL; San Francisco, CA; Washington DC; Boston, MA; Phoenix, AZ; and Bakersfield, CA. Wet-bulb and dry-bulb cumulative temperature curves for these eight sites are shown in Figures D.1 through D.8. The top curve in Figures $D .1$ through 0.8 represents the dry-bulb temperatures, and the bottom curve represents the wet-bulb temperatures. Figure $D .9$ is a dry-bulb temperature distribution for a 11 the sites and Figure 0.10 presents a cumulative graph of the wet-bulb temperature distributions. All temperature profiles were adjusted so that the cumulative hours below $30^{\circ} \mathrm{F}$ were included in the cumulative hours at $30^{\circ} \mathrm{F}$. This adjustment had no effect on the cooling system designs for these sites.

The BNW-II Dry/Wet Optimization Code requires the following information in order to accurately model the meteorology of a specific site.

- Dry-bulb cumulative temperature distribution

- Wet-bulb cumulative temperature distribution

- Turbine back pressure curve corresponding to the dry- and wet-bulb temperature distributions.

Three types of turbines were considered in this analysis. Each turbine has a distinct maximum turbine back pressure curve. High back pressure turbines can operate continuously at $15.0 \mathrm{in.} \mathrm{Hga.} \mathrm{Modified} \mathrm{conventional} \mathrm{turbines} \mathrm{have}$ a maximum continuous turbine back pressure of $8.0 \mathrm{in}$. Hga. Conventional turbines have a maximum continuous back pressure of $5.5 \mathrm{in}$. Hga; however, under certain circumstances operation above $5.5 \mathrm{in}$. Hga is allowed. Westinghouse Electric Company has developed guidelines for operation of their turbines above $5.5 \mathrm{in.} \mathrm{Hga.} \mathrm{An} \mathrm{excerpt} \mathrm{from} \mathrm{their} \mathrm{procedure} \mathrm{follows.}$ 


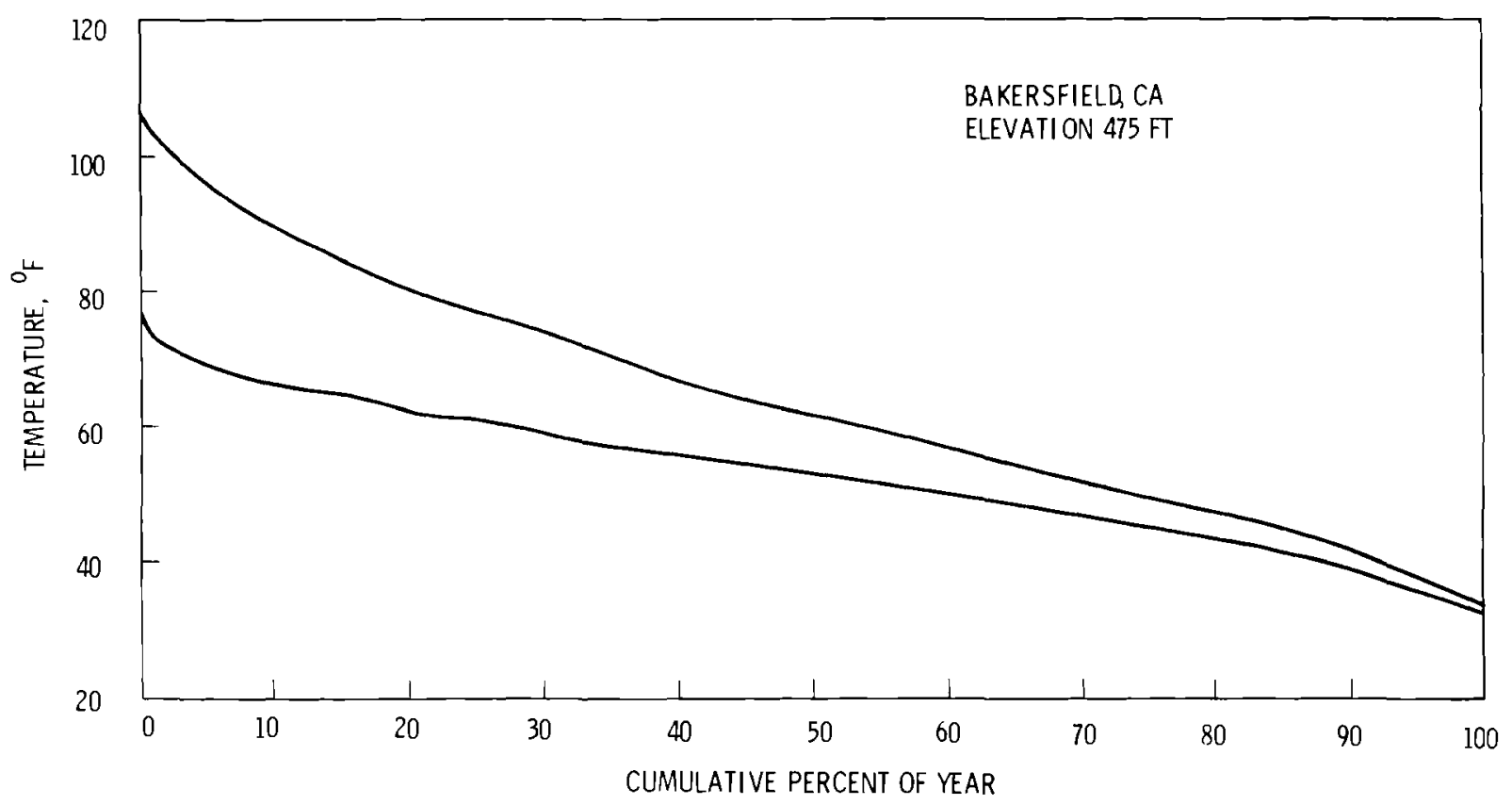

FIGURE D.1. Cumulative Dry-Bulb and Wet-Bulb Temperature Distribution Taken from an Eleven-Year Average for Bakersfield, CA

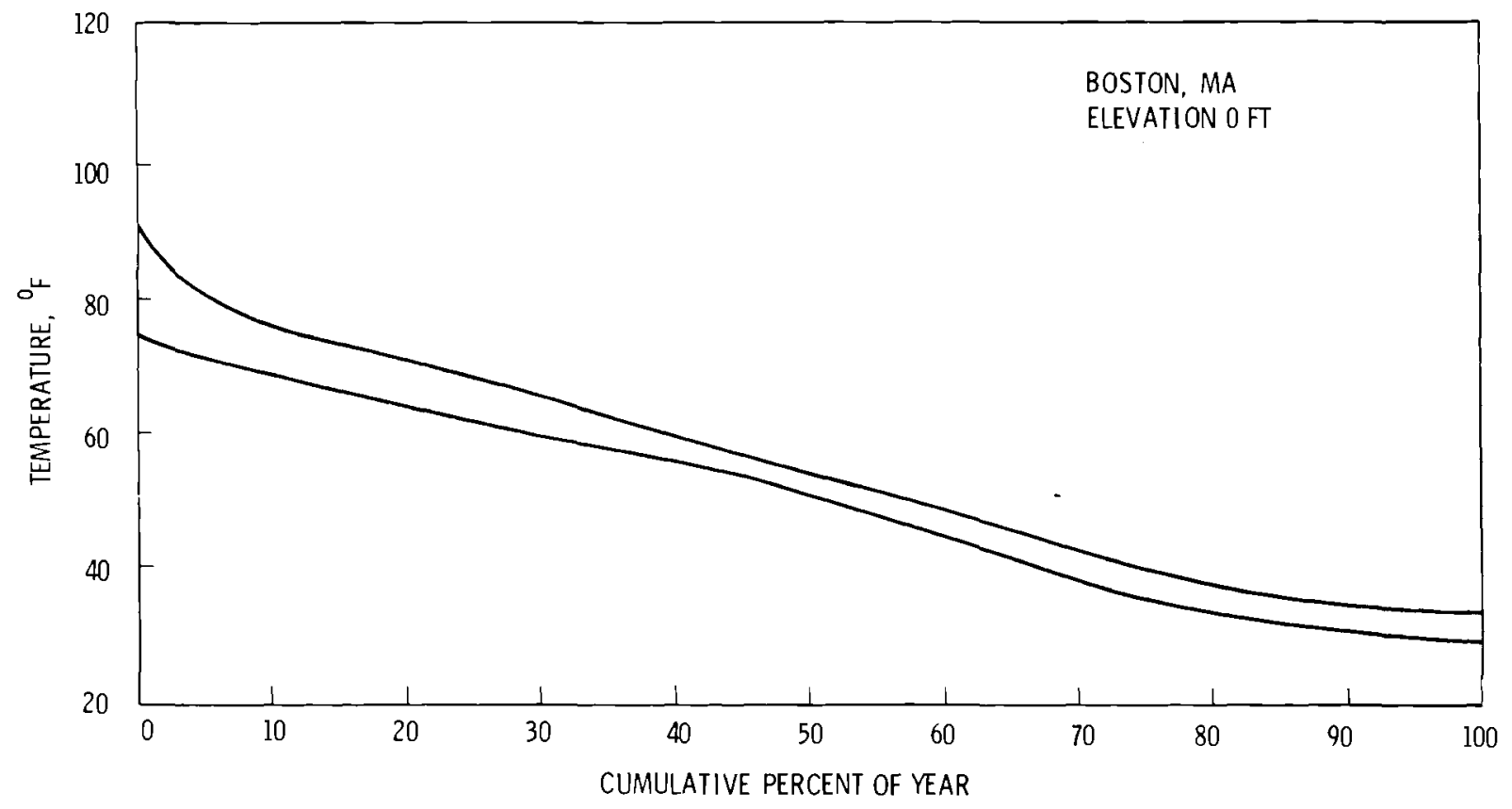

FIGURE D.2. Cumulative Dry-Bulb and Wet-Bulb Temperature Distribution Taken from a Twenty-Year Average for Boston, MA 




FIGURE D.3. Cumulative Dry-Bulb and Wet-Bulb Temperature Distribution Taken from a Nineteen-Year Average for Chicago, IL

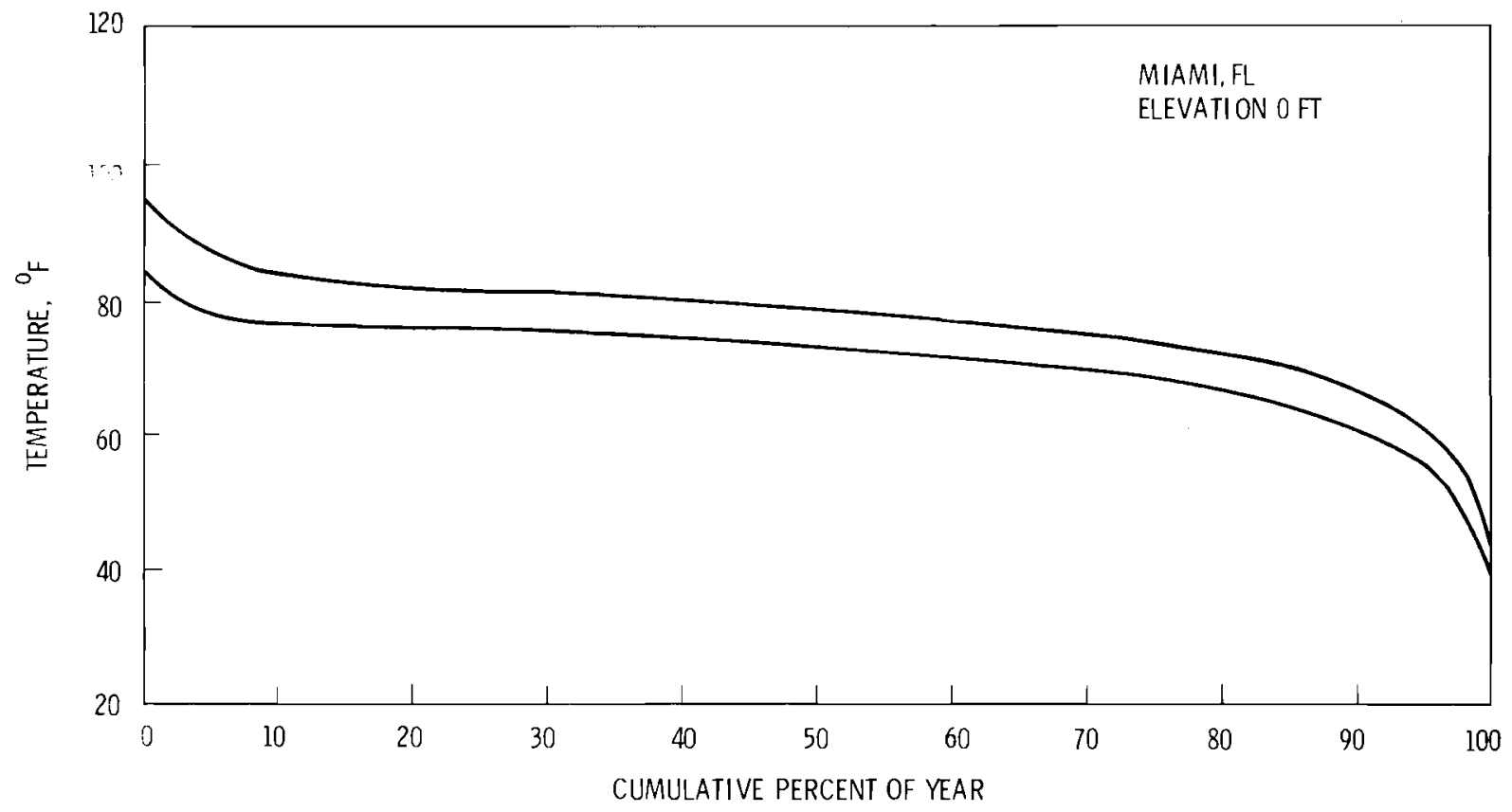

FIGURE D.4. Cumulative Dry-Bulb and Wet-Bulb Temperature Distribution Taken from a Twenty-Year Average for Miami, FL 




FIGURE D.5. Cumulative Dry-Bulb and Wet-Bulb Temperature Distribution Taken from a Twenty-Six Year Average for Phoenix, $A Z$

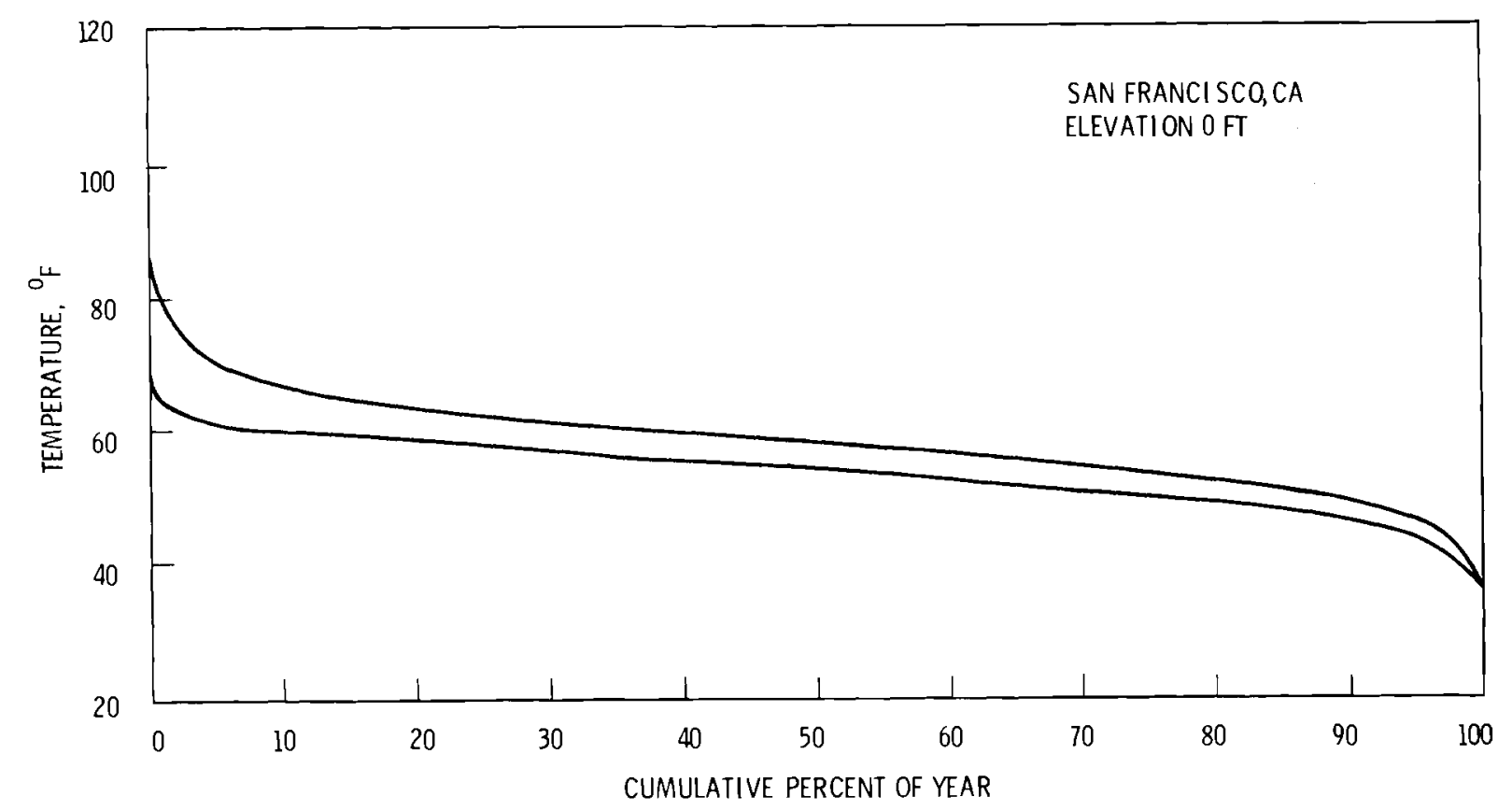

FIGURE D.6. Cumulative Dry-Bulb and Wet-Bulb Temperature Distribution Taken from a Seventeen-Year Average for San Francisco, CA 


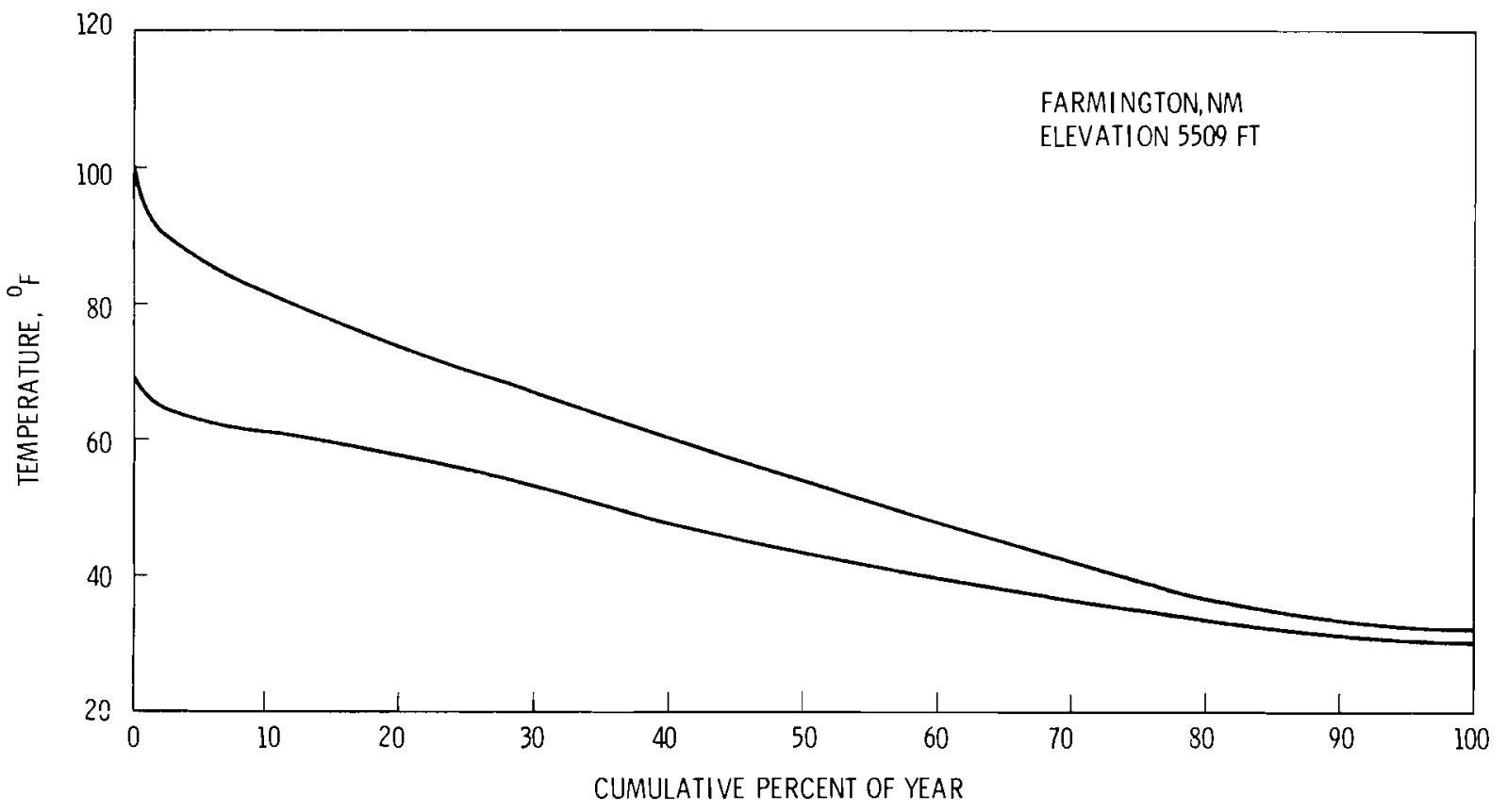

FIGURE D.7. Cumulative Dry-Bulb and Wet-Bulb Temperature Distribution Taken from a Five-Year Average for San Juan, NM

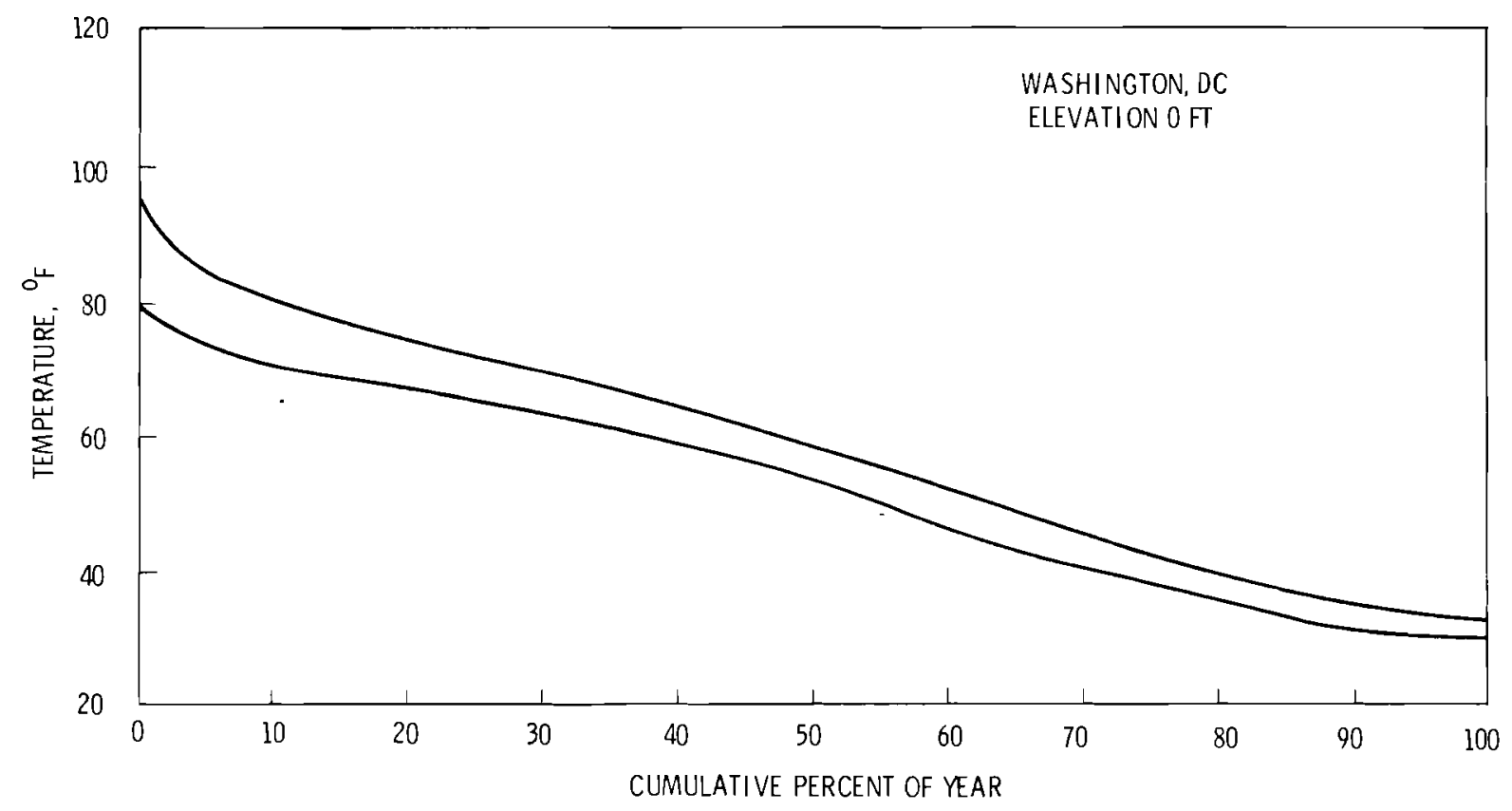

FIGURE D.8. Cumulative Dry-Bulb and Wet-Bulb Temperature Distribution Taken from a Thirty-Three-Year Average for Washington, DC

D. 5 


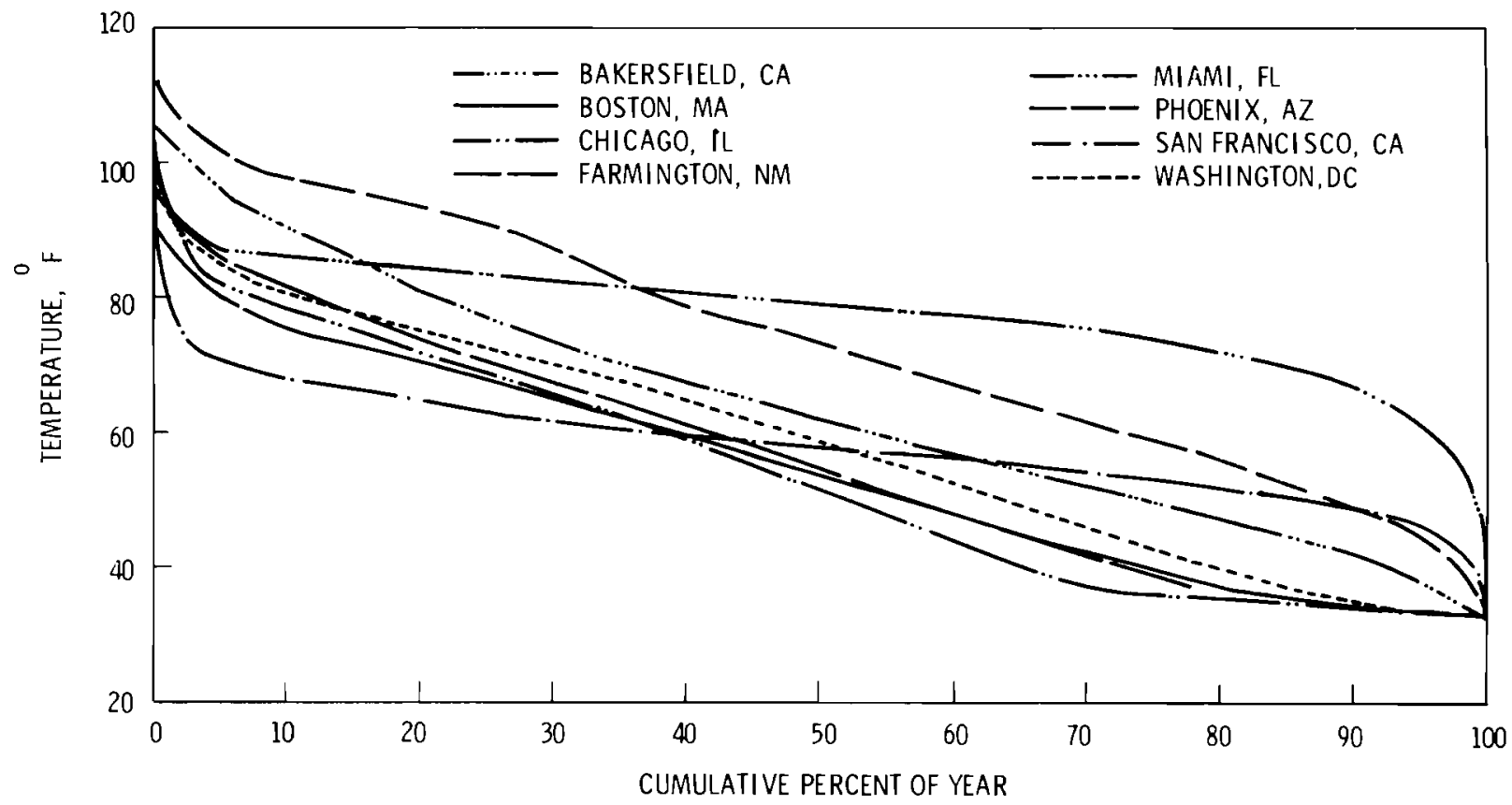

FIGURE D.9. Cumulative Comparison of Dry-Bulb Temperature Profiles for All Eight Meteorological Sites

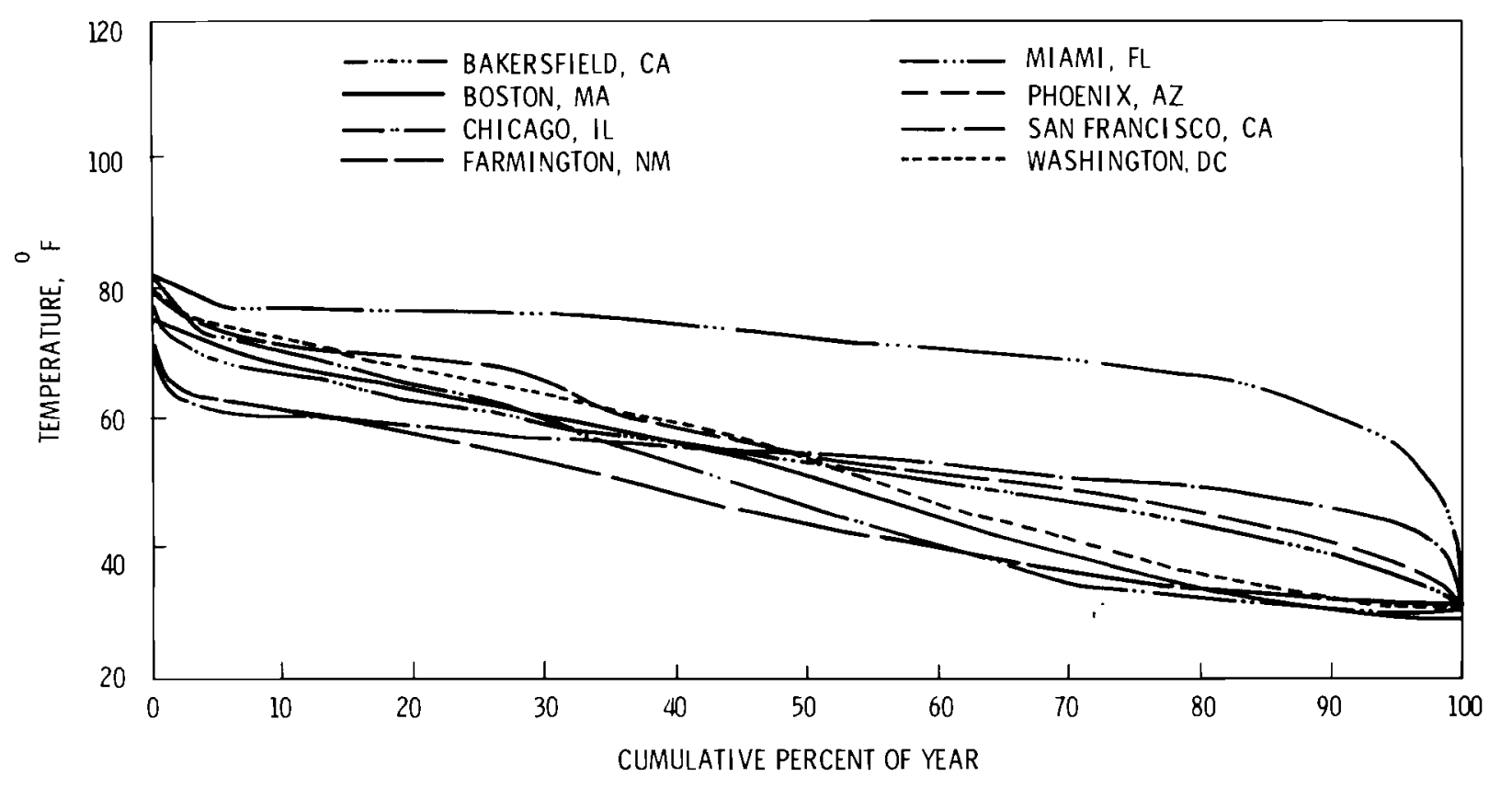

FIGURE D.10. Climulative Comparison of Wet-Bulb Temperature Profiles for All Eight Meteorological Sites 


\section{TURBINE OPERATION AT HIGH CONDENSER PRESSURES}

The turbine may be operated continuously over the load range with condenser pressures up to $5.5 \mathrm{In}$. Hg Abs. For short periods the turbine may be operated with condenser pressures up to $8 \mathrm{In}$. $\mathrm{Hg}$ Abs for a maximum of 72 days or part days in any 12 month period providing such operation is accomplished in accordance with the following guidelines and at loads equal to or greater than those specified in Figure D.11:

1) The turbine may be operated for 36 days or part days with condenser pressures between $5.5 \mathrm{In}$. $\mathrm{Hg}$ Abs and $8 \mathrm{In}$. $\mathrm{Hg} \mathrm{Abs}$;

2) The turbine may be operated for 19 additional days or part days with condenser pressures between $5.5 \mathrm{In}$. $\mathrm{Hg}$ Abs and 7 in. Hg Abs;

3) The turbine may be operated for 17 additional days or part days with condenser pressures between $5.5 \mathrm{In}$. $\mathrm{Hg}$. Abs and 6 In. Hg Abs;

4) Any excursion above $5.5 \mathrm{In}$. Hg Abs, whether for one hour or a full day, shall be considered as a full day in the summation of days;

5) When operating with high condenser pressure, avoid rapid and frequent changes to this pressure.

To use Figure $D .11$, enter at the selected condenser pressure, proceed horizontally to intersect the curve and then vertically downward to read the minimum allowable load (in percent of maximum calculated load) for operation at the selected condenser pressure. Operation below this minimum load at the selected condenser pressure is not permitted.

An example of a maximum turbine back pressure curve for a conventional turbine is shown in Figure D.12. The "steps" in Region 1 correspond to the Westinghouse turbine back pressure model. The conventional turbine will be used throughout the remainder of the meteorology development. Use of the conventional turbine represents the most complex turbine back pressure model. In this model the back pressure is varied from 5.5 to $8.0 \mathrm{in}$. $\mathrm{Hg}$ as the ambient dry-bulb temperature increases. The maximum turbine back pressure limits for the modified conventional turbine and the high back pressure turbine models are 8.0 and $15.0 \mathrm{in}$. $\mathrm{Hg}$, respectively, throughout the entire temperature range. 


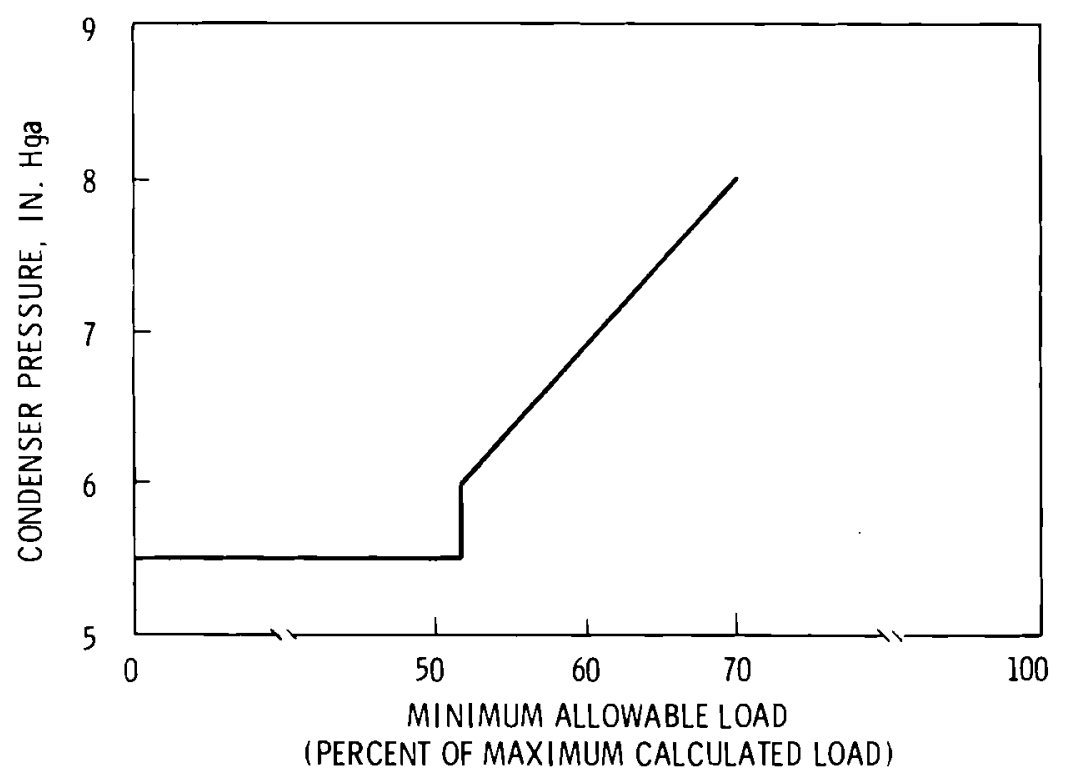

FIGURE D.11. Minimum Al lowable Load at Condenser Pressures Above 5.5 in. Hga

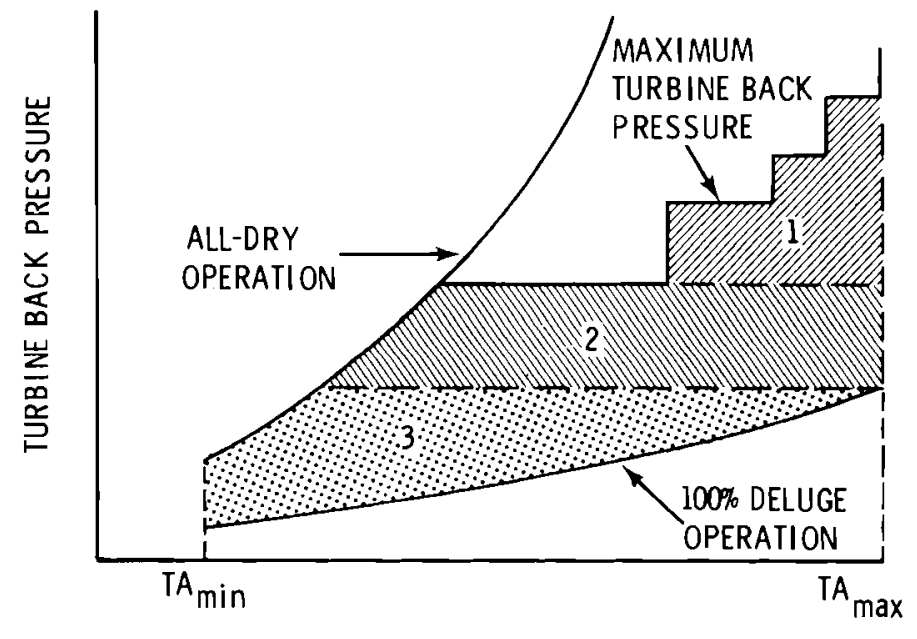

AMBIENT TEMPERATURE

FIGURE D.12. Operating Regimes for a Power Plant with a Deluged Cooling System 
The nature of the turbine back pressure model dictated the format of the input data for the BNW-II Dry/Wet Computer Code. The meteorological profile of each site was divided into 8 or 16 intervals. Each interval was represented by four points:

- average dry-bulb temperature

- corresponding average wet-bulb temperature

- residence time in the interval (expressed as fraction of the year)

- maximum allowable turbine back pressure.

Two types of meteorological data were necessary to complete the meteorological profile of each site in a manner compatible with the turbine back pressure data:

- summary of daily maximum ambient temperature, and

- cumulative summary of dry-bulb and wet-bulb temperatures and their frequency distribution.

These summaries were obtained from the National Climatic Center, Asheville, NC. A summary of the type of information received, the site locations and elevations are presented in Table D.1. When data were not available for a specific site, data from a site with similar meteorological conditions in close proximity to the actual site were obtained. For example, the National Climatic Center had no Summary of Meteorological Observations, Surface for the Bakersfield, CA site; therefore, data from Le Moore, CA was substitutued (see Table 0.1 ).

The local climatological data provided a daily record of maximum temperatures for the period of January through December 1976. This period was considered the reference interval for all the meteorological sites. This data in conjunction with the turbine back pressure data from Westinghouse Electric Company defined the ambient temperature boundaries for the turbine back pressure intervals above $5.5 \mathrm{in}$. $\mathrm{Hg}$.

The local climatological data was tabulated to determine the daily maximum temperature profiles of each site for one year. Table D.2 provides a cumulative summary of this data for the reference site, San Juan, NM. Using 
TABLE D.1. Meteorological Data for Each Site

\begin{tabular}{|c|c|c|}
\hline Site & Elevation, $\mathrm{ft}$ & $\begin{array}{l}\text { Local Climatological Data } \\
\text { January - December } 1976\end{array}$ \\
\hline Bakersfield, CA & 475 & Bakersfield, CA \\
\hline Boston, MA & 0 & Boston, MA \\
\hline Chicago, IL & 614 & Chicago, IL \\
\hline Miami, FL & 0 & Miami, FL \\
\hline Phoenix, $A Z$ & 1083 & Phoenix, $A Z$ \\
\hline San Francisco, CA & 0 & San Francisco, CA \\
\hline San Juan, NM & 5509 & Farmington, NM \\
\hline Washington, $D C$ & 0 & Washington, $D C$ \\
\hline
\end{tabular}

\begin{tabular}{lc}
\multicolumn{2}{c}{$\begin{array}{c}\text { Summary of Meteorological } \\
\text { Observations, Surface }\end{array}$} \\
\hline Le Moore, CA & $1961-1972$ \\
Boston, MA & $1945-1965$ \\
Chicago, IL & $1946-1965$ \\
Miami, FL & $1948-1970$ \\
Phoenix, AZ & $1941-1946$ \\
& $1951-1972$ \\
San Francisco, CA & $1948-1965$ \\
Farmington, NM & $1954-1959$ \\
Washington, DC & $1943-1967$
\end{tabular}


TABLE D.2. Summary of Daily Maximum Temperatures for San Juan, NM

\begin{tabular}{|c|c|c|c|c|c|}
\hline $\begin{array}{c}\text { Temperature, } \\
{ }^{\circ} \mathrm{F}\end{array}$ & $\begin{array}{l}\text { Number of } \\
\text { Occurrences }\end{array}$ & $\begin{array}{l}\text { Cumulative } \\
\text { Occurrences }\end{array}$ & $\begin{array}{c}\text { Temperature, } \\
{ }^{\circ} \mathrm{F}\end{array}$ & $\begin{array}{c}\text { Number of } \\
\text { Occurrences }\end{array}$ & $\begin{array}{l}\text { Cumulative } \\
\text { Occurrences }\end{array}$ \\
\hline 103 & 1 & 1 & 60 & 9 & 254 \\
\hline 102 & & & 59 & 6 & 260 \\
\hline 101 & 2 & 3 & 58 & 7 & 267 \\
\hline 100 & 2 & 5 & 57 & 5 & 272 \\
\hline 99 & 3 & 8 & 56 & 1 & 273 \\
\hline 98 & 3 & 11 & 55 & 9 & 282 \\
\hline 97 & 5 & 16 & 54 & 5 & 287 \\
\hline 96 & 4 & 20 & 53 & 10 & 297 \\
\hline 95 & 7 & 27 & 52 & 2 & 299 \\
\hline 94 & 6 & 33 & 51 & 8 & 307 \\
\hline 93 & 9 & 42 & 50 & 10 & 317 \\
\hline 92 & 6 & 48 & 49 & 3 & 320 \\
\hline 97 & 11 & 59 & 48 & 8 & 328 \\
\hline 90 & 10 & 69 & 47 & 4 & 332 \\
\hline 89 & 6 & 75 & 46 & 4 & 336 \\
\hline 88 & 11 & 86 & 45 & 6 & 342 \\
\hline 87 & 6 & 92 & 44 & 6 & 348 \\
\hline 86 & 5 & 97 & 43 & 1 & 349 \\
\hline 85 & 13 & 110 & 42 & 2 & 351 \\
\hline 84 & 4 & 114 & 41 & & \\
\hline 83 & 5 & 119 & 40 & & \\
\hline 82 & $5^{\circ}$ & 124 & 39 & 1 & 352 \\
\hline 81 & 3 & 127 & 38 & 2 & 354 \\
\hline 80 & 9 & 136 & 37 & 1 & 355 \\
\hline 79 & 3 & 139 & 36 & 3 & 358 \\
\hline 78 & 5 & 144 & 35 & 1 & 359 \\
\hline 77 & 5 & 149 & 34 & & \\
\hline 76 & 5 & 154 & 33 & & \\
\hline 75 & 9 & 163 & 32 & 1 & 360 \\
\hline 74 & 7 & 170 & 31 & 1 & 361 \\
\hline 73 & 3 & 173 & 30 & & \\
\hline 72 & 7 & 180 & 29 & 1 & 362 \\
\hline 71 & 6 & 186 & 28 & & \\
\hline 70 & 5 & 191 & 27 & 1 & 363 \\
\hline 69 & 4 & 195 & 26 & & \\
\hline 68 & 2 & 197 & 25 & & \\
\hline 67 & 4 & 201 & 24 & 1 & 364 \\
\hline 66 & 12 & 213 & 23 & & \\
\hline 65 & 9 & 222 & 22 & 1 & 365 \\
\hline 64 & 2 & 224 & 21 & & \\
\hline 63 & 6 & 230 & & & \\
\hline 62 & 5 & 235 & & & \\
\hline 61 & 10 & 245 & & & \\
\hline
\end{tabular}


this profile and the turbine information from Westinghouse, the 36 highest temperature days were allowed to reach a maximum turbine back pressure of $8.0 \mathrm{in} . \mathrm{Hg}$. For the San Juan site this temperature interval ranged from 94 to $103^{\circ} \mathrm{F}$ and included 33 temperature occurrences. $94^{\circ} \mathrm{F}$ was chosen as the lower limit of the interval because the number of occurrences at this point (33) was still within the limit of 36 allowed occurrences. Because this temperature range was so large these data were separated into two temperature intervals. The 19 next highest temperatures (days 37 through 55) were allowed maximum turbine back pressures of $7.0 \mathrm{in}$. Hg. This interval ranged from 92 to $93^{\circ} \mathrm{F}$ and included up to the 48 th temperature occurrence. Days 56 through 72 were allowed maximum turbine back pressures of $6.0 \mathrm{in}$. Hg. This corresponded to the temperature interval from 90 to $91^{\circ} \mathrm{F}$. For the remainder of the year (days 73 through 365) the back pressure limit was $5.5 \mathrm{in}$. $\mathrm{Hg}$. For the modified conventional turbine and the high back pressure turbine the maximum turbine back pressures would remain constant at 8.0 and $15.0 \mathrm{in}$. $\mathrm{Hg}$, respectively throughout the temperature range.

The turbine back pressure range above $5.5 \mathrm{in}$. Hg was composed of four intervals, one each for 6.0 and $7.0 \mathrm{in}$. $\mathrm{Hg}$ and two for $8.0 \mathrm{in}$. $\mathrm{Hg}$. The $8.0 \mathrm{in}$. $\mathrm{Hg}$ range was divided into two intervals because the 36 highest temperature days usually spanned 10 to 20 degrees. This data defined the turbine back pressure curve and the first four dry-bulb temperature intervals, 90 through $101^{\circ} \mathrm{F}$, 1 isted in Table 0.3 . The remainder of the temperature range was divided equally into 4 or 12 intervals to make a total of 8 or 16 intervals.

The wet-bulb temperatures and the residence time in each interval was determined from the Summary of Meteorological Observations, Surface. The summary presented cumulative dry-bulb and wet-bulb temperature data. An excerpt from the table description follows.

\section{PART E - PSYCHROMETRIC SUMMARIES}

In this section are presented various summaries of dry- and wetbulb temperatures, dew points, and relative humidity. The order and manner of presentation follows: 
TABLE D.3. Meteorological Data for San Juan, NM,
8 and 16 Temperature Intervals

\begin{tabular}{|c|c|c|c|c|c|}
\hline & $\mathrm{Tdb},{ }^{\circ} \mathrm{F}$ & Twb, ${ }^{\circ} \mathrm{F}$ & $\begin{array}{c}\text { Tdb Range, } \\
{ }^{\circ} \mathrm{F} \\
\end{array}$ & Fraction & $\begin{array}{c}\text { Maximum Turbine } \\
\text { Back Pressure, } \\
\text { in. Hga } \\
\end{array}$ \\
\hline \multirow{16}{*}{16 Intervals } & 101 & 71 & $99-103$ & 0.0022 & 8 \\
\hline & 96 & 67 & $94-98$ & 0.0049 & 8 \\
\hline & 92 & 66 & $92-93$ & 0.0059 & 7 \\
\hline & 90 & 65 & $90-91$ & 0.0099 & 6 \\
\hline & 87 & 63 & $85-89$ & 0.0379 & 5.5 \\
\hline & 82 & 61 & $80-84$ & 0.0459 & 5.5 \\
\hline & 77 & 59 & $75-79$ & 0.0501 & 5.5 \\
\hline & 72 & 56 & $70-74$ & 0.0673 & 5.5 \\
\hline & 67 & 53 & $65-69$ & 0.0783 & 5.5 \\
\hline & 62 & 49 & $60-64$ & 0.0811 & 5.5 \\
\hline & 57 & 45 & $55-59$ & 0.0744 & 5.5 \\
\hline & 52 & 42 & $50-54$ & 0.0742 & 5.5 \\
\hline & 47 & 39 & $45-49$ & 0.0784 & 5.5 \\
\hline & 42 & 36 & $40-44$ & 0.0812 & 5.5 \\
\hline & 37 & 34 & $35-39$ & 0.0810 & 5.5 \\
\hline & 33 & 31 & $10 w-34$ & 0.2233 & 5.5 \\
\hline \multirow[t]{8}{*}{8 Intervals } & 101 & 71 & $99-103$ & 0.0022 & 8 \\
\hline & 96 & 67 & $94-98$ & 0.0049 & 8 \\
\hline & 92 & 66 & $92-93$ & 0.0059 & 7 \\
\hline & 90 & 65 & $90-91$ & 0.0099 & 6 \\
\hline & 82 & 61 & $75-89$ & 0.1399 & 5.5 \\
\hline & 67 & 53 & $60-74$ & 0.2268 & 5.5 \\
\hline & 52 & 42 & $45-59$ & 0.2270 & 5.5 \\
\hline & 35 & 32 & $10 w-44$ & 0.3854 & 5.5 \\
\hline
\end{tabular}


3. Bivariate percentage frequency distribution and computations of dry-bulb versus wet-bulb temperature.

This tabulation is derived from hourly observations and is presented by month and annual, all hours and all years combined. The following information is provided:

a. The main body of the summary consists of a bivariate percentage frequency distribution of wet-bulb depression in 17 classes spread horizontally; by 2-degree intervals of dry-bulb temperature vertically. Also provided for each dry-bulb temperature interval is the percentage of observations with dry-bulb and wet-bulb temperature combined; and again for dry-bulb, wet-bulb, and dew-point temperatures separately. Total observations for these four items is also provided in two lines at end of each tabulation table, which may require two pages in some cases.

The average sampling period for the psychrometric summaries was 20 years. The psychrometric summary provided the percentage of temperature observations occurring within each temperature interval. It also provided the wet-bulb temperature corresponding to the same cumulative percentage as the average dry-bulb temperature for each interval.

The following rationale was used to determine the residence time in each of the back pressure regions of the maximum turbine back pressure curve for the conventional turbine. These data were taken from the statistical summaries obtained from the National Climatic Center for each site (see Table D.1). The residence time was determined from the actual meteorological data. For example, from Table 0.3 the fraction of the year at $8.0 \mathrm{in}$. $\mathrm{Hg}$ is 0.0071 . This is equivalent to 2.6 days or 62 hours. This means that during the plant design the turbine back pressure drops from $8.0 \mathrm{in}$. Hg to $7.0 \mathrm{in}$. Hg after 62 hours of operation. It drops to $6.0 \mathrm{Hg}$ after 114 hours of operation and drops to $5.5 \mathrm{in}$. Hg after 200 hours of operation. The amount of time spent in each back pressure region is site specific. This can be noted by comparing the fraction columns in Tables 0.3 through 0.10 . 
TABLE D.4. Meteorological Data for Bakersfield, CA, 8 and 16 Temperature Intervals

\begin{tabular}{|c|c|c|c|c|c|}
\hline & $\mathrm{Tdb},{ }^{\circ} \mathrm{F}$ & Twb, ${ }^{\circ} \mathrm{F}$ & $\begin{array}{c}\text { Tdb Range, } \\
{ }^{\circ} \mathrm{F} \\
\end{array}$ & Fraction & $\begin{array}{c}\text { Maximum Turbine } \\
\text { Back Pressure, } \\
\text { in. Hga }\end{array}$ \\
\hline \multirow[t]{16}{*}{16 Intervals } & 109 & 77 & $107-114$ & 0.0012 & 8 \\
\hline & 104 & 73 & $100-106$ & 0.0176 & 8 \\
\hline & 98 & 70 & $97-99$ & 0.0166 & 7 \\
\hline & 94 & 68 & $93-96$ & 0.0261 & 6 \\
\hline & 88 & 66 & $85-92$ & 0.0678 & 5.5 \\
\hline & 82 & 63 & $80-84$ & 0.0570 & 5.5 \\
\hline & 77 & 61 & $75-79$ & 0.0645 & 5.5 \\
\hline & 72 & 58 & $70-74$ & 0.0728 & 5.5 \\
\hline & 67 & 56 & $65-69$ & 0.0822 & 5.5 \\
\hline & 62 & 53 & $60-64$ & 0.0910 & 5.5 \\
\hline & 57 & 50 & $55-59$ & 0.1033 & 5.5 \\
\hline & 52 & 47 & $50-54$ & 0.1114 & 5.5 \\
\hline & 47 & 43 & $45-49$ & 0.1021 & 5.5 \\
\hline & 42 & 39 & $40-44$ & 0.0836 & 5.5 \\
\hline & 37 & 35 & $35-39$ & 0.0611 & 5.5 \\
\hline & 33 & 31 & $10 w-34$ & 0.0417 & 5.5 \\
\hline \multirow[t]{8}{*}{8 Intervals } & 109 & 77 & $107-114$ & 0.0012 & 8 \\
\hline & 104 & 73 & $100-106$ & 0.0176 & 8 \\
\hline & 98 & 70 & $97-99$ & 0.0166 & 7 \\
\hline & 94 & 68 & $93-96$ & 0.0261 & 6 \\
\hline & 85 & 64 & $75-92$ & 0.1893 & 5.5 \\
\hline & 67 & 56 & $60-74$ & 0.2460 & 5.5 \\
\hline & 52 & 47 & $45-59$ & 0.3168 & 5.5 \\
\hline & 35 & 32 & $10 w-44$ & 0.1864 & 5.5 \\
\hline
\end{tabular}


TABLE D.5. Meteorological Data for Boston, MA, 8 and 14 Temperature Intervals

\begin{tabular}{|c|c|c|c|c|c|}
\hline & $\underline{T d b},{ }^{\circ} \mathrm{F}$ & Twb, ${ }^{\circ} \mathrm{F}$ & $\begin{array}{c}\text { Tdb Range, } \\
{ }^{\circ} \mathrm{F} \\
\end{array}$ & Fraction & $\begin{array}{c}\text { Maximum Turbine } \\
\text { Back Pressure, } \\
\text { in. Hga } \\
\end{array}$ \\
\hline \multirow[t]{14}{*}{14 Intervals } & 95 & 78 & $93-100$ & 0.0023 & 8 \\
\hline & 89 & 74 & $86-92$ & 0.0130 & 8 \\
\hline & 84 & 72 & $83-85$ & 0.0125 & 7 \\
\hline & 80 & 70 & $79-82$ & 0.0251 & 6 \\
\hline & 76 & 68 & $75-78$ & 0.0406 & 5.5 \\
\hline & 72 & 65 & $70-74$ & 0.0768 & 5.5 \\
\hline & 67 & 61 & $65-69$ & 0.0949 & 5.5 \\
\hline & 62 & 57 & $60-64$ & 0.0923 & 5.5 \\
\hline & 57 & 53 & $55-59$ & 0.0892 & 5.5 \\
\hline & 52 & 49 & $50-54$ & 0.0851 & 5.5 \\
\hline & 47 & 43 & $45-49$ & 0.0890 & 5.5 \\
\hline & 42 & 38 & $40-44$ & 0.0906 & 5.5 \\
\hline & 37 & 33 & $35-39$ & 0.0939 & 5.5 \\
\hline & 33 & 29 & low-34 & 0.1947 & 5.5 \\
\hline \multirow[t]{8}{*}{8 Intervals } & 95 & 78 & $93-100$ & 0.0023 & 8 \\
\hline & 89 & 74 & $86-92$ & 0.0130 & 8 \\
\hline & 84 & 72 & $83-85$ & 0.0125 & 7 \\
\hline & 80 & 70 & $79-82$ & 0.0251 & 6 \\
\hline & 75 & 67 & $71-78$ & 0.0992 & 5.5 \\
\hline & 67 & 61 & $60-70$ & 0.2055 & 5.5 \\
\hline & 52 & 49 & $45-59$ & 0.2633 & 5.5 \\
\hline & 35 & 32 & 10w-44 & 0.3791 & 5.5 \\
\hline
\end{tabular}

D.16 
TABLE D.6. Meteorological Data for Chicago, IL, 8 and 14 Temperature Intervals

\begin{tabular}{|c|c|c|c|c|c|}
\hline & $\mathrm{Tdb},{ }^{\circ} \mathrm{F}$ & Twb, ${ }^{\circ} \mathrm{F}$ & $\begin{array}{c}\mathrm{Tdb} \text { Range, } \\
{ }^{\circ} \mathrm{F}\end{array}$ & Fraction & $\begin{array}{c}\text { Maximum Turbine } \\
\text { Back Pressure, } \\
\text { in. Hga } \\
\end{array}$ \\
\hline \multirow[t]{14}{*}{14 Intervals } & 98 & 81 & $95-102$ & 0.0011 & 8 \\
\hline & 90 & 77 & $86-94$ & 0.0208 & 8 \\
\hline & 84 & 73 & $84-85$ & 0.0110 & 7 \\
\hline & 82 & 72 & $81-83$ & 0.0207 & 6 \\
\hline & 77 & 69 & $75-80$ & 0.0640 & 5.5 \\
\hline & 72 & 65 & $70-74$ & 0.0734 & 5.5 \\
\hline & 67 & 61 & $65-69$ & 0.0842 & 5.5 \\
\hline & 62 & 56 & $60-64$ & 0.0759 & 5.5 \\
\hline & 57 & 51 & $55-59$ & 0.0714 & 5.5 \\
\hline & 52 & 47 & $50-54$ & 0.0664 & 5.5 \\
\hline & 47 & 43 & $45-49$ & 0.0672 & 5.5 \\
\hline & 42 & 39 & $40-44$ & 0.0662 & 5.5 \\
\hline & 37 & 34 & $35-39$ & 0.0846 & 5.5 \\
\hline & 33 & 31 & 10w-34 & 0.2931 & 5.5 \\
\hline \multirow[t]{8}{*}{8 Intervals } & 98 & 81 & $95-102$ & 0.0011 & 8 \\
\hline & 90 & 77 & $86-94$ & 0.0208 & 8 \\
\hline & 84 & 73 & $84-85$ & 0.0110 & 7 \\
\hline & 82 & 72 & $81-83$ & 0.0207 & 6 \\
\hline & 75 & 67 & $70-80$ & 0.1374 & 5.5 \\
\hline & 67 & 61 & $60-69$ & 0.1600 & 5.5 \\
\hline & 52 & 47 & $45-59$ & 0.2051 & 5.5 \\
\hline & 35 & 33 & $10 w-44$ & 0.4439 & 5.5 \\
\hline
\end{tabular}


TABLE D.7. Meteorological Data for Miami, FL, 8 and 15 Temperature Intervals

\begin{tabular}{|c|c|c|c|c|c|}
\hline & $\underline{T d b},{ }^{\circ} \mathrm{F}$ & Twb, ${ }^{\circ} \mathrm{F}$ & $\begin{array}{c}\text { Tdb Range, } \\
{ }^{\circ} \mathrm{F} \\
\end{array}$ & Fraction & $\begin{array}{c}\text { Maximum Turbine } \\
\text { Back Pressure, } \\
\text { in. Hga }\end{array}$ \\
\hline \multirow[t]{15}{*}{15 Intervals } & 96 & 82 & $94-98$ & 0.0005 & 8 \\
\hline & 91 & 80 & $89-93$ & 0.0230 & 8 \\
\hline & 88 & 78 & 88 & 0.0191 & 7 \\
\hline & 87 & 71 & 87 & 0.0191 & 6 \\
\hline & 82 & 76 & $80-86$ & 0.2542 & 5.5 \\
\hline & 77 & 71 & $75-79$ & 0.2841 & 5.5 \\
\hline & 72 & 67 & $70-74$ & 0.1962 & 5.5 \\
\hline & 67 & 61 & $65-69$ & 0.0960 & 5.5 \\
\hline & 62 & 57 & $60-64$ & 0.0500 & 5.5 \\
\hline & 57 & 51 & $55-59$ & 0.0310 & 5.5 \\
\hline & 52 & 47 & $50-54$ & 0.0159 & 5.5 \\
\hline & 47 & 42 & $45-49$ & 0.0075 & 5.5 \\
\hline & 42 & 37 & $40-44$ & 0.0028 & 5.5 \\
\hline & 37 & 33 & $35-39$ & 0.0006 & 5.5 \\
\hline & 33 & 31 & $10 w-34$ & 0.0000 & 5.5 \\
\hline \multirow[t]{8}{*}{8 Intervals } & 96 & 82 & $94-98$ & 0.0005 & 8 \\
\hline & 91 & 80 & $89-93$ & 0.0230 & 8 \\
\hline & 88 & 78 & 88 & 0.0191 & 7 \\
\hline & 87 & 77 & 87 & 0.0191 & 6 \\
\hline & 82 & 76 & $75-86$ & 0.5382 & 5.5 \\
\hline & 67 & 61 & $60-74$ & 0.3422 & 5.5 \\
\hline & 52 & 47 & $45-59$ & 0.0543 & 5.5 \\
\hline & 35 & 33 & $10 w-44$ & 0.0036 & 5.5 \\
\hline
\end{tabular}


TABLE D.8. Meteorological Data for Phoenix, AZ, 8 and 16 Temperature Intervals

\begin{tabular}{|c|c|c|c|c|c|}
\hline & $\mathrm{Tdb},{ }^{\circ} \mathrm{F}$ & Twb, ${ }^{\circ} \mathrm{F}$ & $\begin{array}{c}\text { Tdb Range, } \\
{ }^{\circ} \mathrm{F} \\
\end{array}$ & Fraction & $\begin{array}{c}\text { Maximum Turbine } \\
\text { Back Pressure, } \\
\text { in. Hga } \\
\end{array}$ \\
\hline \multirow{16}{*}{16 Intervals } & 112 & 79 & $109-118$ & 0.0054 & 8 \\
\hline & 106 & 76 & $105-108$ & 0.0163 & 8 \\
\hline & 103 & 74 & $102-104$ & 0.0216 & 7 \\
\hline & 100 & 73 & $100-101$ & 0.0178 & 6 \\
\hline & 90 & 68 & $85-99$ & 0.2060 & 5.5 \\
\hline & 82 & 61 & $80-84$ & 0.0859 & 5.5 \\
\hline & 77 & 57 & $75-79$ & 0.0863 & 5.5 \\
\hline & 72 & 53 & $70-74$ & 0.0818 & 5.5 \\
\hline & 67 & 51 & $65-69$ & 0.0858 & 5.5 \\
\hline & 62 & 49 & $60-64$ & 0.0853 & 5.5 \\
\hline & 57 & 46 & $55-59$ & 0.0884 & 5.5 \\
\hline & 52 & 43 & $50-54$ & 0.0791 & 5.5 \\
\hline & 47 & 39 & $45-49$ & 0.0675 & 5.5 \\
\hline & 42 & 35 & $40-44$ & 0.0442 & 5.5 \\
\hline & 37 & 33 & $35-39$ & 0.0220 & 5.5 \\
\hline & 33 & 31 & low-34 & 0.0066 & 5.5 \\
\hline \multirow[t]{8}{*}{8 Intervals } & 112 & 79 & $109-118$ & 0.0054 & 8 \\
\hline & 106 & 76 & $105-108$ & 0.0163 & 8 \\
\hline & 103 & 74 & $102-104$ & 0.0216 & 7 \\
\hline & 100 & 73 & $100-101$ & 0.0178 & 6 \\
\hline & 88 & 65 & $75-99$ & 0.3782 & 5.5 \\
\hline & 67 & 51 & $60-74$ & 0.2529 & 5.5 \\
\hline & 52 & 43 & $45-59$ & 0.2350 & 5.5 \\
\hline & 35 & 32 & $10 w-44$ & 0.0728 & 5.5 \\
\hline
\end{tabular}


TABLE D.9. Meteorological Data for San Francisco, CA, 8 and 13 Temperature Intervals

\begin{tabular}{|c|c|c|c|c|c|}
\hline & $\mathrm{Tdb},{ }^{\circ} \mathrm{F}$ & Twb, ${ }^{\circ} \mathrm{F}$ & $\begin{array}{c}\mathrm{Tdb} \text { Range, } \\
{ }^{\circ} \mathrm{F} \\
\end{array}$ & Fraction & $\begin{array}{c}\text { Maximum Turbine } \\
\text { Back Pressure, } \\
\text { in. Hga }\end{array}$ \\
\hline \multirow[t]{13}{*}{13 Intervals } & 93 & 70 & $90-104$ & 0.0006 & 8 \\
\hline & 86 & 67 & $83-89$ & 0.0030 & 8 \\
\hline & 79 & 65 & $76-82$ & 0.0108 & 8 \\
\hline & 74 & 63 & $74-75$ & 0.0066 & 7 \\
\hline & 72 & 62 & $72-73$ & 0.0101 & 6 \\
\hline & 67 & 60 & $65-71$ & 0.0879 & 5.5 \\
\hline & 62 & 57 & $60-64$ & 0.1434 & 5.5 \\
\hline & 57 & 54 & $56-59$ & 0.2606 & 5.5 \\
\hline & 52 & 49 & $50-54$ & 0.2665 & 5.5 \\
\hline & 47 & 44 & $45-49$ & 0.1400 & 5.5 \\
\hline & 42 & 40 & $40-44$ & 0.0537 & 5.5 \\
\hline & 37 & 35 & $35-39$ & 0.0143 & 5.5 \\
\hline & 33 & 31 & $10 w-34$ & 0.0025 & 5.5 \\
\hline \multirow[t]{8}{*}{8 Intervals } & 93 & 70 & $90-104$ & 0.0006 & 8 \\
\hline & 86 & 67 & $83-89$ & 0.0030 & 8 \\
\hline & 79 & 65 & $76-82$ & 0.0108 & 8 \\
\hline & 74 & 63 & $74-75$ & 0.0066 & 7 \\
\hline & 72 & 62 & $72-73$ & 0.0101 & 6 \\
\hline & 67 & 60 & $60-71$ & 0.2313 & 5.5 \\
\hline & 52 & 49 & $45-59$ & 0.6671 & 5.5 \\
\hline & 35 & 33 & $10 w-44$ & 0.0705 & 5.5 \\
\hline
\end{tabular}


TABLE D.10. Meteorological Data for Washington, DC, 8 and 16 Temperature Intervals

\begin{tabular}{|c|c|c|c|c|c|}
\hline & $\mathrm{Tdb},{ }^{\circ} \mathrm{F}$ & Twb, ${ }^{\circ} \mathrm{F}$ & $\begin{array}{c}\text { Tdb Range, } \\
{ }^{\circ} \mathrm{F} \\
\end{array}$ & Fraction & $\begin{array}{c}\text { Maximum Turbine } \\
\text { Back Pressure, } \\
\text { in. Hga } \\
\end{array}$ \\
\hline \multirow{16}{*}{16 Intervals } & 95 & 80 & $93-96$ & 0.0037 & 8 \\
\hline & 91 & 78 & $90-92$ & 0.0086 & 8 \\
\hline & 88 & 76 & $88-89$ & 0.0090 & 7 \\
\hline & 86 & 75 & $86-87$ & 0.0125 & 6 \\
\hline & 84 & 74 & $82-85$ & 0.0245 & 5.5 \\
\hline & 80 & 72 & $79-81$ & 0.0567 & 5.5 \\
\hline & 76 & 69 & $75-78$ & 0.0465 & 5.5 \\
\hline & 72 & 65 & $70-74$ & 0.1007 & 5.5 \\
\hline & 67 & 61 & $65-69$ & 0.1001 & 5.5 \\
\hline & 62 & 57 & $60-64$ & 0.0861 & 5.5 \\
\hline & 57 & 51 & $55-59$ & 0.0847 & 5.5 \\
\hline & 52 & 46 & $50-54$ & 0.0767 & 5.5 \\
\hline & 47 & 42 & $45-49$ & 0.0792 & 5.5 \\
\hline & 42 & 37 & $40-44$ & 0.0812 & 5.5 \\
\hline & 37 & 33 & $35-39$ & 0.0842 & 5.5 \\
\hline & 33 & 30 & $10 w-34$ & 0.1456 & 5.5 \\
\hline \multirow[t]{8}{*}{8 Intervals } & 95 & 80 & $93-96$ & 0.0037 & 8 \\
\hline & 91 & 78 & $90-92$ & 0.0086 & 8 \\
\hline & 88 & 76 & $88-89$ & 0.0090 & 7 \\
\hline & 86 & 75 & $86-87$ & 0.0125 & 6 \\
\hline & 82 & 73 & $75-85$ & 0.1277 & 5.5 \\
\hline & 67 & 61 & $60-74$ & 0.2869 & 5.5 \\
\hline & 52 & 46 & $45-59$ & 0.2406 & 5.5 \\
\hline & 35 & 31 & $10 w-44$ & 0.3110 & 5.5 \\
\hline
\end{tabular}


According to the turbine specifications for operation at $8.0 \mathrm{in} . \mathrm{Hg} 36$ occurrences are permitted, each with maximum duration of 24 hours. This means the allowed time at $8.0 \mathrm{in.} \mathrm{Hg} \mathrm{could} \mathrm{be} \mathrm{as} \mathrm{great} \mathrm{as} 864$ hours. In fact, the turbine specifications allow 72 days, 1728 hours, of operation above 5.5 in. $\mathrm{Hg}$. Although the turbine specifications allow this much operation above $5.5 \mathrm{in.} \mathrm{Hg}$, this model was not used in the determination of the step size of the turbine back pressure curve. However, it was used as the upper limit of each back pressure interval where the original site specific meteorology was interpreted.

Analysis of the effect of water availability on the maximum turbine back pressure shows that the maximum turbine back pressure rose above $5.5 \mathrm{in}$. Hg for only one case presented in this report. This was where no water was available. A graph of the maximum turbine back pressure versus available water is shown in Figure 6.1. In fact, the representation of the meteorology and the turbine back pressure data used in this study is the exact representation of the data required to model an all-dry heat exchanger. The tight tolerances of the back pressure model did not place any severe restrictions on the optimization process of this computer code.

An example of the input meteorological data is shown in Table D.3 for San Juan, NM, the reference site. Data are shown for both 8 and 16 input intervals. Throughout this parametric study 16 meteorological intervals were used because a greater number of data points provided a more accurate model of the temperature profile. In Table 0.3 the range of each temperature interval is shown for clarity, in comprehension of the meteorology development these data were not necessary for input to the computer code. The input meteorological data for the remainder of the sites are shown in Tables D. 4 through D. 10 . 
APPENDIX E

COMPARISON OF AIR VELOCITY THROUGH DELUGE AND DRY SECTIONS FOR HÖTERV SURFACES 


\section{APPENDIX E \\ COMPARISON OF AIR VELOCITY THROUGH DELUGE AND DRY SECTIONS FOR HÖTERV SURFACES}

The ratio of air velocity during deluging to the air velocity during alldry operation can be determined by computing the total pressure losses as each side of a tower is deluged. The pressure drop correlations for a HÖTERV surface, provided by Babcock and Wilcox, (a) were used as a basis to compute mass flow rates and other related quantities.

The B\&W correlations for dry and wet HÖTERV surfaces are given below:

$$
\begin{aligned}
& \text { Dry Surface: } \quad \Delta P=2.8895 \times 10^{-6}\left(G_{D}\right) 1.76 \\
& \text { Wet Surface: } \quad \Delta P=4.5532 \times 10^{-6}\left(G_{W}\right) 1.76
\end{aligned}
$$

where

$$
\begin{aligned}
\Delta P & =\text { pressure drop across the heat exchanger (psf) } \\
G_{D}, G_{W} & =\text { mass flow rates per unit area }\left(1 \mathrm{bm} / \mathrm{hr}-\mathrm{ft}^{2}\right) .
\end{aligned}
$$

These correlations are for dry air at $20^{\circ} \mathrm{C}\left(\rho_{\mathrm{a}}=0.075221 \mathrm{bm} / \mathrm{ft}^{3}\right)$. The HÖTERV equations should be corrected for air density when different conditions are assumed.

Fan performance under varying degrees of tower deluging was examined using Hudson Corporation fan performance curves. (E-2) The operating point for the fan system was found in the following manner:

1. Assume that the pressure drop through the dry and wet sections will be the same. Guess a value for $\Delta \mathrm{P}_{h . x}$. (pressure drop through the heat exchanger) and solve for the mass flow rates using the HÖTERV equations.

(a) This information was provided by W. W. Sowa, New Products, Power Generation Group, Babcock and Wilcox, Barberton, $\mathrm{OH}$, in a private communication to PNL on March 16, 1977. 
2. Calculate the total air mass flow,

$$
\dot{\mathrm{m}}_{\text {TOTAL }}=G_{D R Y}\left(A_{D R Y}\right)+G_{W E T}\left(A_{W E T}\right)
$$

where

$$
\begin{aligned}
& A_{D R Y}=\text { dry frontal area } \\
& A_{W E T}=\text { frontal area that is deluged. }
\end{aligned}
$$

3. Determine the volumetric flow rate per fan,

$$
Q_{\text {FAN }}=\frac{\dot{m}_{\text {TOTAL }}}{\left(N_{\text {FANS }}\right)\left(\rho_{\text {air }}\right)}
$$

where

$$
\begin{aligned}
N_{\text {FANS }} & =\text { number of fans in one tower } \\
\rho_{\text {air }} & =\text { air density at given elevation and temperature. }
\end{aligned}
$$

4. Using the $Q_{F A N}$ obtained in Step 3, calculate the velocity pressure according to

$$
\text { velocity pressure }=V P_{C O E F F}\left[0.2\left(V E L_{N R}\right)^{2}+0.8\left(V E L_{R}\right)^{2}\right]
$$

where

$$
\begin{aligned}
& { }^{V P_{\text {COEFF. }}} \text { = velocity pressure coefficient } \\
& V E L_{N R}=\text { velocity with no recovery } \\
& V E L_{R}=\text { velocity with recovery. }
\end{aligned}
$$

5. Total Pressure $=\Delta P_{h . x}+\Delta P_{V E L}$. PRESS.

6. The total pressure should correspond to the total pressure read from the fan curve (See Figure E.1). Otherwise, guess a new $\Delta P_{h . x}$. to either increase or decrease the airflow. 


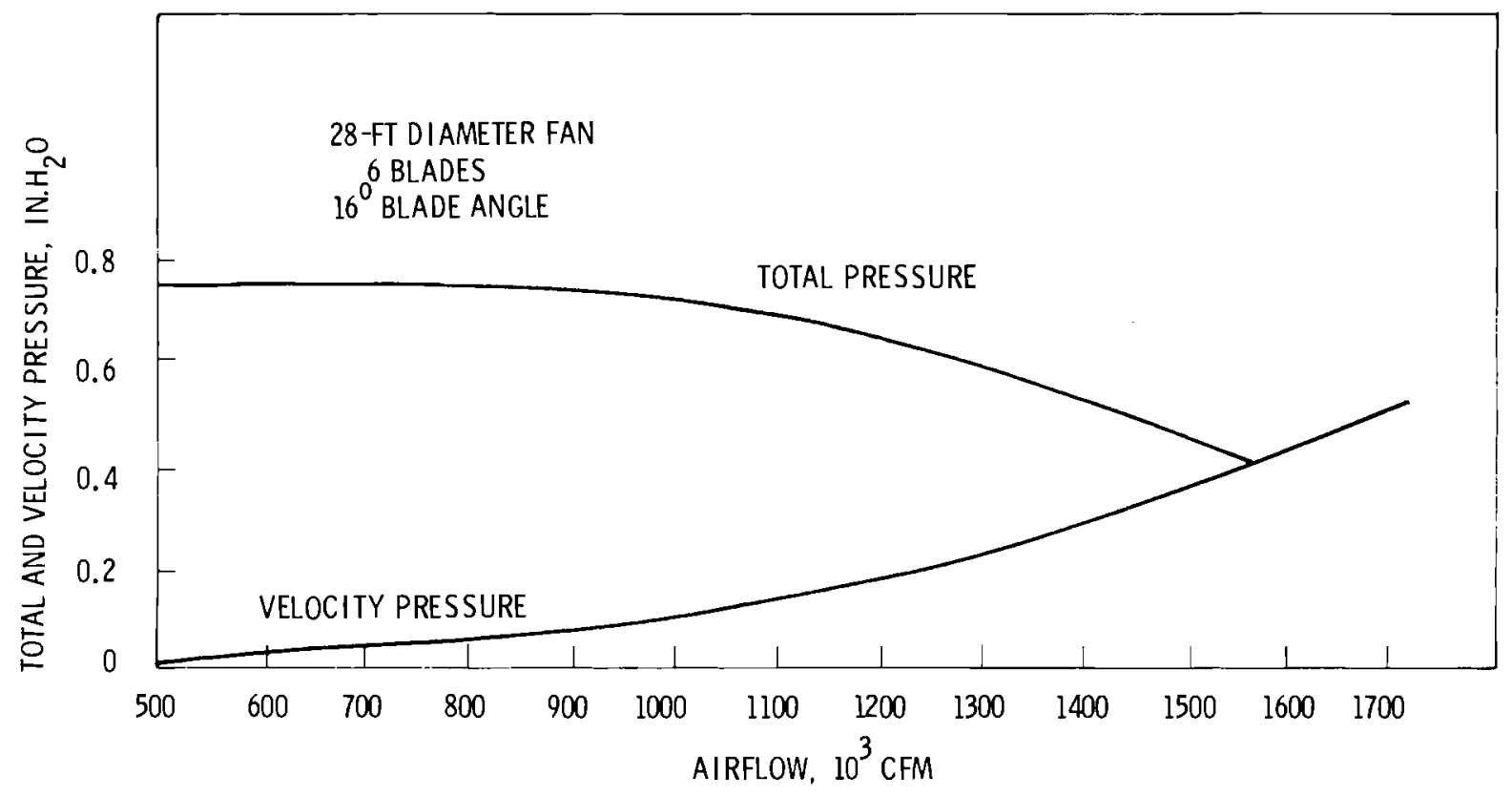

FIGURE E.1. Pressure Versus Airflow for a 27-ft Diameter Fan with 6 Blades and a 16 Degree Blade Pitch Angle

Once the correct pressure drop across the heat exchanger is determined (through successive iterations) the mass flow rates can be used to arrive at the air velocities for the dry/wet sections. The example given below will illustrate the calculational procedures used for a particular fan system.

The reference design case conditions will be used to find the ratio of the air velocity through the deluged section to the air velocity through the dry section.
a) San Juan meteorological site
b) Elevation $=5509 \mathrm{ft}$
c) Exit air temperature $=83.549^{\circ} \mathrm{F}$
d) Type of fans - 28-ft diameter, 6 blades $/ \mathrm{fan}$, and blade angle $=16$ degrees
e) Each tower has 8 sides
f) Number of fans/tower $=23$
g) Frontal area/4 towers $=0.218930 \times 10^{6} \mathrm{ft}^{2}$ 
h) Stack height $-13 \mathrm{ft}$, diffuser angle is 8 degrees

i) Flow area of fan $=584 \mathrm{ft}^{2}$

Calculate the specific volume of air leaving the heat exchanger at the elevation specified for the plant. The altitude correction (Barln) for the density of air can be found by:

$$
\text { Barln }=3.3985-3.8183 \times 10^{-5}(5509 \mathrm{ft})=3.1882
$$

The barometric pressure of air (Bar) is calculated as shown:

$$
\text { Bar }=\exp (\operatorname{Barln})=24.24 \text { in. } H g
$$

The specific volume is found according to

$$
\text { Sp. Vol. }=(459.67+83.549)^{\circ} \mathrm{R} / \mathrm{C} / 24.24
$$

where

$$
\begin{aligned}
C & =\frac{2116.221 \mathrm{bf} / \mathrm{ft}^{2}}{(29.92 \text { in. } \mathrm{Hg})\left(53.34 \frac{\mathrm{ft}-1 \mathrm{bf}}{1 \mathrm{bm}-{ }^{\circ} \mathrm{R}}\right)} \\
& =1.325 \frac{1 \mathrm{bm}-{ }^{\circ} \mathrm{R}}{\mathrm{ft}^{3}-\text { in. } \mathrm{Hg}}
\end{aligned}
$$

Specific Volume $=16.9104 \mathrm{ft}^{3} / 1 \mathrm{bm}$

$$
\rho_{\text {air }}=0.059131 \mathrm{bm} / \mathrm{ft}^{3}
$$

Correct HÖTERV equations for example conditions by multiplying the coefficients in the pressure drop equations by the ratio of the densities:

$$
\frac{\rho_{\text {air }}\left(20^{\circ} \mathrm{C}\right)}{\rho_{\text {example }}}=\frac{0.07522}{0.05913} \frac{1 \mathrm{bm} / \mathrm{ft}^{3}}{1 \mathrm{bm} / \mathrm{ft}^{3}}
$$

The corrected HÖTERV equations for this particular site location and air temperature are: 


$$
\begin{aligned}
& \Delta P=3.6754 \times 10^{-6}\left(G_{D}\right)^{1.76} \\
& \Delta P=5.7917 \times 10^{-6}\left(G_{W}\right)^{1.76}
\end{aligned}
$$

Calculate $\dot{\mathrm{m}}_{\text {TOTAL}}, Q_{\text {FAN }}$, and velocity pressure. Assume all dry tower; $\Delta P_{\text {h.x. }}=0.01382$ psi. Solve for $G$ :

$$
\begin{aligned}
& 0.01382 \frac{\mathrm{lbf}}{\mathrm{in.}^{2}}(144) \frac{\mathrm{in.}^{2}}{\mathrm{ft}^{2}}=3.6754 \times 10^{-6}\left(G_{D}\right) 1.76 \\
& G_{D}=1.810 \times 10^{3} 1 \mathrm{bm} / \mathrm{hr}^{-\mathrm{ft}^{2}} \\
& \dot{\mathrm{m}}_{\text {TOTAL }}=1.810 \times 10^{3} \frac{1 \mathrm{bm}}{{\mathrm{hr}-\mathrm{ft}^{2}}^{2}}\left(54732.5 \mathrm{ft}^{2}\right) \\
& =9.906 \times 10^{7} 1 \mathrm{bm} / \mathrm{hr} \\
& Q_{\text {FAN }}=9.906 \times 10^{7} \frac{1 \mathrm{bm}}{\mathrm{hr}} /(23 \mathrm{fans})\left(0.059134 \frac{1 \mathrm{bm}}{\mathrm{ft}^{3}}\right)\left(60 \frac{\mathrm{min}}{\mathrm{hr}}\right) \\
& =1.214 \times 10^{6} \mathrm{ft}^{3} / \mathrm{min}
\end{aligned}
$$

Velocity Pressure $=\mathrm{VP}_{\text {COEFF. }}\left[\left(0.2\left(\mathrm{VEL}_{\mathrm{NR}}\right)^{2}+0.8\left(\mathrm{VEL}_{\mathrm{R}}\right)^{2}\right]\right.$

$$
\begin{aligned}
& \text { where }{ }_{\mathrm{VP}} \mathrm{COEFF}=\frac{\left(0.07495 \frac{\mathrm{lbm}}{\mathrm{ft}^{3}}\right)(29.92 \mathrm{in.} \mathrm{Hg})\left(13.5951 \frac{\mathrm{in.} \mathrm{H}_{2} \mathrm{O}}{\mathrm{in.} \mathrm{Hg}^{2}}\right)}{2\left(32.174 \frac{1 \mathrm{bm}-\mathrm{ft}}{1 \mathrm{bf}-\mathrm{sec}^{2}}\right)\left(14.694 \frac{\mathrm{lbf}}{\mathrm{in.}^{2}}\right)\left(144 \frac{\mathrm{in.}^{2}}{\mathrm{ft}^{2}}\right)} \\
& =2.238 \times 10^{-4} \text { in. } \mathrm{H}_{2} \mathrm{O}-\frac{\mathrm{sec}^{2}}{\mathrm{ft}^{2}} \\
& V E L_{N R}=Q_{F A N} /(60) \frac{\text { sec }}{\text { min }} \text { (flow area of fan) } \\
& V_{E L}=Q_{F A N} /\left\{(60) \frac{(\mathrm{sec})}{\min } \frac{\pi}{4}\left[\left(\operatorname{FAN}_{\text {DIAM }}(1+E S F)\right)\right]^{2}\right\}
\end{aligned}
$$


where

$E S F=$ exit stack factor

$=2\left(\tan 8^{\circ}\right) \frac{(\text { stack height })}{(\text { Fan diameter })} \frac{\mathrm{ft}}{\mathrm{ft}}$

Velocity Pressure $=2.238 \times 10^{-4}\left[0.2\left(\left(1.214 \times 10^{6} /(60)(584)\right)^{2}\right.\right.$

$$
\left.+0.8\left(\left(1.214 \times 10^{6}\right)\left(2.117 \times 10^{-5}\right)\right)^{2}\right]=0.171 \text { in. } \mathrm{H}_{2} \mathrm{O}
$$

Calculate the total pressure:

$$
\begin{aligned}
& \text { Total pressure }=\Delta P_{h . x .}+\Delta P_{V E L} \text {. pressure } \\
& \text { Correct } \Delta P_{h . x .} \text { to air conditions: } \\
& (0.01382)(1.27)=0.01755 \mathrm{ps} i \\
& \text { Total pressure }=0.01755 \mathrm{ps} i+0.0062 \\
& =0.02375 \mathrm{ps} i
\end{aligned}
$$

The total pressure $\left(0.656\right.$ in. $\left.\mathrm{H}_{2} \mathrm{O}\right)$ corresponds to the total pressure read from the fan performance curve. If one side of the 8-sided towers is deluged, the calculation goes as follows:

$$
\begin{aligned}
& A_{\text {DRY SECTION }}=47891 \mathrm{ft}^{2} \\
& A_{\text {WET SECTION }}=6841 \mathrm{ft}^{2} \\
& \Delta P_{\text {h.x. }}=0.0142 \mathrm{psi} \\
& 0.0142 \mathrm{psi}(144) \frac{\mathrm{in.}^{2}}{\mathrm{ft}^{2}}=3.6754 \times 10^{-6}\left(\mathrm{G}_{D}\right)^{1.76} \\
& G_{D}=1.838 \times 10^{3} 1 \mathrm{bm} / \mathrm{hr}^{2} \mathrm{ft}^{2}
\end{aligned}
$$




$$
\begin{aligned}
& 0.0142 \mathrm{psi}(144) \frac{\mathrm{in.}^{2}}{\mathrm{ft}^{2}}=5.7917 \times 10^{-6}\left(\mathrm{G}_{\mathrm{W}}\right) 1.76 \\
& \mathrm{G}_{W}=1.419 \times 10^{3} 1 \mathrm{bm} / \mathrm{hr}-\mathrm{ft}^{2} \\
& \dot{\mathrm{m}}_{\text {TOTAL }}=1.419 \times 10^{3}(6841)+1.838 \times 10^{3}(47891) \\
&=9.773 \times 10^{7} 1 \mathrm{bm} / \mathrm{hr} \\
& Q_{\text {FAN }}=9.773 \times 10^{7} /(23)(60)(0.059134) \\
&=1.197 \times 10^{6} \mathrm{ft}^{3} / \mathrm{min}
\end{aligned}
$$

$$
\begin{aligned}
\text { Velocity pressure }= & 2.238 \times 10^{-4}\left[0.2\left(\left(1.197 \times 10^{6}\right) / 60(584)\right)^{2}\right. \\
& \left.+0.8\left(\left(1.197 \times 10^{6}\right)\left(2.117 \times 10^{-5}\right)\right)^{2}\right] \\
= & 0.167 \text { in. } \mathrm{H}_{2} \mathrm{O}
\end{aligned}
$$

Total pressure $=\Delta P_{h . x}+\Delta P_{V E L}$. pressure

Correct $\Delta P_{h . x}$. to air conditions: $0.0142(1.27)=0.0180$

$$
\begin{aligned}
\text { Total pressure } & =0.0180 \mathrm{psi}+0.0060 \mathrm{psi} \\
& =0.0240 \mathrm{psi}
\end{aligned}
$$

The procedure for determining the pressure losses for the rest of the deluging amounts are done in the same manner. The results of these calculations are shown in Table E.1.

The air velocity through the deluged and dry sections can be determined as follows:

$$
V E L=\frac{G\left(1 \mathrm{bm} / \mathrm{hr}-f t^{2}\right)}{\rho_{\text {air }} \frac{1 \mathrm{bm}}{\mathrm{ft}}(3600) \frac{\mathrm{sec}}{\mathrm{hr}}}
$$


TABLE E.1. Air Characteristics for a Deluged Cooling Tower

\begin{tabular}{|c|c|c|c|c|c|c|}
\hline & $\begin{array}{c}G_{0} \\
1 \mathrm{bm} / \mathrm{hr}^{-}-\mathrm{ft}^{2}\end{array}$ & $\begin{array}{c}G_{W} \\
1 \mathrm{bm} / \mathrm{hr}-\mathrm{ft}^{2} \\
\end{array}$ & $\begin{array}{l}Q_{E A N} \\
\mathrm{ft}^{3} / \min \end{array}$ & $\begin{array}{c}\text { Velocity Pressure } \\
\text { psi }\end{array}$ & $\begin{array}{l}\Delta P_{h . x .} . \\
-p s i\end{array}$ & $\begin{array}{c}\text { Total Pressure } \\
\text { psi } \\
\end{array}$ \\
\hline All-Dry Sections & $1.810 \times 10^{3}$ & 0 & $1.214 \times 10^{6}$ & 0.0062 & 0.01755 & 0.02375 \\
\hline $\begin{array}{l}7 \text { Sides Dry } \\
1 \text { Side Deluged }\end{array}$ & $1.838 \times 10^{3}$ & $1.419 \times 10^{3}$ & $1.197 \times 10^{6}$ & 0.0060 & 0.0180 & 0.0240 \\
\hline $\begin{array}{l}6 \text { Sides Dry } \\
2 \text { Sides Deluged }\end{array}$ & $1.860 \times 10^{3}$ & $1.436 \times 10^{3}$ & $1.176 \times 10^{6}$ & 0.0058 & 0.0184 & 0.0242 \\
\hline $\begin{array}{l}5 \text { Sides Dry } \\
3 \text { Sides Deluged }\end{array}$ & $1.896 \times 10^{3}$ & $1.464 \times 10^{3}$ & $1.163 \times 10^{6}$ & 0.0056 & 0.0190 & 0.0246 \\
\hline $\begin{array}{l}4 \text { Sides Dry } \\
4 \text { Sides Deluged }\end{array}$ & $1.924 \times 10^{3}$ & $1.486 \times 10^{3}$ & $1.142 \times 10^{6}$ & 0.0054 & 0.0195 & 0.0249 \\
\hline $\begin{array}{l}3 \text { Sides Dry } \\
5 \text { Sides Deluged }\end{array}$ & $1.936 \times 10^{3}$ & $1.498 \times 10^{3}$ & $1.115 \times 10^{6}$ & 0.0052 & 0.0198 & 0.0251 \\
\hline $\begin{array}{l}2 \text { Sides Ory } \\
6 \text { Sides Deluged }\end{array}$ & $1.964 \times 10^{3}$ & $1.520 \times 10^{3}$ & $1.094 \times 10^{6}$ & 0.0050 & 0.0203 & 0.0253 \\
\hline $\begin{array}{l}1 \text { Side Ory } \\
7 \text { Sides Deluged }\end{array}$ & $1.999 \times 10^{3}$ & $1.547 \times 10^{3}$ & $1.076 \times 10^{6}$ & 0.0048 & 0.0209 & 0.0257 \\
\hline 8 Sides Deluged & 0 & $1.563 \times 10^{3}$ & $1.049 \times 10^{6}$ & 0.0046 & 0.0213 & 0.0259 \\
\hline
\end{tabular}




$$
\text { Example: } \begin{aligned}
V E L_{D} & =1.83 \times 10^{3} /(0.059134)(3600) \\
& =8.64 \mathrm{ft} / \mathrm{sec} \\
V E L_{W} & =1.419 \times 10^{3} /(0.059134)(3600) \\
& =6.66 \mathrm{ft} / \mathrm{sec} \\
V_{E L_{W E T}} / V E L_{D R Y} & =6.66 / 8.64=0.77
\end{aligned}
$$

This ratio holds to within $1 \%$ for the wet/dry velocities for each amount of

\begin{tabular}{|c|c|c|}
\hline & $\begin{array}{c}V_{\text {DRY SECTION }} \\
\mathrm{ft} / \mathrm{sec} \\
\end{array}$ & $\begin{array}{c}\text { VEL }_{\text {WET SECTION }} \\
\mathrm{ft} / \mathrm{sec}\end{array}$ \\
\hline C Sides Deluged & 8.50 & 0 \\
\hline 1 Side Deluged & 8.64 & 6.66 \\
\hline 2 Sides Deluged & 8.73 & 6.74 \\
\hline 3 Sides Deluged & 8.91 & 6.87 \\
\hline 4 Sides Deluged & 9.04 & 6.98 \\
\hline 5 Sides Deluged & 9.10 & 7.03 \\
\hline 6 Sides Deluged & 9.22 & 7.14 \\
\hline 7 Sides Deluged & 9.39 & 7.26 \\
\hline 8 Sides Deluged & 0 & 7.34 \\
\hline
\end{tabular}
deluging (1-8 sides deluged). Table 2 presents the air velocities for each section.

TABLE E.2. Comparison of Air Velocities Through Wet and Dry Surfaces 


\section{REFERENCES}

E.1. Hudson Fan Performance Catalogue. Hudson Products Corporation, Houston, Texas, 1974. 


\section{DISTRIBUTION}

No. of

Copies

\section{OFFSITE}

U.S. Department of Energy

A. A. Churm

Chicago Patent Group

9800 South Cass Avenue

Argonne, IL 60439

U.S. Department of Energy

Office of Assistant General

Counsel for Patents

Washington, DC 20545

27 DOE Technical Information Center

10 U.S. Department of Energy

I. Helms

Advanced Concepts Evaluation Branch - G-434

Division of Advanced Systems and Materials

Washington, DC 20545

U.S. Department of Energy

W. F. Savage

Chief, Advanced Concepts

Evaluation Branch

Division of Advanced Systems and Materials

Washington, DC 20545

U.S. Department of Energy

D. C. Bauer

Director, Division of Advanced Systems and Materials

Washington, DC 20545

U.S. Department of Energy

R. B. Morrow

Special Projects Branch

Division of Advanced Systems and Materials

Washington, DC 20545
No. of

Copies

U.S. Department of Energy

N. Gerstein

Chief, Special Projects Branch

Division of Advanced Systems and Materials

Washington, DC 20545

U.S. Department of Energy

W. E. Mott

Director, Energy Control Technology

Division of Biomedical and

Environmental Research

Washington, DC 20545

U.S. Department of Energy

G. A. Newby

Assistant Director, Office of

Technical Development

Division of Advanced Systems

and Materials

Washington, DC 20545

Allied Chemical Company

B. R. Dickey

550 2nd Street

Idaho Fal1s, ID 83401

Allis-Chalmers Power Systems, Inc.

J. S. Joyce

1135 South 70th Street

West A11 is, WI 53214

Aluminum Company of America

E. T. Wanderer

Alcoa Technical Center

Alcoa Center, PA 15069

American Electric Power

H. J. Janzon

2 Broadway

New York, NY 10004

American Electric Power

Service Corporation

C. Swenson

2 Broadway

New York, NY 10004 
No. of

Copies

Aqua-Chem

R. M. Ahlgren

P.0. Box 421

Milwaukee, WI 53201

Arizona Public Service Co.

W. E. Campbel1

P.0. Box 21666

Phoenix, AZ 85036

Arizona Public Service Co.

$T$. Woods

2121 W. Cheryl Drive

Phoenix, AZ 85021

Babcock \& Wilcox

M. W. Peterson

Fossil Power Division

20 South Van Buren

Barberton, $\mathrm{OH} 44203$

Baltimore Aircoil Co., Inc.

E. Schinner

P.0. Box 7322

Baltimore, MD 21227

Baltimore Gas \& Electric Co.

G. C. Creel

Gas \& Electric Building

Baltimore, MD 21203

Battelle-Geneva

J. P. Budliger

7 Route De Drizi

1227 Geneva, SWITZERLAND

Bechtel Corporation

$P$. Leung

P.0. Box 60860

Terminal Annex

Los Angeles, CA 90060

Bechtel Corporation

G. R. Reti

P.0. Box 3965

San Francisco, CA 94119
No. of

Copies

R. W. Beck and Associates

J. P. Rossie

400 Prudential Plaza

Denver, CO 80202

Betz Environmental Engineers

J. Soost

$9317 \mathrm{~J}$, Highway 99

Vancouver, WA 98665

Black, Crow and Eidsness, Inc.

C. G. Thompson

807 South McDonough

Montgomery, AL 35104

Black Hills Power and Light Company

B. Westre

P.0. Box 1400

Rapid City, SD 57701

Boeing Aerospace Division

D. Gilbert (M.S. 2ROO)

P.0. Box 3999

Seattle, WA 98124

Bonneville Power Administration

E. H. Hall

1002 N.E. Holladay Street

Box 3621

Portland, OR 97208

Burns and Roe, Inc.

700 Kinder Kamack Rd.

Oradel, NY 07649

California Energy Commission

C. Webb

1111 Howe Avenue

Sacramento, CA 95825

California State Energy Resources Conservation and Development Commission

L. E. Stamets

1111 Howe Avenue

Sacramento, CA 95825 
No. of

Copies

Carolina Power \& Light Co. J. Sell

336 Fayettesville Street

Raleigh, NC 27602

Catalytic Construction Corp.

J. Morse

P.0. Box 11402

Charlotte, NC 28029

Ceramic Cooling Tower Co.

P. A. Frohwerk

P.0. Box 425

Fort Worth, TX 76101

Columbus and Southern Ohio

Electric Co.

L. W. Meridith

General Manager, Generation Department

215 North Front Street

Columbus, $\mathrm{OH} 43215$

Combustion Engineering

H. H. Osborn

Air Preheater Company

Wellsville, NY 14895

Commonwealth Edison

R. H. Holyoak

One First Plaza

P.0. Box 767

Chicago, IL 60690

Consolidated Edison Co. of New York, Inc.

W. A. Messner

4 Irving Place

New York, NY 10003

Consolidated Edison Co. of New York, Inc.

c. L. Newman

4 Irving Place

New York, NY 10003
No. of

Copies

Cornell University

F. K. Moore

Ithaca, NY 14850

Curtiss-Wright Corporation

R. J. Haberski

One Passaic Street

Wood Ridge, NJ 07075

Dames \& Moore

L. Craton

Suite 1000

1100 Glendon Avenue

Los Angeles, CA 90024

Dames \& Moore

P. Gottlieb

Suite 1000

1100 Glendon Avenue

Los Angeles, CA 90024

Delmarva Power \& Light

F. Cook

800 King Street

Wilmington, DE 19801

Dow Chemical Company

E. Wagener

2800 Mitchel1 Drive

Walnut Creek, CA 94598

Duke Power Company

S. K. Blackley

P.0. Box 2178

Charlotte, NC 28201

Duquesne Light Co.

J. Latshaw

435 6th Avenue

Pittsburgh, PA 15219

Dynatech Company

E. Guyer

99 Erie Street

Cambridge, MA 02139 
No. of

Copies

Ecodyne

J. Slotnik

607 First Street, S.W.

Massilion, $\mathrm{OH} 44646$

Ecodyne Cooling Products Co.

J. K. Swindt

P.0. Box 1267

Santa Rosa, CA 95403

Ecodyne Cooling Products

K. D. Whitehead

P.0. Box 1267

Santa Rosa, CA 95403

Electric Power Research

Institute

J. Maulbetsch

3412 Hillview Avenue

P.0. Box 10412

Palo Alto, CA 94304

Empire State Electric Energy Research Corp.

L. Geller

1271 Avenue of the Americas

New York, NY 10020

Environmental Protection Agency

T. G. Brna (MD-61)

IERL/RTP

Research Triangle Park, NC 27711

Environmental Protection Agency

A. Galley (WH-552)

401 M. Street SW

Washington, DC 20460

Environmental Protection Agency

M. Maxwel1 (MD-61)

IERL/RTP

Research Triangle Park, NC 27711
No. of

Copies

Environmental Protection Agency

F. H. Rainwater

Pacific Northwest Water Laboratory

200 S.W. 35th Street

Corvallis, OR 97330

Environmental Protection Agency

F. A. Roberts

200 S.W. 35th Street

Corvallis, OR 97330

Environmental Sciences and Services

W. G. Hoydysh

150 East 73rd Street

New York, NY 10021

Environmental Systems Corporation

K. Wilber

P.0. Box 2525

Knoxville, TN 37901

ERG Incorporated

G. M. Benson

Lowe11 57th Street

Oakland, CA 94608

Exxon Research Center

J. G. Stevens

Bldg. 1, Rm. 2048

P.0. Box 8

Linden, NJ 07036

Federal Power Commission

E. Si igh

825 N. Capitol Street

Washington, DC 20426

Florida Power \& Light Co.

C. Henderson

9250 W. Flagler Street

Miami, FL 33174 
No. of

Copies

Foster Wheeler Energy Co.

E. L. Damon

$110 \mathrm{~S}$. Orange Avenue

Livingston, NJ 07039

Franklin Institute

A. M. Rubin

Twentieth \& Parkway

Philadelphia, PA 19103

GEA Airexchangers, Inc.

B. Davis

P.0. Box 1377

Thomasville, GA 31792

General Atomic Company

A. C. Eulberg

P.0. Box 81608

San Diego, CA 92138

General Electric Co.

E. H. Miller

Large Steam Turbine Division

300 Nott Street

Schenectady, NY 12301

General Motors Corp.

R. K. Shah

Harrison Radiator Division

Lockport, NY 14094

Georgia Power Co.

T. E. Byerley

P. 0. Box 4545

Atlanta, GA 30302

Gilbert Associates, Inc.

J. F. Sebald

525 Lancaster Avenue

Reading, PA 19603

Heat Transfer Research Inc.

J. E. Taborek

$1000 \mathrm{~S}$. Fremont Avenue

A1hambra, CA 91802
No. of

Copies

Hudson Products

M. W. Larinoff

6855 Horwin Drive

Houston, TX 77036

Hudson Products

E. C. Smith

6855 Horwin Drive

P.0. Box 36100

Houston, TX 77036

H2M Corporation

H. D. Freudenthal

500 Broad Hollow Road

Melville, NY 11746

Ingerso11-Rand

W. R. Scott, Jr.

Phillipsburg, NJ 08865

Italimpianti-Societa Italiana Impianti p.a.

C. Rocco

Piazza, Piccapietra 9

18121 Genoe, ITALY

Los Angeles Department of Water and Power

J. L. Mul1oy

111 N. Hope Street

Los Angeles, CA 90012

Louisiana Power \& Light Co.

D. L. Aswe11

142 Delaronde Street

New Orleans, LA 70174

The Charles T. Main Co.

E. S. Miliaras

Southeast Tower

Prudential Center

Boston, MA 02199

Marley

C. A. Baird

12 S. 12th Street

Philadelphia, PA 19107 
Marley

J. D. Holmberg

5800 Fox Ridge Drive

Mission, KS 66202

Marley

R. Landon

5800 Fox Ridge Drive

Mission, KS 66202

Martin Marietta Laboratories

L. Bongers

1450 South Rolling Road

Baltimore, MD 21227

Massachusetts Institute of Technology

L. R. Glicksman

77 Massachusetts Avenue

Cambridge, MA 02139

Massachusetts Institute of Technology

M. W. Golay

77 Massachusetts Avenue

Cambridge, MA 02139

Massachusetts Institute of Technology

R. Harleman

Department of Civil Engineering

77 Massachusetts Avenue

Cambridge, MA 02139

McDonnel1 Douglas Astronautics Co.

W. H. P. Drummond

5301 Bal sa Avenue

Huntington Beach, CA 92647

McDonnell Douglas Astronautics Co.

S. O'Hare

5301 Balsa Avenue

Huntington Beach, CA 92647
Minnesota Power Cooperative, Inc. L. A. Hillier

Box 1318

Grand Forks, ND 58201

Montana Power Co.

R. Hofacher

40 E. Broadway

Butte, MT 59701

Niagara Blower

W. Kals

405 Lexington Avenue

New York, NY 10017

Northeast Utilities

R. H. Meyer

P.0. Box 270

Hartford, CT 06101

Northern States Power Co.

R. Stansfield

414 Nicollet Mall

Minneapolis, MN 55401

N.U.S. Corporation

S. Lefton

2 Palo Alto Square (Suite 624)

Palo Alto, CA 94304

Oak Ridge National Laboratory

J. W. Michel

OTEC Heat Exchange Project

$$
\text { Activity }
$$

Box Y

Oak Ridge, TN 37830

Orange \& Rockland Utilities, Inc.

R. H. Metzger

Environmental Services Manager

75 West Route 59

Spring Valley, NJ 10977 
No. of

Copies

Oregon State University

L. P. Davis

Department of Mechanical Engineering

Corvallis, OR 97330

Oregon State University

C. E. Wicks

Department of Chemical

Engineering

Corvallis, OR 97330

Oregon State University

J. G. Knudson

Engineering Experiment Station

Corvallis, OR 97330

Pacific Gas \& Electric

A. A. Ariey

77 Beale Street

San Francisco, CA 94106

Pacific Gas \& Electric

F. F. Mautz

77 Beale Street

San Francisco, CA 94106

Pacific Power \& Light Co.

W. C. Bruaer

Public Service Bldg.

Portland, OR 97204

Pennsylvania Power \& Light

W. Dussinger

2 North Ninth Street

Allentown, PA 18101

Pennsylvania Power \& Light

D. G. Pfeiffer

2 North Ninth Street

Al lentown, PA 18101

PFR Engineering Systems, Inc.

T. Rozenmann, President

Suite 832

4676 Admiralty Way

Marina del Rey, CA 90291
No. of

Copies

Philadelphia Electric Co.

J. Allen

2301 Market Street

Philadelphia, PA 19101

Philadelphia Electric Co.

S. J. Kowa lski

2301 Market Street, NZ-1

Philadelphia, PA 19101

Philadelphia Electric Co. J. B. Machel

2301 Market Street, NZ-1

Philadelphia, PA 19101

Philadelphia Electric Co.

D. Marano

2301 Market Street, NZ-1

Philadelphia, PA 19101

Prof. Ing. Carlo Roma

Piazza delle Muse 8

Rome, ITALY

Pickard Low \& Garrick

L. Rust

1200 18th St. NW

Suite 612

Washington, DC 20036

Power Generation Cooling Systems

G. L. Henderson

4714-52nd Street S.

Seattle, Wa 98118

Public Service of Colorado

R. F. Walker

5900 E. 39th Avenue

Denver, CO 80207

Public Service Company

$$
\text { of Indiana }
$$

S. W. Shields

V. P. Engineering

100 E. Main Street

Plainfield, IN 46168 
No. of

Copies

Public Service Company of New Mexico

C. D. Bedford

P.0. Box 2267

Albuquerque, NM 87103

Public Service Company of New Mexico

J. D. Maddox

Corporate Planning Dept.

Albuquerque, NM 87103

Quirk, Lawler and Mattusky, Eng.

J. Lawler

5055 th Avenue

New York, NY 10017

Radian Corporation

F. B. Mesich

P.0. Box 9948

Austin, TX 78766

Research Cottrell

G. E. Collins

Hamon Cooling Tower Division Box 750

Bound Brook, NJ 08805

Research Cottrell

R. H. Hannon

Hamon Cooling Tower Division

Box 750

Bound Brook, NJ 08805

Resources Conservation Company

H. Herrigel

P.0. Box 936

Renton, WA 98055

Resources for the Future

D. Abbey

1755 Massachusetts Avenue NW Washington, DC 20036
No. of

Copies

Reynolds Aluminum Co.

R. Lindberg

Reynolds Metallurgical

Research Laboratory

Richmond, VA 23261

Richmond Field Station

H. H. Sephton

47th and Hoffman Blvd.

Richmond, CA 94804

San Diego Gas \& Electric

R. G. Lacy

101 Ash Street

San Diego, CA 92107

Seattle City Light

T. R. Miller

Principal Mechanical Engineer

1015 Third Avenue

Seattle, WA 98104

Seattle City Light

R. L. Skone

1015 Third Avenue

Seattle, WA 98104

Southern California Edison

R. S. Currie

2244 Walnut Grove Avenue

Rosemead, CA 91770

Southern California Edison

W. C. Martin

2244 Walnut Grove Avenue

Rosemead, CA 91770

Southern California Edison

F. A. McCracken

2244 WaInut Grove Avenue

Rosemead, CA 91770

Southern Services, Inc.

C. H. Goodman

P.0. Box 2625

Birmingham, AL 35202 
No. of

Copies

P. Sporn

Consultant Engineer

74 Trinity P1., Suite 511

New York, NY 10006

Stanford University

A. L. London

Department of Mechanical

Engineering

Stanford, CA 94305

Stearns-Rogers, Inc.

J. Y. Parce

Box 5888

Denver, CO 80217

Stone \& Webster Engineering Corp.

D. H. Guild

225 Franklin Street

Boston, MA 02107

Tampa Electric Co.

H. I. Wilson

P.0. Box 111

Tampa, FL 33601

Tennessee Valley Authority

H. B. Flora, II I

1320 Commerce Union Bank Bldg.

Chattanooga, TN 37401

Texas Electric Service Co.

W. Keel

$115 \mathrm{~W}$. Seventh Street

Fort worth, TX 76102

Tucson Gas \& Electric

A. A. Ward

220 W. 6th Street

Tucson, AZ 85701

Union Carbide Corp.

J. A. Bartz

Linde Division

61 East Park Drive

Tonawanda, NY 14150
No. of

Copies

Union Carbide Corp.

G. J. Kidd

ORGDP - K-25

P.0. Box P, Mail Stop 197

Oak Ridge, TN 37803

Union Carbide Corp.

$F$. Notaro

Linde Division

6l East Park Drive

Tonawanda, NY 14150

United Engineers \& Constructors

G. A. Englesson

$30 \mathrm{~S}$. 17th Street

Philadelphia, PA 19103

United Engineers \& Constructors, Inc.

M. Hu

30 S. 17th Street

Philadelphia, PA 19103

University of Bremen

K. Simhan

Bremen, WEST GERMANY

University of Iowa

J. F. Kennedy

Hydraulic Research Institute

Iowa City, IA 52240

University of Kentucky

T. E. Eaton

Mechanical Engineering Department

Lexington, KY 40506

U.S. Congress

G. Haimes

214 Massachusetts Avenue NE Washington, DC 20510 
No. of

Copies

U.S. Fish and Wildlife Service

B. L. Foder

Information Transfer

Specialist

National Power Plant Team

1451 Green Road

Ann Arbor, MI 48105

United States Steel Corp.

T. L. Myron

Research Laboratory

Monroeville, PA 15146

Utah Power \& Light

M. W. Russon

1407 W. N. Temple

Salt Lake City, UT 84103

Vermont Yankee Nuclear Power

E. Gaines, Jr.

77 Grove Street

Rutland, VT 05701

Virginia Electric \& Power Co.

$S$. Ragone

700 E. Franklin Street

Richmond, VA 23261

Washington Public Power Supply System

J. Chasse

P.0. Box 968

300 George Washington Way

Richland, WA 99352

Washington State University

R. W. Crain, Jr.

Department of Mechanical

Engineering

Pullman, WA 99164

Washington Water Power Co.

D. L. 01 son

E. 1411 Mission Avenue

Spokane, WA 99202
No. of

Copies

Water Purification Associates

H. Gold

238 Main Street

Cambridge, MA 02142

Western States Water Council

J. A. Barnett

Executive Director

220 South 2nd East

Suite 200

Salt Lake City, UT 84111

Westinghouse Electric Corp.

G. E. Jablonka

Power Generation Systems

Engineering

700 Braddock Avenue, Room 9L51

East Pittsburgh, PA 15112

Westinghouse Electric Corp.

K. Kesavan

Advanced Reactor Division

P.0. Box 158

Madison, PA 15663

Westinghouse Electric Corp.

G. J. Silvestri

Steam Turbines Division - G108

Lester Branch

Box 9175

Philadelphia, PA 19113

Westinghouse Electric Corp.

K. A. Oleson

Steam Turbines Division - G108

Lester Branch

Box 9175

Philadelphia, PA 19113

L. E. Wilkinson

Consultant

6582 Ganon Street, S.E.

Salem, OR 97301 
William M. Rice University

W. G. Charackl is

Environmental Science and Engineering

Houston, TX 77001

\section{ONSITE}

DOE Richland Operations Office Energy Programs Division

H. E. Ransom

Westinghouse Hanford Company Hanford Engineering Development Laboratory

\section{J. Fletcher}

\section{Battelle-Northwest}

R. T. Al lemann

J. A. Bamberger

Daniel J. Braun

David J. Braun

J. W. Currie

D. E. Deonigi

R. L. Dillon

D. W. Dragnich

R. L. Drake

D. W. Faletti

J. W. Finnigan

T. J. Foley

B. C. Fryer

J. D. Goodenough

J. J. Hauth

A. J. Haverfield

C. H. Henager

A. B. Johnson

W. S. Kelly

R. S. Kemper

C. J. Knoll

W. V. Loscutoff

R. P. Marsha 11

D. E. Olesen

\section{Battelle-Northwest (contd)}

Y. Onishi

H. L. Parry

L. T. Pederson

H. C. Riches

J. R. Sheff

G. C. Smith

J. S. Stoakes

A. M. Sutey

R. D. Tokarz

D. S. Trent

M. Vagins

R. A. Walter

R. L. Watts

R. D. Widrig

L. E. Wiles

C. E. Willingham

F. R. Zaloudek

File - B. M. Johnson (30)

Technical Information (5)

Technical Publications 
